\title{
DESIGN AND FABRICATION OF A COLLECTIVE AND CYCLIC PITCH PROPELLER
}

CENTRE FOR NEWFOUNDLAND STUDIES

TOTAL OF 10 PAGES ONLY MAY BE XEROXED

(Without Author's Permission)

\section{T. CHARLES HUMPHREY}






\title{
Design and Fabrication of
}

\section{A Collective and Cyclic Pitch Propeller}

\author{
by
}

๑ T. Charles Humphrey

A thesis submitted to the School of Graduate Studies

In partial fulfillment of the requirements for the degree of

Master of Engineering

Ocean and Naval Architectural Engineering

Memorial University of Newfoundland

July 2005

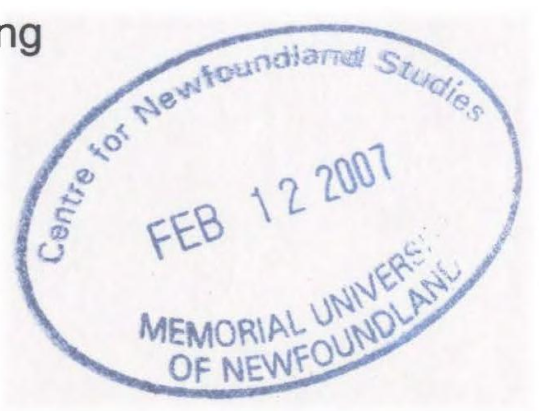

St. John's

Newfoundland 
Library and

Archives Canada

Published Heritage Branch

395 Wellington Street Ottawa ONK1A ON4

Canada
Bibliothèque et

Archives Canada

Direction du

Patrimoine de l'édition

$0-494-15558-2$

395, rue Wellington

Ottawa ON K1A ON4

Canada

Your file Votre référence

ISBN:

Our file Notre reterence

ISBN:

NOTICE:

The author has granted a nonexclusive license allowing Library and Archives Canada to reproduce, publish, archive, preserve, conserve, communicate to the public by telecommunication or on the Internet, loan, distribute and sell theses worldwide, for commercial or noncommercial purposes, in microform, paper, electronic and/or any other formats.

The author retains copyright ownership and moral rights in this thesis. Neither the thesis nor substantial extracts from it may be printed or otherwise reproduced without the author's permission.
AVIS:

L'auteur a accordé une licence non exclusive permettant à la Bibliothèque et Archives Canada de reproduire, publier, archiver, sauvegarder, conserver, transmettre au public par télécommunication ou par l'Internet, prêter, distribuer et vendre des thèses partout dans le monde, à des fins commerciales ou autres, sur support microforme, papier, électronique et/ou autres formats.

L'auteur conserve la propriété du droit d'auteur et des droits moraux qui protège cette thèse. $\mathrm{Ni}$ la thèse ni des extraits substantiels de celle-ci ne doivent être imprimés ou autrement reproduits sans son autorisation.
In compliance with the Canadian

Privacy Act some supporting forms may have been removed from this thesis.

While these forms may be included in the document page count, their removal does not represent any loss of content from the thesis.
Conformément à la loi canadienne sur la protection de la vie privée, quelques formulaires secondaires ont été enlevés de cette thèse.

Bien que ces formulaires aient inclus dans la pagination, il n'y aura aucun contenu manquant. 


\section{Abstract}

Autonomous underwater vehicle propulsion has been primarily driven by conventional thruster arrangements and control fins. The development of a collective and cyclic pitch propeller system provides a highly maneuverable alternative to these conventional designs. Therefore, a computer controlled and fully actuated collective and cyclic pitch propeller was designed and fabricated to fulfill this need.

The new propeller was designed using a helicopter like linkage system. The swash plates mounted inside of the propeller housing, as opposed to propeller hub like a helicopter. Locating the linkages in the housing provided a more maintainable system of linkages, due to space limitations in the propeller hub. The swash plate was positioned using three ball screw electric actuators using absolute positioning feedback. The swash plate position was transmitted to the propeller hub by a set of four control rods, one for each blade. Four blades were chosen for the propeller to reduce pulsing of the propeller when operating in cyclic mode.

Initial testing of the prototype demonstrates the propeller's potential ability to control the underwater vehicle at little or no forward speed. While operating in the $50 \%$ ahead, $100 \%$ to port condition, a thrust value of $26.7 \mathrm{~N}(6 \mathrm{lbf}$ ) with a turning moment of $18.9 \mathrm{Nm}$ (168 in-lb) was measured. The turning moment generated at a forward speed of $1.6 \mathrm{~m} / \mathrm{s}$ was sufficient to turn the C-SCOUT vehicle in $38 \%$ of the present required turning circle using a conventional thruster and control fins. 


\section{Acknowledgments}

Working on this project and writing this thesis was an enjoyable and rewarding experience. Many individuals made the completion of this project possible. I would like to thank Dr. Neil Bose and Dr. Christopher Williams for all of the assistance, suggestions and supervision they have given throughout this project. I would also like to thank NSERC for their sponsorship of this project through a Strategic Project Grant and a PGS-A scholarship. Without this monetary contribution this project would never have made it past the design stage. I would like to thank Mr. Leo Spurrell and all of the people in the machine shop for their amazing work on the construction of the prototype propeller.

To my many colleagues who helped my with the various aspects of the project, I thank you for all of your assistance. A special thanks to Martin Ordonez and Michael Snow for all of their help on the electronics required to make this project work.

Finally I would like to thank the people whose help is often taken for granted, but without whose contributions this project would not have been possible. To my parents, thank you for all of your support throughout my academic career. To my wife Trisha, thank you for moving to Newfoundland to allow me the opportunity to study underwater vehicles. 


\section{Table Of Contents}

1. Introduction ......................................................................................... 1-1

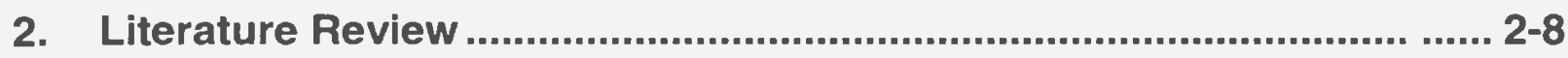

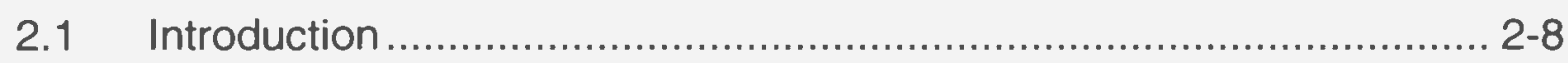

2.2 Development of Cyclic Control................................................... 2-9

2.3 Analysis of Helicopter Rotors .................................................... 2-10

2.4 Haselton Cyclic Pitch Propeller (1965 Patent) .............................. 2-12

2.4.1 Introduction ................................................................... 2-12

2.4.2 Claims

2.5 Haselton Cyclic Pitch Propeller (1966 Patent) ............................. 2-14

2.5.1 Introduction.................................................................. 2-14

2.5.2 Claims........................................................................... 2-15

2.6 Haselton Cyclic Pitch Propeller (1969 Patent) ............................... 2-15

2.6.1 Introduction..................................................................... 2-15

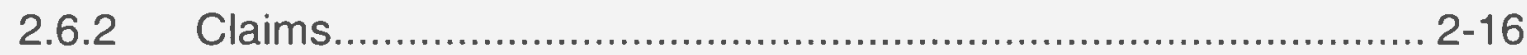

2.7 Reich Cyclic Pitch Propeller (1990 Patent) .................................. 2-16

2.7.1 Introduction .................................................................... 2-16

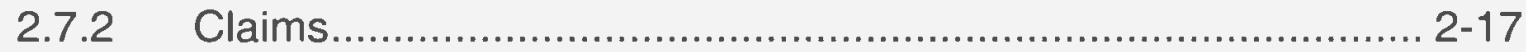

2.8 Paterson Cyclic Pitch Propeller (1991 Patent) ............................... 2-17

2.8.1 Introduction ................................................................ 2-17

2.8.2 Claims ......................................................................... 2-18

2.9 Schneider Cyclic Pitch Propeller (1993 Patent) ............................ 2-18

2.9.1 Introduction...................................................................... 2-18

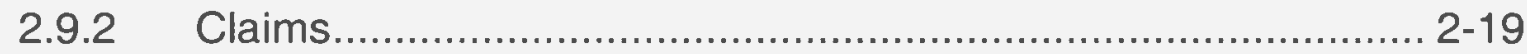

2.10 Other Cyclic Pitch Propeller Technology ....................................... 2-19

2.11 Conclusions from Patent Analysis ............................................ 2-20

2.12 Papers on Cyclic Pitch Propellers ................................................... 2-21

2.13 Bijleveld Cyclic Pitch Propeller.................................................. 2-22

3. Theory Related To Design................................................................ 3-24

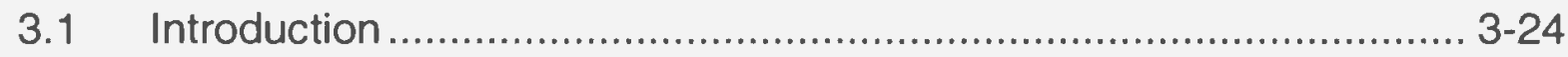

3.2 Swash Plate Mechanics........................................................... 3-24

3.3 Airfoil Theory......................................................................... 30

3.3.1 Lift of Foils ..................................................................... 30

3.3.2 Drag on Foils ..................................................................... 3-32

3.3.3 Thrust and Torque ......................................................... 3-34

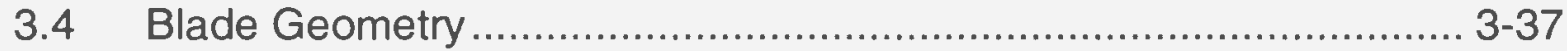

3.4.1 Blade Rake ................................................................. 3-37

3.4.2 Blade Number............................................................... 3-39

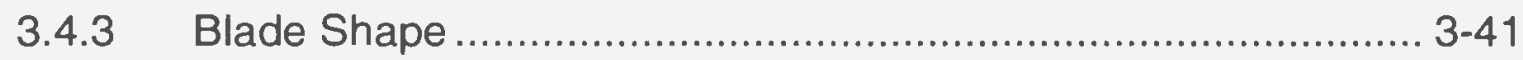


3.4.4 Final Blade Geometry ..................................................... 3-42

3.5 Thrust Predictions ........................................................................ 3-42

3.6 C - SCOUT Drag Curve ......................................................... 3-44

4. Design Concepts.................................................................................... 4-46

4.1 Introduction ..................................................................... 4-46

4.2 Design Parameters .................................................................... 4-46

4.3 Piston Pump Design ................................................................... 4-47

4.4 Concentric Shaft Design ........................................................ 4-49

4.5 Hub Mounted Mechanism ...................................................... 4-50

4.6 Hull Mounted Mechanism .......................................................... 4-52

$4.7 \quad$ Linkage Concepts ..................................................................... 4-54

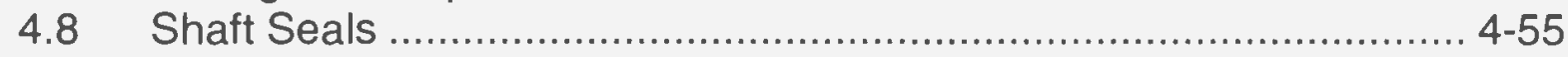

5. Selected Design - Mechanical System .......................................... 5-57

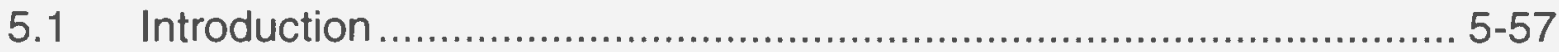

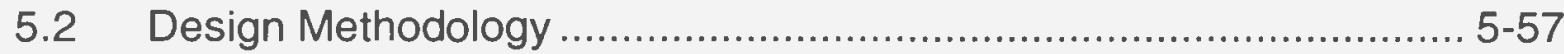

5.3 Drive Shaft Development ...................................................... 5-58

5.4 Component Selection................................................................ 5-60

5.4.1 Rod End Bearings............................................................ 5-61

5.4.2 Swash Plate Spherical Bearing ….................................... 5-62

5.4.3 Radial Bearings ............................................................... 5-63

5.4.4 Mechanical Seal ............................................................. 5-64

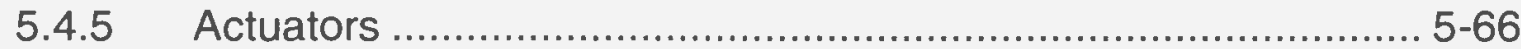

5.4.6 Main Motor Selection ............................................................ 5-67

5.5 Sectioned General Arrangement ............................................... 5-69

5.6 Assembly Considerations ..................................................... 5-71

5.7 Parametric Model Development.............................................. 5-72

5.7.1 Shaft Line ................................................................... 5-72

5.7.2 Swash Plate ............................................................. 5-74

5.7.3 Propeller Hub................................................................ 5-76

5.7.4 Pressure Housing ......................................................... 5-78

5.7.5 Main Bearings.............................................................. 5-80

5.7.6 Main Motor Mounting ......................................................... 5-81

5.8 Design Verification............................................................... 5-82

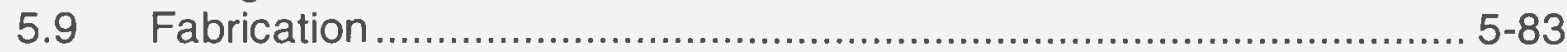

5.9.1 Drawing Development .......................................................... 5-83

5.9.2 Fabrication Techniques ............................................... 5-84

5.9.3 Problems and Solutions ................................................ 5-85

6. Selected Design - Electrical System .................................................. 6-90

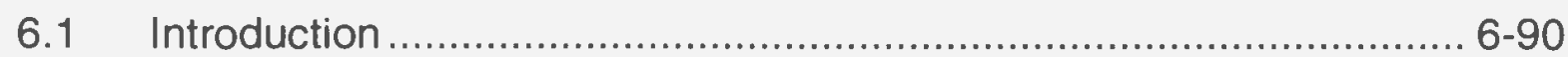

6.2 Main Motor Controller .............................................................. 6-91

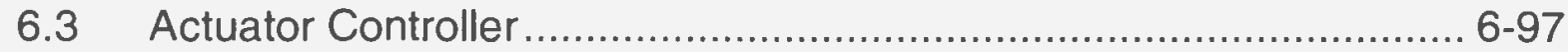


6.4 Power Distribution....................................................................... 6-99

6.4.1 Main Power System.............................................................. 6-100

6.4.2 Control System Power ............................................................ 6-101

6.5 Signal Conditioning .................................................................. 6-102

6.6 Main Processing Unit ............................................................... 6-103

7. Control Algorithm Development...................................................... 7-106

7.1 Introduction .............................................................................. 7-106

7.2 Test Procedure ....................................................................... 7-106

7.3 Test Matrix Development ............................................................... 7-107

7.4 Generation of Equations ........................................................ 7-109

8. Initial Testing And Results ................................................................ 8-113

8.1 Introduction ............................................................................ 8 813

8.2 Data Collection ........................................................................... 8-113

8.3 Test Setup ............................................................................. 8-117

8.3.1 Data Acquisition and Control .............................................. 8-119

8.3.2 Propeller Operation............................................................... 8-120

8.4 Data Collection ...................................................................... 8-121

8.5 Data Analysis ........................................................................ 8-121

8.5.1 Smoothing Algorithm ..................................................... 8-122

8.5.2 Data Rotation...................................................................... 8 8-124

8.5.3 Plotting of Results.............................................................. 8-126

8.6 Results for Test 1 (Ahead / Astern) ........................................... 8-126

8.7 Results for Test 2 (Surface / Dive) .............................................. 8-133

8.8 Results for Test 3 (Ahead 50\%, Left to Right 100\%) ..................... 8-144

8.9 Calculated Values for $\mathrm{K}_{\mathrm{T}}$ and $\mathrm{K}_{\mathrm{Q}}$ at Bollard Conditions ..................... 8-148

9. Conclusions and Recommendations .............................................. 9-156

9.1 Conclusions ............................................................................ 9-156

9.2 Recommendations............................................................ 9-158

Bibliography ...................................................................................................161 


\section{List Of Tables}

Table 4.1: Constraints and Criteria............................................................. 4-47

Table 5.1: General Arrangement System Color Codes .................................. 5-71

Table 6.1: Instrument Amplifier Gains and Gain Resistor Values ................. 6-103

Table 7.1: Table of Control Equations............................................................ 7-110 


\section{List Of Figures}

Figure 2.1: Helicopter Rotor Design Requirements......................................... 2-12

Figure 2.2: Bijleveld Cyclic Pitch Propeller...................................................... 2-22

Figure 3.1: Section of Typical Swash Plate Pair............................................ 3-25

Figure 3.2: Stationary Lock Linkage Detail................................................... 3-26

Figure 3.3: Rotary Synchronization Linkage Detail ....................................... 3-27

Figure 3.4: Spherical Bearing Detail............................................................ 3-28

Figure 3.5: Control Rod to Swash Plate Ball Relationship ............................. 3-29

Figure 3.6: Foil at Angle of Attack With and Without Camber ....................... 3-30

Figure 3.7: Helicopter Rotor Thrust Vectoring ............................................... 3-32

Figure 3.8: Plots of $C_{L}$ vs. Alpha and $C_{D}$ vs. $C_{L}$ for a NACA2415 Section...... 3-34

Figure 3.9: Relationship Between Lift, Drag, Thrust and Torque .................. 3-35

Figure 3.10: Effect of Blade Rake on Thrust Vector ........................................ 3-38

Figure 3.11: Side Force Predictions ............................................................ 3-44

Figure 3.12: Bare Hull Resistance Curve for C-SCOUT.................................. 3-45

Figure 4.1: Piston Pump Design..................................................................... 4-48

Figure 4.2: Concentric Shaft Arrangement for CPCPP ................................ 4-49

Figure 4.3: Swash Plate in Propeller Hub ....................................................... 4-51

Figure 4.4: Hull mounted Mechanism........................................................... 4-53

Figure 5.1: Shaft Line Layout ................................................................... 5-59

Figure 5.2: Main Shaft Bearings.............................................................. 5-63

Figure 5.3: Mechanical Seal Detail............................................................ 5-65

Figure 5.4: Digit Linear Actuator.................................................................. 5-67

Figure 5.5: Main Motor Armature ............................................................. 5-69

Figure 5.6: 2D General Arrangement Sketch ............................................. 5-70

Figure 5.7: Propeller Hub Flange ................................................................ 5-73

Figure 5.8: Bearing Retainer Nut................................................................. 5-74

Figure 5.9: Main Swash Plate Section ...................................................... 5-75

Figure 5.10: Connecting Linkages............................................................. 5-75

Figure 5.11: Lock Linkages ..................................................................... 5-76

Figure 5.12: Blade installation ................................................................ 5-77

Figure 5.13: Aft Pressure Vessel End Cap................................................... 5-79

Figure 5.14: Main Shaft Bearing Installation ............................................... 5-80

Figure 5.15: Main Motor Section ................................................................. 5-81

Figure 5.16: Spring Centered Solution......................................................... 5-89

Figure 6.1: Control System Architecture ....................................................... 6-91

Figure 6.2: Main Motor Controller Schematic ................................................. 6-92

Figure 6.3: Modified Main Motor Controller Schematic ................................... 6-94

Figure 6.4 Buffer Circuit Schematic................................................................. 6-95

Figure 6.5: Commercial Trapezoidal Motor Controller.................................... 6-96

Figure 6.6: Actuator Controller Schematic .................................................... 6-97 
Figure 6.7: Stepper Motor Drivers 6-99

Figure 6.8: Main Power System Schematic

Figure 6.9: Control System Power Schematic.

Figure 6.10: Sample Amplifier Circuit.

6-103

Figure 6.11: Smartcat ${ }^{\mathrm{TM}}$ Single Board Computer

Figure 7.1: Directional Convention and Actuator Orientation

Figure 8.1: Thomas' Setup for Propulsion Thrust and Torque Measurement 8-114

Figure 8.2: Measurement Apparatus for CPCPP

Figure 8.3: 45E15A Load Cell .

Figure 8.4: Mechanical Propeller Test Setup

Figure 8.5: Electrical Propeller Test Setup.

Figure 8.6: Raw Data for Thrust Values

Figure 8.7: Unrotated Axes

Figure 8.8: Rotated Axes

Figure 8.9: Force Results for Ahead / Astern Test.

Figure 8.10: Moment Results for Ahead / Astern Test.

Figure 8.11: Force Results for Surface / Dive Test

Figure 8.12: Moment Results for Surface / Dive Test.

Figure 8.13: Maximum Turning Moment at $20 \%$ Astern Thrust.

Figure 8.14: Maximum Turning Moment at 40\% Astern Thrust

Figure 8.15: Resultant Force and Phase Angle for Maneuvering Force at Zero

Forward Speed

Figure 8.16: Resultant Force and Phase Angle for Maneuvering Force at 50\%

Forward Speed

Figure 8.17: Force Results for Maneuvering While Thrusting Ahead

Figure 8.18: Moment Results for Maneuvering While Thrusting Ahead

Figure 8.19: $\mathrm{K}_{\mathrm{T}}$ and $\mathrm{K}_{\mathrm{Q}}$ Plots for Varying Blade Angle (No Side Thrust)

Figure 8.20: Open Water $\mathrm{K}_{\mathrm{T}}$ and $\mathrm{K}_{Q}$ Curves for B-Series Screw Propeller ... 8-151

Figure 8.21: $\mathrm{K}_{\mathrm{T}}$ and $\mathrm{K}_{\mathrm{Q}}$ Plots for Varying Side Thrust Angle (20\% Astern) ... 8-153 


\title{
List of Abbreviations and Symbols
}

\author{
Abbreviations: \\ 2D - Two Dimensional \\ 3D- Three Dimensional \\ A-Amperes \\ AVD - Analog to Digital Conversion \\ ANOVA - Analysis of Variance \\ AUV - Autonomous Underwater Vehicle \\ AVI - Digitized Video Format \\ BASIC - Beginners All Symbolic Instructional Code \\ BDC - Bolt Circle Diameter \\ CAM - Computer Aided Manufacture \\ CANBUS - Communications Protocol \\ CNC - Computer Numerically Controlled \\ CPCPP - Collective Pitch and Cyclic Pitch Propeller \\ C-SCOUT - Canadian Self Contained Off-The-Shelf Underwater Testbed \\ DEMA - Distributive Embedded Modular Architecture
}




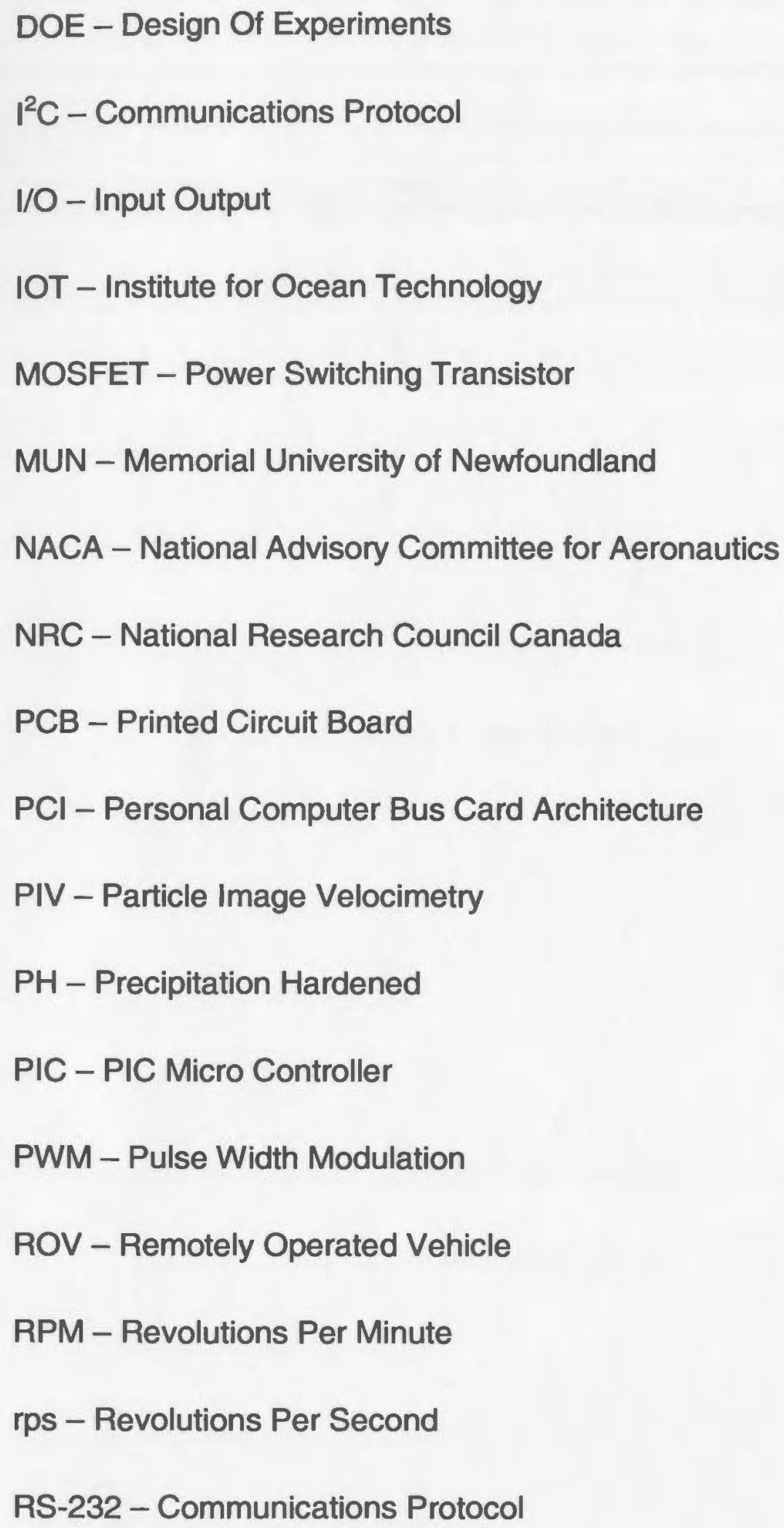


RS-422 - Communications Protocol

RS-485 - Communications Protocol

TCP/IP - Communications Protocol

TDS - Tandem Propeller System

TTL - Transistor-Transistor Logic

VDC - Volts Direct Current

\section{Symbols:}
a Relative Induced Velocity (Va Component)
a' Relative Induced Velocity (wr Component)
$A_{e} / A_{0}$ Area Ratio
C Chord Length
d Diameter of Propeller
D Drag Force
$D_{m} \quad$ Moment Arm from the Propeller Plane to the Load Cell
$F_{R} \quad$ Resultant Force (Combination of $M_{x}, M_{y}$, and $D_{m}$ )
$F_{\mathbf{x}} \quad$ Force in the $\mathrm{X}$-direction
$F_{y} \quad$ Force in the $\mathrm{Y}$-direction
$F_{\mathbf{Z}} \quad$ Force in the Z-direction 
J Advance Coefficient

$\mathrm{K}_{\mathrm{T}} \quad$ Thrust Coefficient

$K_{a} \quad$ Torque Coefficient

L Lift Force

$\mathrm{M}_{\mathrm{x}} \quad$ Moment About the $\mathrm{X}$-axis

My Moment About the $Y$-axis

$M_{z} \quad$ Moment About the Z-axis

n Rotational Speed of Propeller (rps)

P/d Pitch to Diameter Ratio

Q Shaft Torque

$r$ Radius from Center of Rotation to Blade Section

t Time

T Thrust Force

$T_{n} \quad$ Blade Thrust Component $[n=\{1,2,3,4\}]$

$\mathrm{T}_{\mathrm{x}} \quad$ Forward Thrust Component

$T_{y} \quad$ Lateral Thrust Component

$\mathrm{U}_{\mathrm{n}} \quad$ Induced Velocity

$V_{A} \quad$ Speed of Advance 
$V_{R} \quad$ Relative Velocity

z Number of Propeller Blades

\section{Greek Symbols:}

$\alpha \quad$ Angle of Attack (Angle of Incidence)

$\beta i \quad=(\phi-\alpha)$

$\theta \quad$ Rake Angle of Propeller Blades

$\theta^{*} \quad$ Side Thrust Direction

$\phi \quad$ Blade Pitch Angle

$\omega \quad$ Rotational Speed of Propeller Section ( $\mathrm{rad} / \mathrm{s}$ ) 


\section{List Of Appendices}

Appendix A - Fabrication Drawings

Appendix B - Fixed Size Component Data Sheets

Appendix C - Electronic Data Sheets

Appendix D - Load Cell Mounting 


\section{Chapter 1 Introduction}

Ocean exploration has been a dangerous and very expensive pursuit throughout history. Large oceangoing research vessels and submersibles have conventionally been used to collect information about the world's oceans. These research vessels are extremely expensive to operate and manned submersibles endanger the lives of their crew with each expedition.

Technological advances have made ocean exploration safer and more economical. The first step was to remove people from the subsea environment. This task was accomplished with the invention of the remotely operated vehicle (ROV) in the 1960s [McFarlane, 1993]. The ROV is capable of completing many of the same tasks as a manned submersible. While still requiring on-site support from a surface vessel, many ROVs can be launched from ships as small as a zodiac. The operator controls and navigates the vehicle from the surface using a system of video cameras and instrumental feedback. Power to thrusters and onboard equipment is supplied from the support ship through a tether or umbilical cord. The umbilical cord, of course, limits the operational range of the ROV. The next logical step was to reduce the amount of required on-site support. 
Autonomous Underwater Vehicles (AUVs) are capable of carrying out preprogrammed missions with little or no human intervention [Curtis, 2001]. The removal of the human from the underwater system results in a vehicle capable of operating in hazardous and risky environments where an operator would be in immediate danger. Unlike an ROV, tetherless AUVs can operate independent of human support, and keep personnel at a safe distance. AUVs are finding application in many areas of military deployment such as mine detection, mine neutralization, surveillance, and buried object classification. In the scientific community, AUVs are quickly becoming a less expensive method of obtaining ocean data compared to manned submersibles and surface science vessels. Also, AUVs are able to obtain different classes of data that are not as easily attainable with current systems. The underwater gliders, for example, can collect conductivity, temperature and depth (CTD) data to profile an area for mission durations of up to three months without human intervention.

Autonomous Underwater Vehicles are capable of operating independently from a support ship and of storing their data until transmission back to a base station is possible. For these reasons, one support vessel can potentially deploy and monitor a large number of AUVs. This can maximize the amount of data that can be collected during an expedition, using the costly surface support resources more effectively. In addition to vessel launching, AUVs can also be successfully launched from shore. Due to their $100+\mathrm{km}$ range, many AUVs can conduct 
substantial missions from a suitable shore launch site. In certain applications such as harbor defense and coastal monitoring, AUVs can operate without the aid of a support ship further reducing operating costs. For deployment in arctic regions, AUVs are capable of operating from a base on the ice sheet to collect data under the ice.

In the past five years, there has been a noticeable increase in the research and development of AUV technology [Wernli, 2000]. Several subsea companies have undertaken the development of AUVs as part of their vehicle fleets or product lines. Universities around the globe have implemented research programs to develop vehicles and related technology. This growth is primarily being driven by the size, cost and reduction in size of computers and electronics used to operate these vehicles. New and improved sensors are increasing the number of feasible tasks these vehicles are able to perform.

In 1998, Memorial University of Newfoundland (MUN) and the National Research Council of Canada's Institute for Ocean Technology (NRC-IOT) started a joint project to develop a research vehicle. The "Canadian Self Contained Off-theshelf Underwater Testbed" or C-SCOUT was developed to study underwater vehicle related technology. The project was partly funded by a NSERC Strategic Project entitled "Ocean Environmental Risk Engineering Using Autonomous 
Underwater Vehicles (1999-2004)". The aims of the project were to increase the understanding of environmental effects caused by discharges from the offshore oil and gas industry and demonstrate the ability of an AUV to successfully conduct these missions.

One such mission would be the monitoring, mapping and classification of a produced water discharge from an offshore production facility using a mass spectrometer, fluorometer and/or other suitable instruments. This type of mission requires the ability of a vehicle to produce a 3-dimensional map of the plume. The location of the contaminants and their concentrations are recorded at the various locations in the plume. A vehicle using conventional control surfaces for maneuvering can carry out the first task of mapping, as the vehicle is continuously moving with some significant forward velocity. However, the second task of concentration monitoring, or any measurement that requires time to make, demands a vehicle capable of holding station during the sampling and analysis procedure. While sampling can currently be accomplished with existing technology, the exact location of the sample is not known. By holding the vehicle stationary during sampling, the exact location of the sample can be recorded.

Through body thrusters were originally planned to allow a vehicle to remain stationary during this period while maintaining maneuvering control. Research 
conducted at the University of Victoria [Saunders, 2001] concluded that the thruster performance is greatly affected by the complex hydrodynamic flow interaction between the thruster in a duct and the hull. This hull thruster interaction causes an asymmetry in the thrust characteristics between positive and negative yaw angles during operation [Saunders, 2001]. The asymmetric behavior could result in a vehicle failing to hold station during operation due to lack of thrust. Even under non-asymmetric operating conditions, the available amount of thrust is low.

Through body thrusters provide improved maneuvering and positioning of a vehicle at low speed, but are not very electrically efficient. Acceleration of water from one direction to another in a tunnel thruster requires significant power. A more efficient method of maintaining low speed maneuverability was required.

During the 1960's, Haselton developed a novel solution to this problem, the cyclic pitch propeller, discussed in detail in Chapter 2. This new propeller was modeled after the helicopter rotor and was capable of producing forces in all threeprinciple axes. This technology was investigated at Memorial University to determine the feasibility of this technology in providing low speed maneuvering for C-SCOUT [Bijleveld, 2002]. An experimental two-bladed propeller was 
designed and tested. The results of the experimental propeller showed that the technology was feasible and warranted further investigation.

The recommendations presented by Bijleveld [2002] in his thesis were used as the starting point for this thesis. To better understand the feasibility of this type of thruster with respect to C-SCOUT, a more advanced version of the cyclic pitch propeller was required for testing. This thesis addresses the development of a production quality prototype of this style of propeller. The objective of this thesis is stated as follows:

"To design, fabricate, commission and initially test a fullyactuated production prototype collective pitch and cyclic pitch propeller (CPCPP) for the AUV C-SCOUT"

To meet this objective, a detailed study of the existing technology was undertaken and is presented in Chapter 2. Theory relevant to the design of the new prototype propeller is presented in Chapter 3. In Chapter 4, the design process followed during this project is outlined. The more significant conceptual designs and their evaluation are also presented in Chapter 4. The detailed design of the selected concept has been broken into three main parts. Chapter 5 discusses the mechanical aspects of the design. The electrical portion of the 
design is discussed in Chapter 6. The development of the control algorithm for the propeller is discussed in Chapter 7. The results of initial testing of the completed propeller are presented in Chapter 8 . Finally, Chapter 9 puts forth the conclusions, recommendations and outline for future work. 


\section{Chapter 2 Literature Review}

\subsection{Introduction}

When developing a new propulsion system for underwater vehicles, a thorough investigation into similar technology is a necessary first step to the design process. In particular, reviewing previous patents on similar technologies and understanding their claims provides a basis for prior art. Prior art is particularly important when applying for patents to protect intellectual property. As this project was being approached as the development of a production prototype system, patent dates and claims required review to ensure that the production of the new propulsion system would not violate any active patents.

Due to the large amount of information in patent applications, patent discussions in this literature review shall be limited to a brief introduction to the patent and a statement of the author's claims. Where appropriate, a brief description of the invention's function shall also be presented to highlight important aspects of the particular design. The patent numbers for cyclic pitch related propeller technology were compiled by Lechartier [2002]. 
Before examining the more recent developments of cyclic and collective pitch propulsion for underwater vehicles, a study of their development and application in the field of aeronautics should be explored. This provides the necessary understanding for the differences in operation between an underwater Collective Pitch and Cyclic Pitch Propeller and helicopter rotors.

\subsection{Development of Cyclic Control}

During the early development of helicopters and autogyros, researchers and inventors discovered early on that control of these vehicles was the key to the success of vertical flights [Gazzola, 2003]. Many milestones marked the paths that eventually lead to the successful development of the modern helicopter. From a control aspect, there are two developments that represent the major achievement in this area [Leishman, 2000].

Cyclic pitch control of airfoil surfaces was originally developed to control the location of the pitch and roll moments of helicopters providing one component required for control during flight. Crocco first recognized cyclic pitch control as a requirement for control of helicopters in 1906 [Leishman, 2000]. Cyclic pitch control was used in many different forms on many of the early helicopter designs. 
The second component required for successful forward flight of the helicopter was blade flapping hinges. Blade flapping was invented by Juan de la Cierva in 1923 and first implemented on his C-4 auto gyro [Cierva, 1926] [Leishman, 2000]. The blade flapping helps to balance the rolling moment on the helicopter rotor caused by the increased lift on the leading blade and the decrease in lift on the lagging blade [Seddon, 1990].

\subsection{Analysis of Helicopter Rotors}

While flapping hinges are important for horizontal rotating propeller blades advancing edgewise into an advancing fluid, their importance is limited in the application of a collective and cyclic pitch propeller advancing into a conventional flow. A conventional flow has streamlines parallel to the axis of the propeller's revolution. The slight moment imbalances created by the maneuvering forces are not sufficient to destabilize the vehicle as

- The vehicle is already stable due to buoyancy and gravitational forces.

- The principal fluid flow is perpendicular to the propeller blades.

A study of helicopter rotor design was undertaken to better understand the functionality of the components required to develop and build a cyclic and 
collective pitch propeller. Both model and full-scale helicopter rotor designs were analyzed [Domke, 2004], [CHP, 2004]. After the analysis the following components, illustrated in Figure 2.1, were determined to be important to the design of a new CPCPP system:

- Stationary swash plate (A)

- Rotary swash plates (B)

- Swash plate gimble ball (C)

- Stationary swash plate control inputs (D)

- Blade to rotary swash plate linkages $(E)$

- Synchronization linkages for stationary swash plate (F)

- Synchronization linkages for rotary swash plate (F)

Helicopter rotor design and function will be discussed in more detail in Chapter 3 of this thesis. 


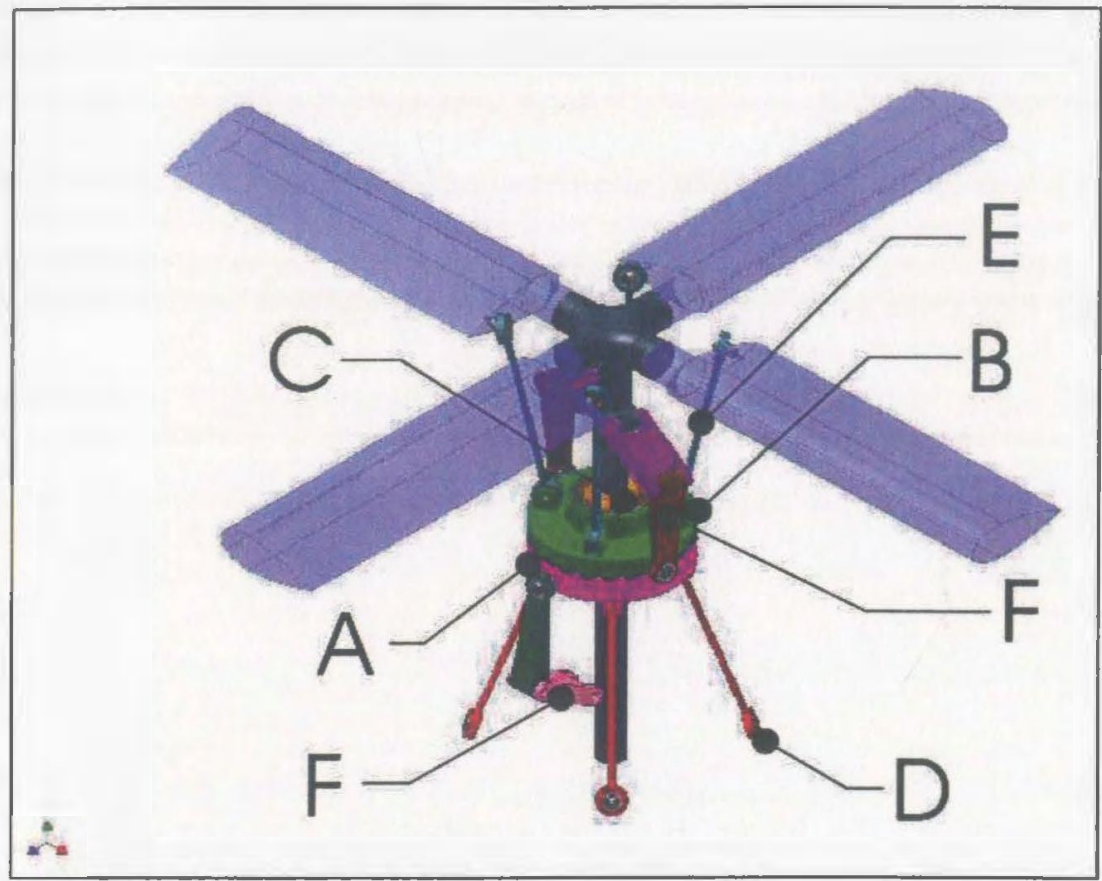

Figure 2.1: Helicopter Rotor Design Requirements

\subsection{Haselton Cyclic Pitch Propeller (1965 Patent)}

\subsubsection{Introduction}

US Patent No. $3,101,066$ outlines the details for the first cyclic and collective pitch propeller system for propulsion and maneuvering of submerged bodies. The propulsion system was able to produce thrust fore and aft by varying the collective pitch of the propeller blades similar to the function of a controllable pitch propeller. By varying the pitch of the propeller blades cyclically as in a helicopter's main rotor, the propulsion system was capable of producing thrust in sway and heave directions. The enhanced maneuverability of the propulsion 
system allowed a vehicle to move in all six degrees of freedom without the aid of conventional control surfaces.

\subsubsection{Claims}

Being the first patent of this technology, the six claims presented are the most broad in scope. The primary claims of the patent are as follows:

1. A pair of peripherally mounted blades on a cylindrical body varied collectively and cyclically produces maneuvering forces in all six degrees of freedom of a neutrally buoyant vehicle operating in a fluid medium.

2. The pair of peripherally mounted blades mounted at the fore and aft ends of a cylindrical water tight submarine body rotate in opposite directions with a means of independently controlling collective and cyclic pitch of both units.

3. The use of a pair of peripherally mounted blades in a spaced relationship for steering an underwater vehicle and providing thrust in directions perpendicular to the vehicle's longitudinal axis of rotation by cyclic variation of blades. Collective variation of the blade pitch controls the speed of the vehicle in the fore and aft directions.

4. The use of an electric motor to drive the propeller unit by means of a rotating armature around the submarine, and a fixed stator including 
windings secured to the submarine hull. The multiple blades of each propeller unit are pivotally mounted to the rotating armature. The pitch of the blades is controlled by means of a non-rotating swash plate mechanism.

5. The rotating armatures form an integral part of the hull exterior mounted in circumferential slots containing all equipment to vary cyclically and collectively the pitch of the blades mounted on the rotating armature.

6. The ability of both ring shaped electric motors to operated in a flooded environment.

\subsection{Haselton Cyclic Pitch Propeller (1966 Patent)}

\subsubsection{Introduction}

US Patent $3,291,086$ represents a continuation of the work started with the patent discussed above. In particular, this new patent discusses the optimization of a spheroid body equipped with two cyclically and collectively controlled propulsion units for maximum maneuverability. This patent has little relevance to the design of a production cyclic pitch propeller, as the information detailed pertains to the testing configurations of a prototype for performance verification. 


\subsubsection{Claims}

The first four claims of this patent are mainly in reference to the different configurations of blade body geometry and orientation. The remaining four claims of the patent deal primarily with different methods of controlling the cyclic and collective pitch of the propulsion units.

\subsection{Haselton Cyclic Pitch Propeller (1969 Patent)}

\subsubsection{Introduction}

US Patent $3,450,083$ primarily outlines the application of technology aimed at simplifying and improving the control of the blade actuation mechanisms. The drive motors were changed from the expensive permanent magnet direct drive system to a simple conventional motor driving a ring gear. The floating swash, plate found in previous designs, was replaced by a swash plate supported by a spherical bearing. The spherical bearing is an important component of all future mechanically controlled cyclic pitch propellers including the new CPCPP. 


\subsubsection{Claims}

The claims of the patent relate to the geometry of the propulsion system and the method to which parts are connected and controlled. The first three claims discuss the actuation and the connection of the swash plate to the propeller blade shafts. The fourth and fifth claims outline the provision in the design to allow the blade to rotate about its shaft should the maximum torque be exceeded. The remaining two claims outline improvements to the positioning of the swash plate and the new drive system.

\subsection{Reich Cyclic Pitch Propeller (1990 Patent)}

\subsubsection{Introduction}

US Patent $4,957,413$ is the first patent where the true potential of the collective and cyclic pitch propeller is outlined. The patent presents the technology as a superior method for low speed propulsion and maneuvering. The patent also provides two more actuation methods for creating cyclic and collective pitch of propeller blades on a submerged body. While both methods of actuation provide the desired result, implementation of the described invention is nearly impossible due to the arrangement of the linkages. This conclusion was made after an examination of the propeller blade pitch actuation described in the patent. 


\subsubsection{Claims}

The two claims presented in this patent outline the configuration of the mechanisms and linkages that make up the proposed propeller design. This first claim discusses the use of offset blade shafts running on a cone. The cone is moved eccentrically to provide cyclic pitch and axially to provide collective pitch. The second claim describes a modification to the first claim with regards to the connection of the blade shafts to the actuation mechanism.

\subsection{Paterson Cyclic Pitch Propeller (1991 Patent)}

\subsubsection{Introduction}

US Patent $5,028,210$ represents a great step forward in the design of collective and cyclic pitch propellers. The design outlined by Paterson addresses many of the shortcomings and reliability issues facing earlier designs. The swash plate and blade connecting linkages bear striking similarities to helicopter rotor design. The main propulsion mechanism for the propeller returned to the permanent magnet torque motor design. This eliminated the need for heavy geared drive systems. 


\subsubsection{Claims}

The nine claims presented in this patent pertain directly to the design, layout and operation of this propulsion unit. The primary claim for the patent is that the actuators, swash plate and linkages are housed within the rotor of the drive motor. The remaining claims depict the variations in this design, such as hydraulic or pneumatic actuators, swash plate configurations and bearing support modifications.

\subsection{Schneider Cyclic Pitch Propeller (1993 Patent)}

\subsubsection{Introduction}

US Patent $5,249,992$ is a variation of the Paterson propeller. Schneider, a coauthor on the US Patent $5,028,210$, patented a cyclic and collective pitch propeller that did not use a conventional swash plate mechanism. The goal of this design was to reduce the number of moving parts to improve the reliability of the propulsion system. This design uses an Oldham coupler [Avallone et al., 1996] and a modified Scotch yoke [Erdman et al., 1997] to vary the blades cyclically and collectively. 


\subsubsection{Claims}

The 15 claims presented in the patent represent the design and construction of this particular propeller design. The claims primarily deal with the control and connection of the Oldham coupler to the propeller blades. The complexity of this design and the manufacturing difficulty made this type of system impractical to a production CPCPP. The implementation of the ball jointed blades to the Oldham coupler would be extremely difficult to produce in a one-off system. Also, the linkages required to operate this propeller required a substantial amount of space in the propeller hub. This space was not available in a C-SCOUT sized propeller.

\subsection{Other Cyclic Pitch Propeller Technology}

While there have been other patents filed on cyclic and collective pitch designs, the aforementioned patents represent the main advancements in this technology from its infancy. US Patent 4,540,341 describes yet another method for controlling the pitch of the propeller blades cyclically and collectively. The proposed system uses an arrangement of hydraulic actuators controlled by porting on the drive shaft. The actuators in the propeller hub are controlled by hydraulic fluid passed down the propeller shaft in individual ducts. 
US Patent $4,648,345$ outlines an attempt to simplify the linkage of the cyclic and collective pitch propeller. In this patent, the authors propose to adjust the blades of the propeller using electromagnetic positioning. This method of control could eliminate the need for swash plate mechanisms in future cyclic pitch development. The problem with this design lies in the response of the mechanical components to the input signals from the electronics. Direct control of the blade position in this manner poses some very difficult control challenges, even with today's computer technology.

\subsection{Conclusions from Patent Analysis}

After a review of published patents on the subject of collective and cyclic pitch propellers, the patented concept of the use of CPCPP to maneuver and control an underwater vehicle has expired. The patents that are still in effect (1991 to present) deal with specific improvements to the CPCPP system. A new production prototype must not infringe on these existing patents. As the designed and built propeller prototype was based on long public helicopter rotor technology, the new CPCPP does not infringe on any of the active patents. 


\subsection{Papers on Cyclic Pitch Propellers}

Due to the observed apparently classified nature of the research conducted into cyclic and collective pitch propellers, there was not a lot of public information about their design or the results obtained in the testing of such devices. However, two published papers were found on this technology. The first paper by Stenovec and Haselton [1987] discusses their work on a Tandem Propeller System (TDS). The paper outlines the development of the TDS as a propulsion method for ROVs and AUVs. The advantages and operation of this system are discussed and outlined in their paper.

The second paper by Murray et al. [1994] discusses the application of cyclic pitch propellers. This paper delves into the governing equations of cyclic and collective pitch propeller operation and provides a good starting point for the development of a future computer model. The paper also looks briefly at the results of the Paterson propeller and lists some of the observations of the test team. The most important of these findings are the vehicle's maneuverability at no forward speed and a reduced turning circle diameter. 


\subsection{Bijleveld Cyclic Pitch Propeller}

The results of work conducted by Bijleveld [2002] at Memorial University and the Institute for Ocean Technology was the prime influence of the research conducted in this thesis. The simple cyclic and collective pitch propeller tested showed tremendous potential for maneuvering an AUV at low speed. This low speed maneuvering was of particular interest to the C-SCOUT vehicle team, in particular for environmental monitoring and iceberg profiling.

Like many of the past CPCPP designs, this propeller used a swash plate mechanism to control the cyclic pitch variation of the propeller blades. A system of wedges was used to control the angle of the swash plate and thus the cyclic pitch, Figure 2.2. Due to the fact that the swash plate could only tip, collective pitch was fixed for this particular propeller application.

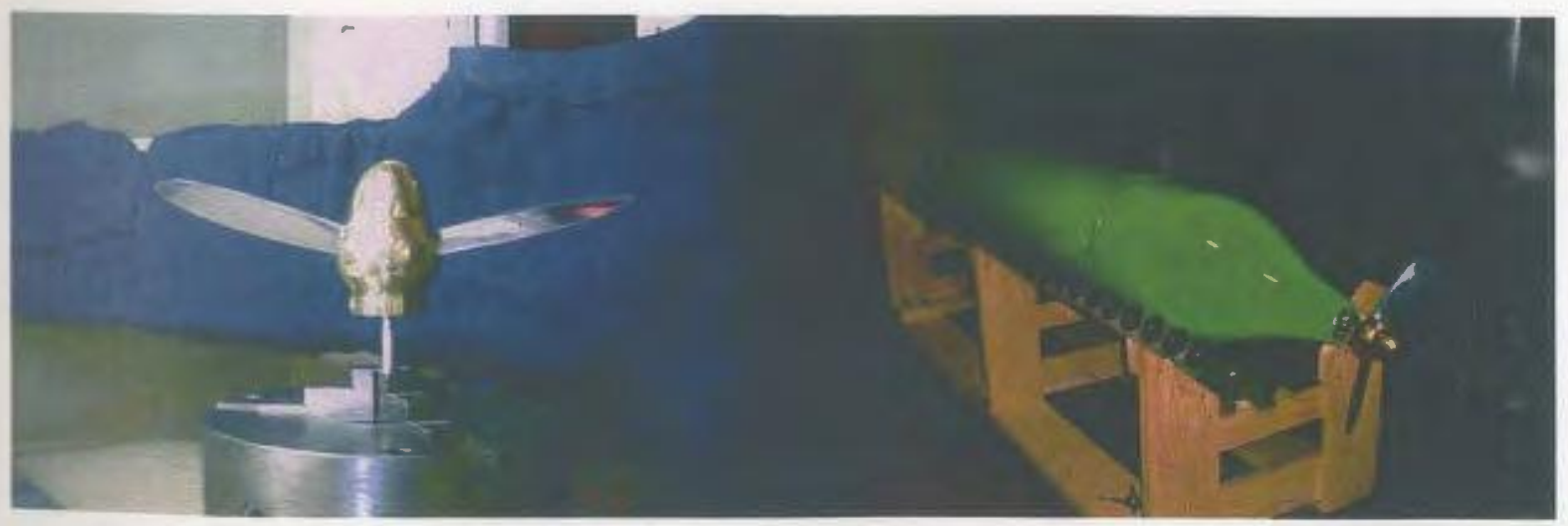

Figure 2.2: Bijleveld Cyclic Pitch Propeller 
The results of testing were found to be very encouraging, but the limitations of the prototype prevented the propeller from reaching its true potential. Bijleveld recommended a fully actuated version of the propeller be created to further test this method of propulsion. 


\section{Chapter 3 \\ Theory Related To Design}

\subsection{Introduction}

Before starting on the design of a new propeller system for an underwater vehicle, one must first have a basic understanding of the relevant theory. The final goal of the prototype is to provide helicopter like control for an underwater vehicle. For this reason, an excellent place to start in the theory is a discussion of the swash plate. The swash plate is what allows the helicopter's pilot to control the flight direction of the vehicle. In addition, a study of sealing techniques and propeller theory are important, as the propeller will be operating underwater.

\subsection{Swash Plate Mechanics}

The function of a swash plate, in its simplicity, is to translate rotary motion into a sinusoidal reciprocating motion. For a hydraulic motor, a swash plate transfers power to the rotating drive shaft from the pistons being displaced by the fluid [Vickers, 1996]. A swash plate on a helicopter rotor works in a similar fashion, except the swash plate is now transferring control signals from the stationary actuators to the rotating blades. 
The transfer of the control signals is actually accomplished using a pair of swash plates that are coupled together using a radial thrust bearing [Marshall, 2000]. The bearing acts as a constraint between the two swash plates allowing them to only rotate about their axis of revolution. Translations in the $X, Y$ and $Z$ directions were prohibited, as was rotation about the $X$ and $Y$ axes, labeled in Figure 3.1. During operation, the swash plates move as a collective group. This motion exactly translates the positions of the control rods or actuators to the rotor blades of the helicopter, while remaining unaffected by the rotation of the rotor. A section of a typical swash plate in Figure 3.1 illustrates the relationship between the rotary and stationary swash plates.

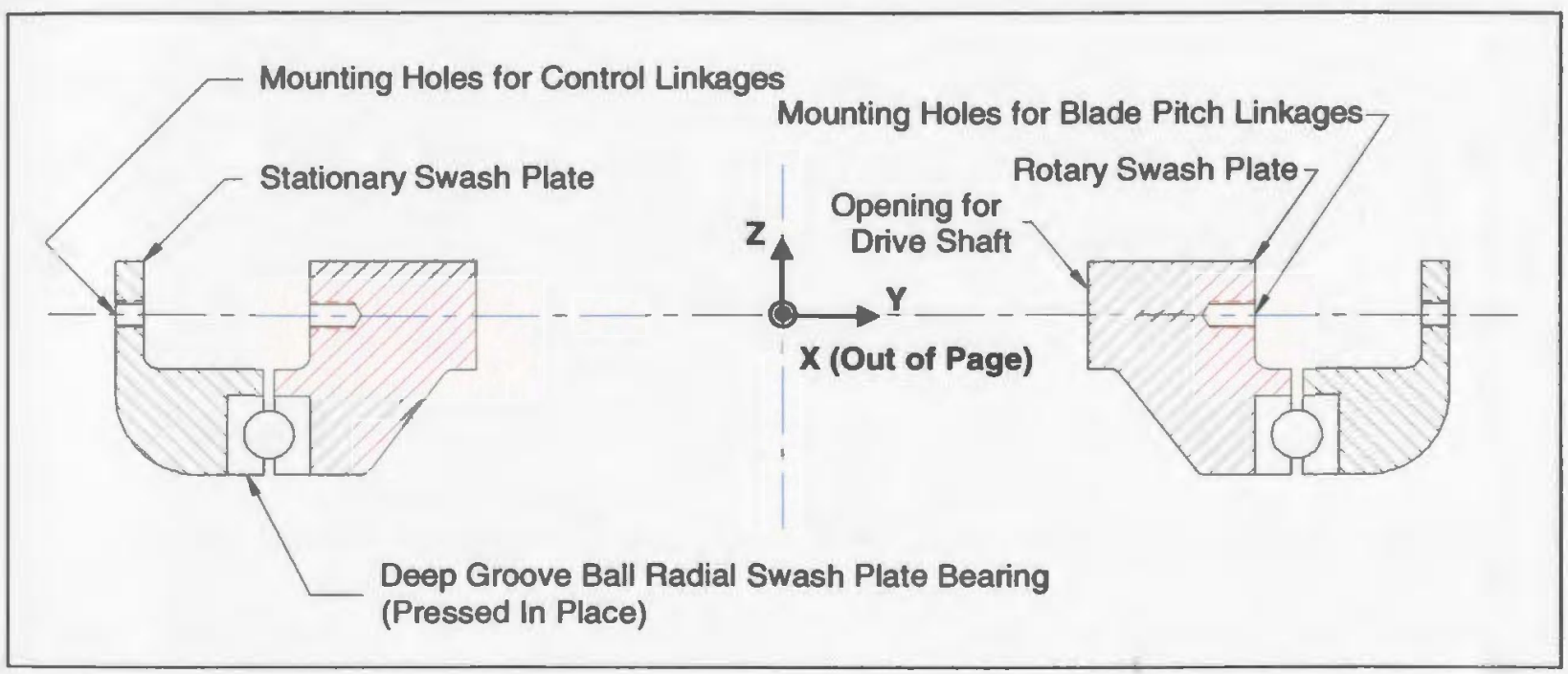

Figure 3.1: Section of Typical Swash Plate Pair 


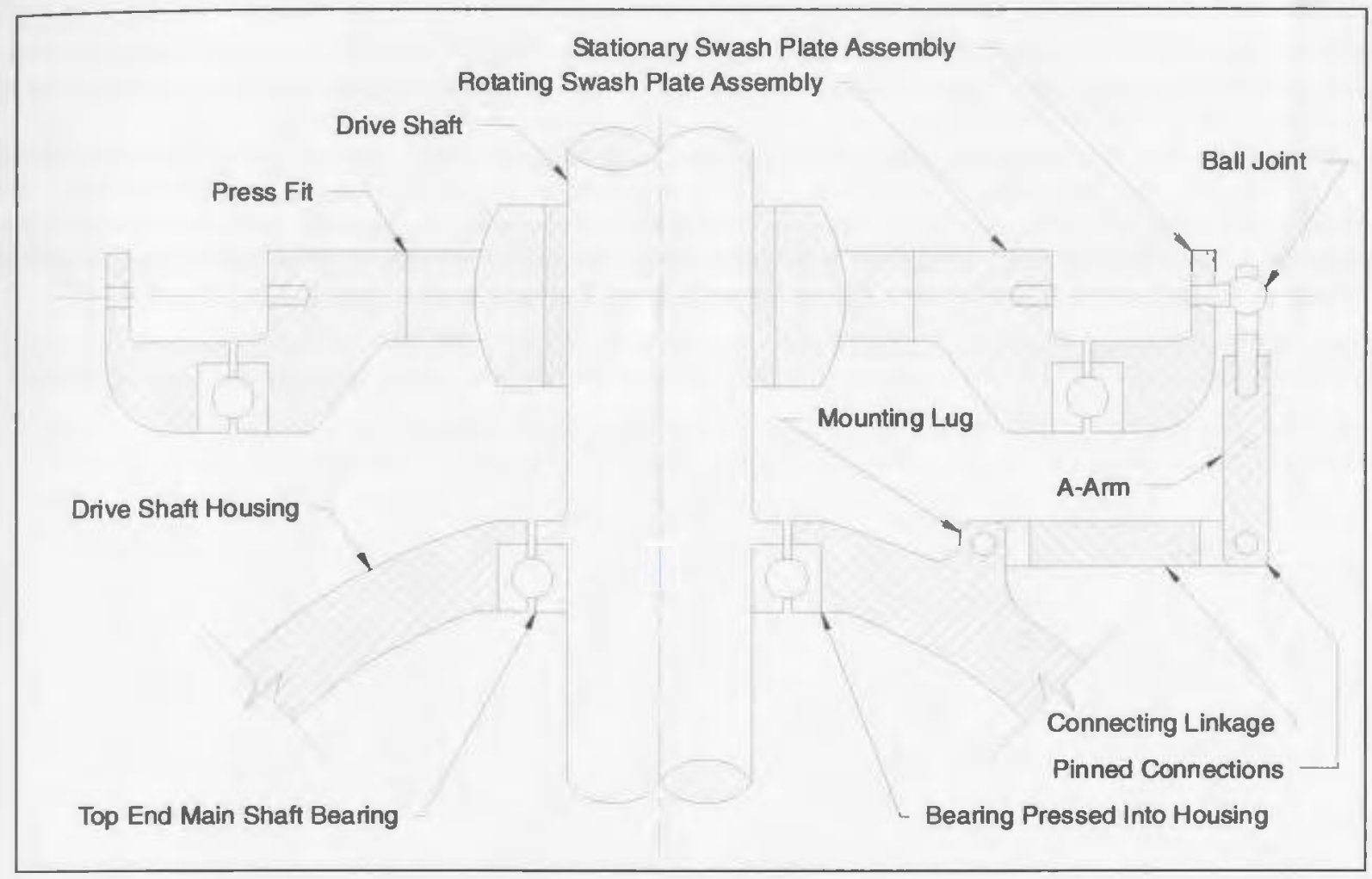

Figure 3.2: Stationary Lock Linkage Detail

For a swash plate to accurately translate the actuator positions to the blades, it is crucial to ensure that the stationary swash plate remains stationary and the rotary swash plate turns in synchronization with the drive shaft. This is accomplished by a series of lock or synchronization mechanisms [Domke, 2004]. There is a single locking linkage that connects to a stationary part of the helicopter that prevents the stationary swash plate from rotating due to friction in the radial thrust bearing, Figure 3.2 above. The lock linkage consists of an Aarm and a connecting linkage that attaches to the fuselage at the mounting lug. This lock linkage ensures that the actuators always remain in alignment with the control lugs. The rotary swash plate has two synchronization linkages to ensure 
that the rotating swash plate remains in synch with the drive shaft, Figure 3.3. These linkages connect from a clamped collar on the drive shaft to the rotating swash plate. While one linkage is sufficient to accomplish this task, one linkage would set up a mass imbalance in the shaft. This is the reason for using two symmetric linkages.

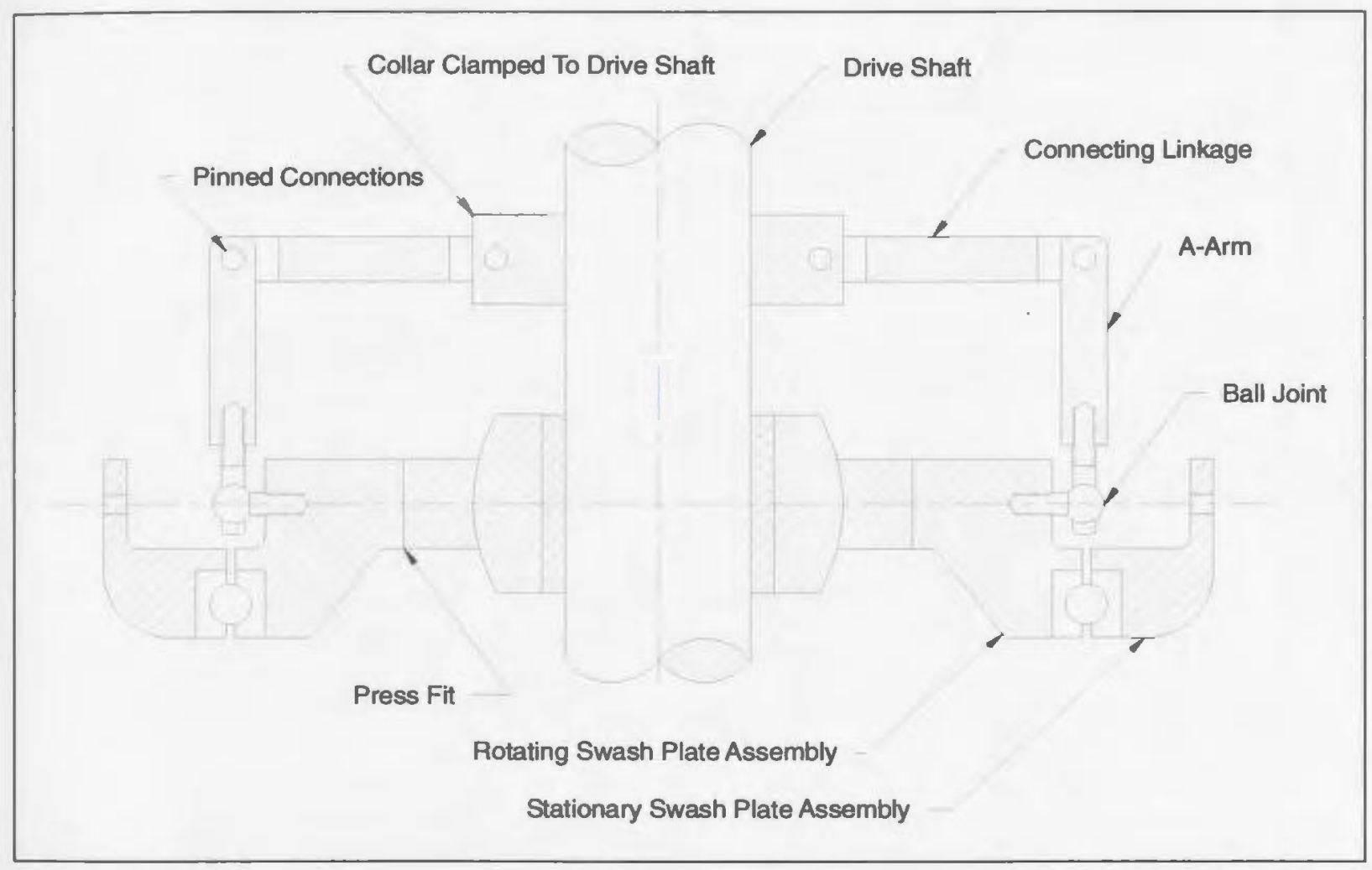

Figure 3.3: Rotary Synchronization Linkage Detail

During operation, the swash plate pair can be inclined or translated. This posed a problem of how to keep the point of zero pitch on the axis of rotation of the shaft. The solution to this problem is to use a spherical ball joint to ensure the swash plate pair remains centered, Figure 3.4. The ball joint allows the swash 
plate pair the ability to be inclined and to translate up or down the rotor drive shaft [CHP, 2004]. The translation of the swash plate pair controls the collective pitch of the rotor blades and the inclination controls the cyclic pitch of the rotor blades. The center of the spherical ball bearing usually contains a bushing to reduce the friction associated with sliding the ball joint up and down the drive shaft.

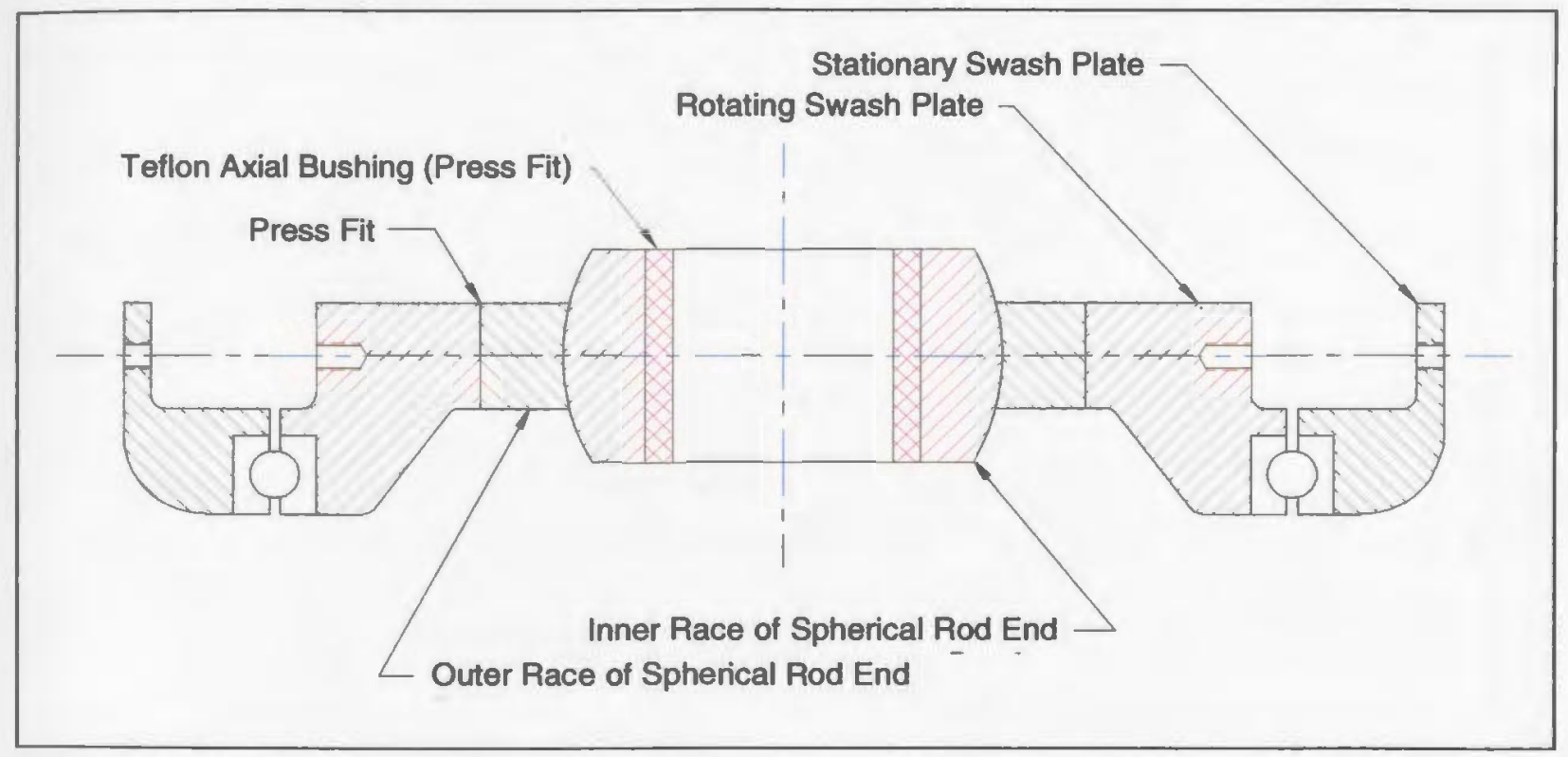

Figure 3.4: Spherical Bearing Detail

As with most complicated linkages, there are subtle details with the linkage configuration that are important for proper operation. With helicopter swash plates, the relationship of the rotating control rods to the point of zero pitch is extremely important. The only configuration that will allow proper operation of the swash plate pair is shown in Figure 3.5. Note that the plane created by the 
mounting holes for the blade pitch controls must also contain the point of zero pitch of the swash plate, which is located at the vertex of rotation for the spherical ball joint.

Understanding the mechanics of swash plate operation is important for understanding how the CPCPP operates. It is the relationship between the swash plate pair, lock and synchronization linkages and spherical ball bearing that allow the blades of the CPCPP to generate the required thrust field. The relationship of the swash plate to the control linkages and blades can be seen in Figure 2.1.

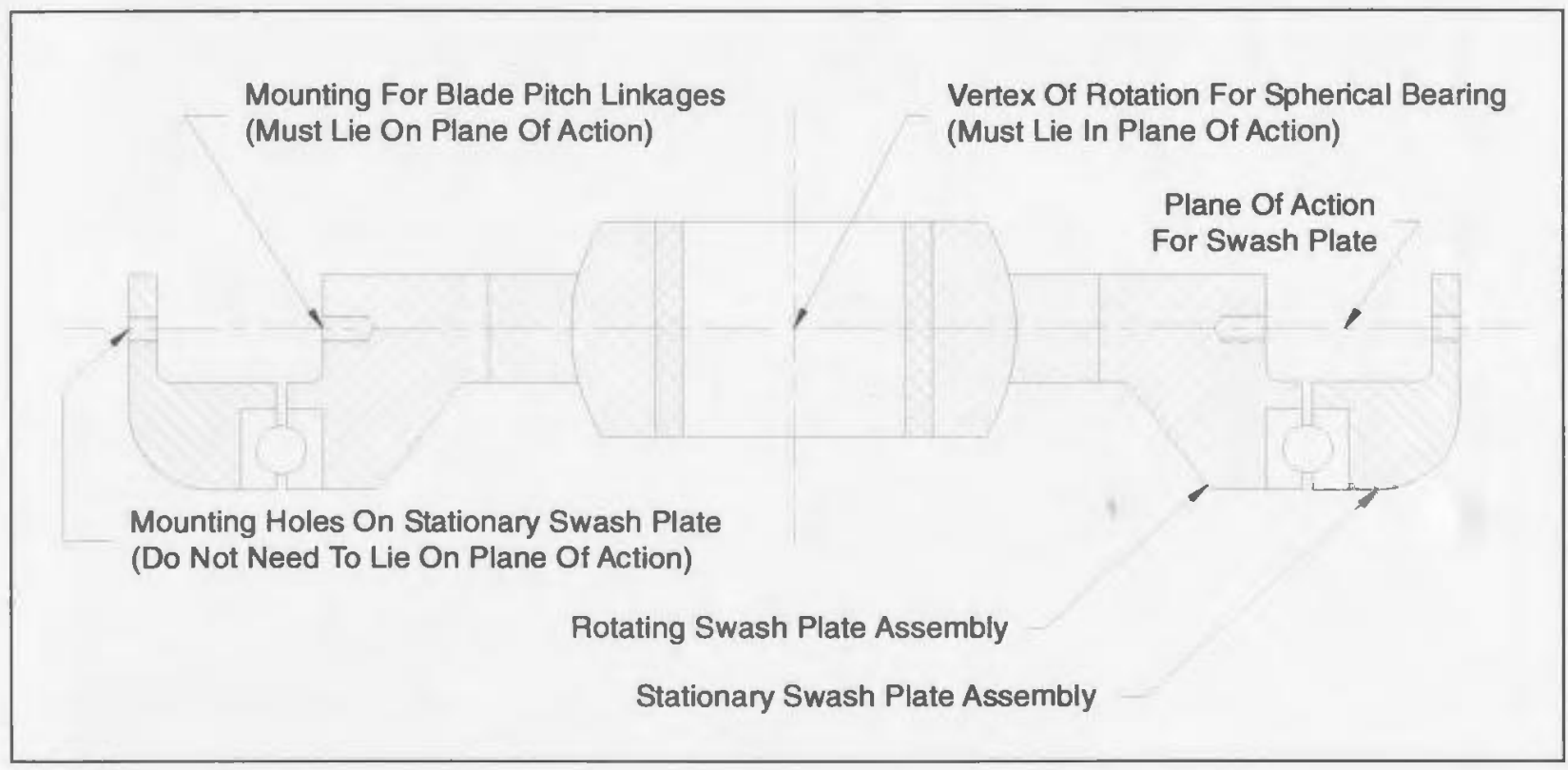

Figure 3.5: Control Rod to Swash Plate Ball Relationship 


\subsection{Airfoil Theory}

Airfoil or hydrofoil theory is an important consideration for all propeller design problems. It is the lift and drag generated by the propeller blades that create the thrust of a propeller. While foil theory is fairly simple as far as the concepts presented in this thesis, a brief overview shall be presented for completeness.

\subsubsection{Lift of Foils}

Airfoils or hydrofoils are streamlined bodies that create lift forces and have low drag forces [Shevell, 1989]. A differential pressure between the top and bottom of the foil primarily creates lift from a foil. The differential pressure is developed by inclining the foil to the incoming flow and/or by introducing camber in the foil,

Figure 3.6 [Hess et al., 1967].

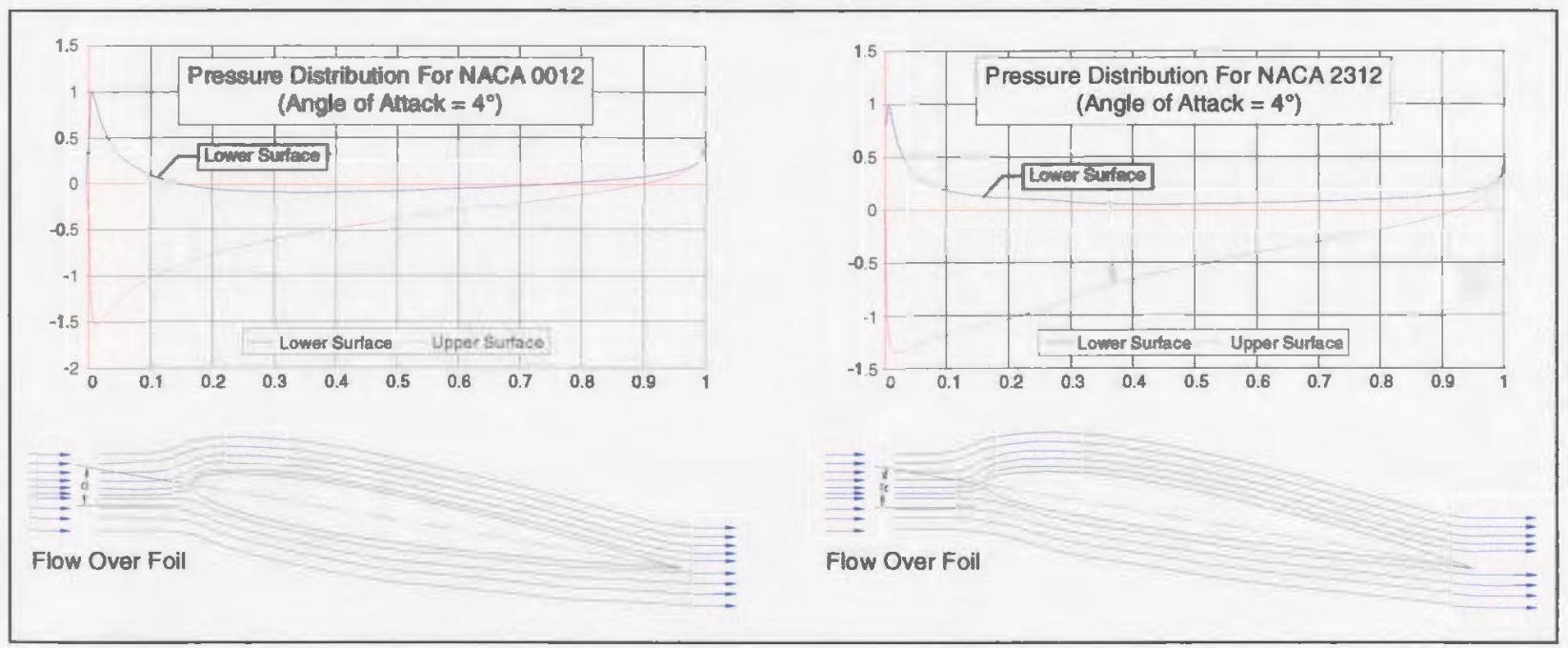

Figure 3.6: Foil at Angle of Attack With and Without Camber 
While both types of foil produce lift, the primary difference between the two methods is that a foil with camber will produce lift at zero angle of attack. This generated lift occurs with a lower pressure peak at the leading edge. The generation of lift at zero angle of attack has an important effect on the drag of the foil, which will be discussed later. Propeller blades are typically manufactured from cambered type foil sections with some degree of blade twist. The cambered section improves the efficiency of the propeller near the optimum operating point of the propeller, while the blade twist improves efficiency and can reduce tip loading of the propeller in the off design condition [Lewis, 1988].

Helicopter rotors, on the other hand, are typically manufactured using symmetric airfoil sections having no camber [Cantrell, 2004]. This style of foil is popular in this application due to the nature of helicopter blade operation. A ship's weight is entirely supported by water and the propeller provides predominately forward motion at some efficient cruising speed. A helicopter's rotor must not only lift the weight of the vehicle, but also provide the ability to fly forwards, backwards and side to side, Figure 3.7. While ship propellers are usually designed to be efficient at one operating condition, a helicopter rotor must be efficient over a wide range of operation. Therefore, rotor blades tend to be constructed with no blade twist. This is due to two primary reasons. The first reason is that the blades of the helicopter tend to have relatively small angles of attack to the flow compared to a 
propeller. The second reason is that most of the lift generated from a helicopter rotor occurs in the outer 30 percent of the blade length. Twisting the blade has a minimal effect on the efficiency at the blade root. Also, as the blade is operating in air, there is no need to reduce the tip loading to reduce cavitation.
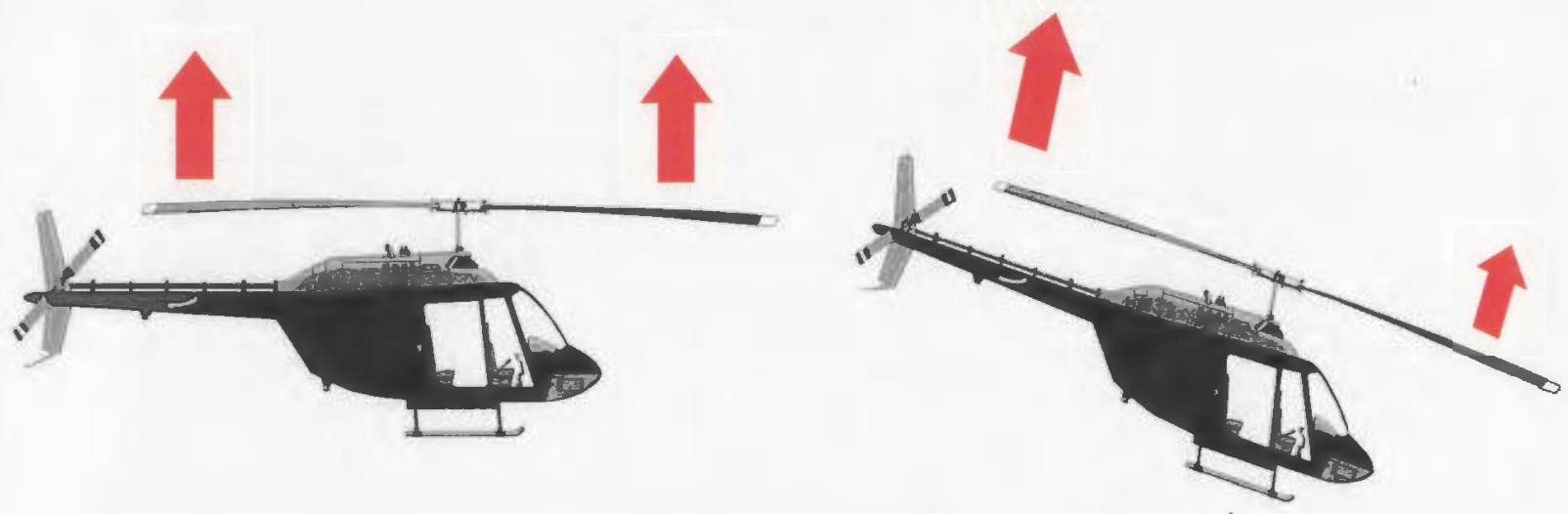

Figure 3.7: Helicopter Rotor Thrust Vectoring

\subsubsection{Drag on Foils}

All bodies moving in a fluid experience drag. Foil sections experience drag resulting from the integration of pressures around the foil and drag induced by lift generation. The first type of drag is referred to in the literature as parasitic drag, while the second type of drag is referred to as induced drag [Shevell, 1989]. The amount of parasitic drag is highly dependent on whether the flow of the fluid is laminar or turbulent. In the majority of cases, although not as important for small low speed propellers, the flow of the fluid is turbulent in the boundary layer for all practical foil designs including propellers. 
The amount of induced drag is related to the amount of lift being generated by the foil. A foil generating lift produces a vortex wake field around the foil. The strength of this vortex field, and the consequential downwash, is related to the lift created by the foil section. As the lift generated by the foil increases, the strength of the vortices increases [Shevell, 1989]. This in turn increases the magnitude of the downwash and the drag.

The plot of experimental data from Abbott and von Doenhoff [1959] illustrates this relationship between induced drag and lift coefficient. From the plot of lift coefficient $\left(C_{L}\right)$ vs. angle of attack $(\alpha)$ in Figure 3.8, it can be seen that the value of $C_{L}$ is approximately equal to $\alpha$ for an airfoil operating below its value of maximum lift. There is a parabolic relationship between the values of $C_{L}$ and Drag coefficient $\left(C_{D}\right)$, as shown in the plot of $C_{L}$ vs. $C_{D}$ in Figure 3.8. From these observations, equation 3.1 can be written.

$$
C_{D}=C_{D O}+k C_{L}{ }^{2}
$$

The parasitic drag is represented in this equation by the value $C_{D o}$. The induced drag is represented by the $\mathrm{C}_{\mathrm{L}}{ }^{2}$ term in the equation. The constant $\mathrm{k}$ allows for the steepness of the parabolic relationship, which is dependent upon the Reynolds number and the extent of turbulent flow over the foil. 


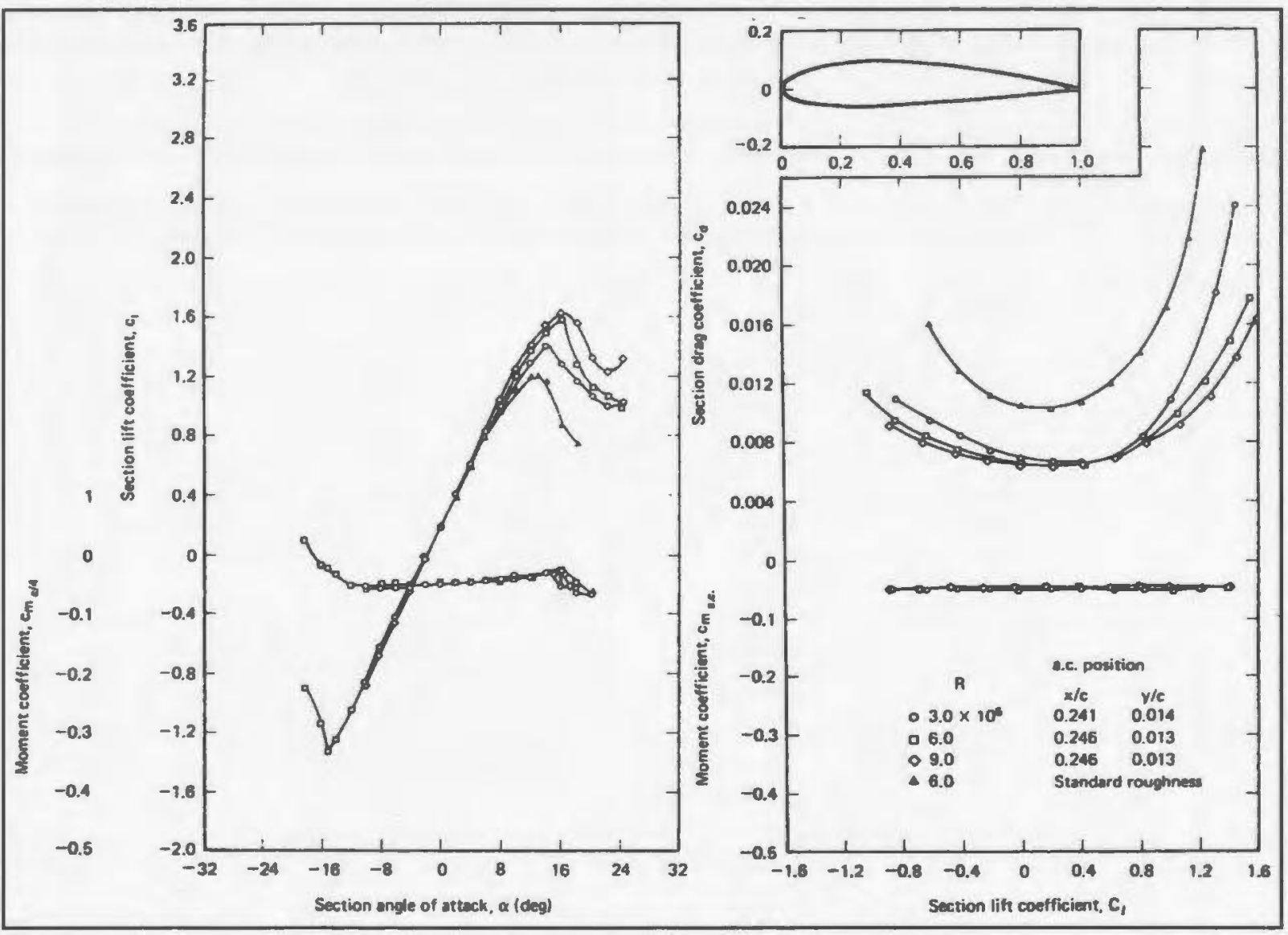

Figure 3.8: Plots of $C_{L}$ vs. Alpha and $C_{D}$ vs. $C_{L}$ for a NACA2415 Section

\subsubsection{Thrust and Torque}

When designing a propeller, the amount of thrust and required torque for the propeller are the primary concerns [Lewis, 1988]. To determine the thrust and torque values, the lift and drag on the propeller blades must first be calculated. It 
is important in foil design to remember that the drag force (D) is always parallel to the free stream velocity, while the lift force $(L)$ is always perpendicular to the free stream velocity. Therefore, one needs to translate the lift and drag values into thrust and torque. A vector diagram illustrating this translation can be seen in Figure 3.9.

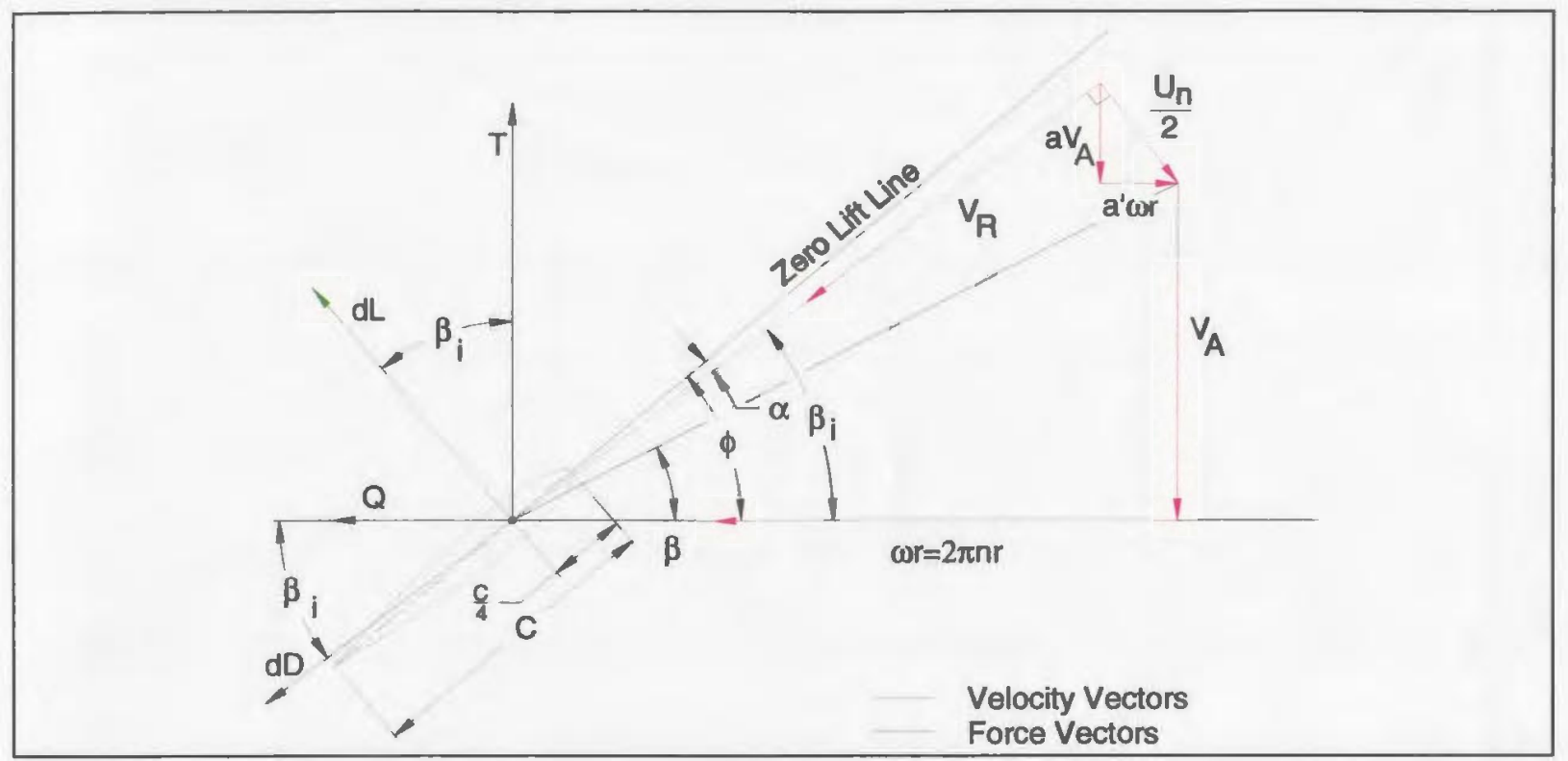

Figure 3.9: Relationship Between Lift, Drag, Thrust and Torque

From the diagram, one can see that the equations for calculating the thrust and torque for a propeller blade in uniform flow are as follows:

$$
\begin{aligned}
& d T=d L \cdot \cos \left(\beta_{i}\right)-d D \cdot \sin \left(\beta_{i}\right) \\
& d Q=\left(d L \cdot \sin \left(\beta_{i}\right)+d D \cdot \cos \left(\beta_{i}\right)\right) \cdot d r \\
& \beta_{i}=\tan ^{-1}\left[\frac{V_{A} \cdot(1+a)}{2 \cdot \pi \cdot n \cdot r \cdot\left(1-a^{\prime}\right)}\right]
\end{aligned}
$$


As the blade of the propeller is rotating as well as advancing into the flow, the formulae are dependent on the radial distance from the hub centerline. These formulae are the starting point for most propeller design calculations.

The CPCPP adds a further level of complexity to the equations above [Cantrell, 2004]. While a conventional propeller blade has the same angle of attack to the flow as the propeller rotates, the cyclic pitch of the CPCPP blades is varying the pitch angle of the blades to the flow as the propeller rotates about its axis of rotation. For example, for a two-bladed CPCPP, the cyclic pitch increases the angle of attack on one blade (the advancing blade) of the propeller and decreases it on the other blade (the retreating blade) of the propeller. It is this variation in angle of attack that produces the differential thrust across the propeller and provides the maneuvering forces. These variations in lift and drag due to radial position, variation in angle of attack, and complex flow regimes created make thrust and torque more difficult to calculate. In addition, the induced velocity from the wake, which in this case is unsteady, really makes the thrust and torque extremely difficult to calculate analytically. 


\subsection{Blade Geometry}

There are many geometric considerations that must be taken into account when designing a propeller. Blade twist, loading, area ratio, skew, rake, number and shape are just some of the things that must be considered. For collective and cyclic pitch propeller systems blade rake, number and shape are more important than most of the other considerations and will be discussed in more detail. Blade area ratio, twist, skew and loading are of lesser importance, at least in the first design cycle, for a CPCPP. The area ratio for example affects the blade loading and the propellers tendency to cavitate during operation. While blade area ratio is not as critical for this propeller, it would become very important in a highly load propeller.

For the CPCPP prototype, blade twist is undesirable as it can only be optimized for one design pitch of the blades. As the CPCPP relies on changing the blade pitch to produce changes in both collective and cyclic thrust, having a blade with twist would not be optimal in most operating conditions.

\subsubsection{Blade Rake}

Blade rake is one of the most important considerations when designing a CPCPP [Bijleveld, 2002]. While rake of a standard propeller is typically done to allow 
larger propellers to be installed at the stern of ships, blade rake has a large effect on the side forces generated by a cyclic pitch propeller. The lift and drag generated by the propeller blades is perpendicular and parallel to the free stream velocity respectively. The resulting vectors for thrust and torque can be found in Figure 3.10.

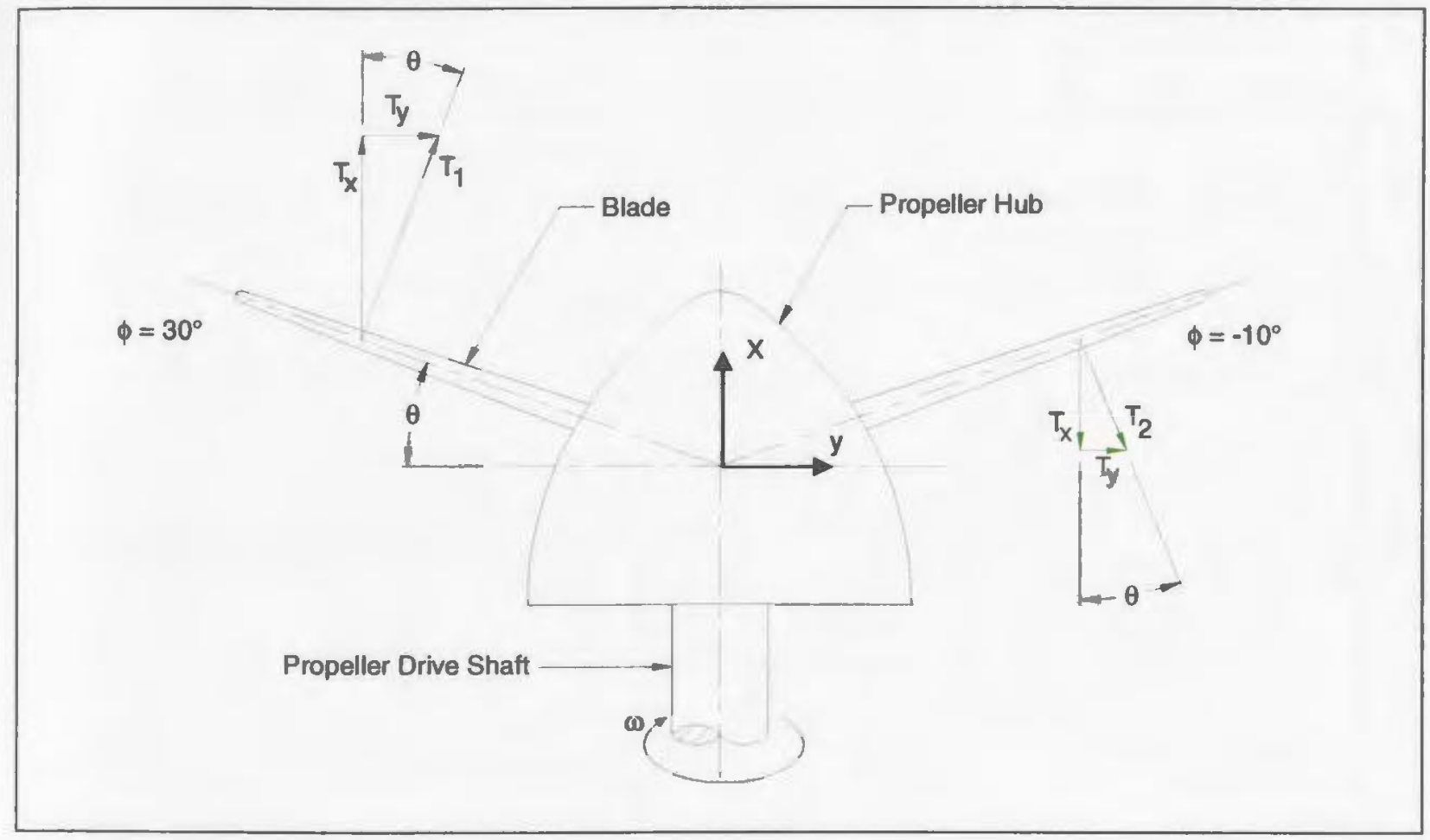

Figure 3.10: Effect of Blade Rake on Thrust Vector

As the thrust from the propeller blade is perpendicular to the blade axis of rotation, the thrust vector has components in the $x$ and $y$ directions. The $x$ component thrusts the vehicle ahead or astern. The y component provides lateral or maneuvering thrust. As seen in equations 3.5 and 3.6, the amount of lateral thrust is dependent on the rake angle $\theta$ of the propeller. As rake angle 
increases the amount of lateral thrust increases. If you follow this example to the extreme, the configuration of the propeller behaves like that of a Voith-Schneider or Kirsten-Boeing Propeller [Lewis, 1988]. These two vertical axis propellers, however, produce no thrust along the axis of rotation. In the case of a CPCPP, it is desirable to have the majority of thrust along the axis of rotation in order to propel the vehicle forward. Maneuvering or lateral thrust is also desired. For this reason, $\mathrm{PhD}$. student Jungyong Wang, to determine the optimum rake, analyzed the rake angle between 0 and 45 degrees. Using the thrust prediction model discussed in Section 3.5, values of ahead/astern thrust and side thrust were calculated at various rake angles in this range. A rake angle of $20^{\circ}$ was determined to provide a good compromise in forward thrust for a gain in maneuvering thrust.

$$
\begin{aligned}
& T_{X}=T_{1} \cdot \cos (\theta)-T_{2} \cdot \cos (\theta) \\
& T_{Y}=T_{1} \cdot \sin (\theta)+T_{2} \cdot \sin (\theta)
\end{aligned}
$$

\subsubsection{Blade Number}

While blade number has a relatively small effect on the efficiency of a conventional propeller, the number of blades has a fairly large effect on the effectiveness of a CPCPP. The blades of the CPCPP oscillate cyclically as the propeller hub rotates. The greater the number of blades, the smoother the thrust 
vector produced from the propeller becomes [Lewis, 1988]. If one looks at the simplest case, a two bladed propeller, it is easy to visualize the shortcomings. Assuming the generated thrust vector is aft and pointing to the right, then the lateral thrust generated as the propeller blades rotate $90^{\circ}$ drops to zero. As the propeller rotates a further $90^{\circ}$, the lateral thrust is increased to its original value. This cyclic loading continues as the propeller rotates and generates a pulsed type operation.

Pulsed operation, though always present in blade propellers, produces unnecessary vibration and problems with fluid acceleration. The CPCPP operates more effectively by reducing the cyclic variations during operation. This can be accomplished by adding more blades to the propeller. The addition of blades ensures that the lateral thrust vector is always present as the propeller rotates.

During the testing of a number of different vertical axis propellers, MARIN [Van Manen, 1966] determined that these types of propellers produce the greatest efficiency when configured with six blades. It is therefore reasonable to assume that CPCPP systems with six propeller blades would show a similar result, as operation is similar to the vertical axis propeller. However, building a six bladed CPCPP for an AUV would prove very difficult due to the limited space inside of 
the propeller hub for all of the required linkages. For this reason, a four bladed propeller was deemed to be the best option, as this was the maximum number of blades that could be installed in the propeller hub.

\subsubsection{Blade Shape}

The shape of a propeller blade depends largely on blade loading and the desire to reduce the onset of cavitation during operation [Lewis, 1988]. Loading the blade too heavily at the tip can cause tip cavitation and unusually high bending loads at the blade root. The selection of blades for the CPCPP followed the convention of other similar technologies. The helicopter rotor and vertical axis propeller all use thin high aspect ratio blades to improve efficiency. When operating in water, the area ratio must be kept high enough to prevent blade loading induced cavitation. For lightly loaded or deeply submerged propeller blades, cavitation is usually not a problem. The minimum area ratio for CSCOUT was determined to be 0.110 by Thomas (2003). Due to limits in machining and blade mounting, the projected area ratio for the CPCPP has a value of 0.180 . 


\subsubsection{Final Blade Geometry}

For the prototype collective pitch and cyclic pitch propeller, a propeller hub with four blades was constructed. The blades were designed with a section containing no camber or twist to allow the propeller to have similar thrust properties in both the ahead and astern directions. The cross section of the finished blade was a NACA section that varied from a NACA 0050 at the root to a NACA 0006 at the blade tip. The NACA 0050 section at the root provided sufficient thickness and rigidity for the blade attachment at the propeller hub. The blade tapered quickly from the NACA 0050 section to a NACA 0012 section to reduce the drag on the propeller blades during operation. The propeller blades were constructed with no skew and installed in the hub of the propeller at a rake angle of $20^{\circ}$.

\subsection{Thrust Predictions}

A calculation of the thrust a propeller will be able to generate is a very useful design tool. Most designs begin with this type of calculation in order to predict the performance of a new propeller. While there are many aids available for calculation of conventional propeller performance, there is no simple solution for cyclic and collective pitch propellers. For this reason, a spreadsheet was 
developed to calculate the thrust and torque for the propeller by co-student Jungyong Wang.

The cyclic operation of the propeller poses a problem during calculation as the blade pitch angle changes as the propeller rotates. To solve this, an integration approach is required. The lift and drag produced by the propeller blades was calculated for thin sections along the length of the propeller blade at each pitch angle. The results were then summed to produce the thrust and torque created by each blade as it rotated through $360^{\circ}$ of operation. A typical plot for the generated side force can be seen in Figure 3.11. Lifting line theory was used to produce these calculations [Eckhardt et al., 1955].

From the preliminary analysis, a propeller $305 \mathrm{~mm}$ (12 in) in diameter with a rotational speed of 600 RPM was determined to be a good choice for a vehicle the size of C-SCOUT. 


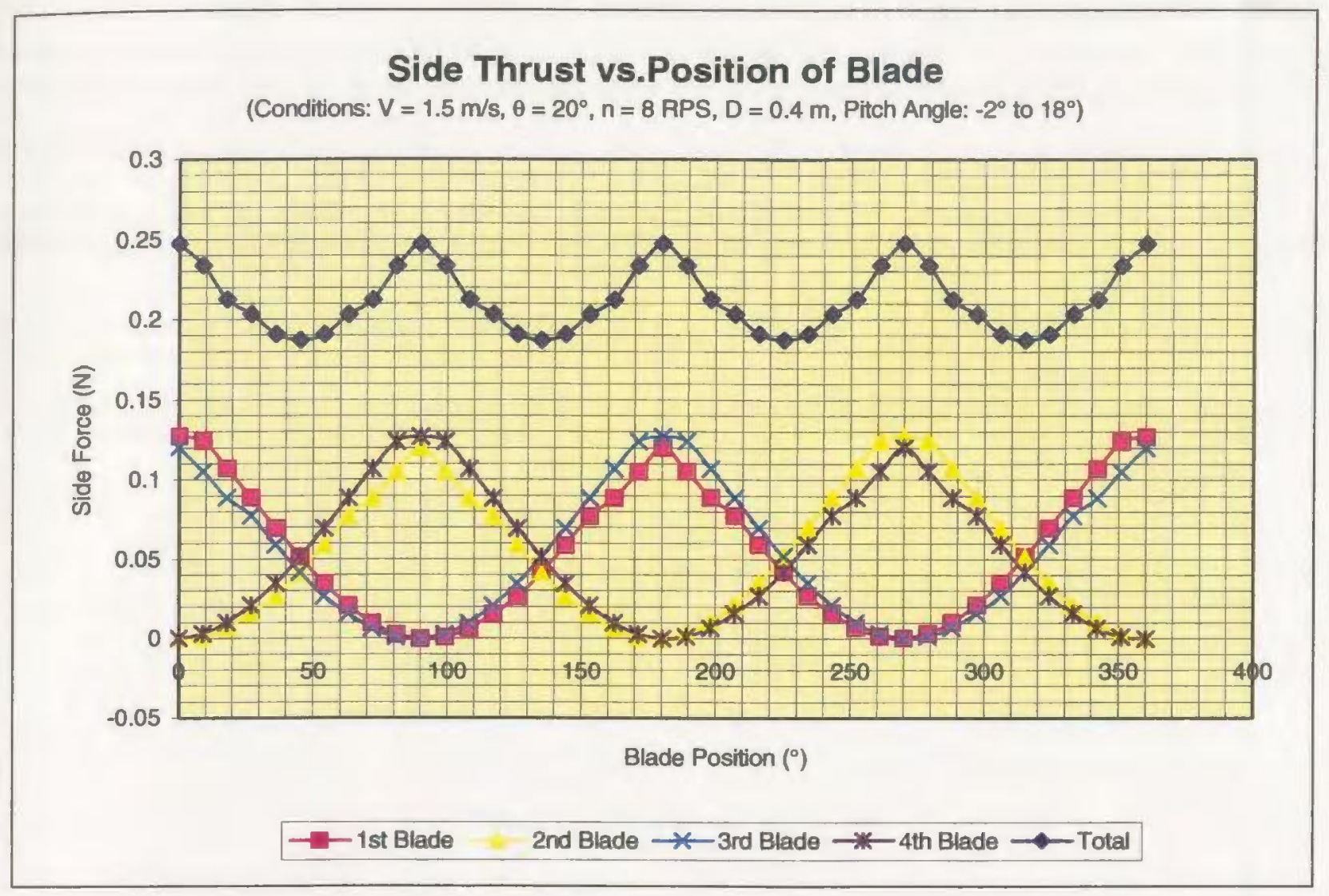

Figure 3.11: Side Force Predictions

\subsection{C - SCOUT Drag Curve}

In order to determine the propulsive thrust required, it is important to know the drag characteristics of the vehicle as the speed increases. This information allows the designer to determine values for blade pitch, propeller diameter, propeller RPM, etc. A graph illustrating this information can be seen in Figure 3.12. The graph was generated using data from the self-propulsion trials by 
Thomas [2003]. This graph will be used later in this thesis to determine the approximate speed of a C-SCOUT vehicle propelled using a CPCPP system.

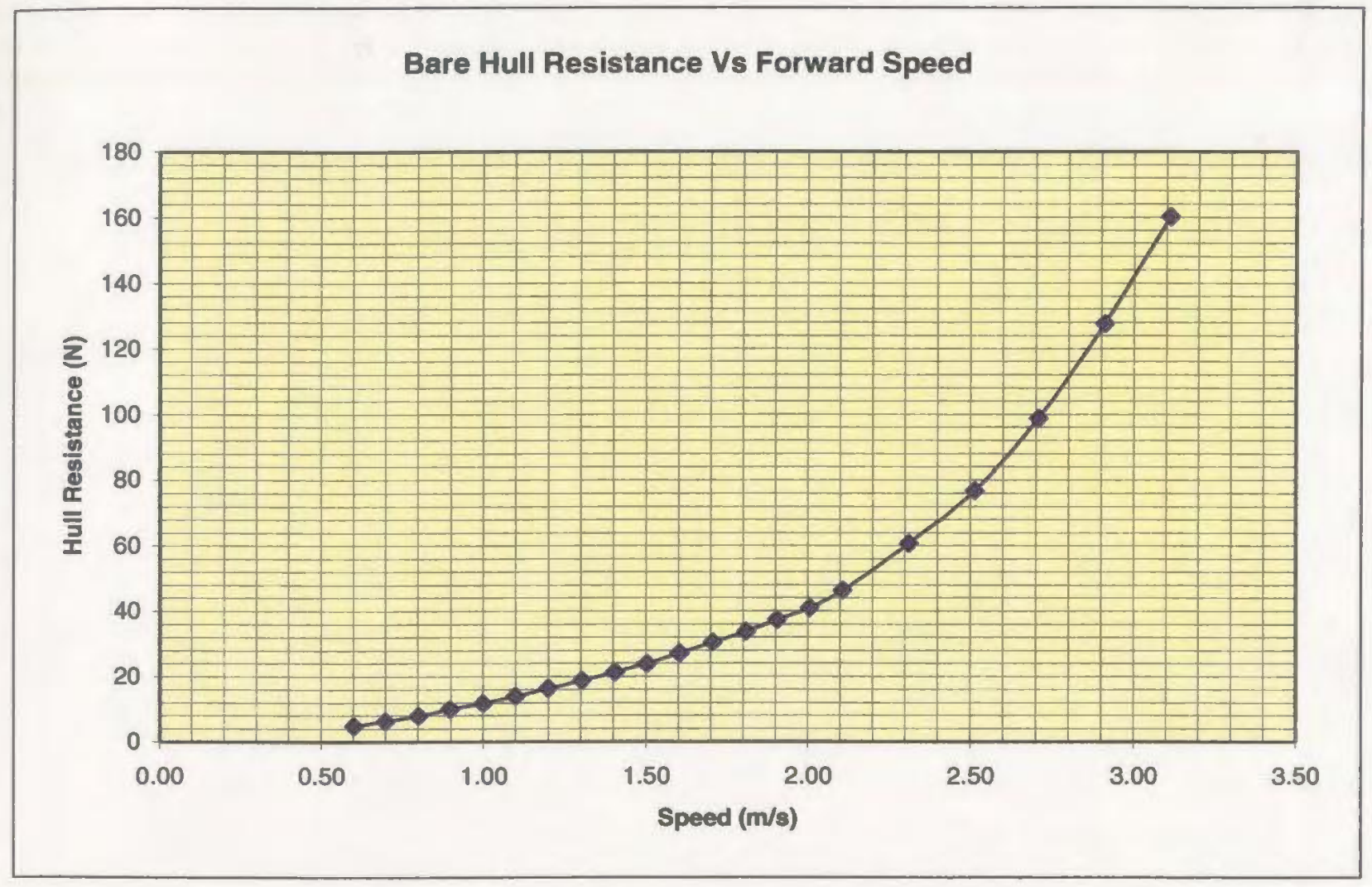

Figure 3.12: Bare Hull Resistance Curve for C-SCOUT 


\section{Chapter 4 Design Concepts}

\subsection{Introduction}

Due to the complexity of a CPCPP, the propeller was broken down into sub systems to make a comparison of candidate designs. Before initiating design concept, the parameters of the propeller, the constraints and the criteria need to be outlined. These specifications ensure that the completed design will function as intended.

\subsection{Design Parameters}

As this was a new propeller design, there was a fair amount of freedom in how the final product was to be designed. The final propeller was going to be used with C-SCOUT, so the design had to work with the existing power and communication systems. The final design was also required to be capable of being bolted onto the stern of the C-SCOUT vehicle. The following constraints and criteria were established to achieve these functions. They are outlined in Table 4.1. 
Table 4.1: Constraints and Criteria

\begin{tabular}{|c|c|}
\hline Constraints & Criteria \\
\hline $\begin{array}{l}\text { - Maximum Diameter of Propeller } \\
\text { Housing: } 0.400 \mathrm{~m} \text { (15.75 in) }\end{array}$ & $\begin{array}{l}\text { - Final design neutrally buoyant or } \\
\text { slightly positively buoyant }\end{array}$ \\
\hline $\begin{array}{l}\text { - Maximum Propeller Diameter: } 0.400 \mathrm{~m} \\
\text { (15.75 in) }\end{array}$ & $\begin{array}{l}\text { - Compatible with existing control and } \\
\text { power systems }\end{array}$ \\
\hline - Minimum Depth Rating: 30 m (98 ft) & - Semi intelligent control system \\
\hline $\begin{array}{l}\text { - Main Bus Voltage: } 24 \text { VDC or } 48 \text { VDC } \\
\text { - Control Input: TCP/IP, I²C or CANBUS }\end{array}$ & $\begin{array}{l}\text { - Electrically controlled and positioned } \\
\text { swash plate mechanism }\end{array}$ \\
\hline $\begin{array}{l}\text { Mounting: } 4 \text { Bolts on } 0.350 \mathrm{~m} \\
\text { (13.748 in) BCD. }\end{array}$ & $\begin{array}{l}\text { Generate maneuvering and control } \\
\text { forces in addition to vehicle thrust, } \\
\text { forward and reverse } \\
\text { - Robust, easily maintainable design. }\end{array}$ \\
\hline
\end{tabular}

\subsection{Piston Pump Design}

The first concept was modeled on the barrel design of a hydraulic piston pump, Figure 4.1. The hydraulic piston pump uses a swash plate and pistons mounted in a barrel to pump hydraulic fluid [Vickers, 1996]. By inclining the swash plate, the pump can increase or decrease the amount of fluid flow. In the case of a CPCPP, this would allow the control of the cyclic pitch. To control the collective 
pitch, an additional motion would need to be incorporated. By moving the location of the swash plate pin, the blade pitch could be adjusted collectively. This design would be limited to two bladed propellers, due to the failure of the pivoting arrangement of the swash plate to provide the necessary cyclic motion required. As testing of a multiple-bladed propeller was desired for performance, this design was not investigated further.

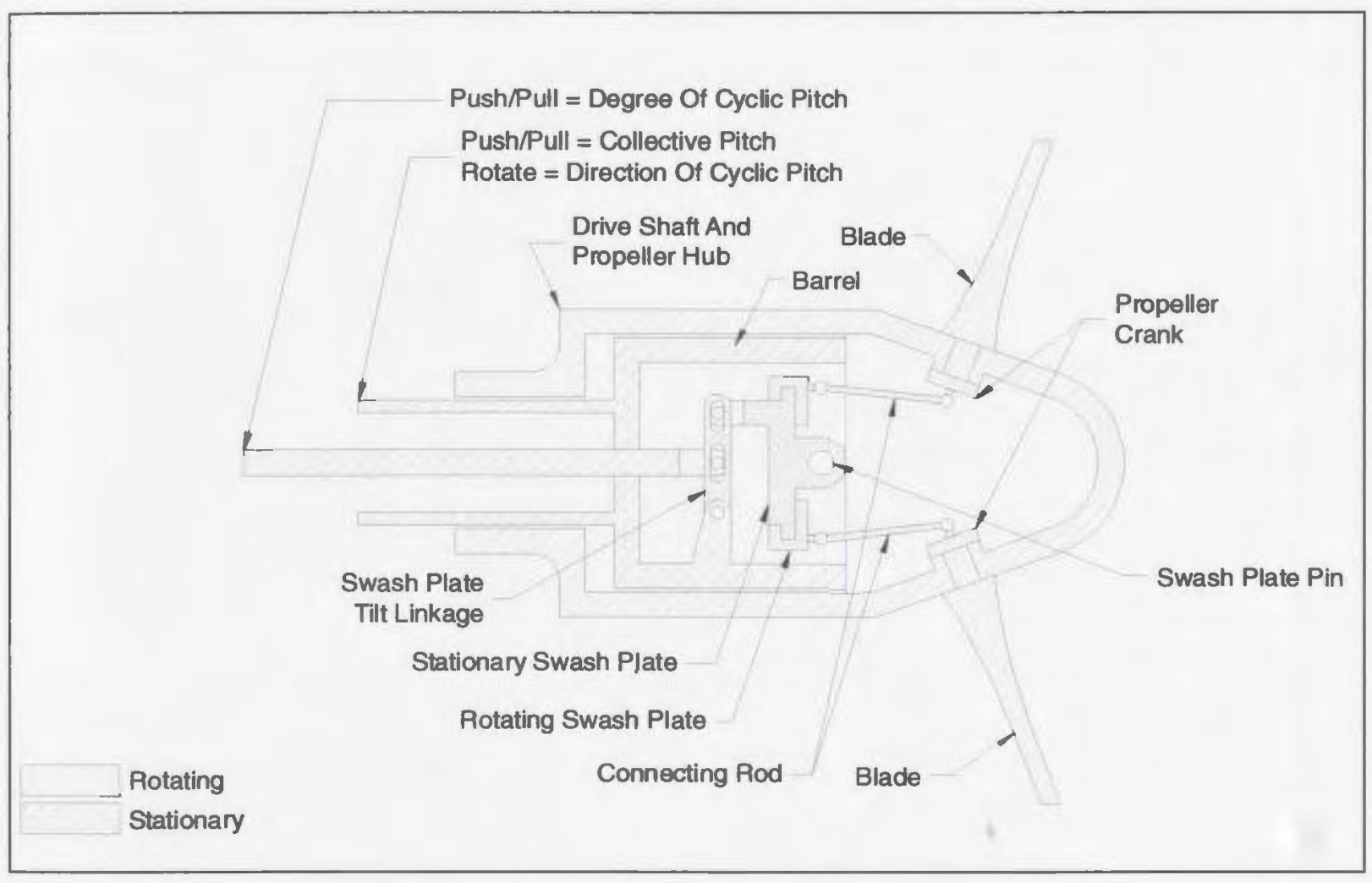

Figure 4.1: Piston Pump Design 


\subsection{Concentric Shaft Design}

The limitations of the cranks on the propeller blades, led to the investigation of a geared connection between the swash plate and the propeller blades. The swash plate would transmit the required translations down a series of concentric shafts. The shafts would then be connected to a gear system in the propeller hub that would connect the gear system to the blades. One of the possible solutions is illustrated in Figure 4.2.

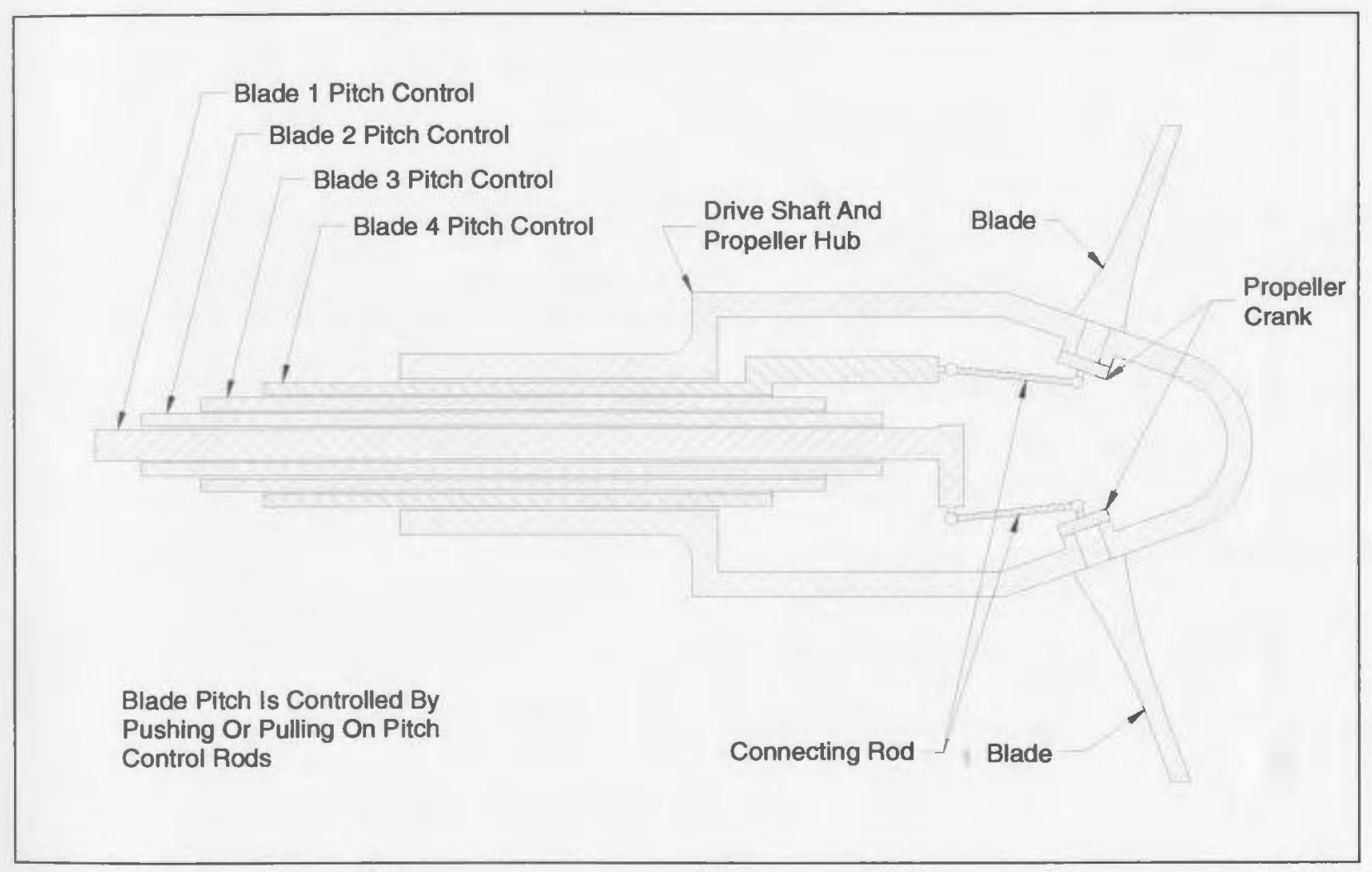

Figure 4.2: Concentric Shaft Arrangement for CPCPP 
There are a large number of seals required to make this propeller system function correctly. The difficulty in sealing this system was the primary reason this design was not investigated further during the design of this CPCPP. The manufacture of all of the gears required for this propeller would have made the propeller expensive to build in a one off scenario. While this option was not viable for this particular CPCPP, this method of actuation holds great promise for future CPCPP development.

\subsection{Hub Mounted Mechanism}

The next concept placed the swash plate mechanism inside of the propeller hub,

Figure 4.3. This swash plate could be tilted to obtain cyclic pitch or moved along the axis of the propeller shaft to obtain collective pitch [Bijleveld, 2002]. This concept was modeled in greater detail and appeared to be a practical solution. Placing the swash plate inside of the propeller hub means that the four control rods, which can be seen in the bottom left corner of Figure 4.3, only need to be moved to position the swash plate. This conserves energy and reduces the wear on parts in the dry side of the propeller system.

Upon further investigation, it was discovered that there was insufficient space in the hub to house both the connecting linkages and the swash plate 
synchronization linkages. These synchronization linkages ensure that the stationary swash plate does not rotate and that the rotary swash plate rotates in sync with the shaft. Due to lack of space for all of the required linkages, a different approach was required for this particular application.

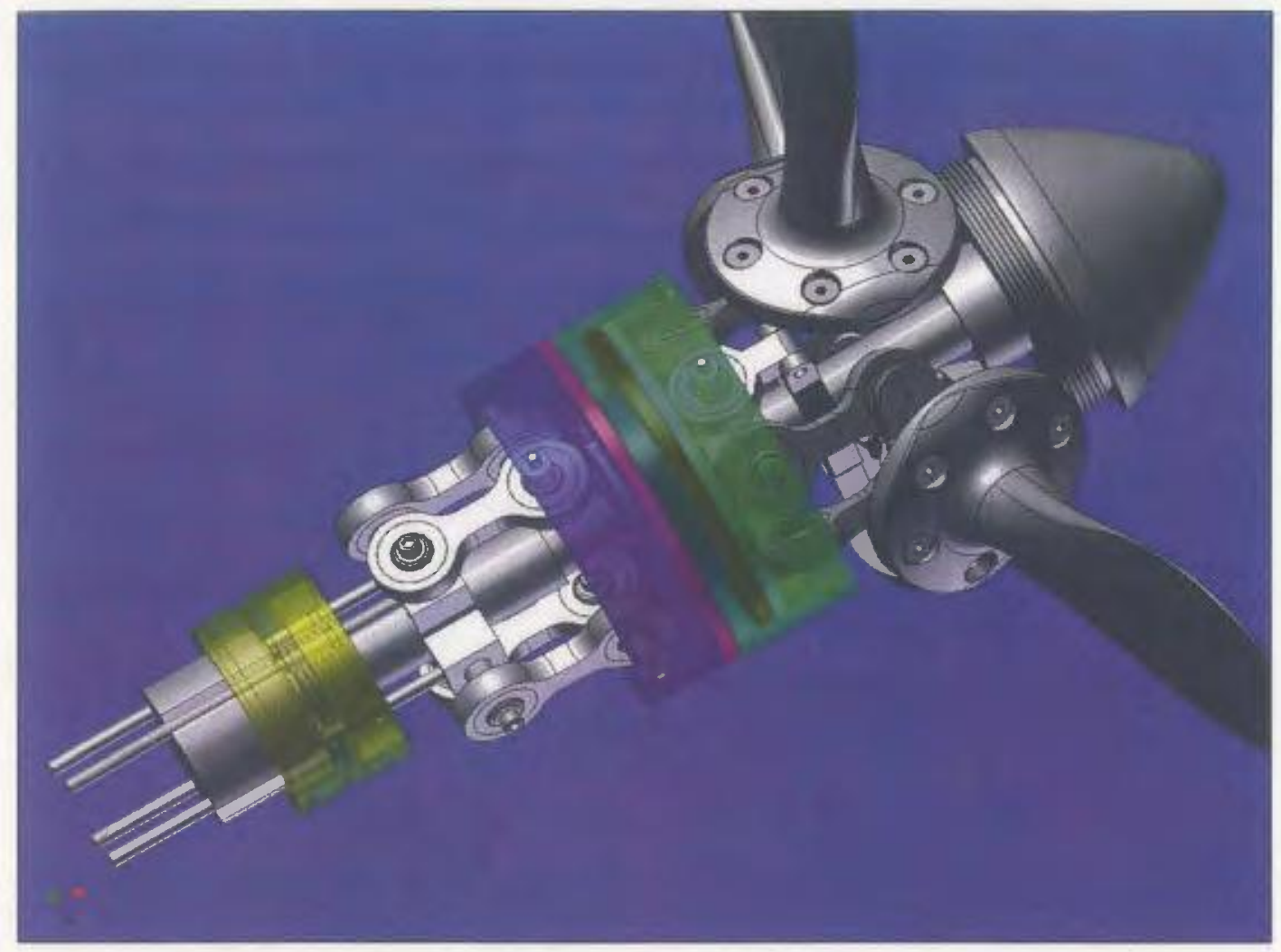

Figure 4.3: Swash Plate in Propeller Hub

This design potentially places all moving parts within the propeller hub. As the propeller hub is filled with lubricant to prevent water ingress, all the mechanical parts are in an oil bath. This would greatly reduce the lubrication maintenance 
required. As far as CPCPP designs go, this is one of the best options provided that there is sufficient hub space for the mechanisms.

\subsection{Hull Mounted Mechanism}

Due to the lack of space in the propeller hub, placing the swash plate inside of the main propeller pressure vessel was explored, Figure 4.4. This configuration has advantages and disadvantages. The primary advantages to the swash plate inside the main vessel are the increased space and reduced size of the propeller hub and the need for only a rotating drive shaft. The blades of the propeller are then connected using four control rods that run down the length of the propeller shaft. As these tie rods rotate at the same speed as the propeller, there is no need for a stationary shaft to carry the control rods like the hub-mounted solution.

By placing the swash plate mechanism inside of the pressure hull, the actuators that are used for position control could be connected directly to the stationary swash plate. This arrangement allows for easier maintenance of the moving parts and related components.

There are some disadvantages with this system. First we now need to seal four dynamic tie rods instead of four static ones. Second, the shaft must be drilled to 
allow the porting of the tie rods from the pressure hull to the propeller hub. Finally, the ends of the tie rods must be restrained to prevent buckling under the loads from the swash plate. The solutions to these problems and other design issues will be discussed in more detail in Chapter 5, as this was the chosen design for fabrication.

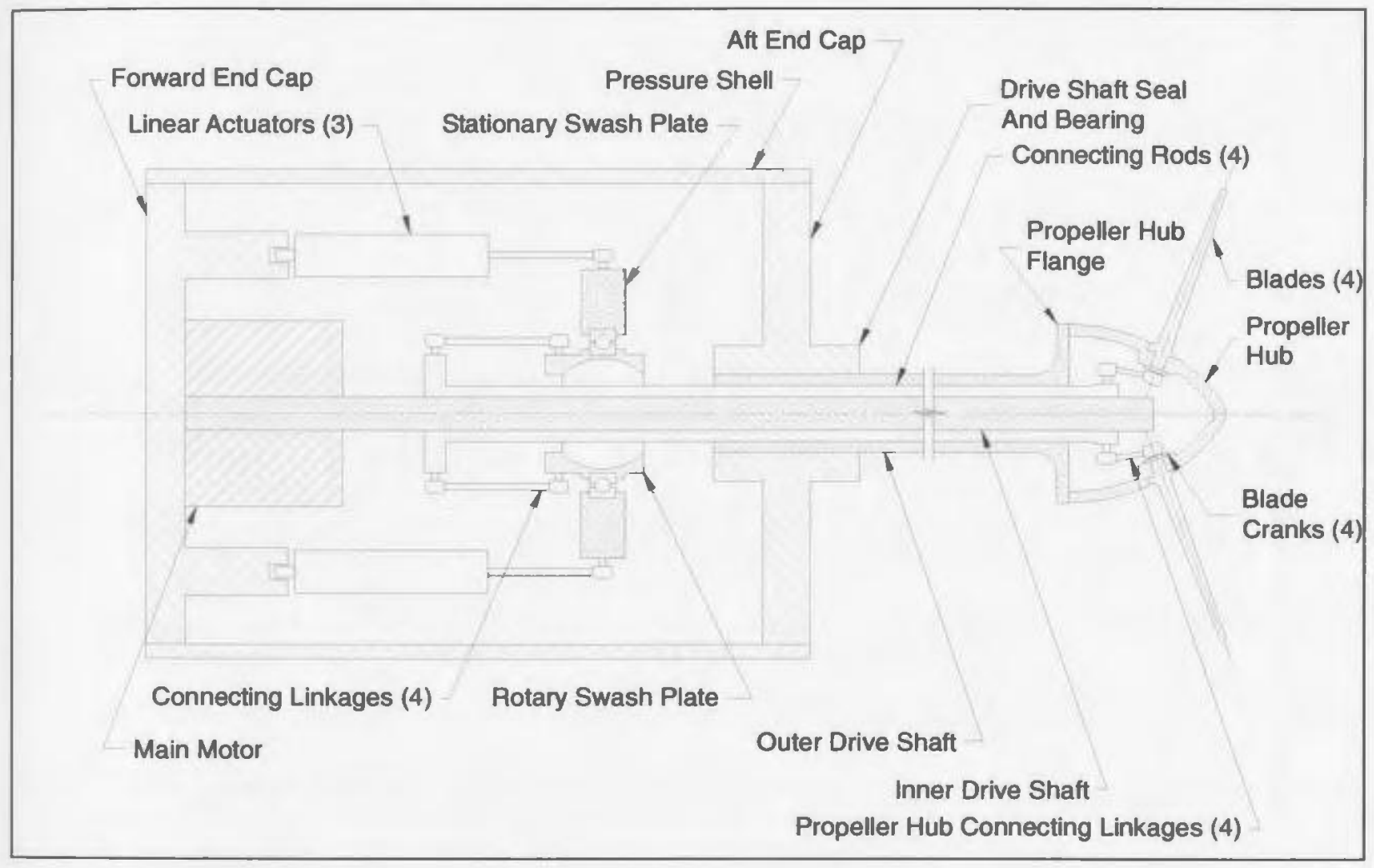

Figure 4.4: Hull mounted Mechanism 


\subsection{Linkage Concepts}

Helicopter rotors utilize a bar linkage system to connect the rotor blades and hydraulic actuators to the swash plate mechanism. For the CPCPP, a modified version of this arrangement seemed to be the best option. This system of connecting parts to swash plates can be found in just about all applications.

One other linkage concept that was investigated involves the use of gears instead of the crank and linkage concept. While this method was ruled out at an early stage due to manufacturing cost on a one off component, this connection system shows great promise. The gear connection system does not suffer from the motion range limitations of the crank solution. The potential for a crank mechanism to lock during operation limits the possible range of angular motion. A gear system does not have this weakness. The geared solution could be particularly useful for further work in feathering propeller systems for underwater gliders, double ended vehicles and, towed vehicles. Double-ended vehicles are fitted with a CPCPP at the bow and at the stern, as in the TPS. 


\subsection{Shaft Seals}

Sealing systems on submersible propulsors and related technologies are always a challenge. Most sealing systems commonly used can suffer from leakage problems. Many thruster designs, like those used in ROVs and AUVs, deal with this issue by filling the thruster with mineral oil and pressure compensating the case. The pressure compensation ensures that the pressure of the oil on the inside of the case matches the water pressure on the outside of the case, and reduces loading on the seals. This allows the thruster's housing to use a thinner wall thickness and hence be considerably lighter than a pressure-retaining version of the same case.

Some manufactures have taken this design to higher levels of sophistication by using a magnetic coupling between the propeller and the motor [RIL, 2002]. This reduces the need for a shaft seal completely. The torque from the motor is transmitted through the wall of the motor housing via rare earth permanent magnets. The propeller is then mounted on external bearings and has a matching set of magnets mounted in its hub. While this solution eliminates the shaft seal, it is not practical for large thrusters (greater than $3.7 \mathrm{~kW}(5 \mathrm{HP})$ ) due to limited torque transmission. The necessity for control rods in the shaft negates the use of this technology on CPCPP systems. 
Another popular solution is to use some form of packing gland and keep the housing at atmospheric pressure [Avallone et al., 1996]. There are many different types of seals that fit into this category. Stuffing boxes, mechanical seals, lip seals and o-rings are some of the more common. Most of these seals have issues with leakage. While this is acceptable for a nuclear submarine or a surface ship, submersible thrusters do not have the volume to deal with leakage. Some seals work very well, such as o-rings and lip seals, but are subject to pressure limitation. Dynamic o-ring seals work better at lower pressures (less than 1.37 MPa (200 psi)). Dynamic lip seals work better at higher pressures (above 1.37 $\mathrm{MPa}(200 \mathrm{psi})$ ), as they require pressure to complete the sealing action. There is always a trade off between sealing ability and shaft friction.

Mechanical seals are a good choice, as they have low friction and leakage. Contrary to manufactures' marketing ploys, mechanical seals do leak. This leakage is small but it must be dealt with in some manner if these types of seals are to be used. 


\section{Chapter 5 \\ Selected Design - Mechanical System}

\subsection{Introduction}

Developing a conceptual design for a collective and cyclic pitch propeller is only a small portion of the work required to construct a working prototype for testing. There are a great many details that need to be investigated and developed. This detailed design phase of the project is where the majority of the design work begins. This chapter will look at the detailed design of the CPCPP mechanical systems.

\subsection{Design Methodology}

The design of this project began with the design of a control scheme followed by the sourcing of appropriate fixed size components. The decision to make this propeller a self contained semi-intelligent system was one of the first choices made in the detailed design phase. This decision allowed the determination of many of the electronic components that would be integrated with the C-SCOUT communications system and the mechanics of the CPCPP. 
The sourcing of the fixed size components was also a very important first step in the design process. The controlling actuators, bearings and seals were all sourced and specified before the detailed mechanical design started. By sourcing these components first, it was ensured that there was sufficient space for all of the components to fit together and function as intended. The mechanical and structural components can then be built around these components to complete a functional design.

\subsection{Drive Shaft Development}

While there were other methods of translating cyclic and collective pitch from a set of control actuators to the blades of a propeller, the swash plate pair was the simplest and most effective method. For this reason the swash plate pair was chosen for the CPCPP. The stationary swash plate was direct coupled to the linear actuators for precise position control. However, the swash plate being located inside of the pressure vessel necessitated the connection of the rotary swash plate to the propeller blades in the hub. A system of four control rods was required to connect the propeller blades to the rotary swash plate. 


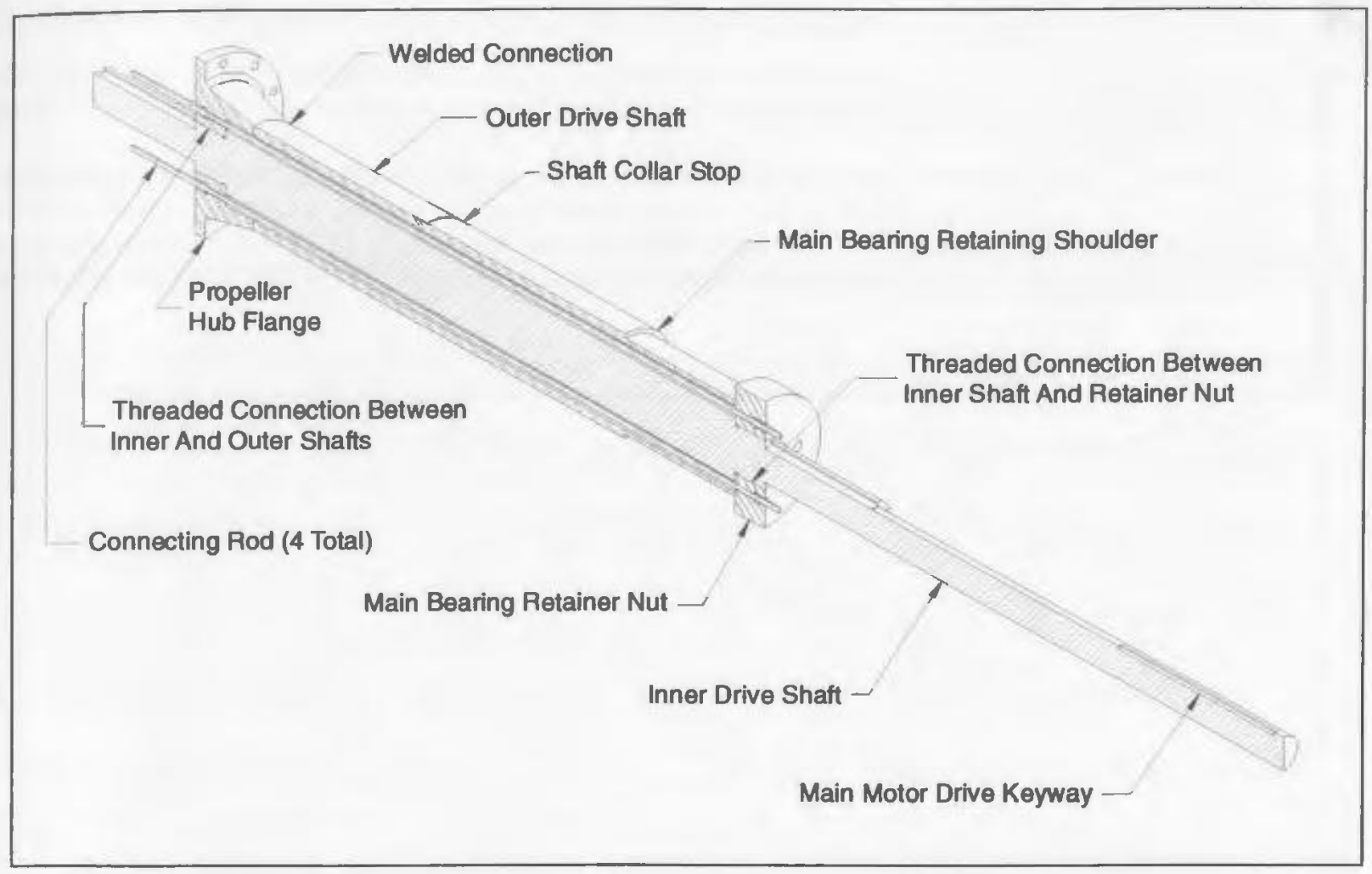

Figure 5.1: Shaft Line Layout

The control rods had to pass down the length of the drive shaft from the pressure vessel to the propeller hub. The best method of accomplishing this task would be to drill four holes $3.18 \mathrm{~mm}(0.125 \mathrm{in})$ diameter, located on the quadrant, axes down the length of the shaft (333 $\mathrm{mm}(13.1 \mathrm{in}))$. Unfortunately, the level of precision $( \pm 0.13 \mathrm{~mm}( \pm 0.005 \mathrm{in}))$ required to drill these holes down the drive shaft was not achievable in the Memorial University Machine shop. The shaft consequently had to be made in two pieces. An inner shaft was used to transmit the torque and carry the control rods in machined slots. An outer shaft was used for mounting of bearings and shaft seals. The control rods would be sealed at the propeller hub end of the shaft using dynamic o-ring seals. The ends of the 
control rods could then be connected to the rotating swash plate on the pressure vessel end, and to the cranks on the propeller blades on the hub end of the shaft. A sketch of this arrangement can be seen in Figure 5.1 above.

The completed drive shaft becomes the backbone of the CPCPP system. The drive shaft serves as a locating component of the main motor, swash plate and propeller hub in addition to transmitting torque from the main motor to the propeller blades. The relationship between the drive shaft and the other components will be discussed in more detail in Section 5.5 .

\subsection{Component Selection}

As mention in the Section 5.2, the fixed size components were selected prior to conducting a detailed design. These components were selected based on load, function and size constraints for the selected conceptual design. While this does not form a complete list of all fixed size components, these components were deemed critical for the development of a CPCPP system. These six components, discussed in Sections 5.4.1 to 5.4.6, were required for the CPCPP to function correctly. 


\subsubsection{Rod End Bearings}

The rod end bearings on the connecting rods of a helicopter rotor provide the necessary degrees of freedom required for proper operation. This was also the case for the CPCPP. The selection of these bearings was based on size, material, loading and range of movement.

The size of the bearings was the first consideration in the selection process, as space in the propeller hub is very limited. The eight selected bearings and their associated linkages had to fit inside of the propeller hub, and move without collisions with each other or the walls of the hub during operation. The large angles associated with motion in the propeller hub also dictated that the bearings required a large usable range of motion.

The materials chosen had to be suitable for seawater service. In the unlikely event that the propeller hub was contaminated with seawater, the bearing would be required to function until the CPCPP could be serviced. For this reason, stainless steel races and balls were chosen, using a Teflon bearing material. The balls were made from a hardened 400 series stainless steel and the races from a PH grade stainless steel. 
The loads imparted to the rod end bearings were determined to be fairly light as the pitching axis of the propeller blades was at the quarter chord point. The moment on the propeller blade at this point is theoretically zero for reasonable angles of attack to the flow.

After searching suppliers for bearings, a suitable bearing was found at Pacific International Bearing Inc. The WSSX3T was selected for this bearing. The detailed information can be found in Appendix B.

\subsubsection{Swash Plate Spherical Bearing}

The spherical swash plate bearing was important to ensure that the swash plate remains centered on the drive shaft. The selected bearing required a large operating angle and a bore large enough to install a Teflon axial bearing around the drive shaft. Pacific International Bearings Inc. had a bearing suitable for this purpose. The WSSX16T had a maximum unmodified inclination angle of $12^{\circ}$ and a bore of $25.4 \mathrm{~mm}(1.00 \mathrm{in})$ diameter. The material of the swash plate ball bearing was the same as selected for the linkage rod end bearings. More details about this bearing can be found in Appendix B. 


\subsubsection{Radial Bearings}

The main shaft bearings of a propeller must be capable of accepting both thrust and radial loading during operation. The radial bearings resisted the cantilevered loading produced by the propeller, while ensuring the propeller shaft could rotate with a minimum of resistance. The thrust bearing resisted the ahead or astern loads transmitted to the vehicle by the propeller. By using an arrangement of angular contact ball or roller bearings, as shown in Figure 5.2, the developed loads could be resisted by using only two bearings.

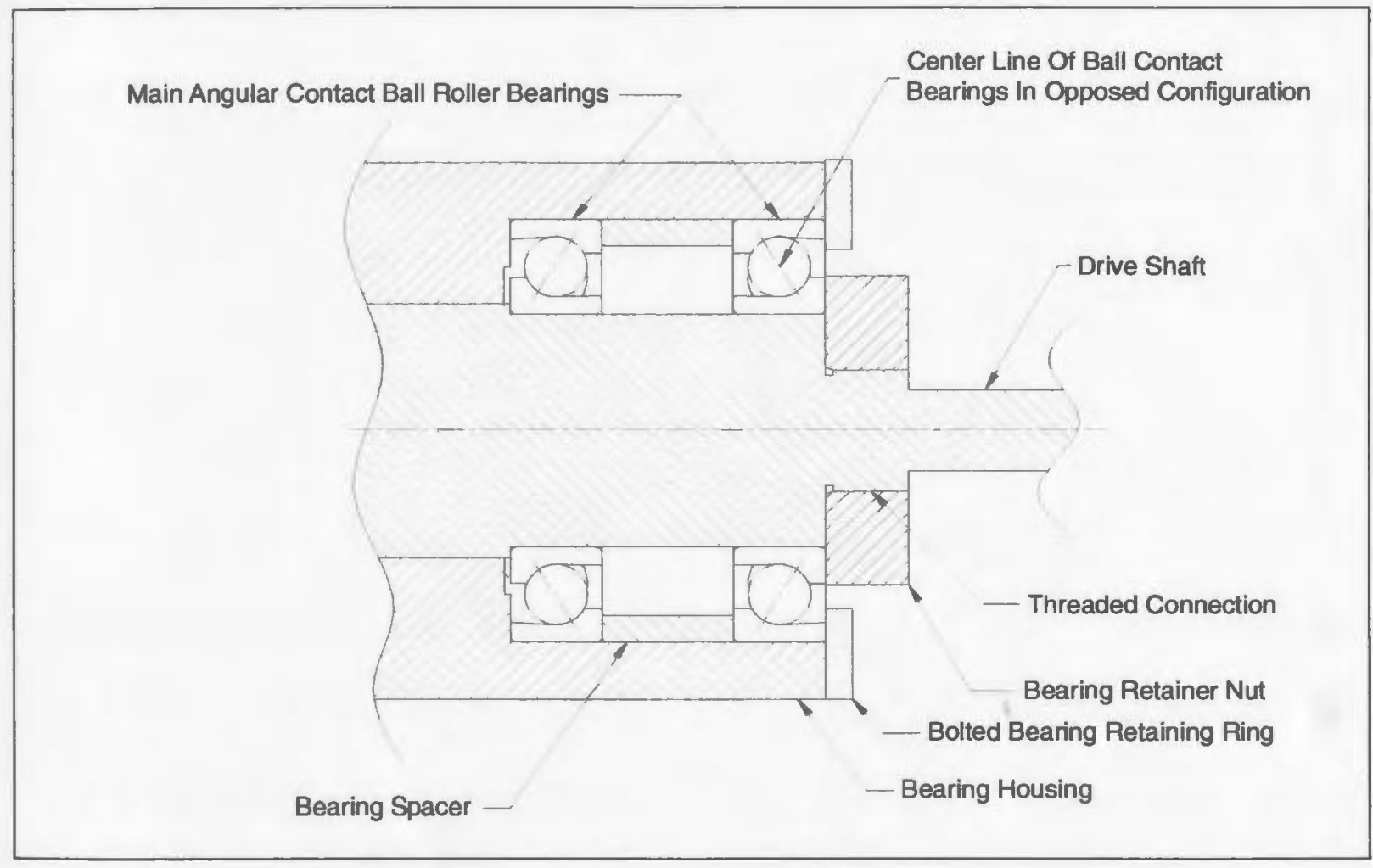

Figure 5.2: Main Shaft Bearings 
Angular contact ball bearings from SKF were selected for this application. These bearings could be preloaded to eliminate any backlash and run out present in the installation. The SKF 7211-BEP bearings were found to be sufficiently large to fit over the drive shaft.

The swash plate pair also required a radial bearing to keep the two-swash plates correctly aligned with each other. For this application, a deep groove ball bearing was selected. A deep groove ball bearing was capable of resisting the mild thrust and radial loads imparted by the swash plate. An SKF 61816-2RZ1 bearing was chosen for this application. This bearing also incorporated grease seals on both sides of the bearing races, providing a maintenance free bearing.

\subsubsection{Mechanical Seal}

The sealing of the gap between a rotating shaft and a stationary housing is a particularly difficult problem for underwater vehicles. Creating a seal with zero leakage is very important for propulsor operation. For the CPCPP, a mechanical seal was elected as the primary shaft seal. The mechanical seal has nearly zero leakage during operation, and very low operating friction. By keeping the operating friction low, a reduction in the torque to overcome friction in the seal could be obtained. 


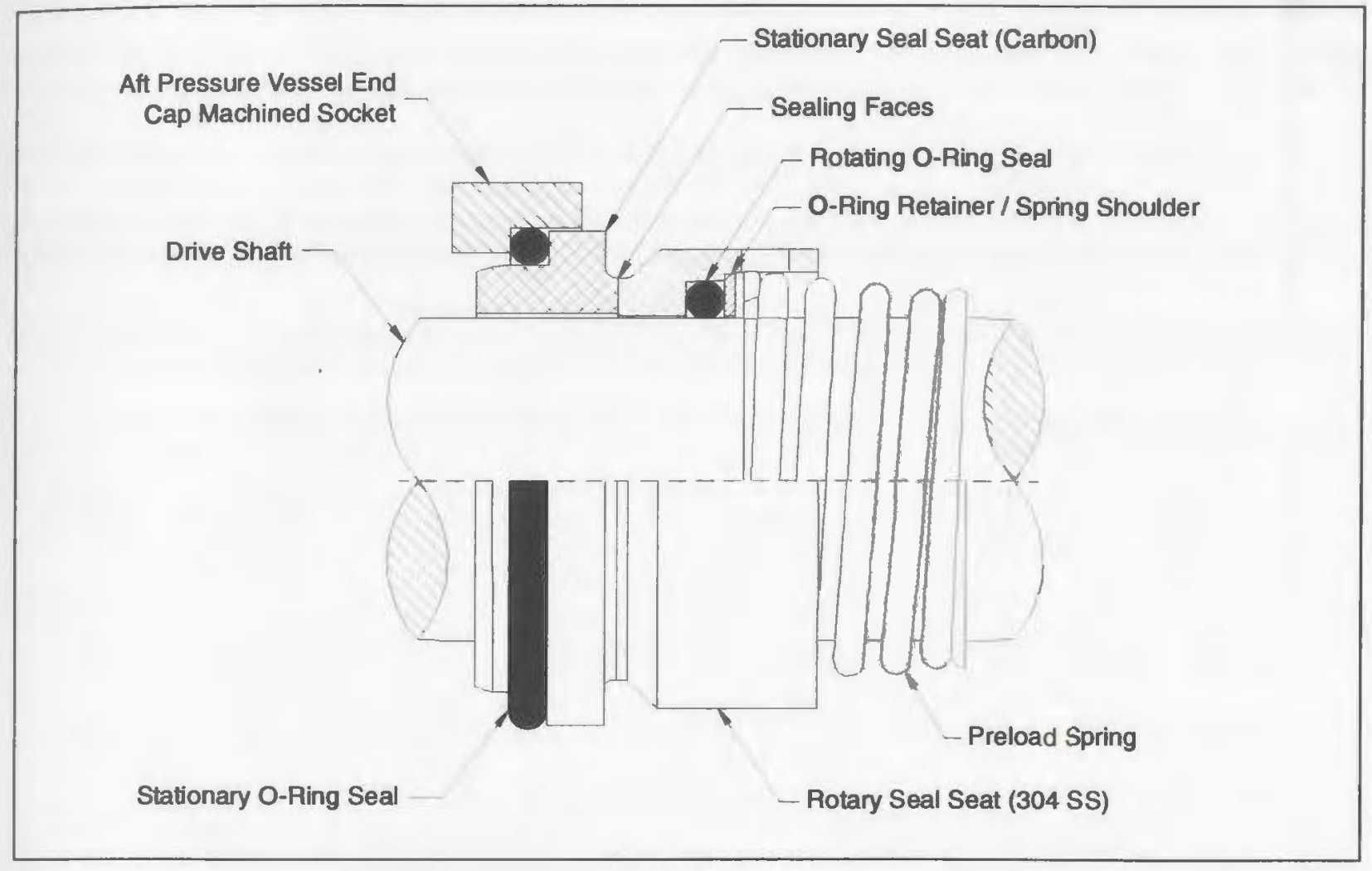

Figure 5.3: Mechanical Seal Detail

Locating a suitable mechanical seal proved to be a difficult challenge, as most seals were manufactured to be used in an existing housing or mount. For the CPCPP, an open frame style seal was required to allow maximum configurability. NE Seal located in Vancouver, British Columbia, stocked a wide variety of mechanical seals for pumps and shaft lines of ships. After consultation with NE Seal an NES-12 was determined to be the best choice for this application. The chosen seal has a shaft basic diameter of $60 \mathrm{~mm}$, a stationary face of carbon, a rotating face of stainless steel, and was configured for right hand operation. The requirement of the preload spring to clamp the rotating components to the shaft limits the seal to right hand operation only. Life of the seal is largely dependent 
on operation conditions such as quantities of abrasives and amount of lubrication. A seal of this nature would typically last one to five years depending on the severity of service. A cross-section of the seal can be seen in Figure 5.3 above and dimensional information can be found in Appendix B.

\subsubsection{Actuators}

The actuators make the positioning of the swash plate to generate collective and cyclic pitch possible. During the conceptual design phase, an electric ball screw style actuator was determined to be the most energy efficient method of controlling the swash plate position and orientation. A search of available technology was conducted to find a suitable actuator.

The actuator required a $50.2 \mathrm{~mm}$ (2 in) stroke with a maximum thrust of around $445 \mathrm{~N}$ (100 lbf). As the actuator had to be positioned very accurately, a ball screw was selected for rotary to axial transformation. The actuator also required a potentiometer to provide positional feedback for control purposes. The Digit Actuator by Ultra Motion was determined to be ideal and included the required position feedback, Figure 5.4 [Ultra Motion, 2002]. The details for this actuator can be found in Appendix B. 


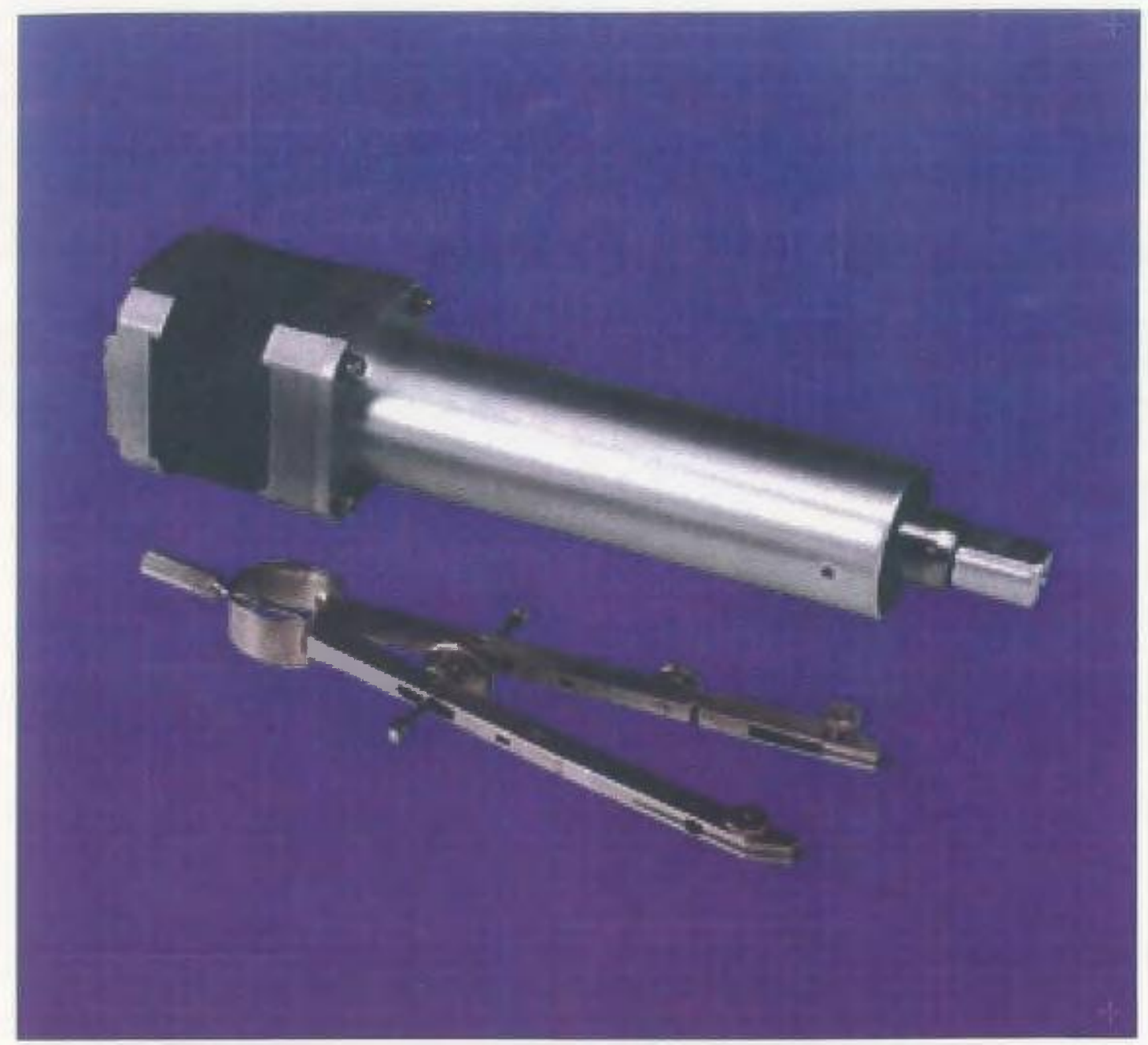

Figure 5.4: Digit Linear Actuator

\subsubsection{Main Motor Selection}

The main drive motor needed to be of the low speed, high torque variety, as there was no gearbox used in the design. The bus voltage for the motor was specified by the architecture of the C-SCOUT vehicle as 48 VDC. The initial calculations to predict the thrust output of the propeller indicated that a rotational speed of about 600 RPM was desirable for a $305 \mathrm{~mm}$ (12 in) diameter propeller. 
A power output of $800 \mathrm{~W}$ was determined to be the minimum power output required.

Several manufacturers listed frameless motors suitable for use in the CPCPP. A frameless motor is essentially an armature, rotor, and timing electronics. This type of motor is preferred by original equipment manufacturers, as it allows the greatest flexibility in mounting and installation options. However, finding a company to supply a suitable motor was extremely difficult, due to the just in time manufacturing process. Most of the manufacturing companies refused to tool up to make one motor, regardless of the fact that the motors were supposed to be stock items.

After phoning a large majority of the major motor manufacturers that produced a suitable motor, a company was finally located that would produce a single motor for the prototype CPCPP. Bayside Motion Group specializes in manufacturing one-off motors for the scientific and military community. After selecting the parameters required for the motor from their catalogue, they custom wound a rare earth permanent magnet brushless DC motor for the CPCPP, Figure 5.5. The manufacture's specifications and information for the main motor can be found in Appendix B. 


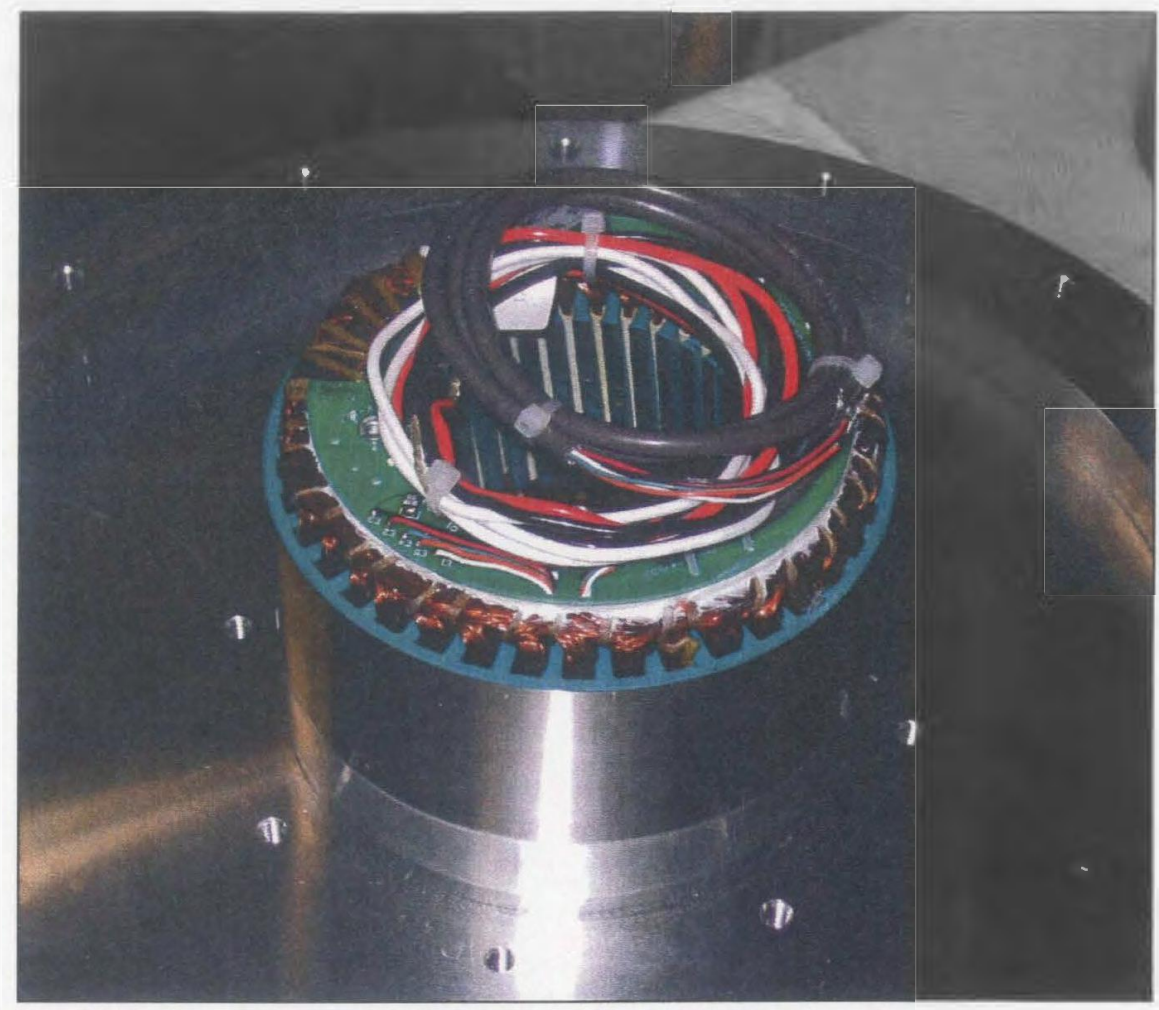

Figure 5.5: Main Motor Armature

\subsection{Sectioned General Arrangement}

Before developing a full 3D assembly of the CPCPP, a sectioned 2D general arrangement was constructed, Figure 5.6. The general arrangement permitted the layout of major parts and determination of rough sizes, sealing requirements and assembly order of the completed design. A rough general arrangement helped to plan and visualize how the completed design needed to be manufactured to allow easy assembly. 


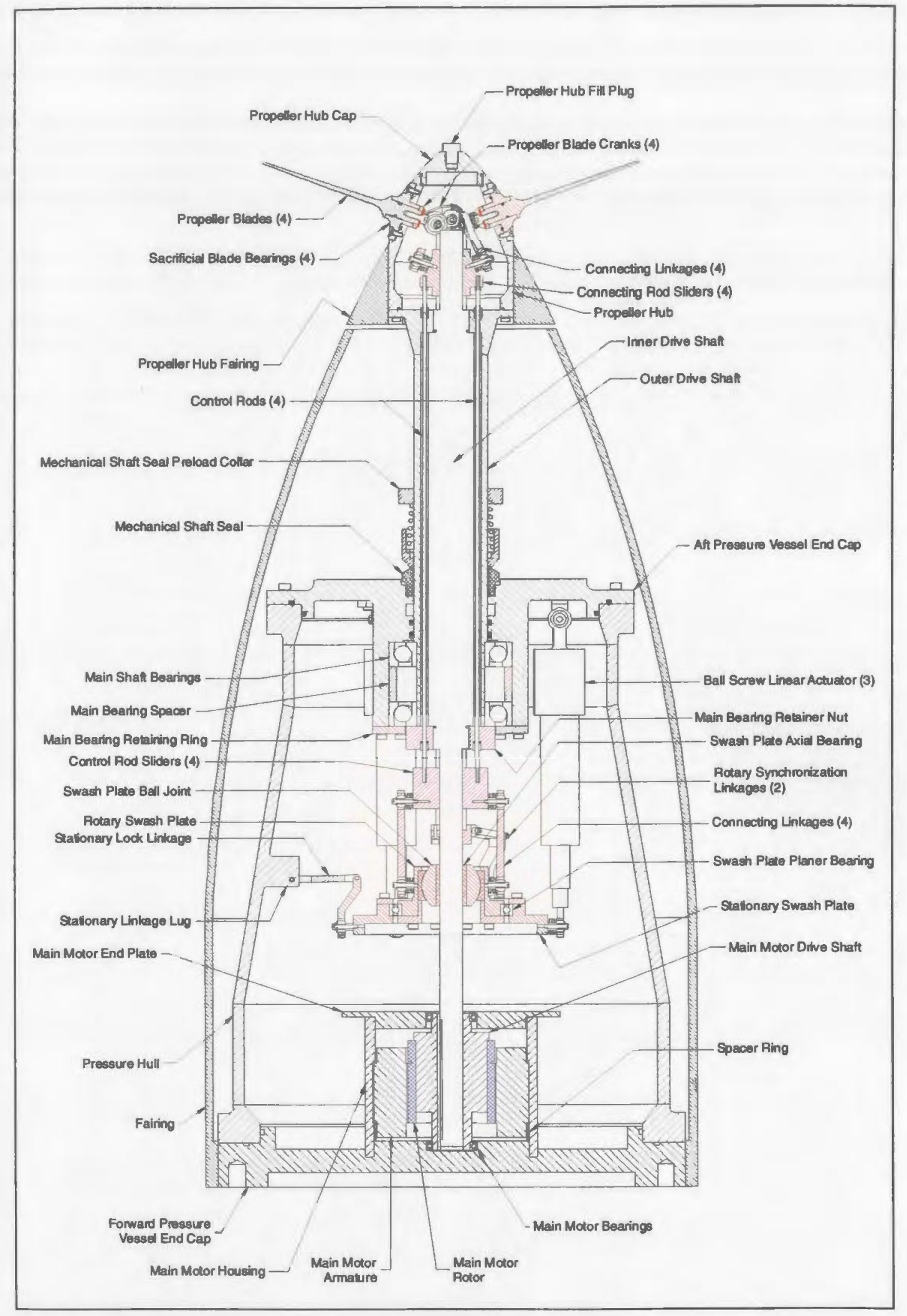

Figure 5.6: 2D General Arrangement Sketch 


\subsection{Assembly Considerations}

There were three primary items considered with the CPCPP, as far as assembly was concerned. First, all of the mechanical components of the propeller system would be mounted to the aft end cap of the pressure vessel. This solution permitted the remainder of the pressure housing to be removed, making all of the moving parts easily accessible for maintenance. This configuration proved invaluable after construction for troubleshooting and fine-tuning the propeller linkages and mechanisms. Second, all of the electrical components were attached to the forward end cap of the pressure vessel, with the exception of the linear actuators. This permitted all of the electronics and electrical penetrations to be removed as a single unit after the linear actuators were unplugged. This made trouble-shooting problems with the electrical system more straightforward. Finally, the propeller hub was designed for blade removal or replacement. While blade replacement was not as important as for a commercial version of this propeller, a CPCPP that was configurable was indispensable for research. The various subassemblies are color coded in Figure 5.6, as indicated in Table 5.1.

Table 5.1: General Arrangement System Color Codes

\begin{tabular}{|c|l|}
\hline Color & \multicolumn{1}{|c|}{ System } \\
\hline Blue & Forward Pressure Vessel End Cap and Electrical Systems \\
\hline Cyan & Hydrodynamic Fairings \\
\hline Green & Pressure Hull \\
\hline Red & Swash Plate Assembly \\
\hline Magenta & Aft Pressure Vessel End Cap and Drive Shaft Assembly \\
\hline Orange & Propeller Blade Assembly \\
\hline
\end{tabular}




\subsection{Parametric Model Development}

The designer developing a complicated mechanical system can benefit considerably from using parametric modeling and design. A parametric model allows the designer to spatially verify component fit and interaction. If a problem with the parts in the model occurs, the designer can change the defining parameters to correct the problem without having to completely redraw the assembly. Parametric models are also extremely useful for checking the kinematics of a mechanism. Any collisions between parts or binding of the mechanism can be detected and corrected prior to manufacturing the components.

\subsubsection{Shaft Line}

The shaft line was the most important part in the development of a parametric model of the CPCPP. This shaft formed the backbone for the completed propeller. The shaft line transmitted the torque of the main motor to the propeller blades, and acted as a guide for the swash plate mechanism. The main shaft also included the main bearing mounts. The guiding system for the axial control rods that transmit the swash plate orientation to the propeller blades was a part of the main shaft assembly. At the propeller end of the shaft, a mounting flange was designed to allow the attachment of the propeller hub, Figure 5.7. Forward 
of the main bearing seat, a threaded part of the shaft allowed the installation of a retaining nut, Figure 5.8. This retaining nut secured the shaft to the aft pressure housing cap via the main shaft bearings. The main motor end of the shaft was fitted with a trapped key to allow the main motor to be splined onto the drive shaft.

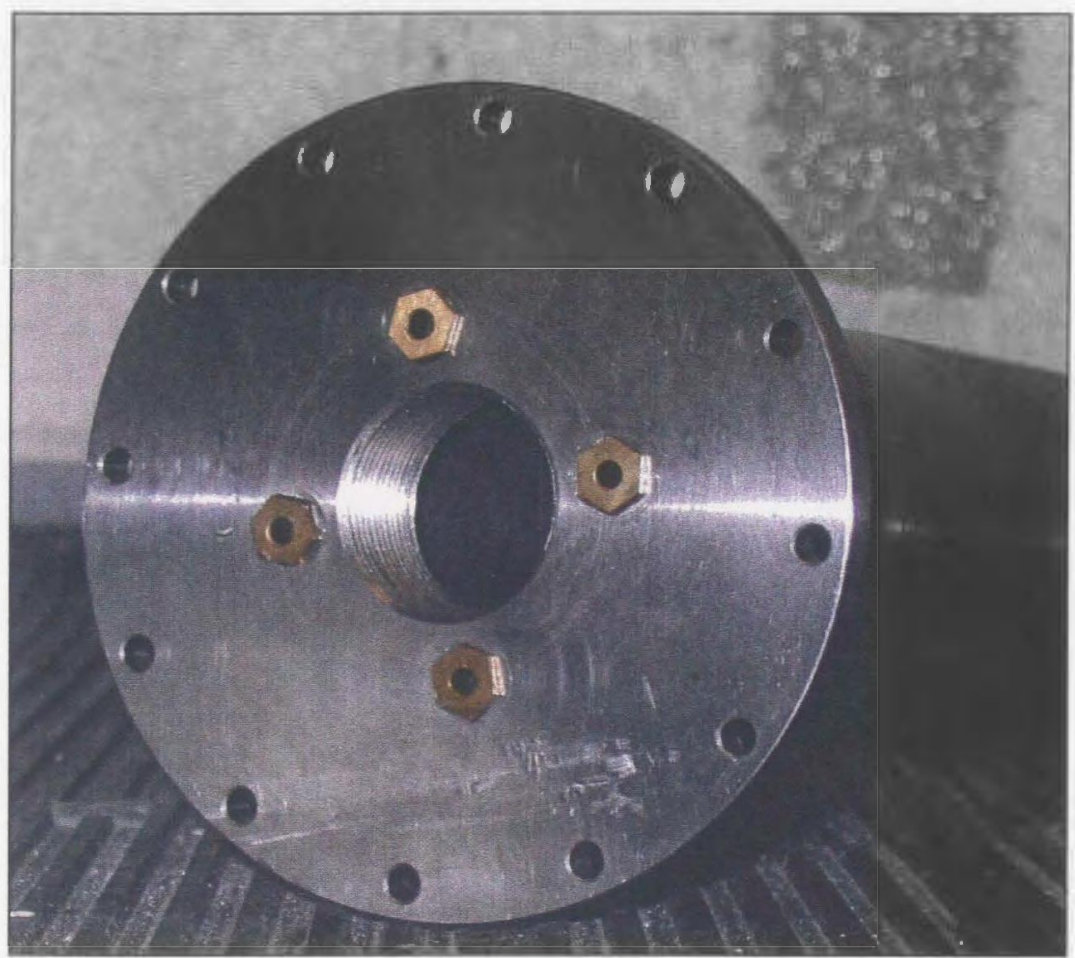

Figure 5.7: Propeller Hub Flange 


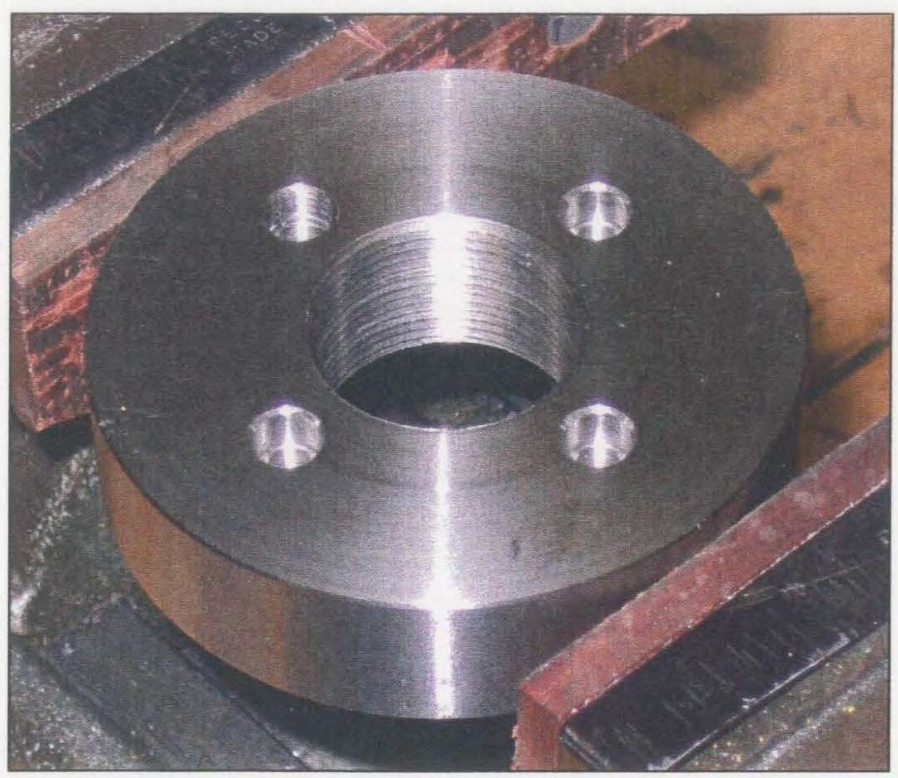

Figure 5.8: Bearing Retainer Nut

\subsubsection{Swash Plate}

The swash plate mechanism was the next part of the model to be completed. The parts of the swash plate were designed to hold and retain the main spherical ball rod end bearing and the swash plate radial bearing. A section of the completed swash plate can be seen in Figure 5.9.

The design of the swash plate also included the development of the connecting and locking linkages, Figure 5.10. The connecting linkages connect the control rods to the swash plate. These dumb bell shaped components translate the complex motion of the swash plate to the linear motion of the connecting rods running to the propeller hub. 


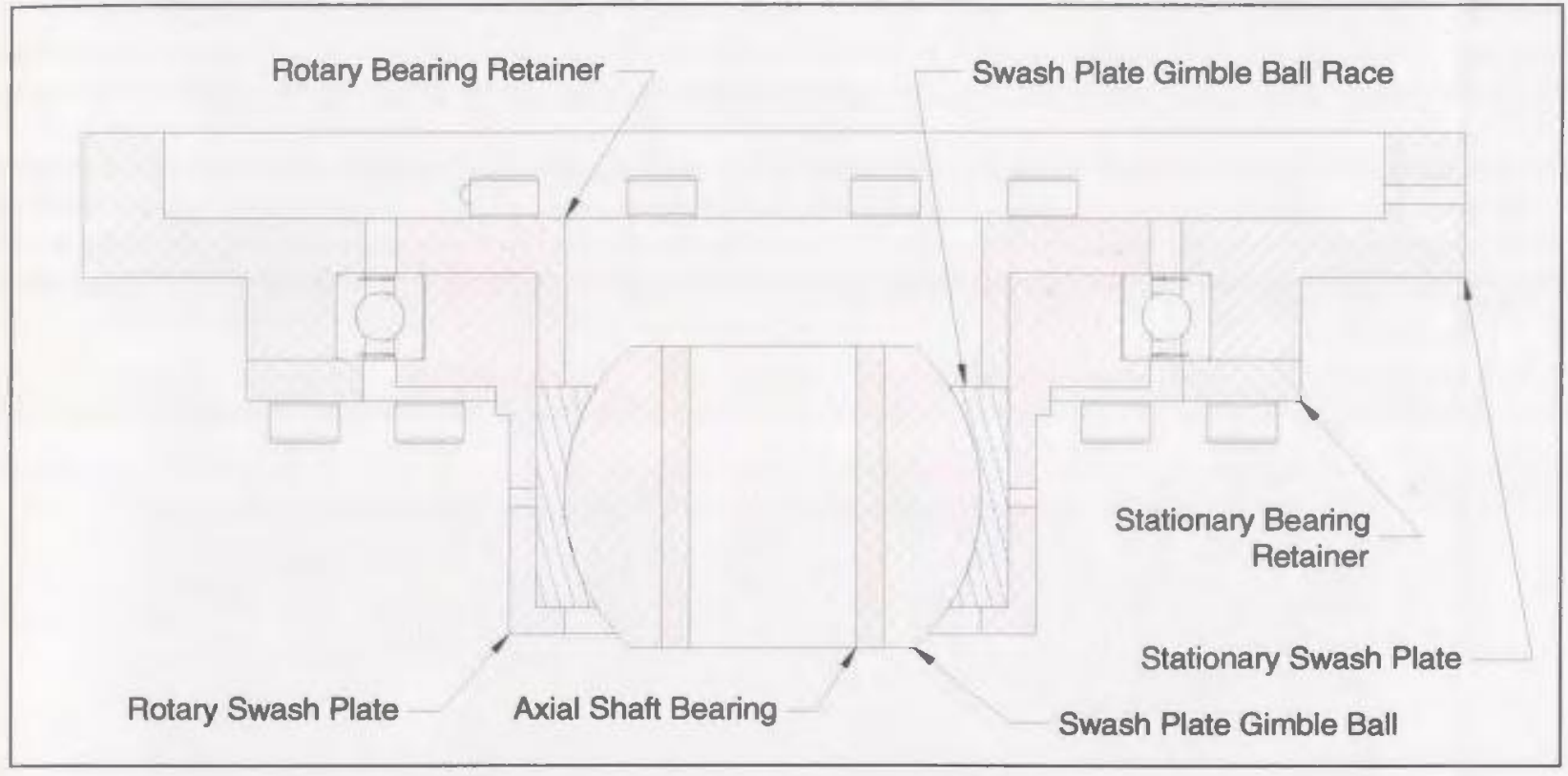

Figure 5.9: Main Swash Plate Section

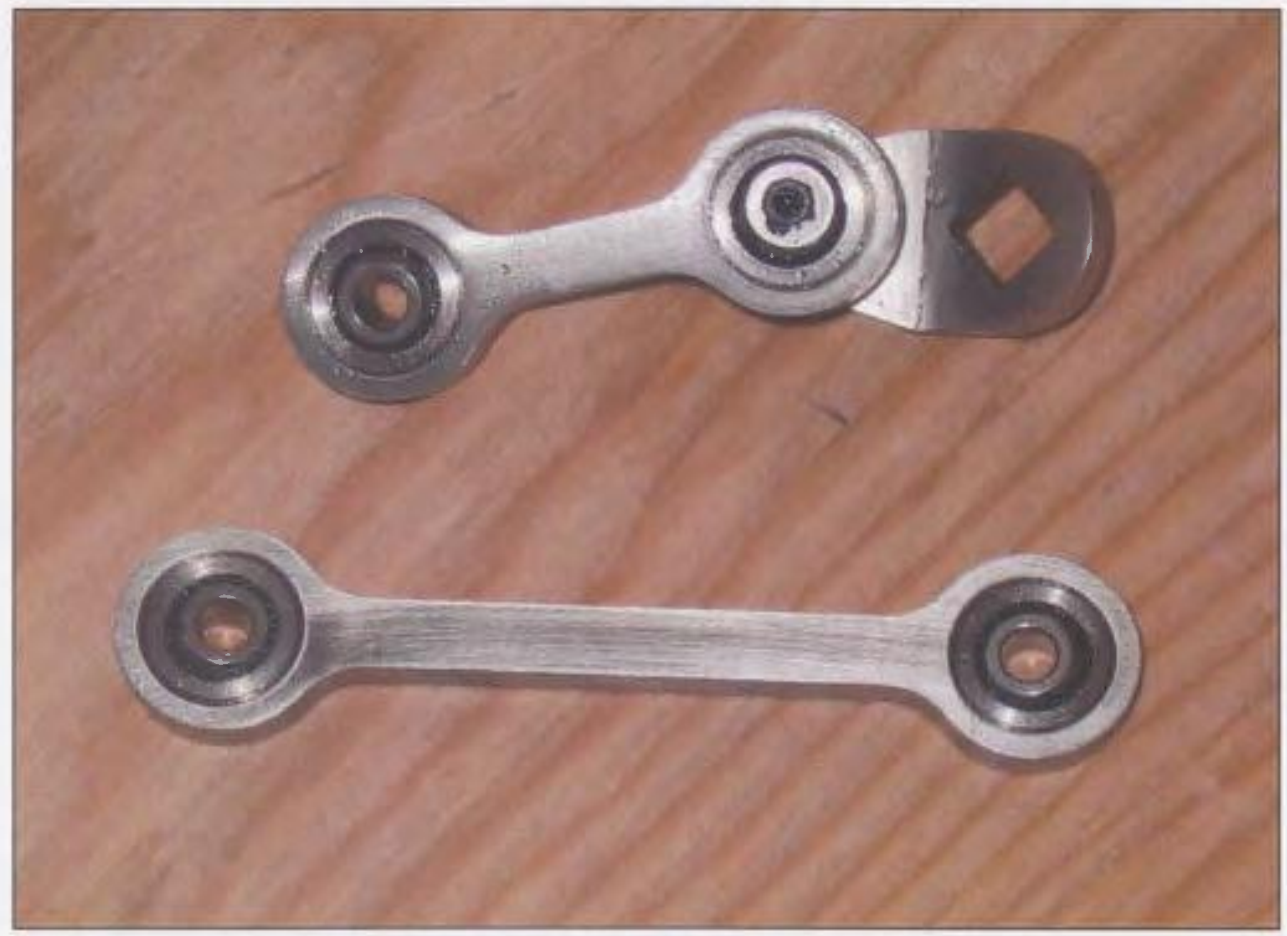

Figure 5.10: Connecting Linkages 
The lock linkages, described in Section 3.2 Swash Plate Mechanics, were an important part of the swash plate design. Adding these components to the model secured the swash plates in the axial rotation degree of freedom. The stationary swash plate was prohibited from rotating, while the rotary swash plate was forced to rotate in synchronization with the main shaft, Figure 5.11.

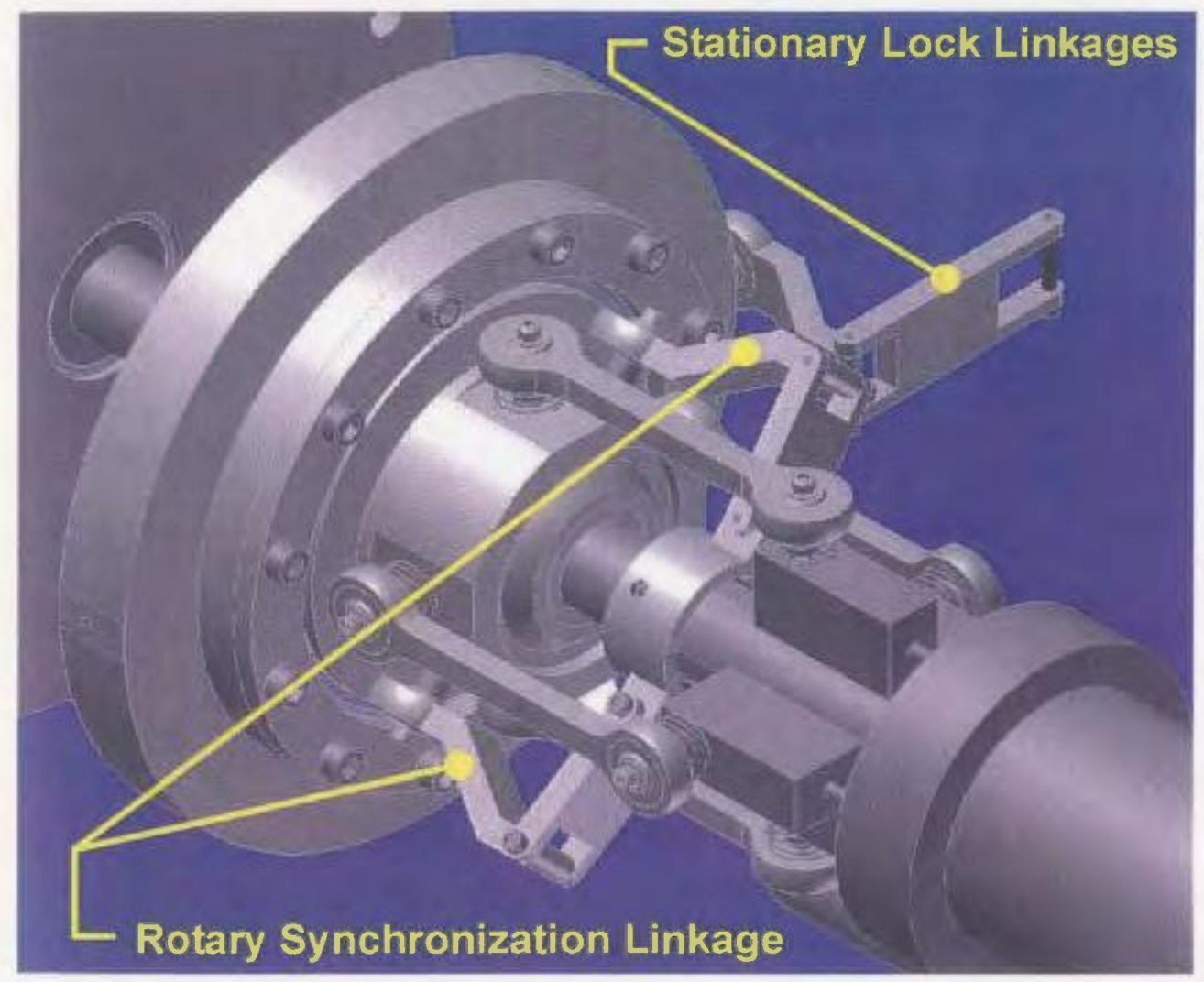

Figure 5.11: Lock Linkages

\subsubsection{Propeller Hub}

With the swash plate mechanism complete, the next part of the propeller to be modeled was the propeller hub. The propeller hub contains the connecting 
linkages, cranks and propeller blades. The blades of the propeller need to be free about the axis of rotation of their shafts and constrained in all other dimensions. The constraining of the propeller blades was accomplished by using a bronze blade bearing. The installation of the crank on the bottom of the blade shaft trapped the blade between the crank and a shoulder on the blade, Figure 5.12. The crank of the blade was then connected using a connecting linkage to the control rods.

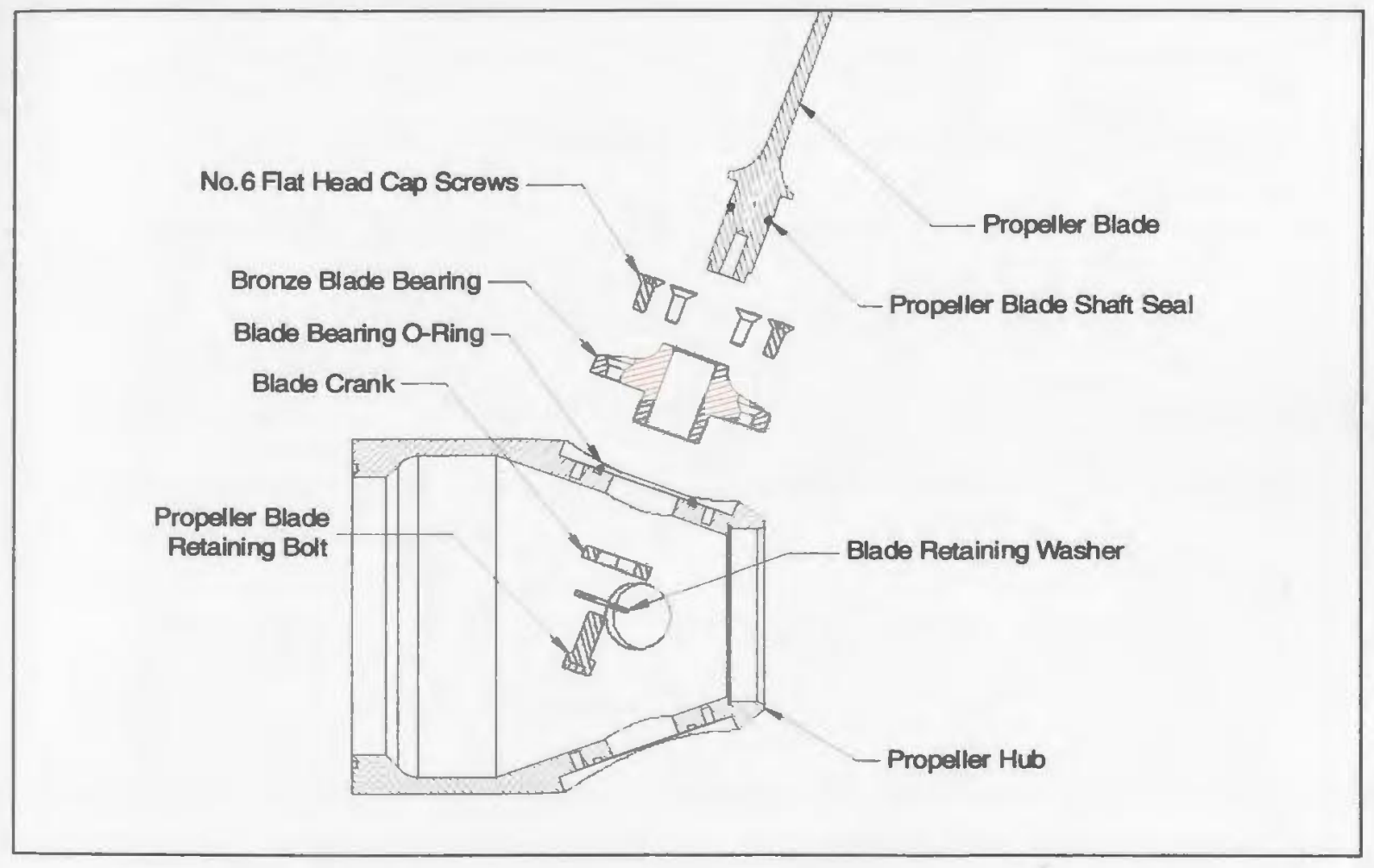

Figure 5.12: Blade installation

The seats for the blade bearings were installed in a streamlined hub at the desired rake angle of $20^{\circ}$. The blade bearings were designed to be the sacrificial component in the blade system and were secured with six screws. The blades 
themselves were secured in place by a Loctited single No 10 socket head cap screw. This allowed the blades to be easily removed and replaced. While this was a very useful feature for replacing a lost or damaged blade during operation, this feature also could allow the use of different blade geometries during testing and development.

\subsubsection{Pressure Housing}

The pressure vessel housing not only kept the water out of the electrical system, but also served as mounting points for the propeller and components inside. The aft end cap of the pressure housing performed as a boss for the main shaft bearings that held the main drive shaft in place. The aft end cap also acted as an anchor for the three swash plate positioning actuators, Figure 5.13.

The hull of the pressure vessel incorporated a lug that serves as the attachment point for the stationary swash plate lock. There were also clips attached to the inside of the hull to secure the wiring harnesses for the linear actuators. These clips prevented the wires from becoming entangled in the swash plate mechanism and being damaged. 


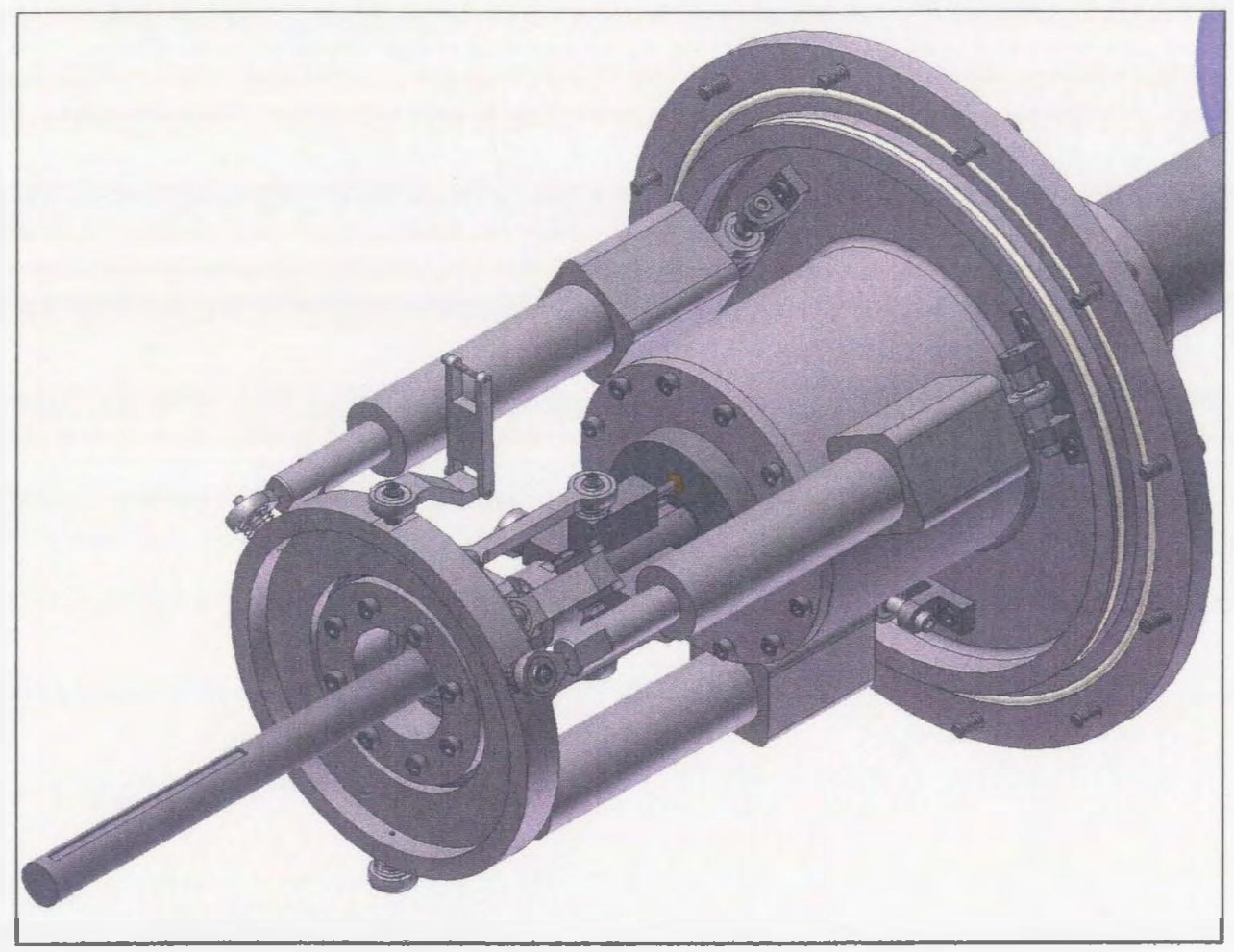

Figure 5.13: Aft Pressure Vessel End Cap

The forward end cap of the pressure vessel served as a mounting point for the CPCPP's electronics and the main motor. By attaching the main motor and the electronics to the forward end cap, all of the wiring and electrical systems could be removed in one piece. This made the system easy to maintain. The forward end cap was also fitted with four tapped blind holes on the outside mounting flange. These bolt holes allowed the propeller to be attached to C-SCOUT's modular frame. 


\subsubsection{Main Bearings}

The main bearings of the CPCPP have to be able to resist the cantilevered loads applied at the end of the drive shaft, as well as the thrust and torque loads that were applied during operation. The bearings chosen for this task were angular contact ball roller bearings. When installed in a back-to-back opposed configuration they were able to resist the required loads, Figure 5.14. The spacer between the two bearings could be custom machined to provide a shaft installation with zero run out.

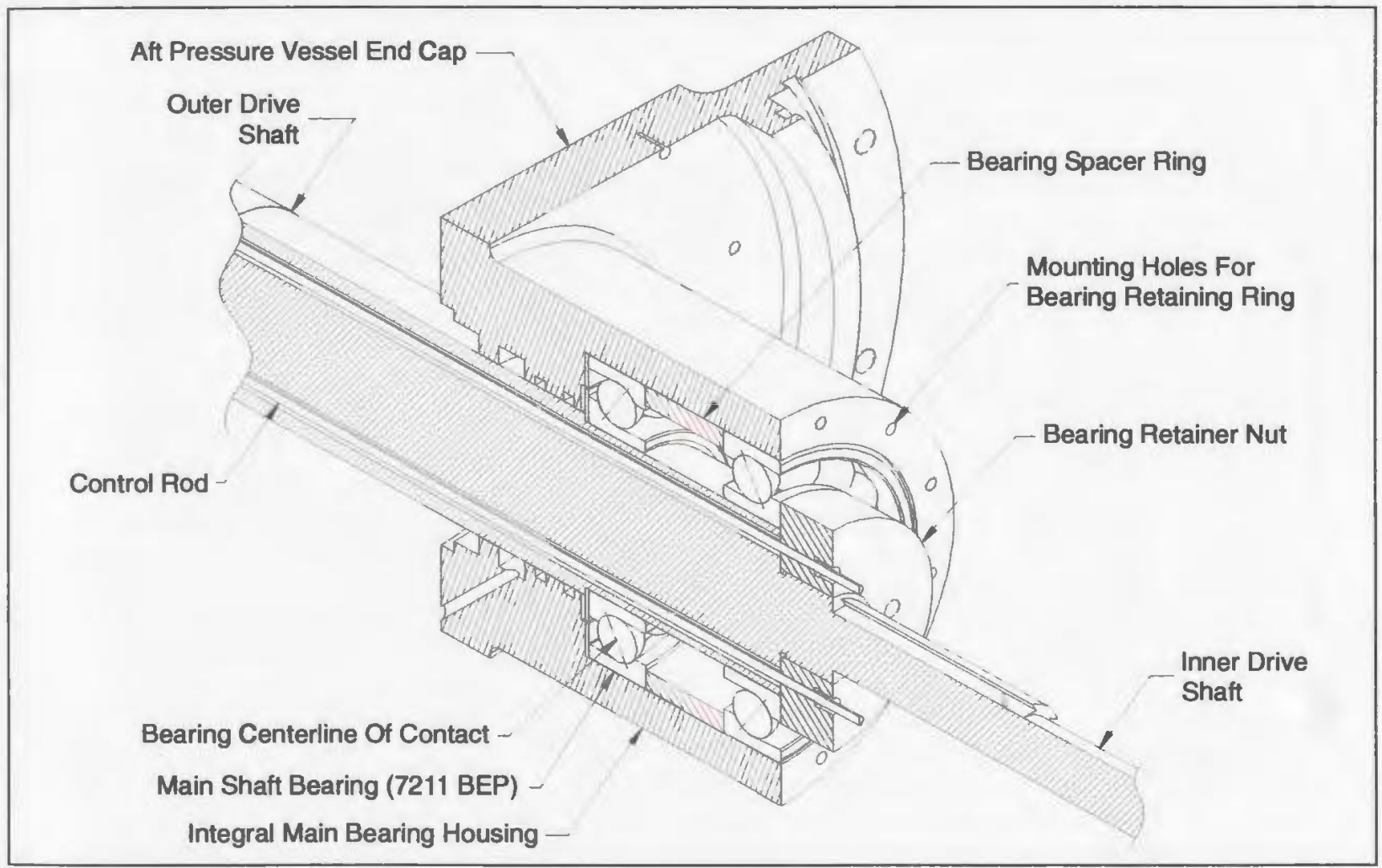

Figure 5.14: Main Shaft Bearing Installation 


\subsubsection{Main Motor Mounting}

The main motor was designed as an integral part of the forward pressure vessel end cap. As a frameless motor was used to reduce the space used in the design, a drive shaft had to be designed for holding the rotor. The main motor outer drive shaft was keyed to the main drive shaft of the propeller. The outer drive shaft was then held concentric in the motor armature by two radial ball bearings at either end of the shaft. One bearing was cut into the forward pressure vessel end cap, while the other bearing was machined into the top of the motor housing, Figure 5.15. The motor housing was then tie bolted into place.

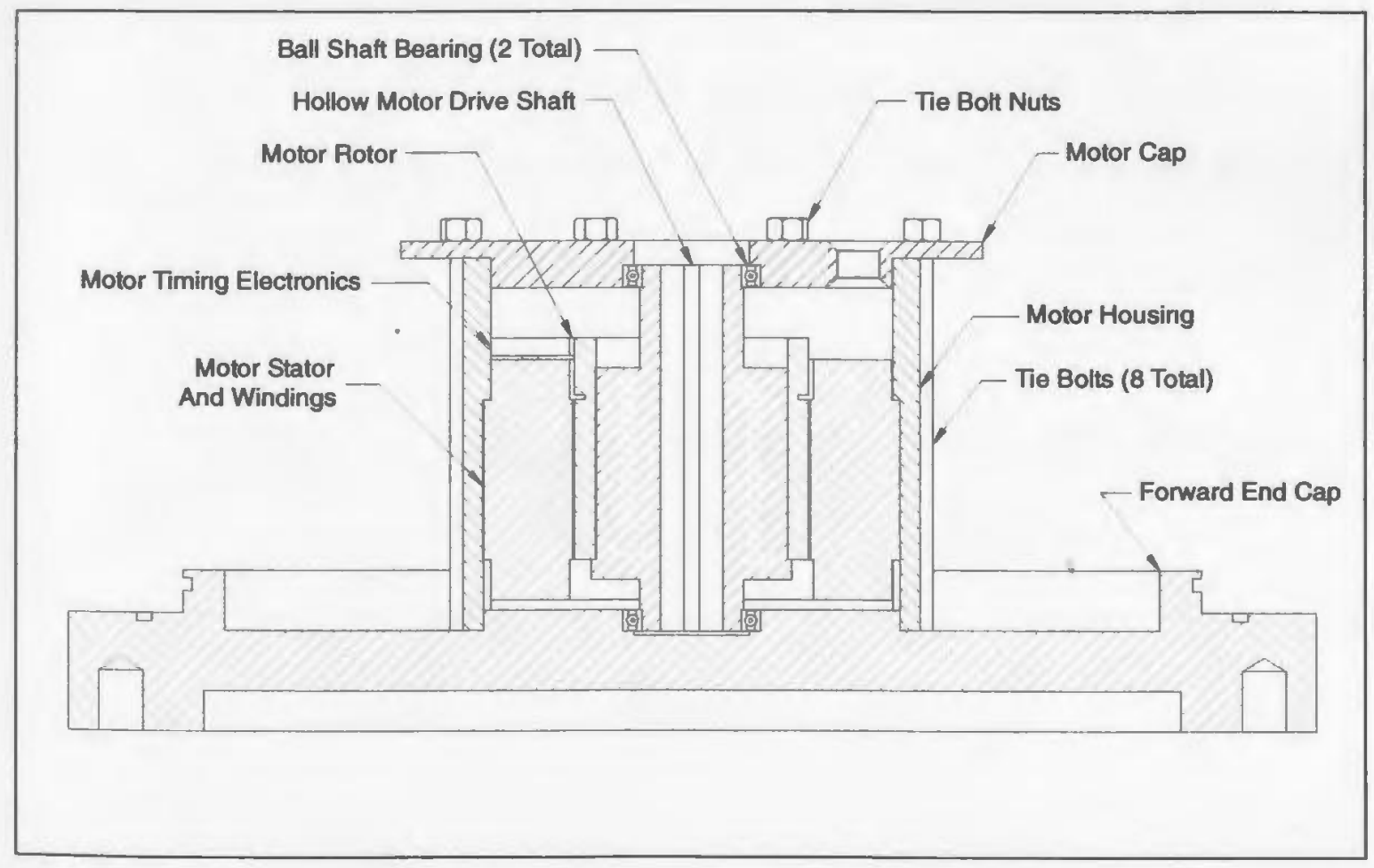

Figure 5.15: Main Motor Section 


\subsection{Design Verification}

Once the parametric model was completed, the CPCPP system could be fully kinematically tested to ensure proper operation. All of the problems with alignment, range of motion, collisions and binding could be diagnosed before cutting the propeller in metal. Potentially, this greatly reduced the cost of fabricating the propeller by avoiding unexpected problems.

There were problems associated with the design of the model during the computer testing. The first problem was with the swash plate mechanism. During the design phase, the need for the swash plate ball rotation vertex to be on the line of action of the rotary swash plate linkages was overlooked. This problem was quickly remedied. The next problem that was encountered was with the collision of the connecting linkages in the propeller hub. The inside of the propeller hub was redesigned to solve this problem. The last major problem was the tendency of the crank linkages to travel over center and lock. This problem turned out to be the result of an incorrect angle between the connecting linkages and the propeller blade cranks. By rotating the propeller hub slightly about the axis of the shaft, the problem was solved. 
The propeller model could now be fully animated for demonstration purposes by driving four constraints in the model. The actuator lengths could be set to position the swash plate mechanism. The propeller shaft was then turned about its axis by driving the angular model constraint between the keyway in the end of the shaft and the $X Z$ world plane. The resulting animation could be captured as an $\mathrm{AVI}$ video file for use in presentations and design meetings.

\subsection{Fabrication}

After the parametric model of the propeller was completed and the design verified for functionality, the fabrication stage of the project commenced. The majority of the propeller was fabricated in the Technical Services Shop at Memorial University. The pressure hull was the only component that was not completely made at Memorial University, as they do not have the facilities needed for the forming operations.

\subsubsection{Drawing Development}

Before the machine shop could start on the parts, detail shop drawings were required, Appendix A. The parametric model was very useful for this process. The final parts could be used to create the orthographic projections, details and sections required to make dimensioned 2D drawings. A small 3D view of the part 
was included in the upper right hand corner of the sheet to allow the machinists to better visualize the parts they were fabricating.

In addition to the standard shop drawings for the CPCPP, an exploded assembly diagram was produced and given to the machine shop during fabrication. This exploded view served two primary purposes. The first reason for creating this exploded diagram was to provide a complete part list for the project. The second purpose of producing the exploded diagram was to help the machinists understand how the parts related to each other. When developing something as complicated as a CPCPP, it was felt to be important that all parties involved in the design and construction understood the relationship of the parts being manufactured.

\subsubsection{Fabrication Techniques}

The CPCPP was designed to make the fabrication of individual parts as simple as possible. While the machine shop at Memorial University has some er:cellent CNC machines, the majority of the parts were designed to be made on conventional lathes and milling machines. This procedure ensured the greatest flexibility with regards to availability of machines while the propeller was being made. The simplicity of parts also results in lower manufacturing costs. 
As it turned out, the majority of the parts were made on the CNC machines. Due to the development of the propeller as a parametric solid, a 3D CAM file could be easily created. This greatly reduced the programming time required by the machinists. The CNC machines could create a part more quickly and more accurately than a conventional machine, especially when there were more than one of the same part.

\subsubsection{Problems and Solutions}

The creation of a new piece of technology is never without its problems regardless of the amount of modeling conducted beforehand. The CPCPP project was no exception. While many of the potential problems were solved in the design stage, problems with manufacturing, materials and parts always exist.

\subsubsection{Bearings}

The first problem encountered during manufacturing was with the main shaft bearings. The bearings that were received from the supplier had a bore fillet that was not to the manufacturers specification. This resulted in the locating shoulder turned on the main drive shaft not being sufficient to locate the bearing. There were two different solutions devised to solve this problem. The first solution was 
to turn a chamfer on the shaft shoulder and use the radius to locate the bearing. The second solution was to install a locating washer between the bearing and the shaft shoulder. After a discussion with the machinist, the first option was selected to solve the problem. If this solution did not work, the second more difficult option could still be implemented. The chamfering of the shaft shoulder was successful.

\subsubsection{Keyway Broaching}

The broaching of a keyway through a hole in a boss is a relatively simple process. The broaching of the main motor shaft, however, posed a significant challenge. On the first attempt, the broach became jammed in the guide and exploded in the press. The shaft was damaged beyond repair and had to be

remanufactured. Before the second shaft was broached, a determination of what caused the first one to fail was required.

The length of the broach cut was deemed the cause of the broach failıre. A broach consists of a series of teeth that increase in cut depth along the broach. The broach is pushed or pulled through the hole using a guide block and a press. As the teeth of the broach cut, the chips are collected in between the teeth. If the cut is too long, the teeth clog up and jam the broach. This was the cause of the failure of the first broaching. 
A series of steps were taken to prevent this problem from occurring on the second shaft. The first step was to drill a hole the diameter of the key in both ends of the shaft at the key location. This reduced the amount of material the broach had to remove and prevented the teeth from being clogged with chips. The second step was to use a series of shims in the guide block to reduce the amount of material cut by the broach. This required many passes to cut the keyway, but reduced the clogging problem.

\subsubsection{Drive Shaft}

Due to the limitations of the manufacturing facilities at Memorial University, the control rod ports could not be machined into the shaft directly. The shaft had to be manufactured in two pieces. The inner piece of the shaft was machined with four slots that would allow the passage of the control rods. The outer shaft was then threaded over the top of the inner shaft. The outer shaft was machined incorporating the bearing mounts and the propeller hub flange. The holes for the

connecting rods were drilled through the face of the propeller hub flange and fitted with o-rings to prevent leakage. 
A shaft that had drilled control rod ports would be a better design. However, there are no machine shops available in Newfoundland capable of drilling an

accurate hole over the required distance of $333 \mathrm{~mm}(13.122 \mathrm{in})$. The only facilities capable of reliably drilling these ports in the shaft are rifle barrel manufacturers. While not practical to have one of the shafts made in this manner, this method of manufacture could be useful in a production cyclic pitch propeller.

\subsubsection{Connecting Linkages}

The placing of a ball joint at the ends of a linkage created an unconstrained structure. While this was not generally an issue for helicopters due to the straight connections, the linkages in the propeller hub operated at considerably greater angles. The high operating angles have a tendency to cause the linkages to move outside their maximum operating range. To solve this problem, a pair of springs were installed on each end of the connecting linkage, Figure 5.16. The springs force the connecting linkage to assume a centered position, while still allowing the required range of motion of the ball joint. Finding suitable off the shelf springs proved impossible and custom wound springs were designed and purchased from Chamberlain Spring Ltd. 


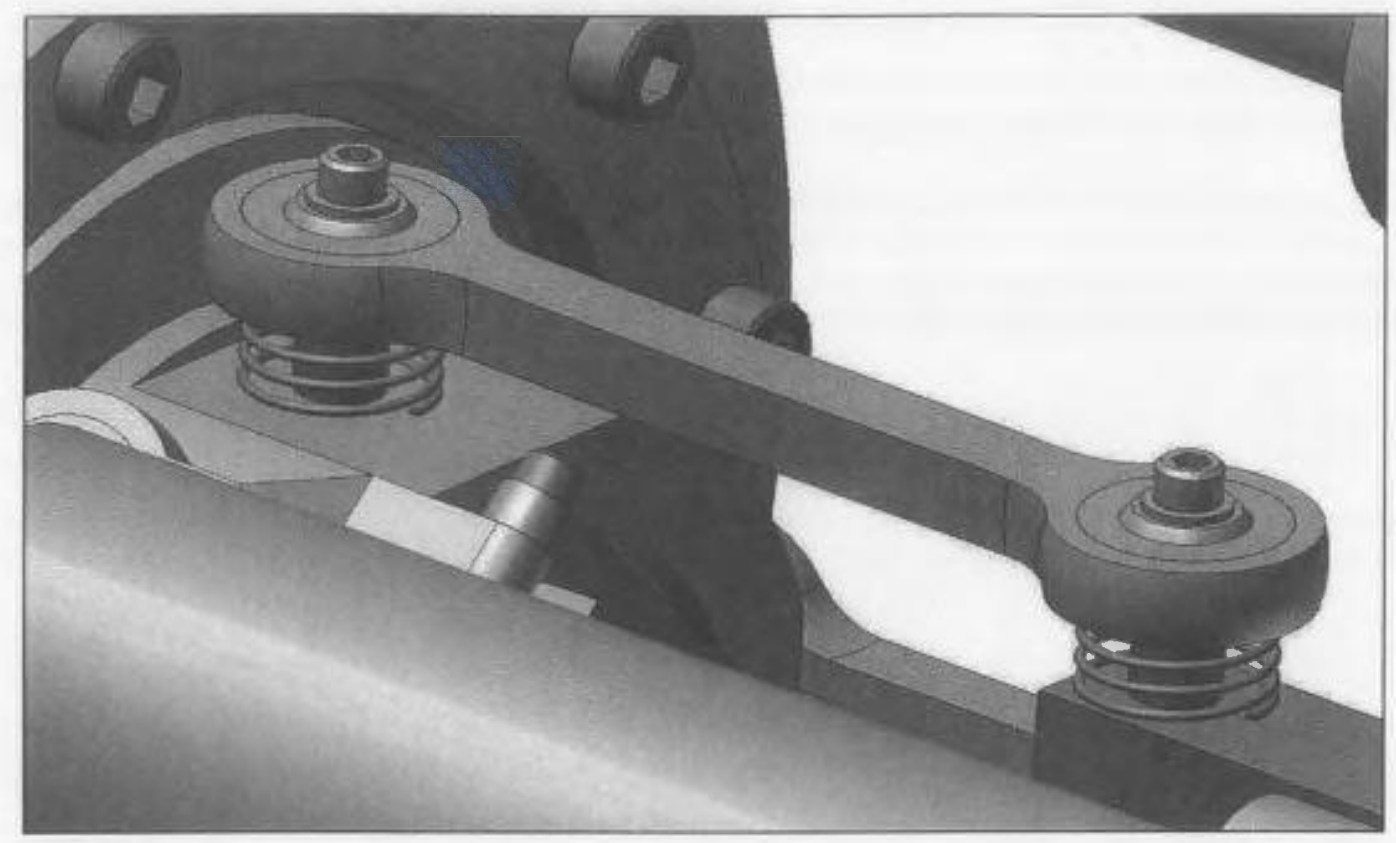

Figure 5.16: Spring Centered Solution 


\section{Chapter 6 Selected Design - Electrical System}

\subsection{Introduction}

Before going into the detailed design of each part of the electrical and control system, a general overview of the system was developed, Figure 6.1. The system was based on the distributed embedded modular architecture (DEMA) of C-SCOUT developed by Master of Engineering student Steve Taylor. The completed control system was designed to be a semi-intelligent system requiring only high-level control functions. This unloads the routine tasks of actuator positioning to the single board computer onboard the propeller instead of taking up valuable processing power from the mission control computer on the AUV. 


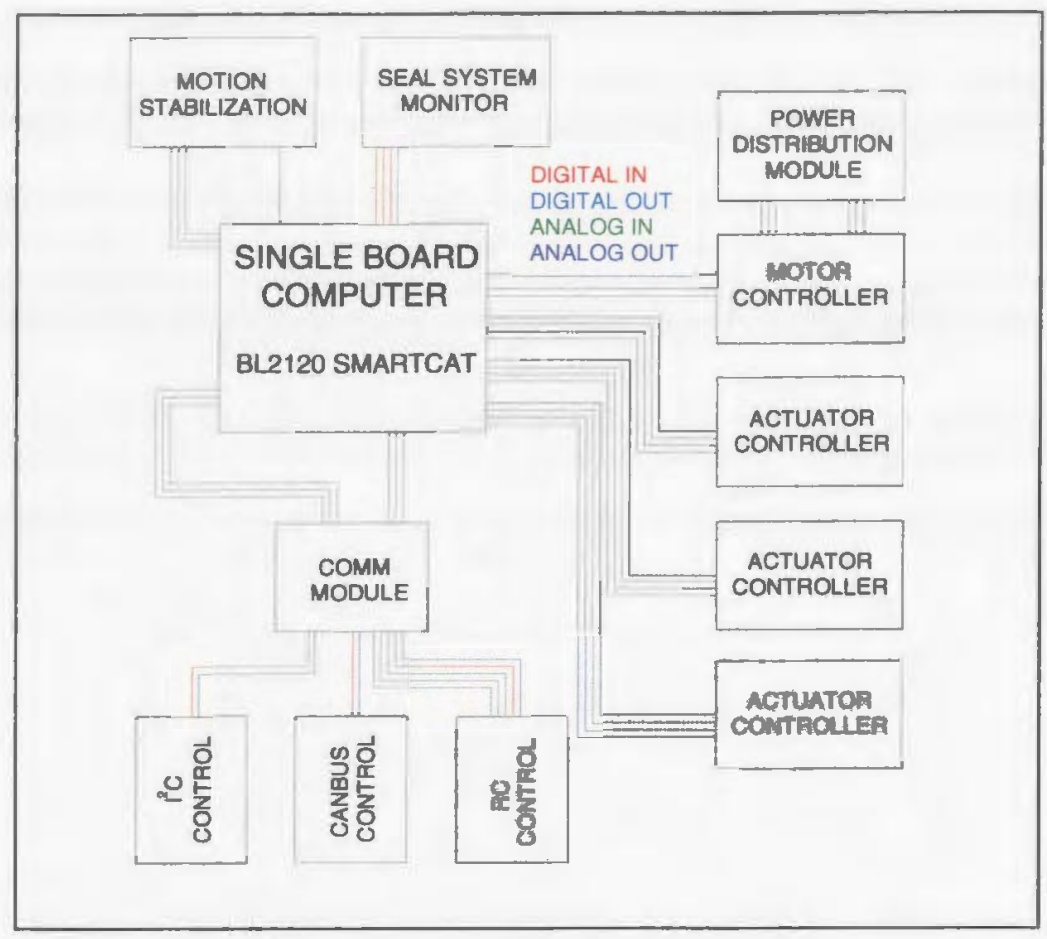

Figure 6.1: Control System Architecture

\subsection{Main Motor Controller}

The main motor controller was the first component that was developed for this project. The main drive motor required a three-phase brushless direct current driver that could supply $20 \mathrm{~A}$ at a 48 VDC bus voltage. Brushless DC motors are manufactured with three phase windings. Electronic Commutation switches these windings appropriately to make the motor rotate. Due to cost and size constraints, an attempt to manufacture this driver from scratch was undertaken. After a search for suitable electronics the following controller schematic was developed, Figure 6.2. 


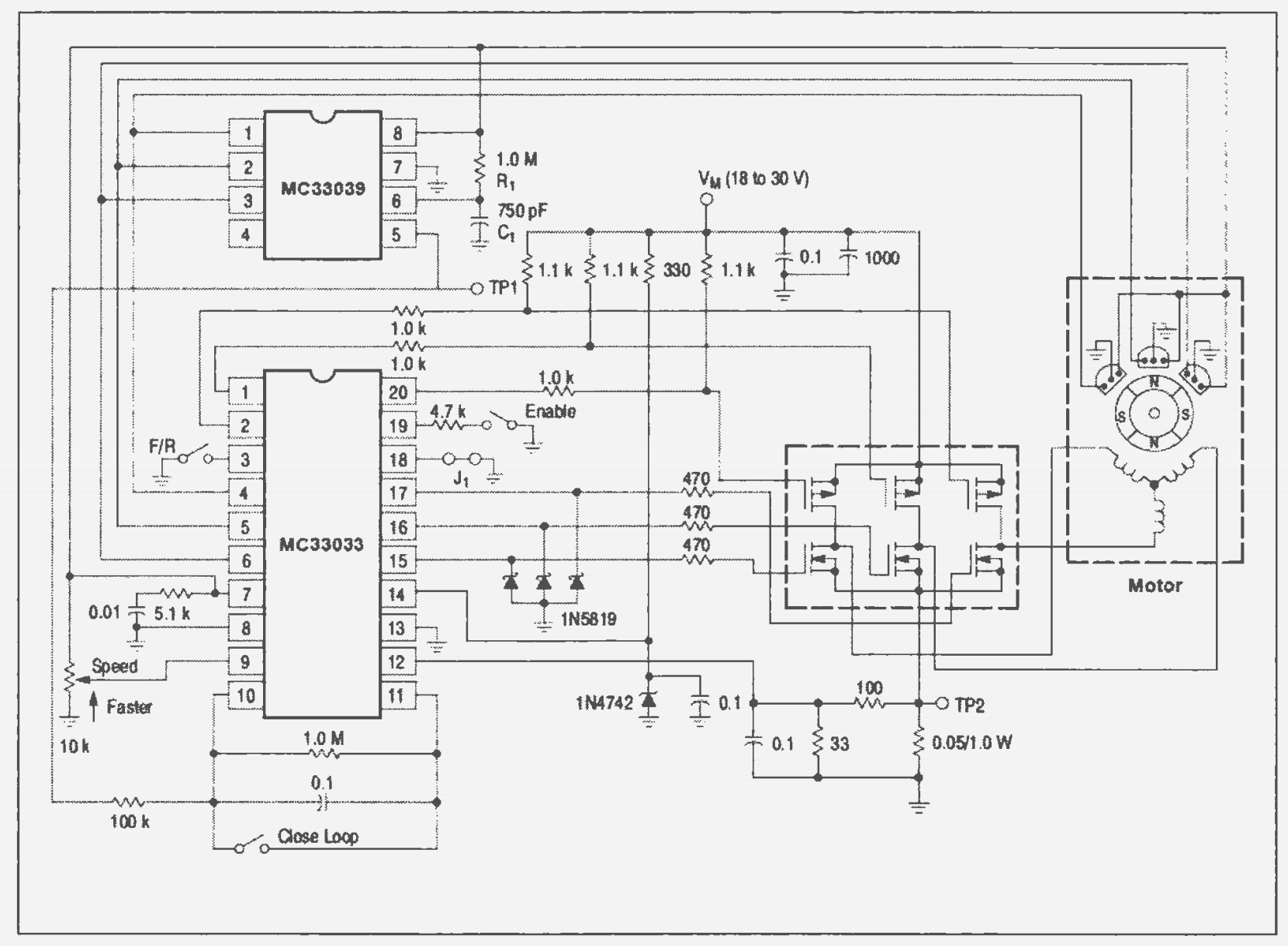

Figure 6.2: Main Motor Controller Schematic

The heart of this controller was a MC33033 motor control chip with a MC33039 closed loop speed control chip [On Semiconductor Inc., 2004]. The motor control chip was used to trigger a series of MOSFET power transistors that supply current to the main motor windings. The MOSFETs are switched on and off in sequence to provide current to the correct windings causing the motor rotor to rotate. The position of the motor rotor was sensed using three Hall effect sensors. The generated pulses were fed into the МСЗ3033 and МС33039. The signals to the MC33033 told the motor controller when to turn on the MOSFETs, 
while the signal to the $\mathrm{MC} 33039$ was analyzed to determine the pulse rate. The pulse rate was then fed into an integrator circuit connected to the МСз3033. The integrator circuit was used to close the loop for speed control.

Speed control for the main motor was controlled using pulse width modulation (PWM) of the MOSFETs. The pulse width modulation effectively reduced the voltage to the main motor windings [Stiffler, 1992]. By varying the duty cycle of the PWM signal it was possible to control the speed of the motor. The speed of the motor was set using a digital potentiometer (pot). This digital pot was used to adjust the reference voltage that was fed into the integrator circuit. By changing the reference voltage using the digital pot, the input voltage to one side of the error amp in the integrator was changed [Stiffler, 1992]. This change caused the PWM signal to be increased or decreased to speed up or slow down the motor. When the new motor speed signal balances with the reference signal the new motor speed has been reached.

There were some problems with the initial circuit schematic due to bus voltage limitations. I modified the controller schematic to address these issues, Figure 6.3. The first issue was that the maximum supply voltage for the $\mathrm{MC} 33033$ was 30 VDC. Splitting the circuit into power and control stages solved the bus voltage problem. The second problem was with the use of P-channel MOSFETs. 
A drop of 4 VDC in the source-gate voltage switched a P-Channel MOSFET. As the source voltage for the P-Channel MOSFETs was 48 VDC, a buffer circuit had to be installed between the gates of the MOSFETs and the topside drive outputs for the МСз3033, Figure 6.4 .

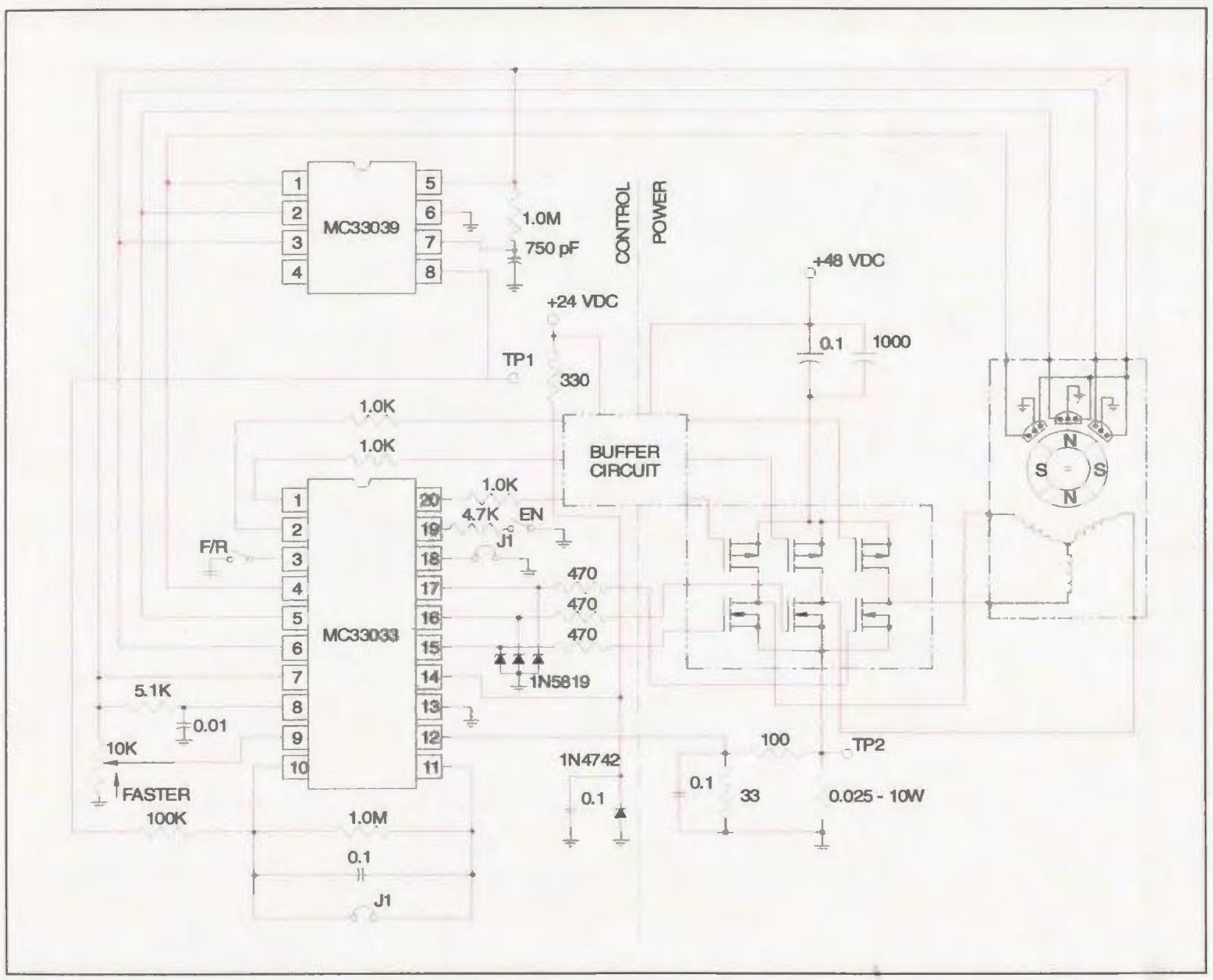

Figure 6.3: Modified Main Motor Controller Schematic 


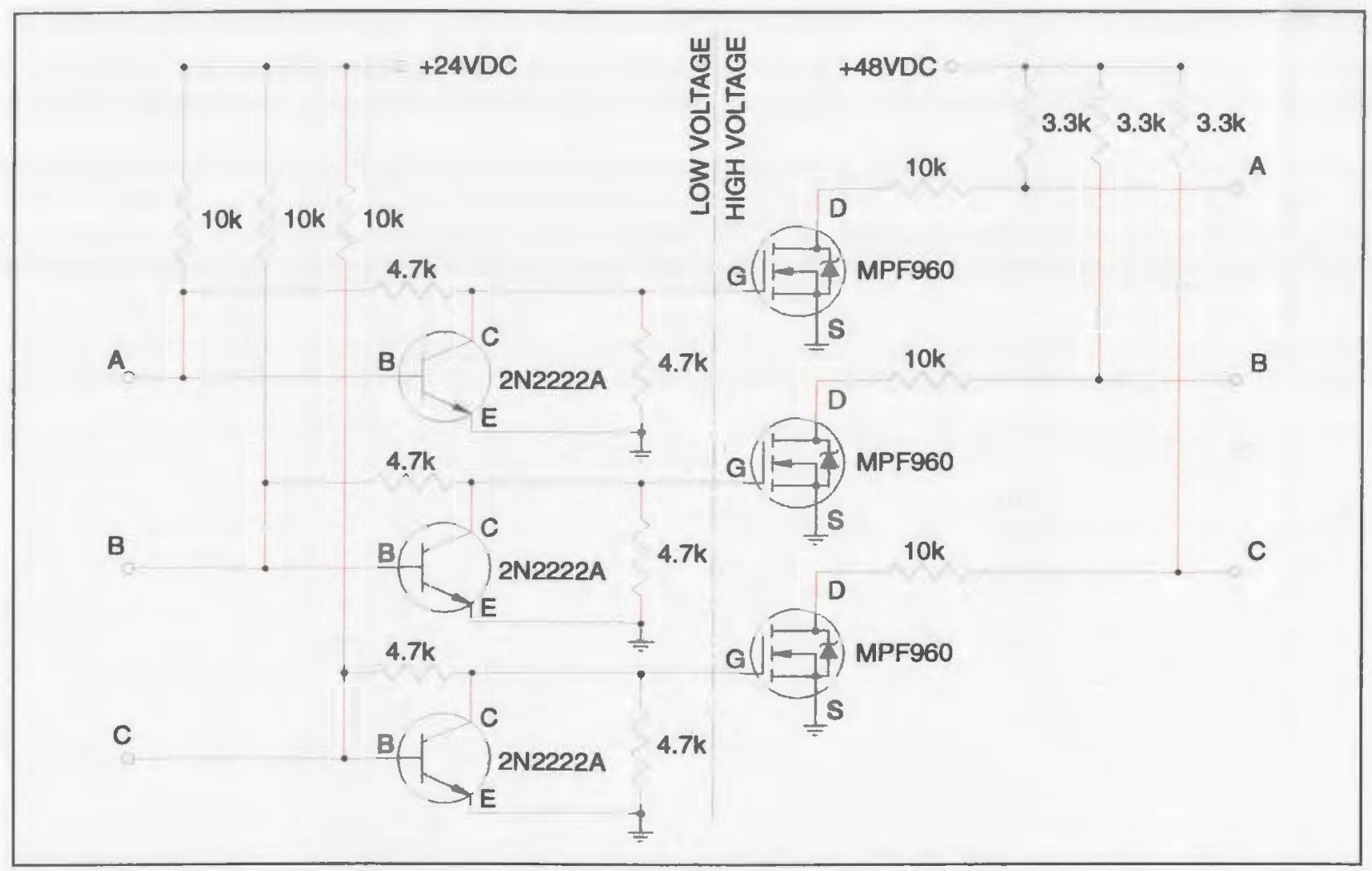

Figure 6.4 Buffer Circuit Schematic

The schematic for the main motor controller was implemented on two printed circuit boards (PCBs) that were built and populated by Technical Services at MUN. The testing of the completed circuits demonstrated that there was a considerable amount of work required for tuning and optimization of the final main motor controller. The P-channel MOSFETs were proving to be troublesome, as there were switching delay issues as a result of the necessary buffer circuit. The controller was going to require some redesign and a new PCB made to incorporate the modifications. In the interest of time, it was elected to use a less flexible trapezoidal servo motor controller for the prototype CPCPP, Figure 6.5 . 


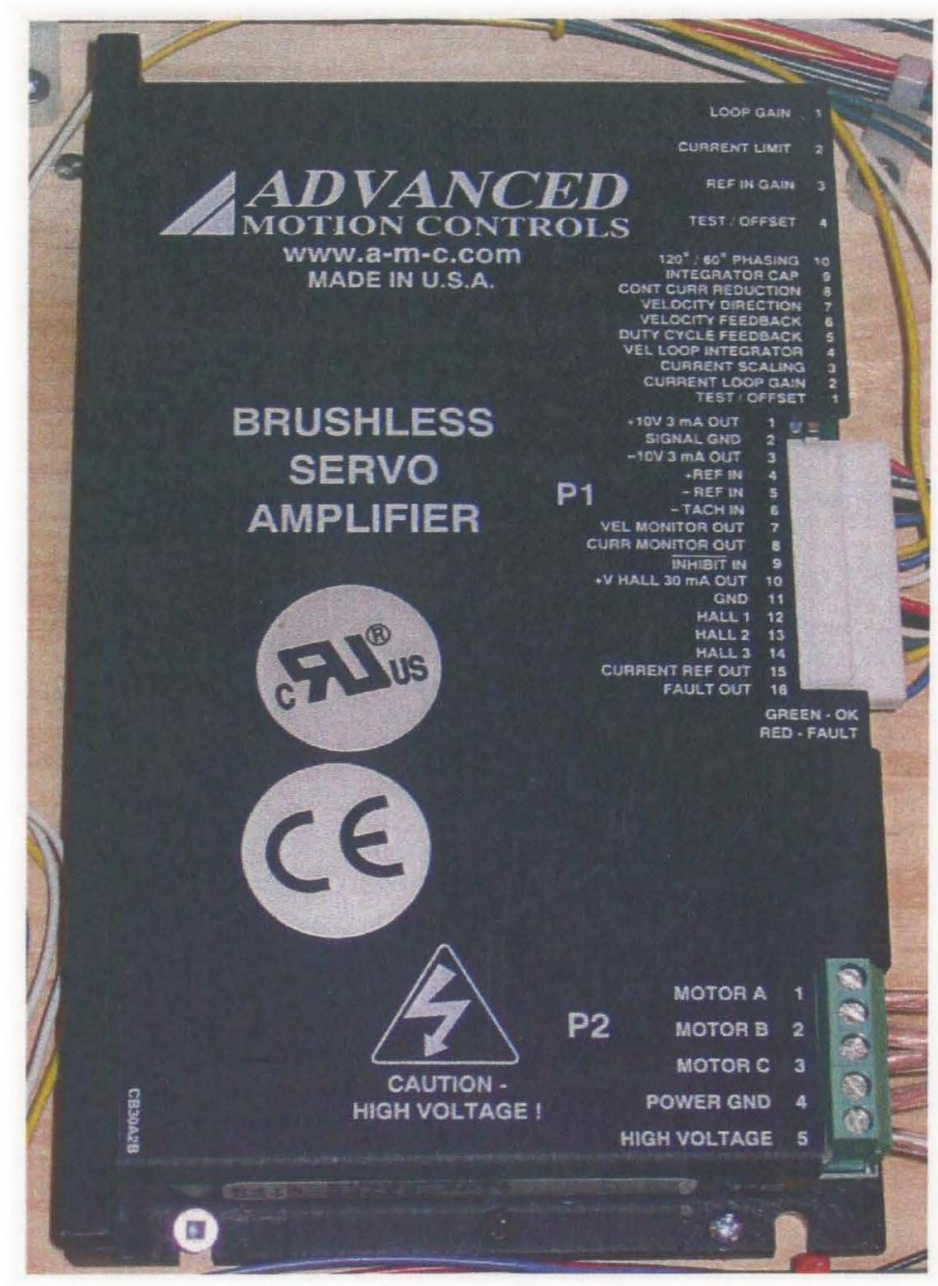

Figure 6.5: Commercial Trapezoidal Motor Controller

While this controller could operate the main motor at the maximum rated speed, it was not designed to allow speed control. While this would be an inconvenience for the testing of the cyclic pitch propeller, when installed on the free swimming version of C-SCOUT, the speed could be controlled in the captive tests by varying the bus voltage for the motor using an external power supply. As the propeller is required, during normal operation, to run at a continuous speed, this controller would prove very suitable for a production CPCPP. 


\subsection{Actuator Controller}

The actuator controllers were also developed from scratch for the CPCPP. These controllers were designed around the SLA7024M stepper motor controller. These prepackaged motor controllers were capable of providing the required 1.2 A at a 24 VDC bus voltage needed by the actuators. The timing logic and control feedback were accomplished using a Microchip Corp. PIC16C715 Microprocessor. The completed circuit schematic can be seen in Figure 6.6 [Allegro Microsystems, 2002].

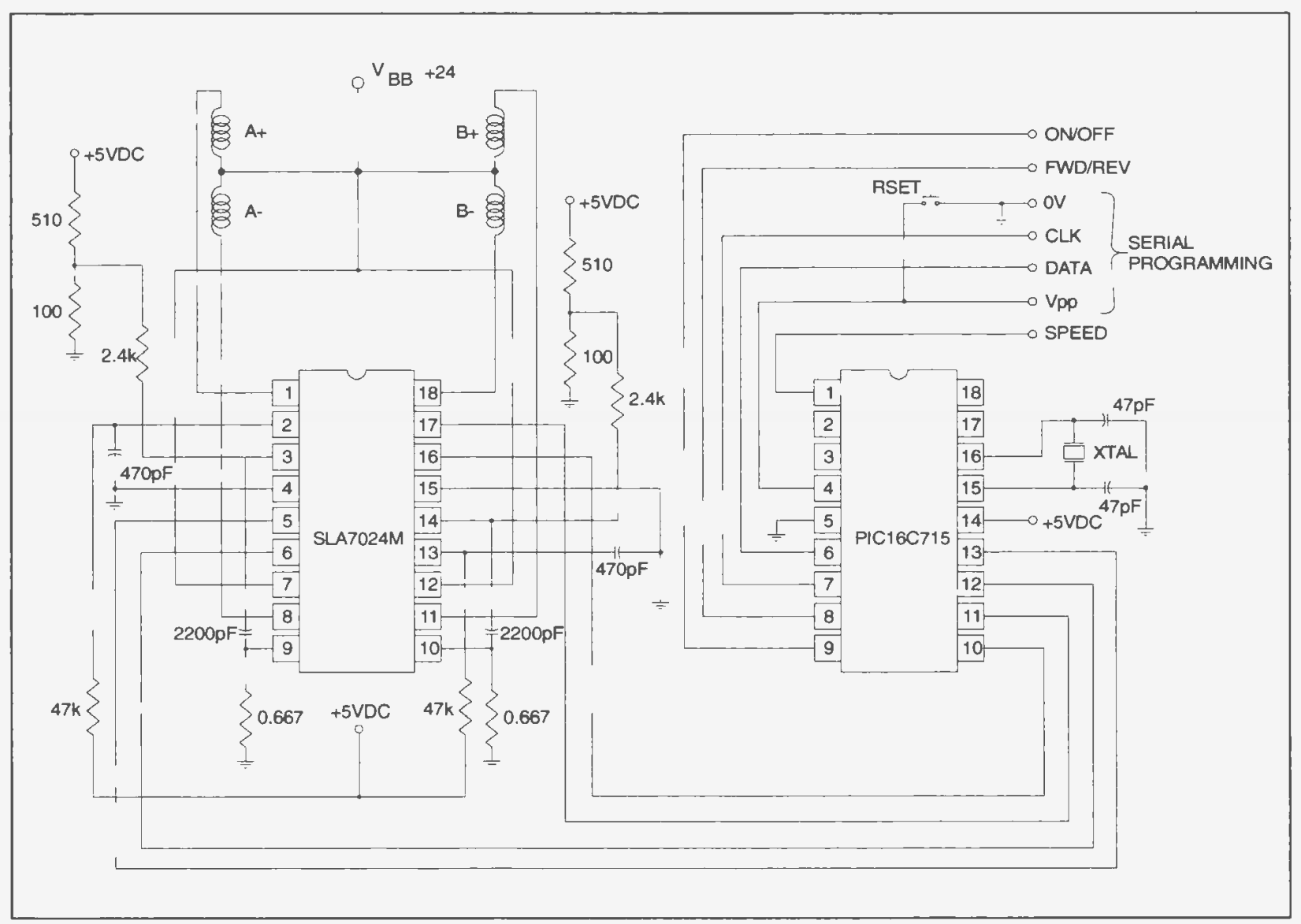

Figure 6.6: Actuator Controller Schematic 
These controllers were constructed and assembled by Technical Services at MUN. The initial testing of these controllers presented some problems with their design. The feedback control was the worst of these problems. The operational amplifiers used to increase the voltage spread for the AVD converter in the PIC suffered from excessive noise in the signal. A redesigned version of this controller was going to be necessary before a working version could be installed on the CPCPP.

In the interest of time, the development of these controllers was discontinued and a commercial stepper motor controller was sourced. The Applied Motion Products $3540 \mathrm{~m}$ Step Motor Drive was selected for this application, Figure 6.7. These commercial drivers provided half step control to the swash plate actuators [Stiffler, 1992]. The $0.9^{\circ}$ half step resulted in an actuator motion of $0.0079 \mathrm{~mm}$ (0.0003125 in) of linear travel. The stepper drive required three 5 VDC logic signals. The first signal was to enable the drive. The second signal set the actuator direction of travel. The final signal told the controller to step the motor. This step signal could be used to control the motor's speed using PWM with a $50 \%$ duty cycle. The faster the pulses to the driver, the faster the stepper motor would turn, while the number of pulses controlled the amount of extension or retraction of the actuator. 


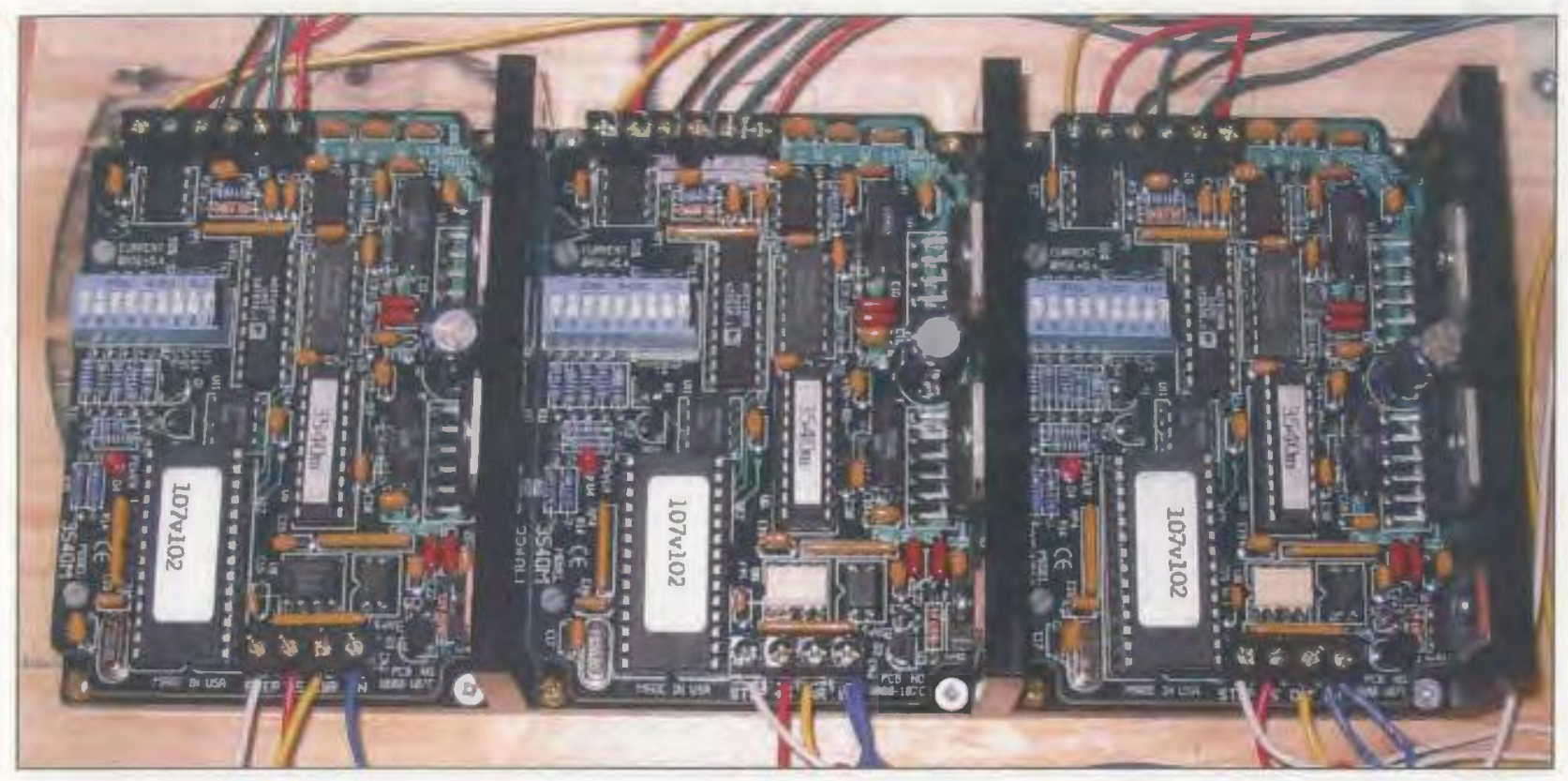

Figure 6.7: Stepper Motor Drivers

\subsection{Power Distribution}

The power distribution system for the CPCPP was divided into two separate systems: main power system and control system power. The separation of the two systems helped to eliminate the transfer of signal noise from the power stage to the control stage. Noise in the control stage of the electrical system could cause unwanted errors in the analog filters and amplifiers used to determine the position of the swash plate. 


\subsubsection{Main Power System}

The main power system consisted of a positive 24 VDC rail, a negative 24 VDC rail and a ground rail. This allowed the actuators to be powered between one of the 24 VDC rails and ground, while providing 48 VDC for the main motor controller. A schematic of this system can be seen in Figure 6.8. As shown in Figure 6.8, the main motor controller and the actuator drivers circuits were fused to prevent them from being damaged in the event of an over current condition. This protection was in addition to the current limiting circuits that are built into each controller. The actuator drivers have a maximum current draw of $1.2 \mathrm{~A}$ and are protected with a $1.5 \mathrm{~A}$ fast-blow fuse. The main motor controller was rated for $20 \mathrm{~A}$. The current limiting adjustment on the controller was set at $17 \mathrm{~A}$, as this was the maximum rated continuous current for the motor. Therefore, a $20 \mathrm{~A}$ slow blow fuse was used to protect the main motor circuits.

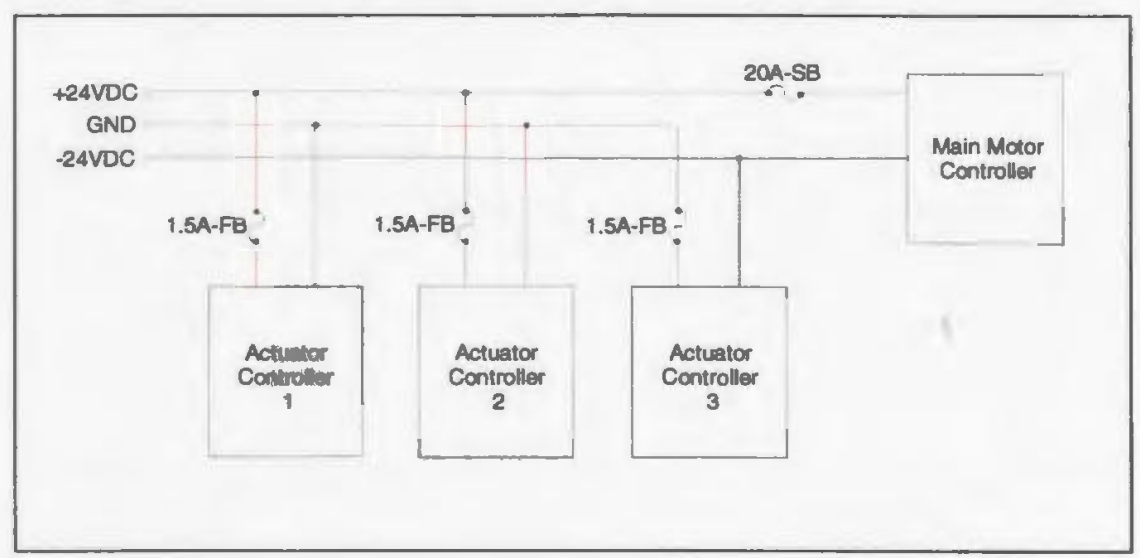

Figure 6.8: Main Power System Schematic 


\subsubsection{Control System Power}

Using an extension of C-SCOUT's existing power system, the control system power architecture for the CPCPP was developed. The CPCPP control system required +24 VDC, \pm 12 VDC, +5 VDC and Signal Ground. The 24 VDC was required to power the single board computer used to control the CPCPP. The \pm 12 VDC were required to provide the rail voltages for the instrument amplifiers used by the RPM, current and actuator position sensors. The 5 VDC was used as a reference voltage for the potentiometers and for digital TTL logic circuits. The 5 VDC voltage also supplied the digital I/O ports on the single board computer for logic operations. A schematic of the control system power layout can be found in Figure 6.9. 


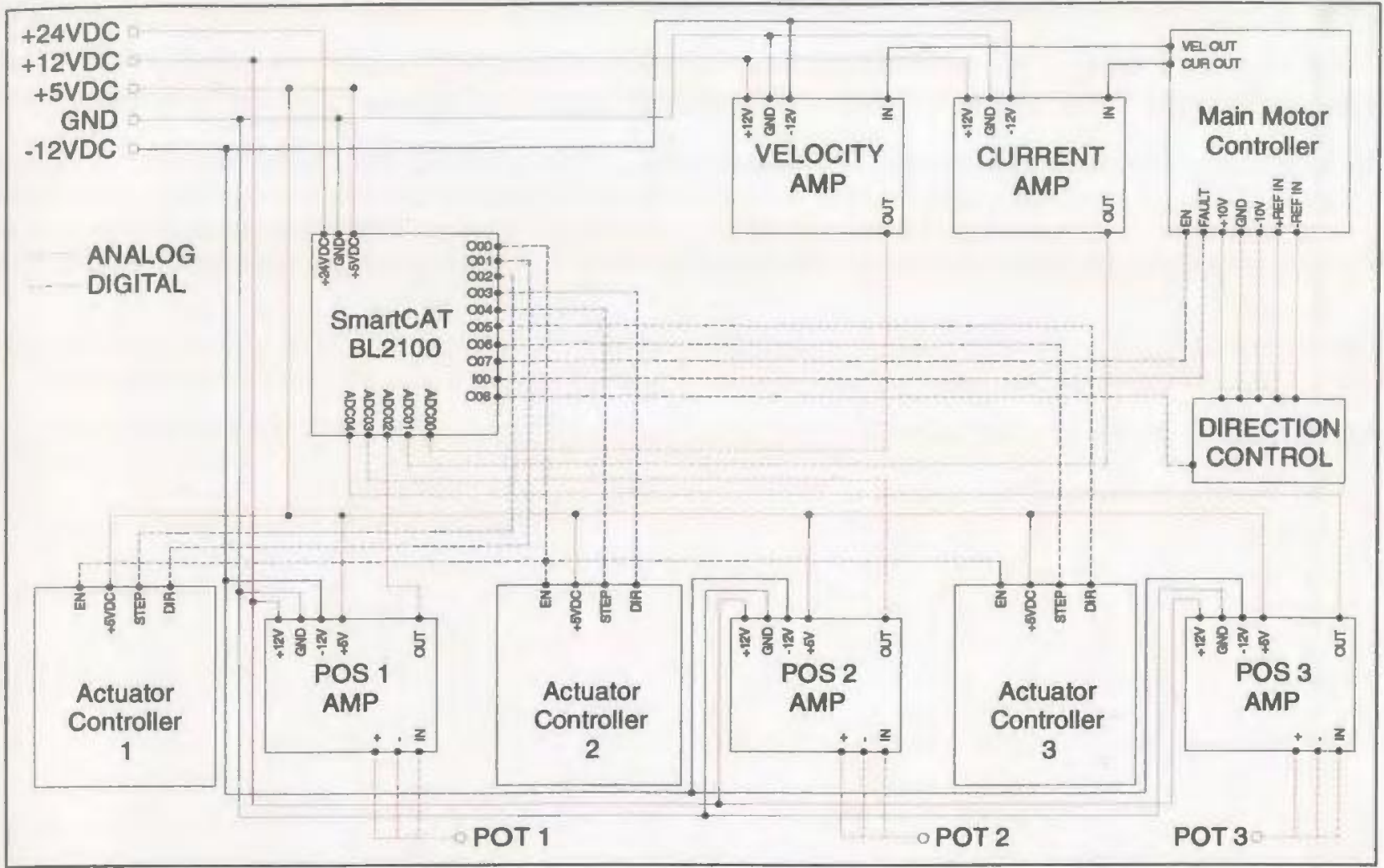

Figure 6.9: Control System Power Schematic

\subsection{Signal Conditioning}

When using a single board computer to monitor analog signals, signal conditioning was required to ensure optimal operation. The digital to analog converters used by the single board computer have a resolution of 12 bits over a \pm 10 VDC range. The signals developed by the potentiometer and other sensors should be modified to operate over this \pm 10 VDC range if possible. It was recommended that they operate over the 0 VDC to 10 VDC range as a minimum providing 11 bits of resolution. This could be accomplished using instrument amplifiers. These instrument amplifiers increased the voltage span of the 
potentiometers and the main motor controller outputs. A sample instrument amplifier circuit can be seen in Figure 6.10. The gain resistor $R_{G}$ shown in Figure 6.10 could be chosen to control the amplification of the instrument amplifier. The gains and resistor values for all five amplifiers can be seen in Table 6.1.

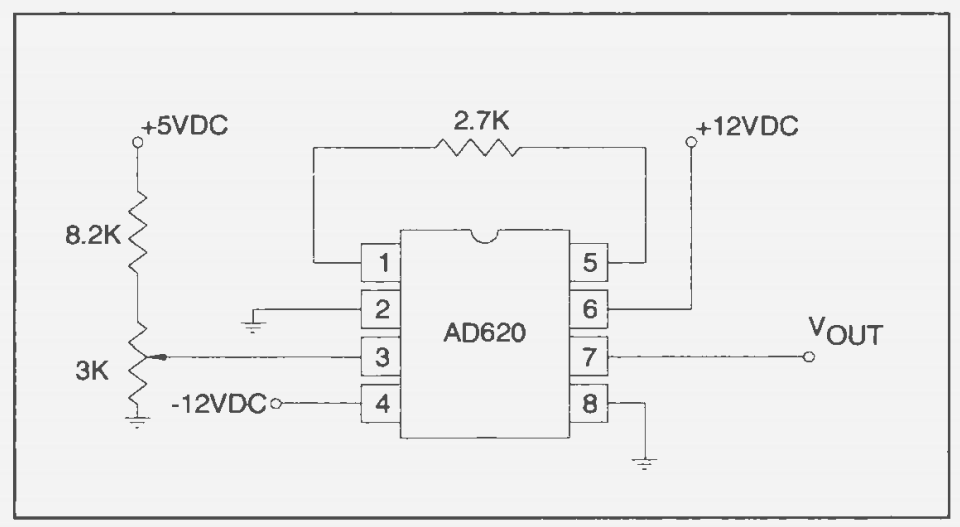

Figure 6.10: Sample Amplifier Circuit

Table 6.1: Instrument Amplifier Gains and Gain Resistor Values

\begin{tabular}{|c|l|c|c|}
\hline Amp No & Description & Required Gain & Resistor Value \\
\hline 1 & Main Motor Speed & 48.78 & $1 \mathrm{k}$ \\
\hline 2 & Main Motor Current & 4 & $16.2 \mathrm{k}$ \\
\hline 3 & Actuator 1 Position & 18.4 & $2.7 \mathrm{k}$ \\
\hline 4 & Actuator 2 Position & 18.4 & $2.7 \mathrm{k}$ \\
\hline 5 & Actuator 3 Position & 18.4 & $2.7 \mathrm{k}$ \\
\hline
\end{tabular}

\subsection{Main Processing Unit}

As the CPCPP was designed to be a semi-intelligent system, a suitable microprocessor was required to control the main motor and the three actuators. 
This main processing unit obtained the high-level control inputs from the command and control computer of the AUV, and converted them into the required actuator positions. The main processor also controlled the start/stop and directional functions of the main motor controller.

The selection of the main processing unit was determined based on experiences with several micro controllers. The BASIC Stamp microprocessor, PIC microprocessor and the Rabbit $2000 / 3000$ series microprocessors were investigated for processing capabilities, input/output capabilities and reliability. The simplest processor was the BASIC Stamp, but lacked the speed and input/output requirements for this project. The PIC microprocessor was used in other areas of the C-SCOUT project, but has shown to be relatively unreliable in application. The Rabbit 2000/3000 Series microprocessor was also used on the C-SCOUT project, and has shown to be more reliable than the PIC processors. The Rabbit processor also has the input/output and processing power requirements needed for the project when coupled with an interface card. The BL2100 Smartcat ${ }^{\mathrm{TM}}$ Single Board Computer was used in the project, Figure 6.11. Details and specification for this computer can be found in Appendix C. 


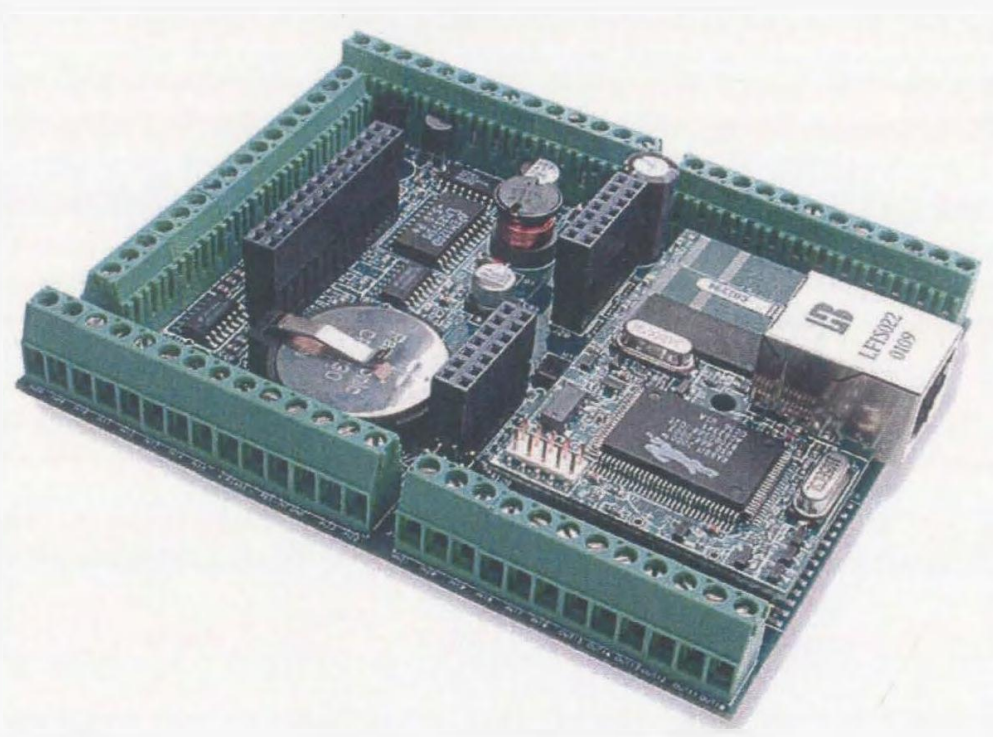

Figure 6.11: Smartcat ${ }^{\mathrm{TM}}$ Single Board Computer

The BL2100 could be communicated with using serial RS-232/RS-422/RS-485 or TCP/IP communications. These protocols allowed commands and instructions to be sent to the Rabbit 2000 microprocessor. Programming of the processor was achieved using an RS-232 port located on the Rabbit 2000 processor and a proprietary programming cable. The RS-232 programming port was passed though the pressure housing using a waterproof connector to allow easy reprogramming without disassembling the CPCPP. The TCP/IP and RS-232/RS485 serial connection were also passed through the housing using waterproof connectors. This allowed the control configuration to be selected based on vehicle control capabilities. The connector wiring diagrams can be seen in Appendix C. 


\section{Chapter 7 \\ Control Algorithm Development}

\subsection{Introduction}

The three independent actuators that control the swash plate required precise positioning for the CPCPP to function correctly. The positioning of the blades and the thrust generated by the propeller were both nonlinear functions. The thrust generated by the propeller blades in relation to the blade angle of the propeller is a relationship that can be solved using experimental analysis or detailed propeller theory. The non-linear relationship between the blade angle and the actuator positions could be modeled using a dynamic simulation of the moving parts. This simulation was done using AutoDesk Inventor.

\subsection{Test Procedure}

The AutoDesk Inventor model used to simulate and verify the CPCPP design could be used in reverse to determine the relationship between actuator position and blade angle. The constraints on the actuator lengths were suppressed and new constraints were added to the angle of the blades. By driving the blade angles, the actuators would be positioned through the dynamic simulation of the 
model. The actuator displacements could then be read and recorded for each angle to generate a system of equations for each actuator.

After the equations were derived for the actuators of the CPCPP, the constraints on the blades could be suppressed and the constraints on actuator lengths released. Using the required inputs for the actuator equations, the conformance of the developed model could be thoroughly tested in the computer before implementation on the CPCPP prototype. This preliminary testing helped eliminate possible damage to the prototype.

\subsection{Test Matrix Development}

The development of the test matrix for the dynamic simulation of the CPCPP was the process by which a solution was chosen that converted ahead / astern, starboard/port and dive/surface signals from the control computer into the required blades angles. The input control signals have a range from $-100 \%$ to $+100 \%$, where zero is the all stopped condition. Actuator orientaticn and direction convention can be seen in Figure 7.1. 


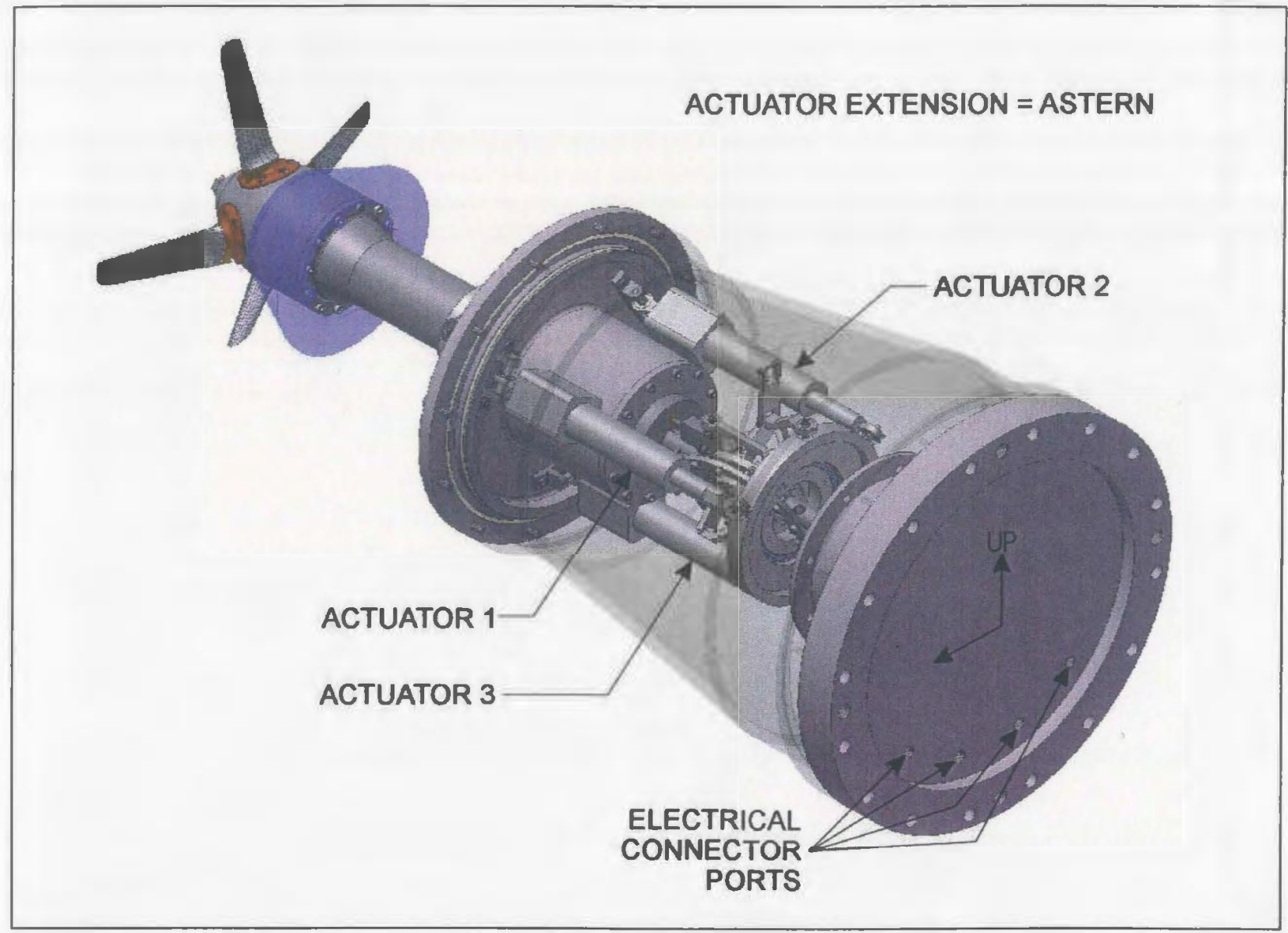

Figure 7.1: Directional Convention and Actuator Orientation

The test matrix was developed using Design of Experiments (DOE) statistical techniques, [Montgomery, 2001]. This technique assumes that in order to determine the output of experimental tests, only intentional changes will be made to the input variables. DOE is the application of statistics to experimental design. The result of using DOE is an optimal mathematical model that predicts the interaction between the input variables and the output response. There are different experimental methods available depending on the output and input variables, which include full factorial, fractional factorial and response surface 
methodology, [Montgomery, 2001]. The DOE analysis used to develop the model equations was a response surface method. By using this method, the curvature or non-linearity of the system could be captured in the equations. Design Expert DOE software was used to generate a test matrix based on the response surface method. In the test matrix, the three principal directions (forward/reverse, up/down and left/right) were the input variables, and the positions of each actuator were the output responses. A linear relationship between blade angle and the percentage of output thrust $\left(100 \%=29^{\circ}\right)$ was assumed to create the test matrix. While this assumption was not completely accurate, it provided a starting point of the control system development. Design Expert generated a standard list of changes to the input variables that were required to capture the necessary actuator motions. These changes were entered into the CPCPP dynamic model in AutoDesk Inventor, and the responses for each actuator recorded.

\subsection{Generation of Equations}

Once the results of the dynamic simulation were entered into Design Expert, the data could be analyzed using DOE statistical methods to find an equation that fit the CPCPP model. An analysis of variance (ANOVA) was conducted in Design Expert to determine which variables and their interactions were significant to the model. After each actuator was analyzed, a set of three equations was 
developed to control the actuators based on the desired control inputs. The equations for actuators 1,2 and 3 are given in Table 7.1.

Table 7.1: Table of Control Equations

\begin{tabular}{|c|c|c|c|c|c|}
\hline \multirow{2}{*}{ 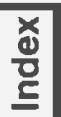 } & \multicolumn{3}{|c|}{ Coefficients } & \multirow[t]{2}{*}{ Relation } & \multirow[t]{2}{*}{ Variables } \\
\hline & Actuator 1 & Actuator 2 & Actuator 3 & & \\
\hline 0 & $-5.937 E-05$ & -0.0005131 & -0.0034143 & Coeff & * 1 \\
\hline 1 & -0.2682 & -0.2680444 & -0.2696444 & * Forward Reverse & ${ }^{*} A$ \\
\hline 2 & -0.0012 & -0.3004815 & 0.3007963 & * Up Down & ${ }^{\star} B$ \\
\hline 3 & 0.34712963 & -0.1732963 & -0.1736481 & ${ }^{\star}$ Left Right & ${ }^{\star} \mathrm{C}$ \\
\hline 4 & -0.0058244 & -0.0065985 & -0.0022673 & * Forward Reverse2 & ${ }^{*} A \wedge 2$ \\
\hline 5 & 0.0011952 & -0.0067161 & -0.005483 & * Up Down2 & ${ }^{\star} \mathrm{B}^{\wedge} 2$ \\
\hline 6 & -0.0039421 & 0.00532312 & -0.0110516 & ${ }^{\star}$ Left Right2 & ${ }^{*} \mathrm{C}^{\wedge} 2$ \\
\hline 7 & 0 & -0.0283529 & 0.02858824 & * Forward Reverse * Up Down & ${ }^{*} A * B$ \\
\hline 8 & 0.03280392 & -0.0164118 & -0.0162549 & * Forward Reverse * Left Right & ${ }^{*} A * C$ \\
\hline 9 & 0.00539216 & 0.0015098 & -0.0053529 & * Up Down * Left Right & ${ }^{*} B{ }^{*} \mathrm{C}$ \\
\hline 10 & 0 & 0 & 0 & * Forward Reverse3 & ${ }^{*} A \wedge 3$ \\
\hline 11 & 0 & -0.0562895 & 0.05856524 & ${ }^{\star}$ Up Down3 & ${ }^{\star} \mathrm{B}^{\wedge} 3$ \\
\hline 12 & 0.06558746 & -0.0334063 & -0.0327647 & * Left Right3 & ${ }^{*} \mathrm{C} \wedge 3$ \\
\hline 13 & 0 & 0.03288205 & -0.0339897 & * Forward Reverse2 * Up Down & ${ }^{\star} A \wedge 2{ }^{*} B$ \\
\hline 14 & -0.038 & 0.01937436 & 0.01921026 & ${ }^{\star}$ Forward Reverse2 * Left Right & ${ }^{\star} A^{\wedge} 2{ }^{*} C$ \\
\hline 15 & 0 & 0 & $\begin{array}{r}0 \\
\end{array}$ & * Forward Reverse * Up Down2 & ${ }^{*} A * B^{\wedge} 2$ \\
\hline 16 & 0 & 0 & $\begin{array}{r}0 \\
\end{array}$ & * Forward Reverse * Left Right2 & ${ }^{*} A * C \wedge 2$ \\
\hline 17 & -0.1184923 & 0.05851282 & 0.05982564 & ${ }^{\star}$ Up Down2 * Left Right & ${ }^{\star} \mathrm{B}^{\wedge} 2{ }^{*} \mathrm{C}$ \\
\hline 18 & 0 & 0.10177436 & -0.1026359 & * Up Down * Left Right2 & ${ }^{*} \mathrm{~B}^{*} \mathrm{C}^{\wedge} 2$ \\
\hline 19 & 0 & 0 & 0 & ${ }^{*}$ For./Rev. ${ }^{*}$ Up Down * Left Right & ${ }^{*} A * B{ }^{*} C$ \\
\hline
\end{tabular}

$$
\begin{aligned}
& A c t_{1}=c_{1,0}{ }^{*}(1)+c_{1,1}{ }^{*}(A)+C_{1,2}{ }^{*}(B)+C_{1,3}{ }^{*}(C)+\ldots+C_{1,19}{ }^{*}\left(A^{*} B^{*} C\right) \\
& A c t_{2}=c_{2,0}{ }^{*}(1)+c_{2,1}{ }^{*}(A)+c_{2,2}{ }^{*}(B)+C_{2,3}{ }^{*}(C)+\ldots+C_{2,19}{ }^{*}\left(A^{*} B^{*} C\right) \\
& A c t_{3}=c_{3,0}{ }^{*}(1)+c_{3,1}{ }^{*}(A)+C_{3,2}{ }^{*}(B)+C_{3,3}{ }^{*}(C)+\ldots+C_{3,19}{ }^{*}\left(A^{\star} B^{\star} C\right)
\end{aligned}
$$

${ }^{\star \star}\left(c_{m, n}\right.$ is the polynomial coefficient where $m$ is the actuator and $n$ is the index) 
This table lists the equations for each actuator in tabular format. Equations 7.1 to 7.3 illustrate the conversion of the equations into standard format. The first column in the table represents the index for the polynomial coefficients. The next three columns are the polynomial coefficients for each actuator. By multiplying these coefficients with the variables found in the last column, the three actuator equations can be formed. The coded coefficient, $A$, represents the percent of ahead or astern thrust with a positive value being ahead and a negative value being astern. The coded coefficient, $B$, represents the percent of surface or dive thrust with the positive value being upward or surface thrust. Similarly, the coded coefficient, C, represents the percent of port or starboard thrust with thrust to starboard being the positive value.

The validity of this control model was then tested using the dynamic simulation of the parametric model. The actuator displacements in the dynamic solid model were compared to the actuator responses calculated from the mathematical equations. The actuator displacements generated from the equations were found to be statistically agreeable to the dynamic model results. Random points were also collected from the dynamic solid model and recorded. These positions were calculated from the equations and compared to the dynamic solid model results for each value. The absolute error between the dynamic model values and the equation-generated values was calculated for all three actuators. The 
mean error over the operating range of the actuators was found to be $0.00 \mathrm{~mm}$ (0.00 in) with a standard deviation of $0.79 \mathrm{~mm}(0.031 \mathrm{in})$ or less.

The equations will require fine-tuning once performance data has been collected, which will allow the propeller to compensate for other non-linear effects. These non-linear effects include:

- Compensation for the initial assumption that the thrust varies linearly with propeller blade angle

- Compensation for unsteady flow effects, discussed in more detail in Section 8.7. 


\section{Chapter 8 Initial Testing And Results}

\subsection{Introduction}

Tests of the propeller were conducted to provide proof of concept. These tests were designed to demonstrate the mechanical, electrical and software aspects of the propeller. The ability of the propeller to produce side thrust was also a requirement of the tests. The resulting data collected, test procedure and setup for these tests have been outlined and discussed in the first part of this chapter. The second part of this chapter examines and discusses the raw data collected from the experiments. The final portion of the chapter discusses the results from analysis of the data collected.

\subsection{Data Collection}

One of the first challenges to overcome was how to accurately collect the forces and moments generated by the propeller. Previous work conducted by Bijleveld [2002] demonstrated that using a yacht dynamometer attached to a towing carriage would not provide sufficient resolution to record the relatively small forces generated by the CPCPP. However, following a technique employed by 
Thomas [2003] of measuring the forces and moments as close to the propeller as possible, capture of the generated forces and moments was possible, Figure 8.1.

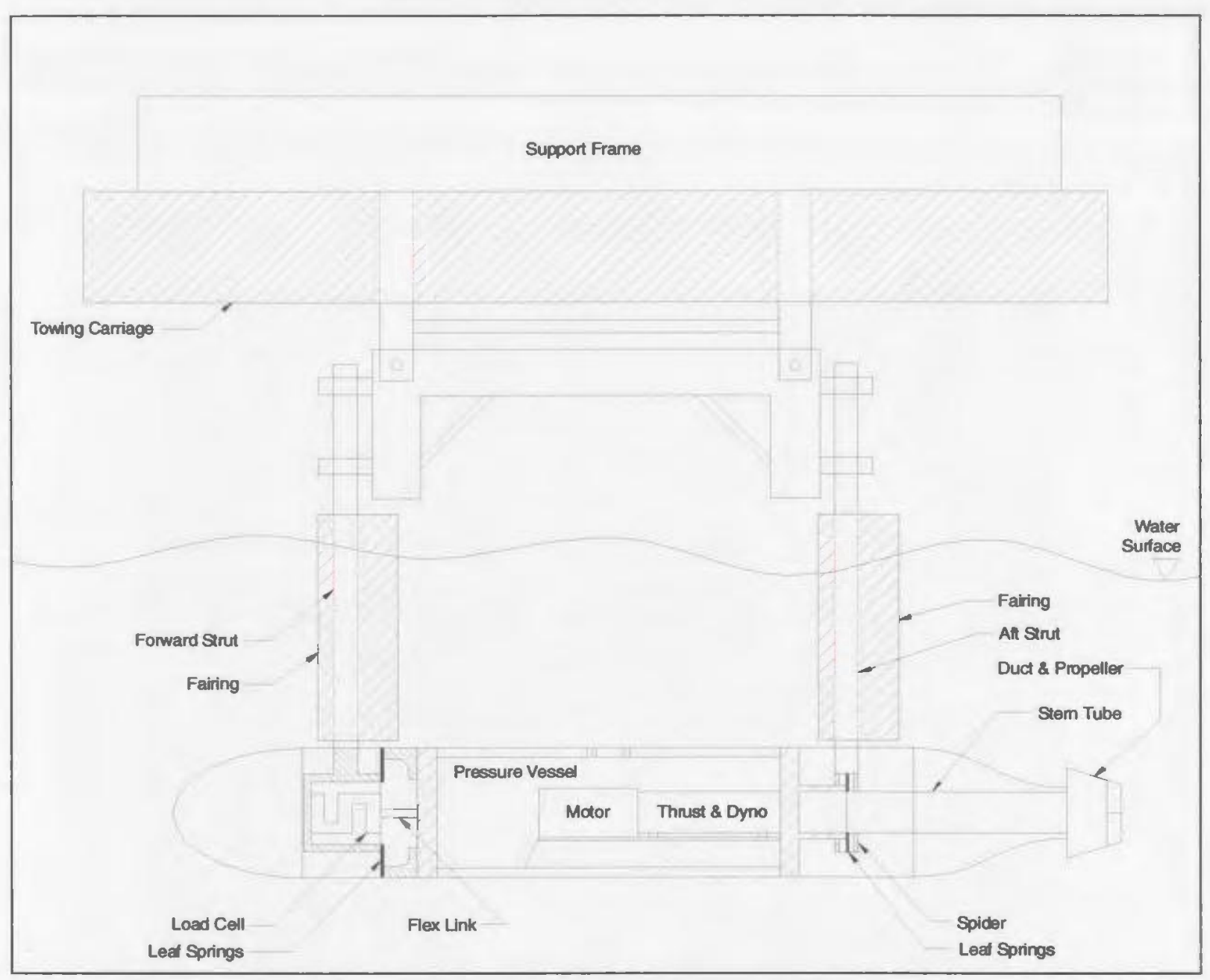

Figure 8.1: Thomas' Setup for Propulsion Thrust and Torque Measurement

While Thomas was only interested in thrust and torque and the CPCPP was designed as a production prototype as opposed to an experimental model, some modifications to the measurement technique were required. Instead of the 
instrumentation being installed inside the propeller housing, a six-component load cell puck was mounted in a waterproof housing and attached between the CPCPP and the remainder of the hull, Figure 8.2. By placing the six-component load cell between the CPCPP and the hull, a complete set of forces and moments generated by the propeller could be accurately measured with as little interference from the hydrodynamic effects on the hull as possible. The detailed drawings for the load cell and mounting apparatus can be found in Appendix D.

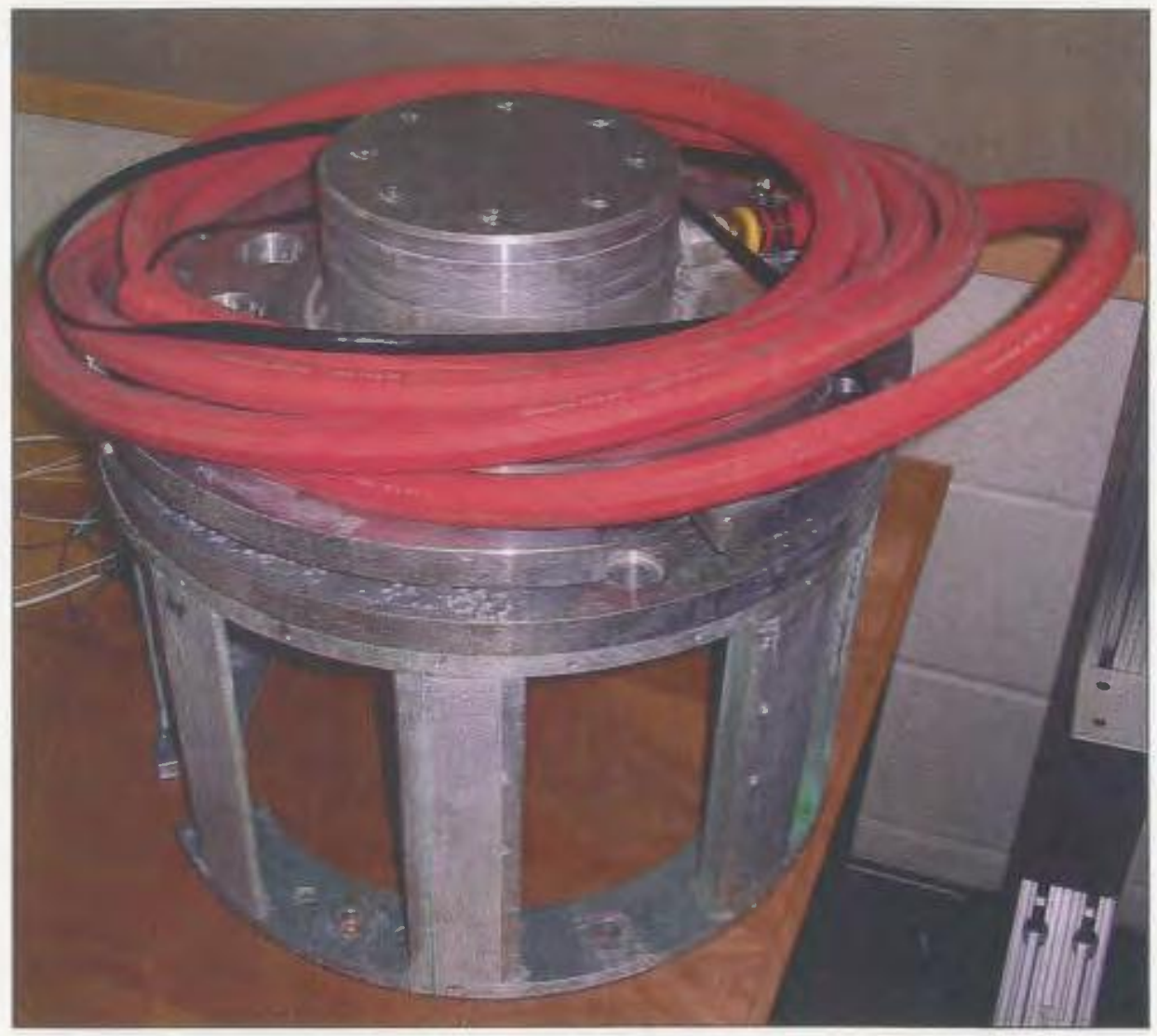

Figure 8.2: Measurement Apparatus for CPCPP

The load cell chosen to collect the data from the CPCPP was a model 45E15A six-component load cell with internal sensor electronics manufactured by JR3 
Inc., Figure 8.3. The load cell was custom calibrated to provide full-scale readings that would be within the range of operation of the CPCPP. While the maximum range of the lateral forces were estimated to be in the range of $44.5 \mathrm{~N}$ (10 lbf), the corresponding bending moments were estimated to be $41 \mathrm{Nm}$ (365 lb-in). The long moment arm of $927 \mathrm{~mm}$ (36.5 in), between the load cell and the propeller plane of action, was the cause of these large moment values.

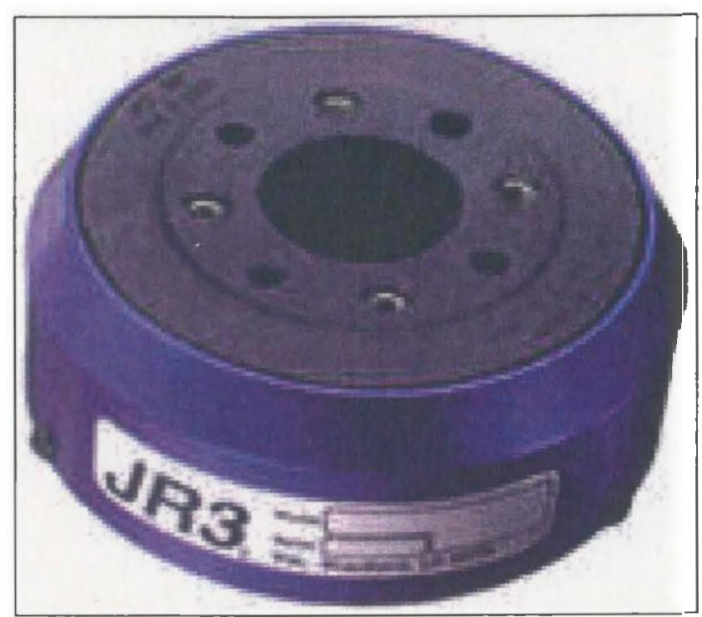

Figure 8.3: 45E15A Load Cell

Another consideration for the sizing of the load cell was the level of the forces and moments exerted when the propeller housing was not supported in water. The weight force was $578 \mathrm{~N}(130 \mathrm{lb})$ and the moment was $179 \mathrm{Nm}(1586 \mathrm{lt}$-in). These loads could occur when lifting the vehicle into and out of the water during testing. Jacking bolts could be installed on the lifting apparatus to reduce these forces. The load cell had to be sized to support the cantilevered load of the CPCPP, while still maintaining good sensitivity in the lateral measurements. The 
overall calibration ranges for the load cell can be found on the data sheet in appendix D

\subsection{Test Setup}

For the required preliminary testing, the CPCPP was mounted to the wall of a test tank. A bracket was manufactured that would clamp to the side of the tank. A short section of the C-SCOUT hull was then bolted to the frame at one end, and the load cell housing was bolted to the other. The propeller was then bolted to the load cell and prepared for operation, Figure 8.4. The electronics and main computer that control the propeller were mounted to a board externally as opposed to inside the propeller, Figure 8.5. By mounting the electronics in this fashion, any problems with the programming or wiring could easily be repaired or corrected. All of these components, except the breadboard in the left hand corner of Figure 8.5, were sized to fit within the propeller housing. 


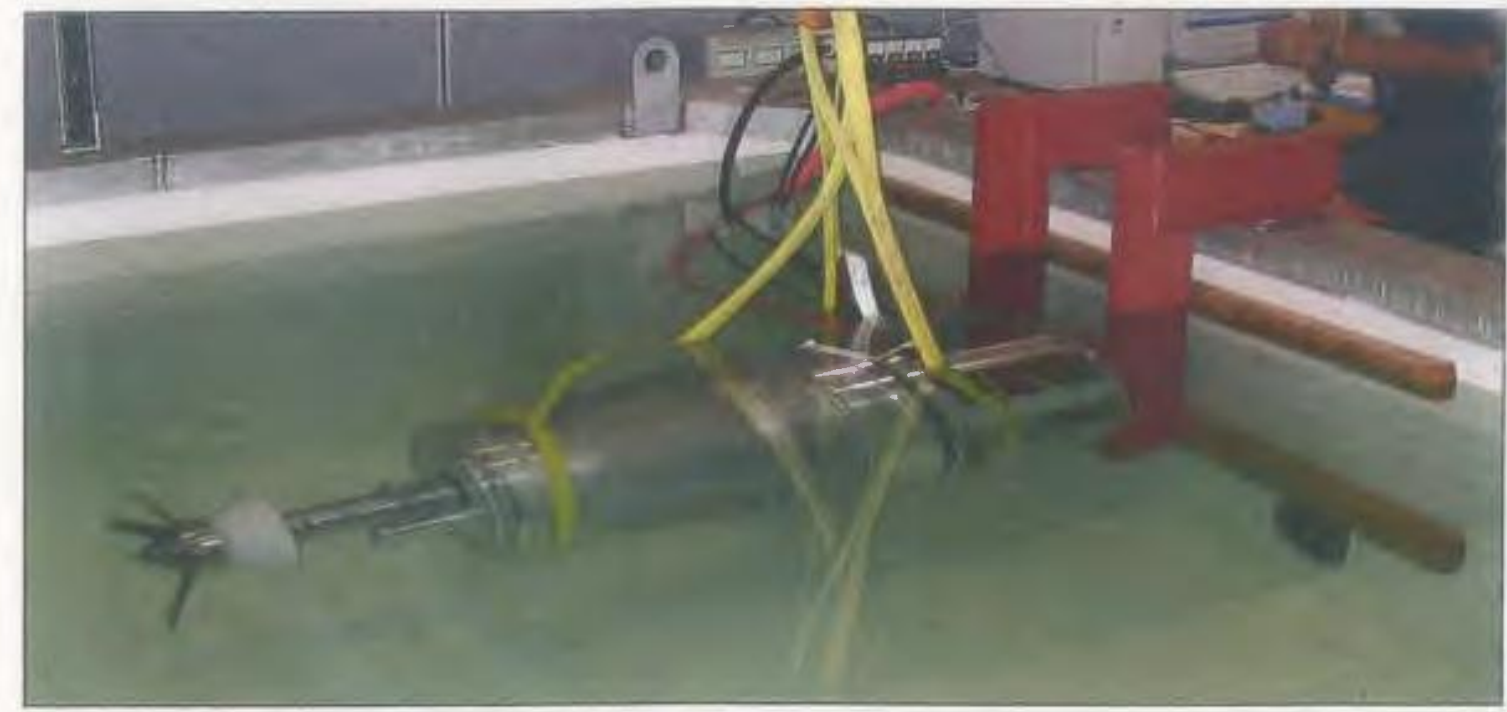

Figure 8.4: Mechanical Propeller Test Setup

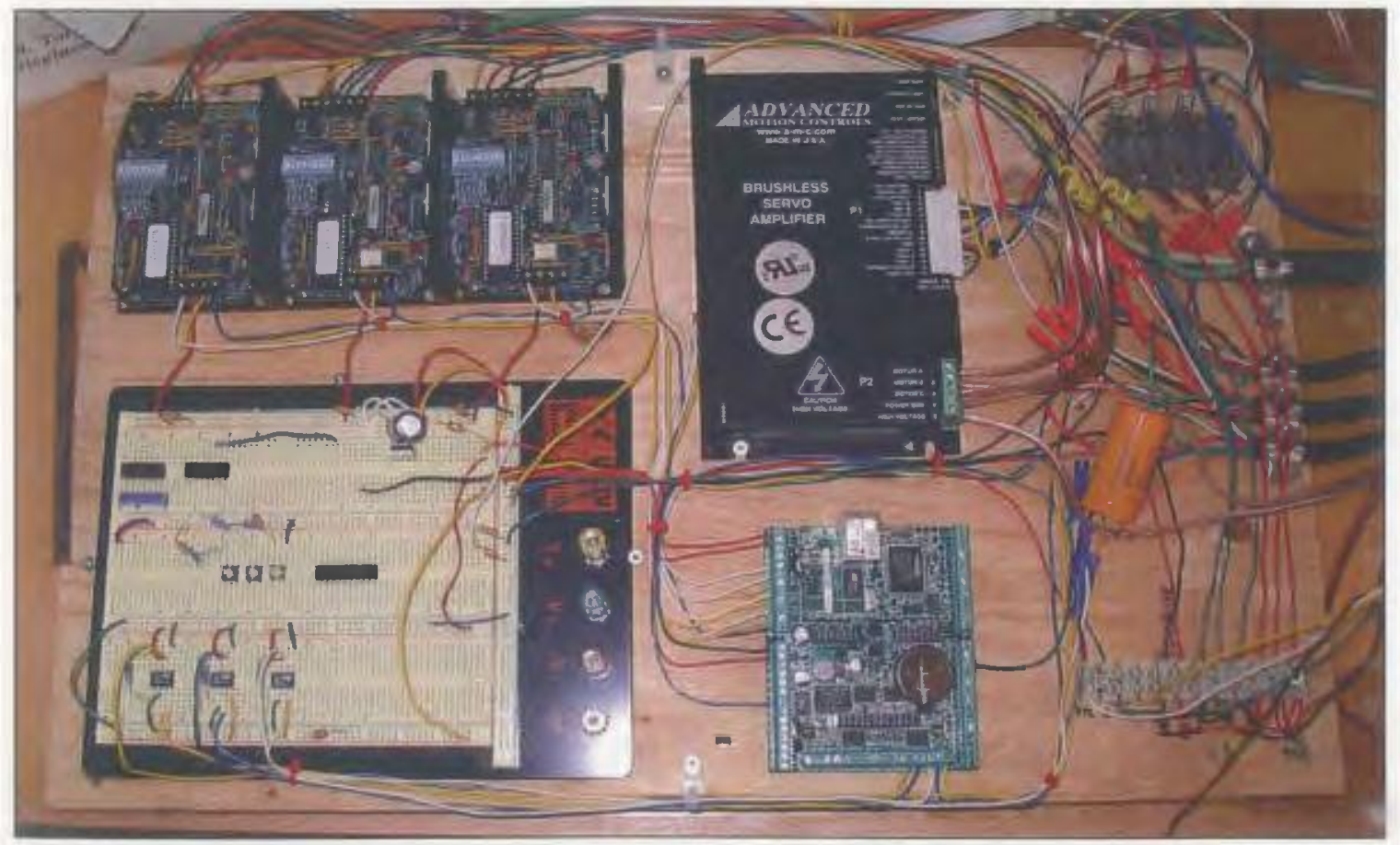

Figure 8.5: Electrical Propeller Test Setup

The controllers, computer and main motor were powered using a series of three power supplies. One power supply provided 24 VDC and 5 VDC to operate the 
electronics and the stepper motor drivers. A second power supply generated the \pm 12 VDC and ground reference required for the operation of the instrumentation amplifiers. A high current 40 VDC power supply was used to provide power to the main motor controller and the main motor. For the test, the required 48 VDC power supply was not available.

\subsubsection{Data Acquisition and Control}

The operator, using the Smartcat ${ }^{\mathrm{TM}}$ programming computer, controlled the propeller. The programming computer was also fitted with the data acquisition card for the JR3 load cell. A program, running in the background, was used to capture the load cell data and log it to a text file for future processing and analysis. The text file was stored in a comma-delimited format to allow easy importation into Matlab ${ }^{T M}$ or Microsoft Excel ${ }^{T M}$ for analysis. The data was sampled at a rate of $2 \mathrm{kHz}$ and sampling was triggered using an internal counter on the $\mathrm{PCl}$ data acquisition card. Each line of data in the file consisted of the date time stamp for the data followed by the $F_{x}, F_{y}, F_{z}, M_{x}, M_{y}$ and $M_{z}$ values. As these data values were in coded format, the full-scale settings for each axis and the applicable conversion factors were read from the load cell and recorded at the start of each file. 


\subsubsection{Propeller Operation}

The testing of the propeller occurred in two phases. A series of ramping up and down trials were conducted to verify that the propeller was generating combinations of axial and radial thrust. For these trials the propeller was run continuously, while the propeller blade angles were cycled through the expected range of motions. During these trials, the circulation of the water in the tank ( $3 \mathrm{~m}$ Long $\times 3 \mathrm{~m}$ Wide $\times 1 \mathrm{~m}$ Deep) was determined to have an important effect on the hydrodynamics of the propeller operation. As a true bollard pull test occurs at an advance coefficient $(\mathrm{J}=0)$, the circulation in the tank distorts the test results. The data collected was therefore not at true bollard pull conditions, but at some unknown advance coefficient. The circulation in the tank also induces unwanted vibration into the test results, as a result of fluctuating pressure distributions over the propeller hull and drive shaft. For these reasons, keeping the circulation in the tank to a minimum reduces any distortion in the collected data.

The second phase of the testing was therefore conducted with the circulation problem in mind. As the propeller was being operated in a tank to obtain bollard pull values, the propeller blades were set to a given thrust value and then run for a period of 10 seconds. The propeller was then stopped and the water in the tank allowed to settle before the next test was conducted. The process was repeated three times for each thrust setting of the propeller. The thrust values of 
the three runs could then be averaged to obtain the thrust values at each setting. Allowing the tank to settle between runs and keeping the run times to about ten seconds reduced the influence of the tank circulation on the collected values.

\subsection{Data Collection}

The first phase of the testing consisted of ramping the propeller blade pitch from ahead to astern and back to neutral. The same procedure was then conducted for the port to starboard and then the surface and dive directions. To determine the effectiveness of maneuvering while thrusting ahead or astern, a set of data was also collected using the $50 \%$ ahead setting while ramping the propeller from starboard to port and then back to neutral. The collected data demonstrated that the propeller was developing axial and radial thrust variations, and the results are presented in Sections 8.6, 8.7 and 8.8.

\subsection{Data Analysis}

The data collected was analyzed using Microsoft Excel ${ }^{\mathrm{TM}}$. As the data collected by the data acquisition system was in coded or bit data format, the data was transformed from the coded units of the load cell to real units. This was accomplished by multiplying the internal load cell calibration factors by the collected data. For example, the axial or $z$-axis force $\left(F_{z}\right)$ bit value was multiplied 
by the internal full scale factor of 267 and then multiplied by $1 / 16384$ to convert the $F_{z}$ value into the units of pounds force. The load cell was professionally calibrated in units of pounds force prior to use. Calibration of the load cell should be verified and corrected if necessary before further tests are conducted. The data was also rotated so that the measurements of the load cell corresponded to the directions entered into the control computer. The data rotation is discussed in more detail in section 8.5.2.

\subsubsection{Smoothing Algorithm}

Due to the random and periodic noise in the data collected, Figure 8.6 , a smoothing algorithm was applied to the data before plotting. The smoothing algorithm takes a midpoint average of the data and writes the average out to a new text file. The user could specify the span of the average when applying the algorithm. A span value of 100 samples was applied to the data presented in this thesis. By taking the midpoint average, time biasing of the data can be eliminated. The program that was written to apply this smoothing algorithm allowed the user to specify the span of the average and also allowed the user to thin the data. 


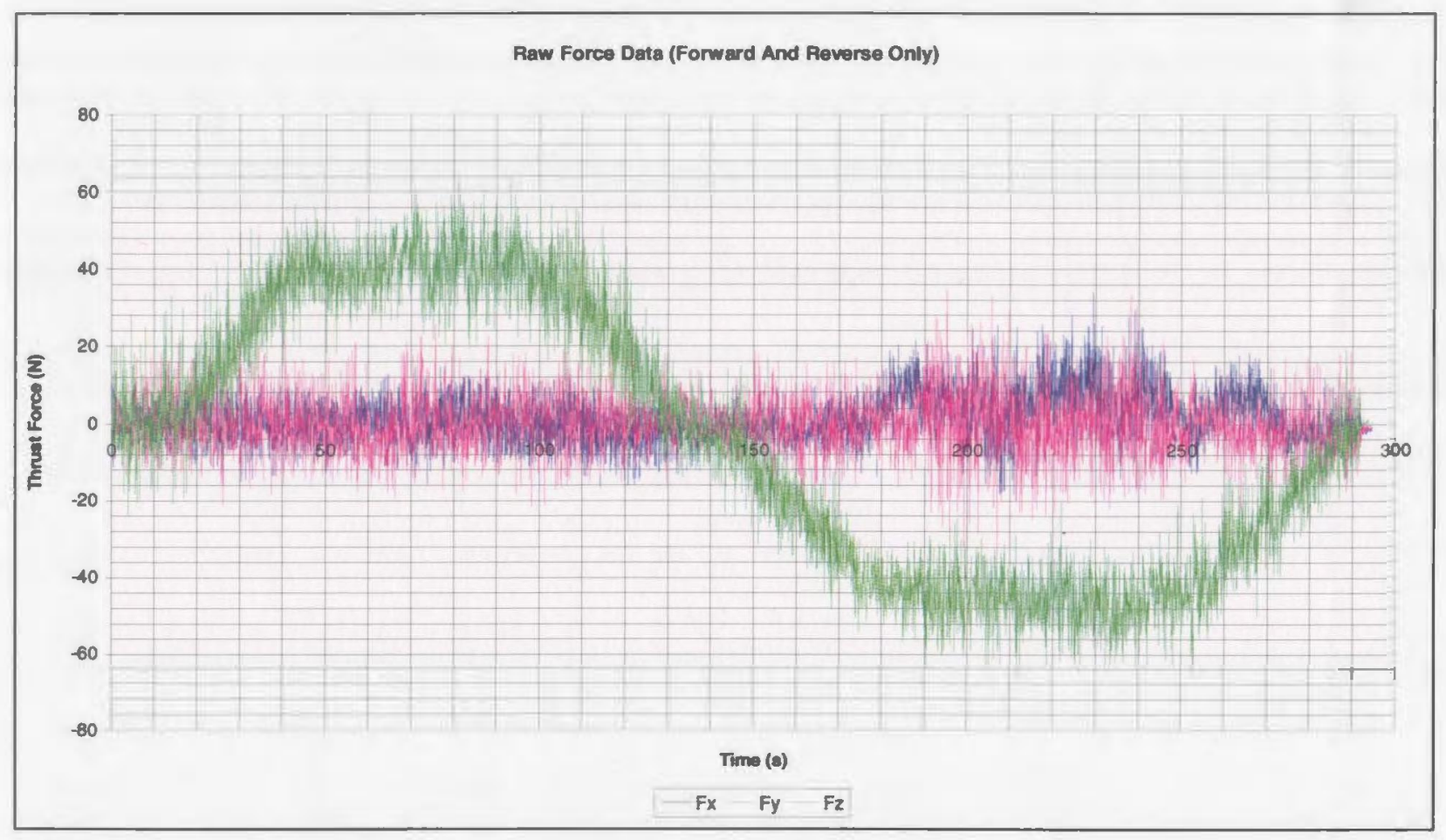

Figure 8.6: Raw Data for Thrust Values

Thinning the data is useful when plotting results. Due to the number of sampled data points, a plot without thinning would result in a fuzzy representation of the results. The thinned plot however, provides a smoother graphic representation of the data. While some of the information due to variations in the readings was lost in this representation, the general trend of the data is captured in the plot. Data presented in this thesis were thinned from $2 \mathrm{kHz}$ to $10 \mathrm{~Hz}$ for ease of plotting. 


\subsubsection{Data Rotation}

Due to constraints in the mounting of the load cell, the orientation of the load cell axes varied from the axis of convention for the CPCPP control system. A set of rotation matrices was applied to the raw data to rotate the data into a similar coordinate frame as the CPCPP control system [Gerber, 1990]. The first rotation matrix rotated the data about the z-axis by an angle of $45^{\circ}$ to align the $x$-axis of the load cell with the $x$-axis of the propeller system. The second rotation matrix rotated the data about the $\mathrm{x}$-axis by an angle of $180^{\circ}$ to align the $z$-axis and $y$ axis of the load cell with their corresponding propeller system axes. The orientation of the unrotated, as measured, axes and the rotated axes can be seen in Figures 8.7 and 8.8 respectively. The completed transformation of the data provides the correct values in the correct directions. All force and moment data in this thesis was presented according to the directional conventions shown in Figure 8.8. 


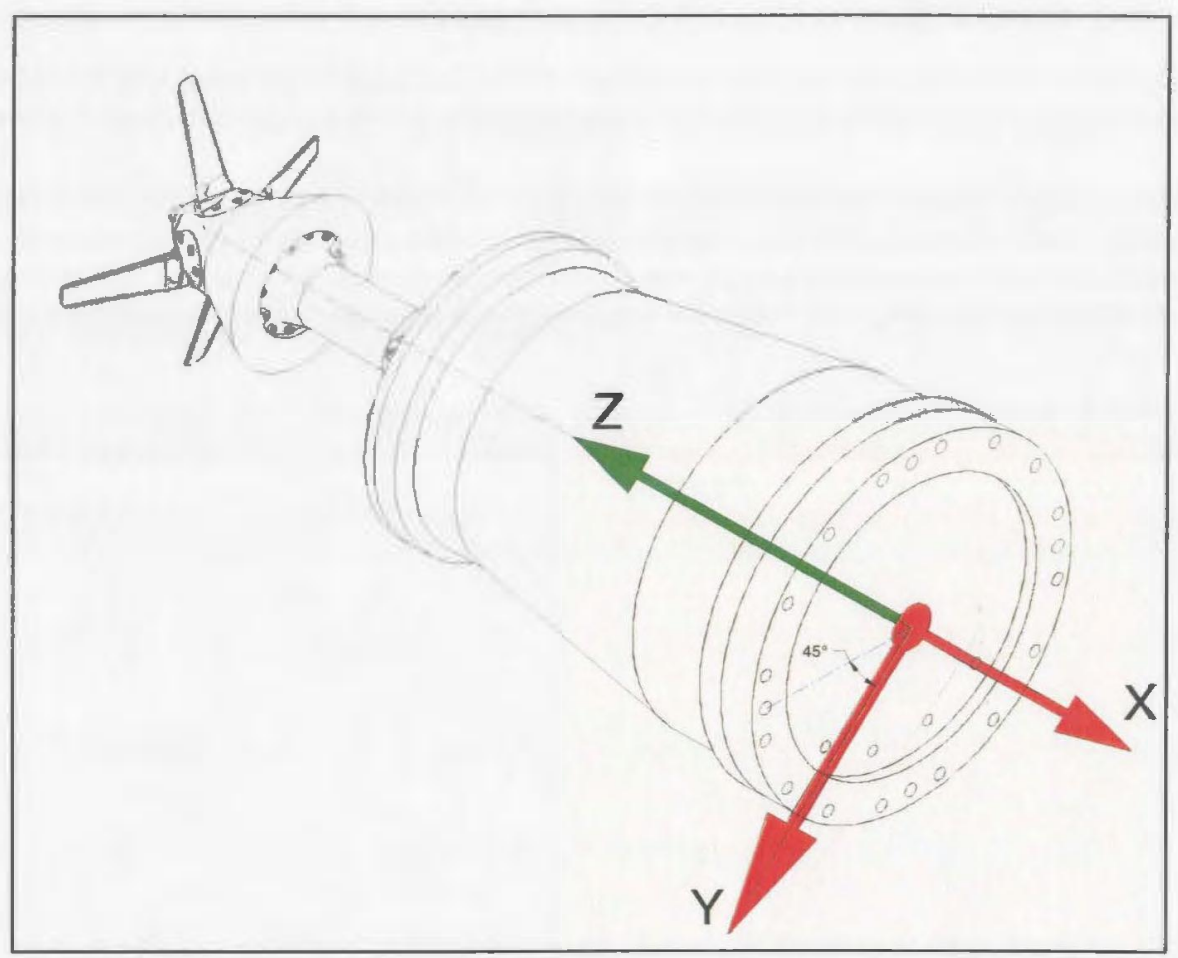

Figure 8.7: Unrotated Axes

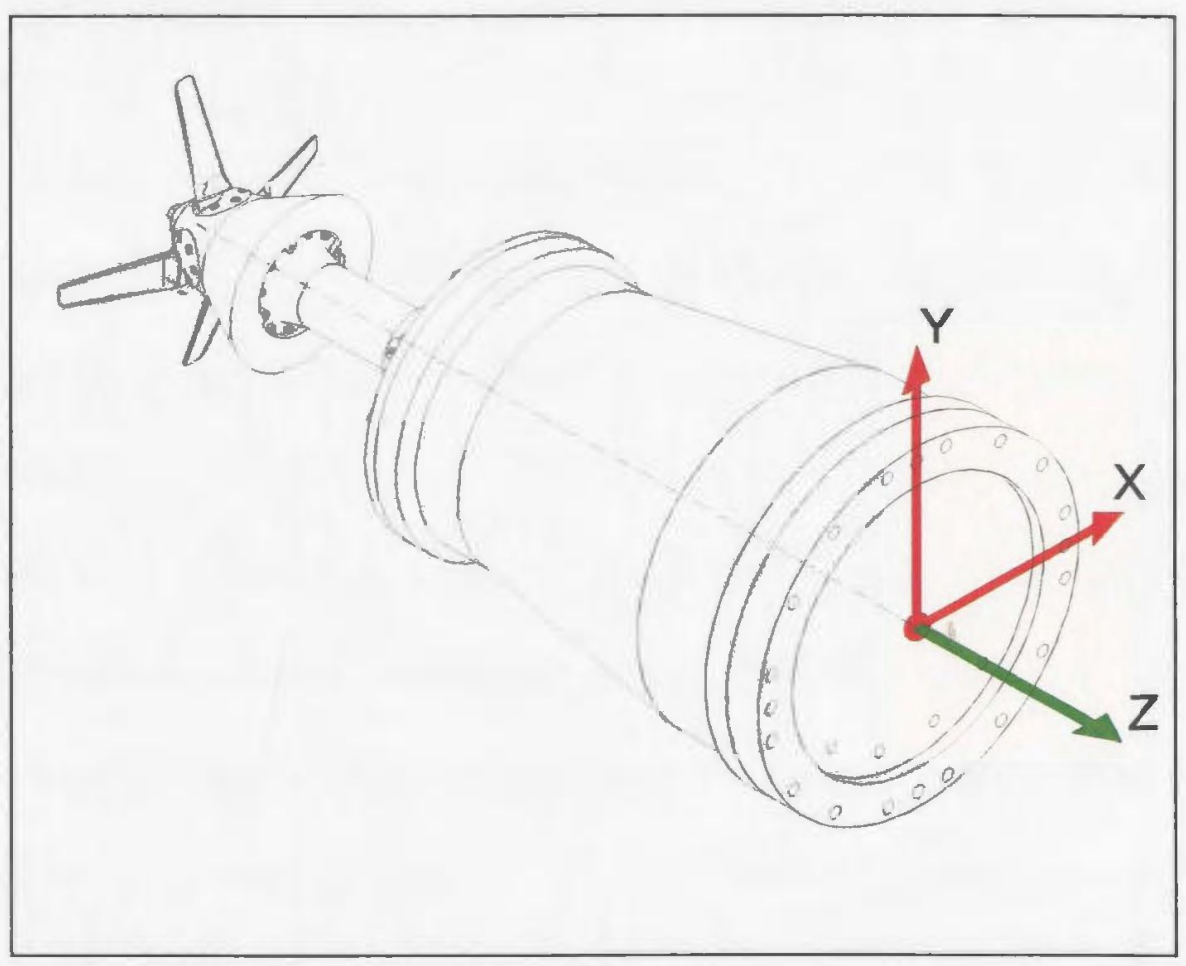

Figure 8.8: Rotated Axes 


\subsubsection{Plotting of Results}

After the data collected had been smoothed and thinned, the new data file was loaded into Microsoft Excel ${ }^{\mathrm{TM}}$. The conversion from coded units and the rotation matrices were applied to produce a table of the forces and moments generated by the CPCPP. These values were then plotted on two graphs. The first graph plots the forces measured against time. The second graph plots the moments measured against time. Plots were generated for the ahead / astern condition, the surface / dive condition and the 50 percent ahead / left / right condition.

\subsection{Results for Test 1 (Ahead / Astern)}

The first set of tests that were conducted with the CPCPP were the ahead / astern tests. These tests were designed to test the collective pitch function of the new propeller, and gain an understanding about the maximum thrust capabilities of the propeller. During this first test, the propeller was stepped in $10 \%$ increments from full ahead to full astern and then back to neutral. The forces and moments were collected, tabulated and plotted in Figure 8.9 and Figure 8.10. During this set of tests, the supply voltage to the main motor was $40.5 \mathrm{VDC}$, and this resulted in a neutral velocity of 380 RPM. Neutral velocity refers to the blades at zero collective and cyclic pitch. 


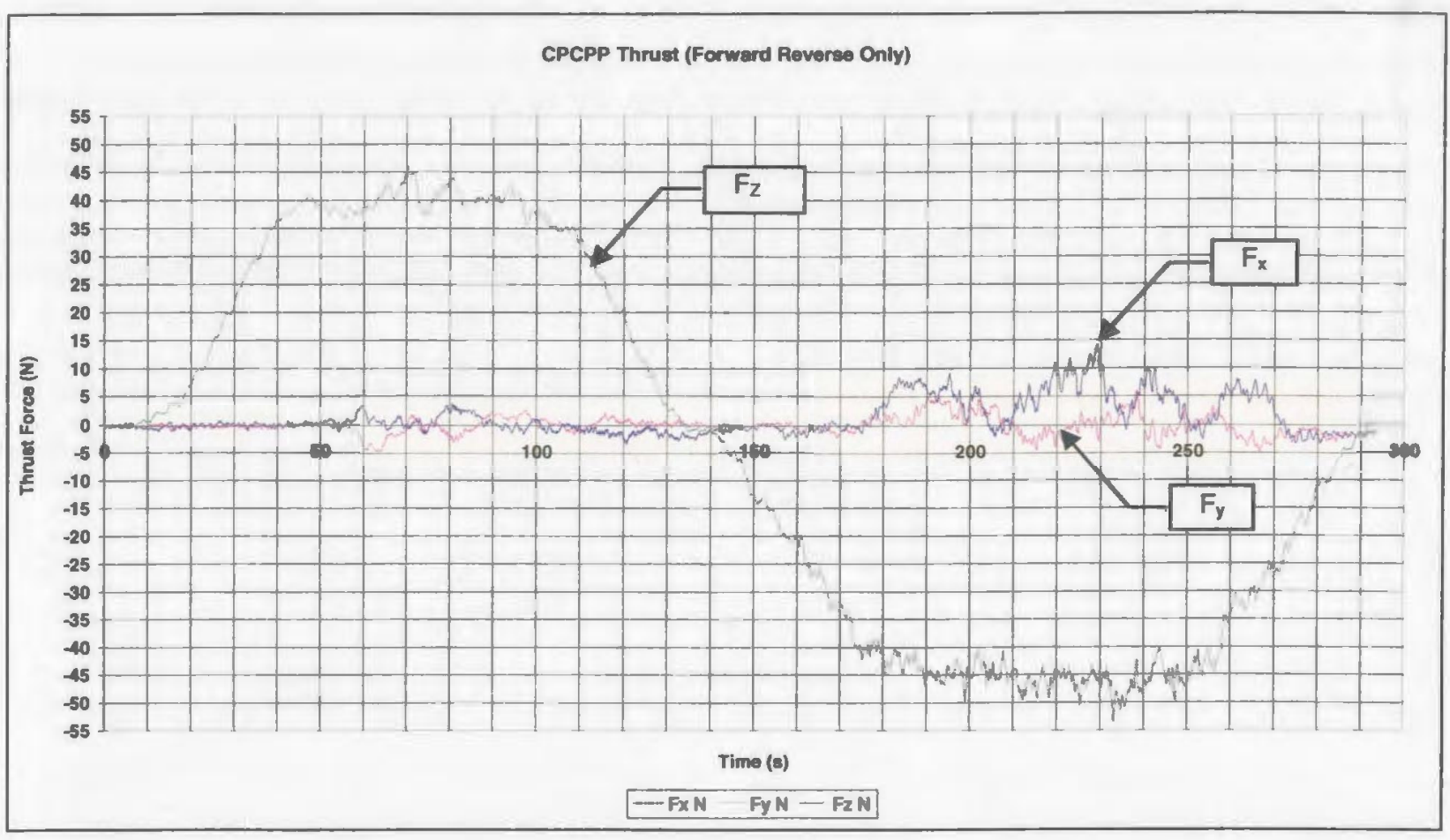

Figure 8.9: Force Results for Ahead / Astem Test.

The effects of increasing the blade angle on the thrust output from the propeller $\left(F_{z}\right)$ can be seen in Figure 8.9. As the blade angle is increased from the neutral position to the maximum pitch of $+29^{\circ}$ in $10 \%$ increments, the forward thrust $\left(F_{z}\right)$ increases from zero to a maximum value of about $44.4 \mathrm{~N}(10 \mathrm{lbf})$. The forward thrust fluctuates at this point between $35.5 \mathrm{~N}(8 \mathrm{lbf})$ and $44.4 \mathrm{~N}(10 \mathrm{lbf})$ as the blade angle was varied from $90 \%$ to $100 \%$ and back to $90 \%$ twice to observe the response of the propeller. From time $t=100 \mathrm{~s}$ to $t=135 \mathrm{~s}$ the thrust of the propeller was decreased from $100 \%$ back to the neutral position. The blades were then pitched in the astern direction to a maximum pitch angle of $-29^{\circ}$ in increments of $10 \%$. The thrust was not varied in this time, as in the ahead condition, but allowed to remain constant to observe the level of fluctuation in the 
thrust produced by the propeller. Examining $F_{z}$ for time $190 \mathrm{~s}<\mathrm{t}<250 \mathrm{~s}$, this force fluctuation can be observed. As the propeller was operating in an off design condition, some fluctuation in the thrust value was expected. The fluctuation of the force was determined to be $\pm 5 \mathrm{~N}( \pm 1 \mathrm{lbf})$ or about $10 \%$ of the total thrust output. The propeller was then ramped back down in $10 \%$ increments to the neutral position and the test stopped.

The shape of the $F_{z}$ thrust curve between $t=0 \mathrm{~s}$ and $t=20 \mathrm{~s}$ exhibits some nonlinear characteristics that were not taken into account when developing the control model in Chapter 7. Due to the linear relationship between blade angle and thrust output used to construct the equations of motion for the actuators, the thrust output $F_{z}$ exhibits a concave up curvature at low blade angles and a concave down shape at higher blade angles. The curvature of $F_{z}$ between $t=0 \mathrm{~s}$ and $t=20 \mathrm{~s}$ is more pronounced than at $t=130 \mathrm{~s}$ to $\mathrm{t}=140 \mathrm{~s}$, as the actuators were being incremented more slowly to observe the formation of circulation in the tank. A linear relationship between blade angle and thrust produced will be important for controlling an AUV in future tests. As most control systems have been designed to work with linear inputs and outputs, having a linear drive model will make integrating the СРCPP into other systems as straight forward as possible. The non-linear controller for the CPCPP would maintain the desired linear input / output relationship. With the quantification of the small amount of 
non-linearity in the control model, this desired linear relationship of thrust to blade angle can be improved.

The values of the lateral forces $\left(F_{x}\right.$ and $\left.F_{y}\right)$ are also shown in Figure 8.9. These forces hover around the zero mark throughout the test. During the ramping up of the blade angle from neutral to maximum ahead thrust, the fluctuations in $F_{x}$ and $F_{y}$ were nearly zero. This smooth behavior was expected, as the tank circulation was minimal at the start of the test. As the circulation increased, a small amount of fluctuation was observed in the $F_{x}$ and $F_{y}$ Values. This fluctuation was reduced as the propeller was ramped back down to the neutral position and the water in the tank began to settle down. As the propeller was ramped to full astern, the values of $F_{x}$ and $F_{y}$ exhibited the same type of behavior as during the ahead condition. Comparing the values of $F_{x}$ and $F_{y}$ during the astern part of the test to the ahead part of the test, it can be observed that the fluctuations in the astern condition are much larger in magnitude. This increase in magnitude was a result of the propeller wash and the resulting tank circulation. In the ahead condition, the wash of the propeller was directed to the opposite end of the tank. In the astern condition, the wash of the propeller was directed over the propeller housing where it quickly collided with the tank wall to which the propeller was mounted. The resulting turbulence from the propeller wash created the greater fluctuation that occurred in the astern part of the test. 
Figure 8.10 shows the result of increasing blade angle on the moments produced by the propeller. As the thrust produced increases, the torque required to turn the propeller $\left(\mathrm{M}_{\mathrm{z}}\right)$ increased as expected. Examining the plot of propeller shaft torque $\left(M_{z}\right)$, it can be seen that the shaft torque for the propeller was positive for the ahead and astern portions of the test. This phenomenon is unique to controlled pitch type propellers, as a reversal in propeller rotation is not required to generate astern thrust. The propeller blade pitch is changed resulting in an increase in thrust output and consequently an increase in torque, but the propeller shaft remains turning in the same direction. Near the end of the test a negative value of $M_{z}$ was recorded.

Examination of the lateral moments $\left(M_{x}\right.$ and $\left.M_{y}\right)$ illustrates the same instability present in the lateral forces $\left(F_{x}\right.$ and $\left.F_{y}\right)$ discussed previously. As the moment arm of the propeller was large $(927 \mathrm{~mm}(36.5 \mathrm{in}))$, the relatively small fluctuations in the lateral force values result in a relatively large moment value. This can be observed in Figure 8.10. At the start of the tests the magnitude of the fluctuations in $\mathrm{M}_{\mathbf{x}}$ and $\mathrm{M}_{\mathrm{y}}$ were minimal as the circulation in the tank was also minimal. As the circulation in the tank increases and decreases, the fluctuations also increased and decreased. Examination of the magnitude in the fluctuations between the ahead and astern parts of the test, exhibit the same increase in magnitude for the astern cases as seen with the lateral forces. This similarity was due to the coupling of $M_{x}$ with $F_{y}$ and $M_{y}$ with $F_{x}$. 


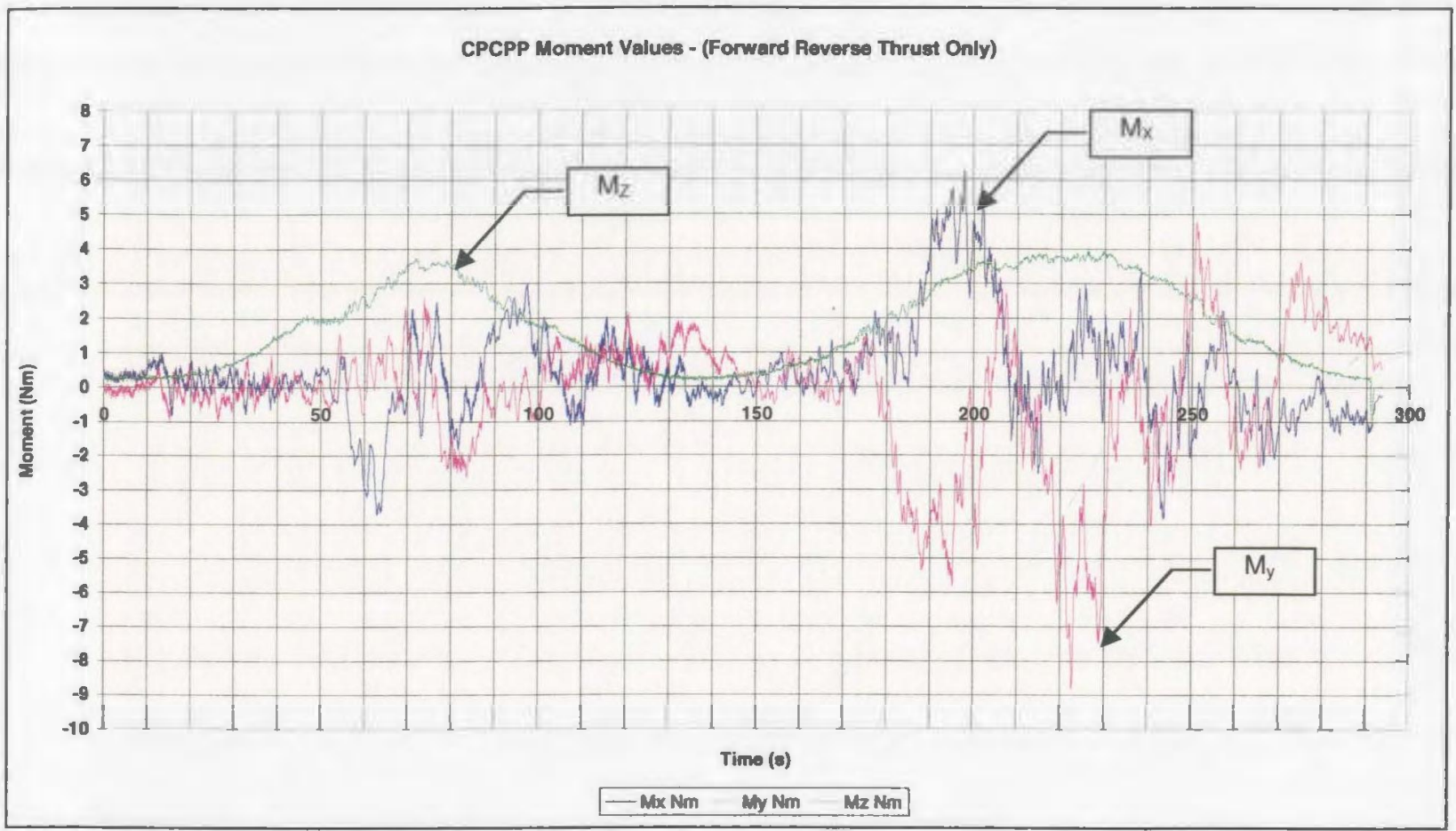

Figure 8.10: Moment Results for Ahead / Astern Test.

The moment values plotted in this thesis are measured about the load cell axes. The measured moment represents the total moment measured by the load cell and has two primary components. The first component is the direct moment measured at the load cell. This moment could be shifted to any location on the vehicle axis of rotation. The second component is the force-generated moment. This value is a result of the force-moment arm product. This moment value is dependent on distance the force is acting from the plane of the propeller. 
Although the test was conducted using $10 \%$ increments in the blade angle, the plots presented in Figure 8.9 and Figure 8.10 were fairly smooth. The smoothness of these plots could be attributed to four contributing factors. The first factor contributing to the smoothness of the plots was the application of the smoothing algorithm. The plotted raw data can be seen in Figure 8.6. As the data collected was smoothed before it was plotted, some of the fluctuations resulting from the step increase in blade angle were also smoothed out at this time. The second factor was related to the thinning of the data before plotting of the results. By thinning the data, some of the effects of the step change in blade angle were also lost. The third factor was related to the acceleration of the fluid. While a step change in the blade angle may have been made, the fluid takes time to accelerate as the result of the new applied force. This delay in fluid velocity change helped to smooth out the step changes in the blade angle. The final factor contributing to the smoothness of the graphs was the change in blade angle itself. As the actuators that position the swash plate move sequentially, there was a time delay of about three seconds for the $10 \%$ change to occur. This delay also helped to smooth out the plots.

A longer delay between the changes in blade angle would have resulted in more prominent steps between the different thrust values. These factors that contributed to the smoothness of the plots in Figure 8.9 and Figure 8.10 were evident in all of the plots of collected data presented in this chapter of the thesis. 


\subsection{Results for Test 2 (Surface / Dive)}

The second set of tests that were conducted with the CPCPP were the surface / dive tests. These tests were designed to test the cyclic pitch function of the new propeller, and to gain an understanding of the maximum side thrust capabilities of the propeller at zero forward speed. During this second test, the propeller was stepped in $10 \%$ increments from full rise to full dive and then back to level trim. The forces and moments were collected, tabulated and plotted in Figure 8.11 and Figure 8.12. During this test, the supply voltage to the main motor was 40.5 VDC, and this resulted in a neutral velocity of 380 RPM.

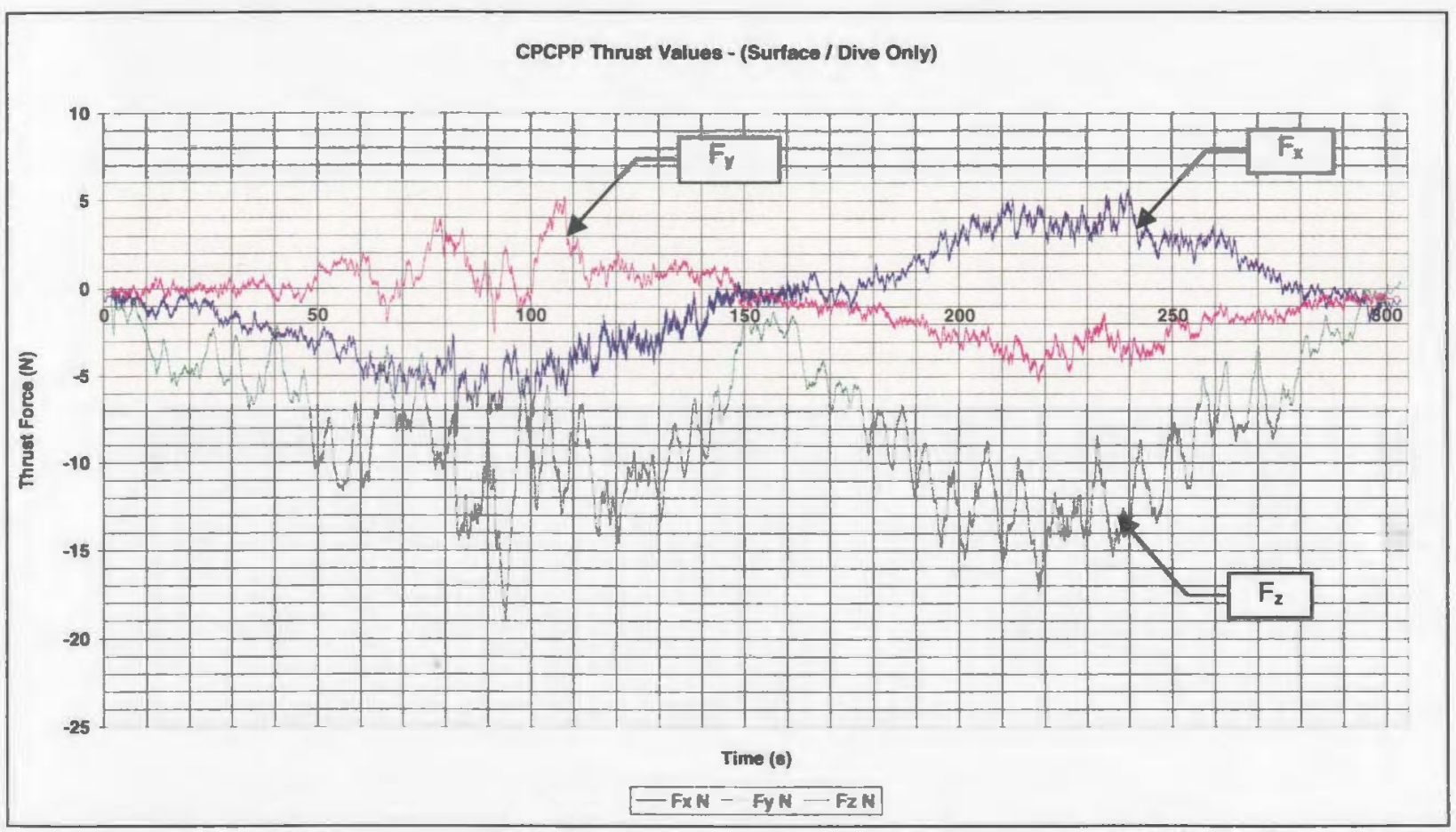

Figure 8.11: Force Results for Surface / Dive Test 
The effects of increasing the degree of cyclic pitch of the propeller blades on the amount of radial thrust produced can be seen in Figure 8.11. As the swash plate of the propeller pitches about the x-axis to produce an upward force, the amount of cyclic pitch of the blades increases to its maximum value of $+29^{\circ}$ on one side and to its maximum value of $-29^{\circ}$ on the opposite side. While the propeller rotates, the swash plate of the propeller adjusts the pitch of the blades smoothly from $+29^{\circ}$ to neutral, to $-29^{\circ}$ to neutral, and finally back to $+29^{\circ}$ in one rotation. This cyclic pitch results in the lateral force values $\left(F_{x}\right.$ and $\left.F_{y}\right)$ that were recorded during this test.

As the degree of cyclic pitch was ramped up to the aforementioned maximum value, $F_{x}$ in Figure 8.11 shows an increase in side force to port. The value of $F_{y}$ also exhibits an increase in force upward, but to a lesser extent than $F_{x}$. As the degree of cyclic pitch was then ramped back down to the neutral position, we see the lateral forces $F_{x}$ and $F_{y}$ return to zero. The cyclic pitch was then applied in the downward direction from time $160 \mathrm{~s}<\mathrm{t}<290 \mathrm{~s}$. The plots of $F_{\mathrm{x}}$ and $F_{\mathrm{y}}$ reverse directions from the previous case, and the magnitude of the forces increases and then decreases as the magnitude of the cyclic pitch is increased and decreased. 
Examination of the shape of the Figure 8.11 , reveal a $\pm 50 \%$ maximum fluctuation in the $F_{x}$ and $F_{y}$ force values. This fluctuation is even larger in the $F_{z}$ values recorded in the plot. While the value of $F_{z}$ should be zero for this test, there appears to be some coupling between the axial force $F_{z}$ and the radial forces $F_{x}$ and $F_{y}$. This coupling of forces was the result of swash plate operation. As cyclic pitch is applied to the swash plate, the swash plate shifts slightly due to linkage connections. This shift produces the axial thrust seen in the test, and could be counteracted by moving the swash plate. As discussed in Section 8.6, the plots do exhibit some nonlinear tendencies near the minimum and maximum pitch conditions. These non-linearities can be incorporated into the control model at a later date to improve the linear fit of the model, as discussed in Section 8.6.

From the results from the side thrust tests, it became evident that the moment data, Figure 8.12 , provides a more meaningful picture about the magnitude of the maneuvering forces. Comparison between Figure 8.11 and Figure 8.12 demonstrates that the moments $M_{x}$ and $M_{y}$ more clearly represent the side forces developed by the propeller. The moment $M_{y}$, which is related to $F_{x}$, clearly exhibits an increase as the amount of cyclic pitch of the propeller increases. The moment $M_{x}$, which is related to $F_{y}$, depicts that the moment in this direction is substantially lower in magnitude than $M_{y}$. 


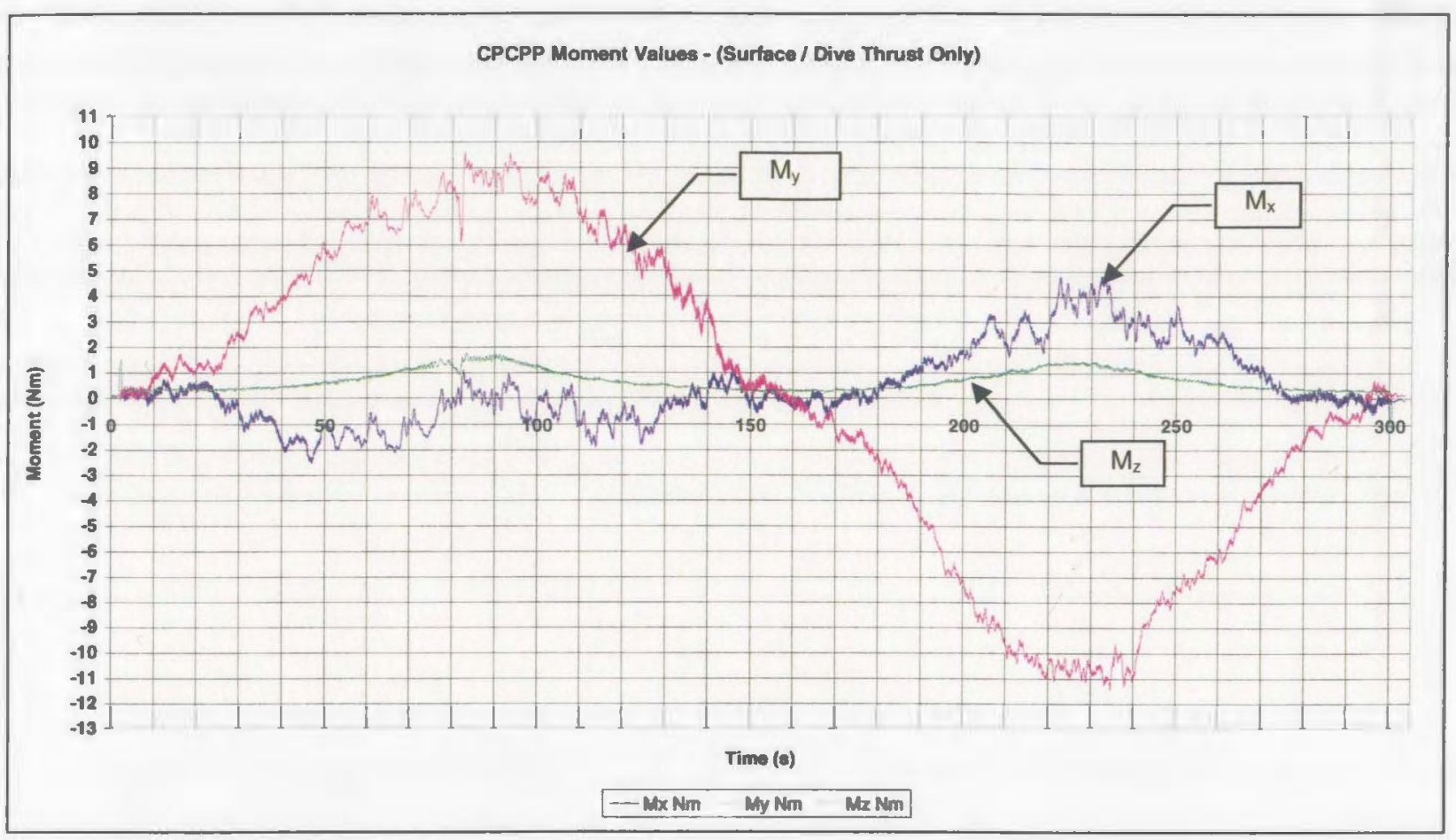

Figure 8.12: Moment Results for Surface / Dive Test

The shape of the $M_{z}$ curve was very similar to the curve observed in Section 8.6. The value of $M_{z}$ increases positively for both the upward and downward thrusting cases as expected. A sharp blip in the moment reading at the start of the test shows the moment impulse recorded to overcome the seal friction during startup.

One of the most significant things this test of the propeller showed was the phase shift in the direction of the expected maneuvering force. The motion of the swash plate was checked against the computer model used to generate the actuator motion equations. There were now discrepancies found between the computer model and the assembled propeller. Therefore some other 
phenomenon was causing the phase shift. The plot of forces and moments developed by the CPCPP, while forward thrust is zero, indicated that the larger moment is produced some angle to the direction intended. The resultant moment is a combination of $M_{x}$ and $M_{y}$ components. While the control inputs to the propeller were calling for upward or downward thrust, the recorded thrust was largely to the left and right. This shift in the maneuvering force was the result of unsteady fluid flow effects [Bose, 1995] [Riijarvi et al., 1994]. While the angle of attack of the blade is increasing or decreasing to the flow or when the blade is oscillating, there is a delay in the thrust produced by the blade. There is phase lag in the effective lift and moment generated by the blade. In the case of the CPCPP, this delay resulted in the thrust lagging out of phase from the control input in this test.

The actual direction of the side force produced by the propeller was in a direction that lagged the control input. Further investigation into the actual direction showed that the direction was dependent on the amount of axial thrust being produced by the propeller. Figure 8.13 and Figure 8.14 show the moment values of the propeller thrusting astern with blade angles of $20 \%\left(5.8^{\circ}\right)$ and $40 \%\left(11.6^{\circ}\right)$, respectively. In Figure 8.13, the propeller was started, run for about 10 seconds and then stopped three times. In Figure 8.14, this process was completed two times. This allowed the water in the tank to settle between measurements. For Figure 8.13 , the average value of $M_{x}$ was $11.3 \mathrm{Nm}(100.2 \mathrm{lb}$-in), and the average 
value of $M_{y}$ was $-1.1 \mathrm{Nm}\left(-9.5 \mathrm{lb}\right.$-in). In Figure 8.14, the average value of $M_{x}$ was decreased to $8.9 \mathrm{Nm}$ (78.7 lb-in), while the value of $M_{y}$ has increased to -7.8 $\mathrm{Nm}(-69.1 \mathrm{lb}-\mathrm{in})$. The value of $\mathrm{M}_{\mathrm{z}}$ also increased from $1.2 \mathrm{Nm}$ (10.7 lb-in) to 2.0 $\mathrm{Nm}(17.3 \mathrm{lb}-\mathrm{in})$, due to the increase in thrust from the propeller. There was less noise in Figure 8.14 than in Figure 8.13. This variation was due to the stabilization of flow around the propeller as axial thrust increased.

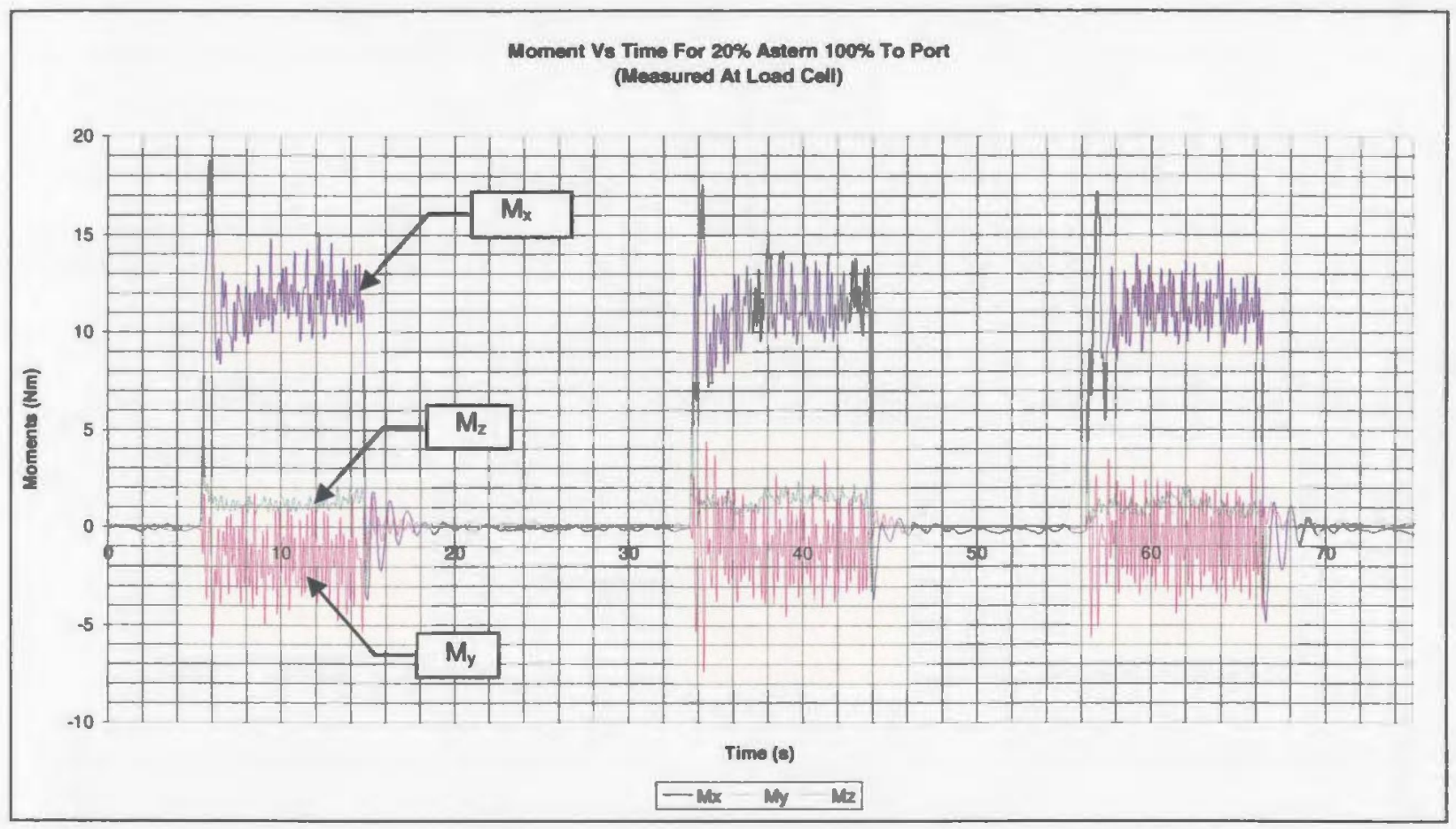

Figure 8.13: Maximum Turning Moment at $20 \%$ Astern Thrust 


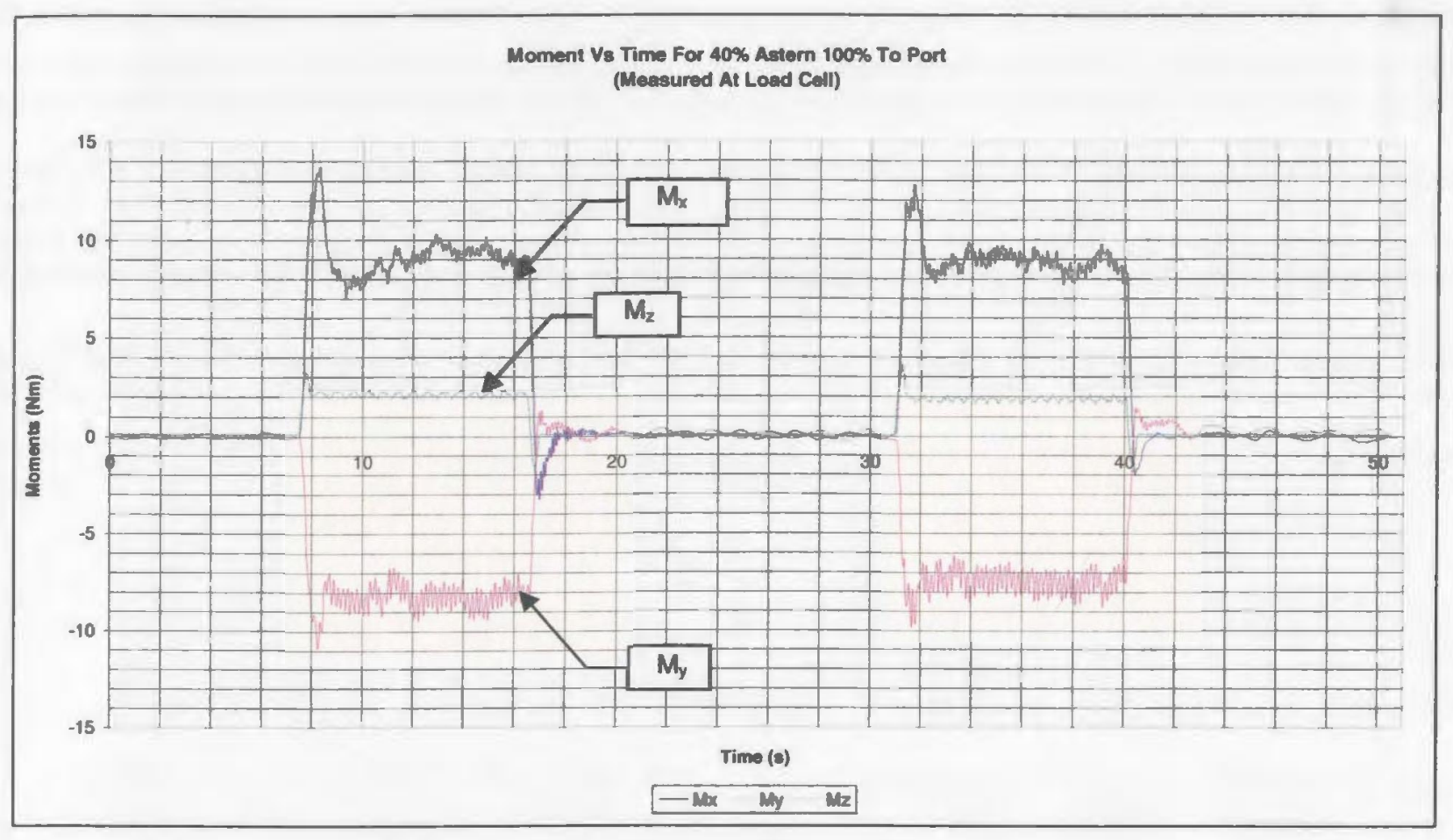

Figure 8.14: Maximum Turning Moment at $40 \%$ Astern Thrust

Assuming the thrust developed by the CPCPP is a vector traveling radially outward from the axis of propeller rotation, the actual maneuvering force developed by the propeller is given by equation 8.1 . The direction that the maneuvering force acts is given by equation 8.2. These formulae have been simplified as they pertain to discussion in this thesis. The moment values used in these equations are the total moment as measured at the load cell. Translating these moments to the center of gravity of the vehicle would require the decomposition of the moments as discussed in Section 8.6. For the values presented in this thesis, the moment arm $\left(D_{M}\right)$ is the distance from the propeller plane to the load cell axes of measurement. 


$$
\begin{aligned}
& F_{R}=\frac{\sqrt{M_{X}^{2}+M_{Y}^{2}}}{D_{M}}=\sqrt{F_{X}^{2}+F_{Y}^{2}} \\
& \theta^{*}=\tan ^{-1}\left[-\frac{M_{X}}{M_{Y}}\right]=\tan ^{-1}\left[\frac{F_{Y}}{F_{X}}\right]
\end{aligned}
$$

*Note: A sign algorithm is required to ensure the angle is in the correct quadrant.

The actual direction and magnitude of the lateral force for Figure 8.13 would be 11.4 Nm (100.6 lb-in) at an angle of $5.4^{\circ}$ as measured counter clockwise from the $x$-axis. The direction and magnitude of the lateral force for Figure 8.14 would be (104.7 $\mathrm{lb}$-in) at an angle of $41.3^{\circ}$. The original control force was intended to move the bow of the vehicle right while the AUV was reversing. The moment that would actuate the desired maneuvering force would be a negative moment about the y-axis. This would translate to the moment of some magnitude at an angle of $90^{\circ}$. Therefore, from the analysis of the moments represented in Figure 8.13 and Figure 8.14 , the direction of the maneuvering force produced by the propeller was converging on the intended direction as the amount of axial thrust was increased. As the propeller turns counter clockwise as viewed from the back, these angles calculated for the actual direction of thrust lag the desired control input of the propeller. 


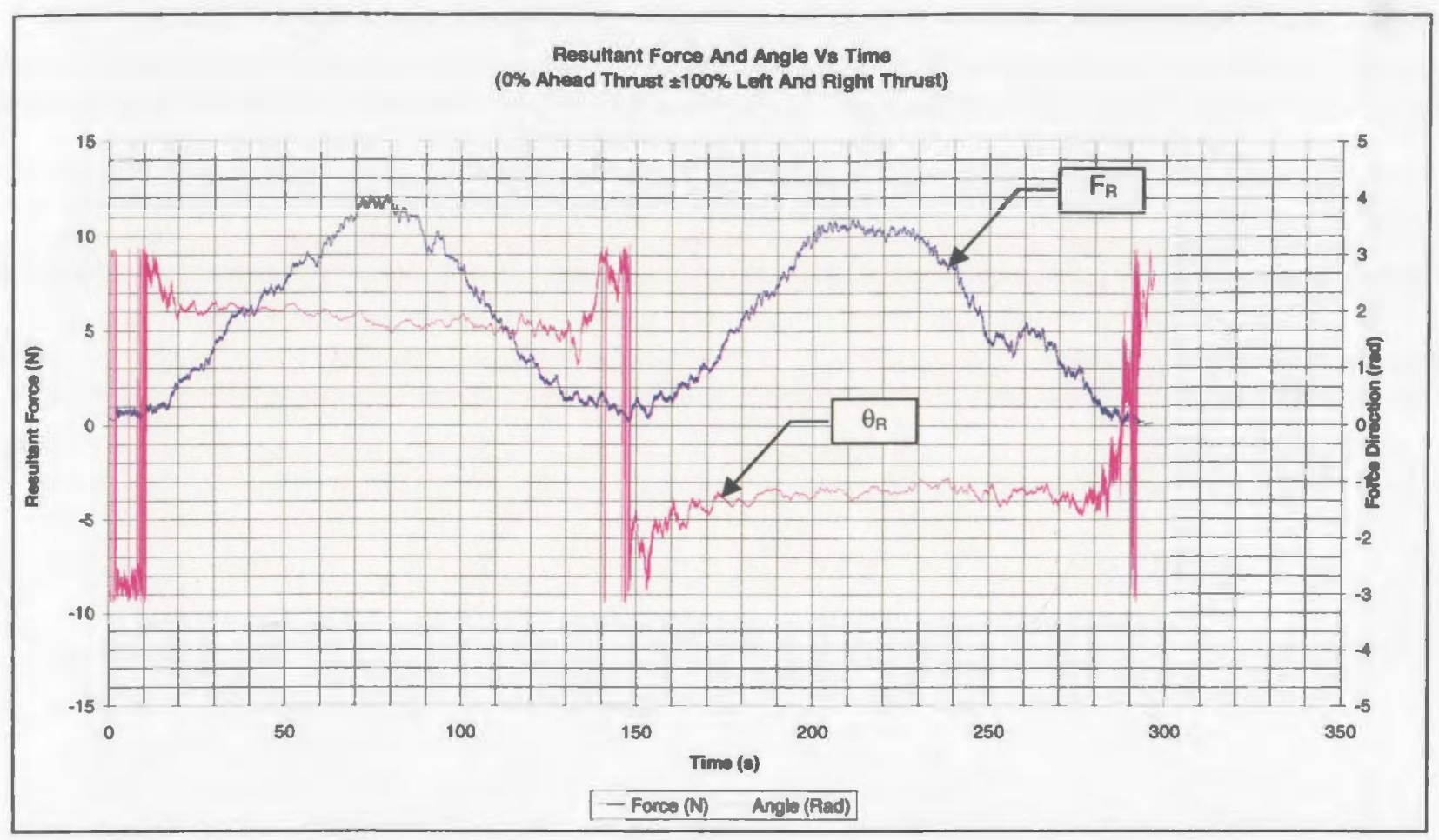

Figure 8.15: Resultant Force and Phase Angle for Maneuvering Force at Zero Forward Speed

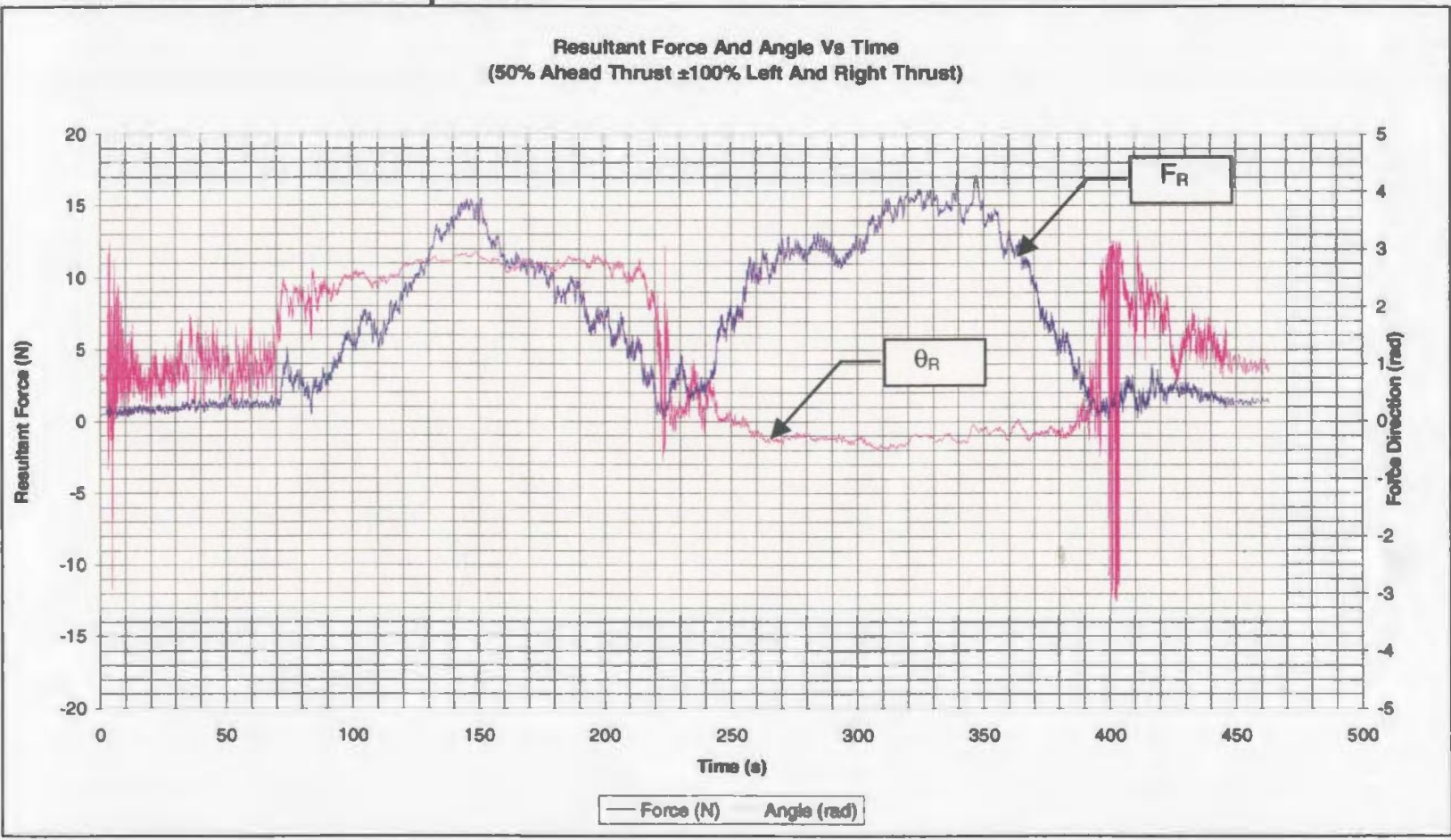

Figure 8.16: Resultant Force and Phase Angle for Maneuvering Force at 50\% Forward Speed 
The application of equations 8.1 and 8.2 to the data can be seen in Figure 8.15 and Figure 8.16. Figure 8.15 plots the magnitude of the resultant force, and its corresponding direction in radians measured from the $x$-axis. This figure was for the CPCPP not providing thrust in the axial direction, while the lateral thrust was varied in the $x$ direction from $-100 \%\left(-29^{\circ}\right)$ to $+100 \%\left(+29^{\circ}\right)$. The process is described at the start of this section for thrust in the $y$ direction. Similarly, in Figure 8.16 , the magnitude and direction of the maneuvering thrust was plotted for the CPCPP thrusting ahead $50 \%$, while varying the lateral thrust in the $\mathrm{x}$ direction.

In Figure 8.15, the propeller was thrusting to port from a time $20 \mathrm{~s}<\mathrm{t}<130 \mathrm{~s}$, and the average angle for the thrust was determined to be $1.88 \mathrm{rad}\left(107^{\circ}\right)$. As the input to the control system was requesting thrust in the $-x$ direction (3.14 rad $\left.\left(180^{\circ}\right)\right)$, the propeller thrust was lagging the control input by $1.26 \mathrm{rad}\left(73^{\circ}\right)$. From a time $160 \mathrm{~s}<\mathrm{t}<240 \mathrm{~s}$, the propeller was thrusting to starboard, and the direction of the thrust was $-1.20 \mathrm{rad}\left(-69^{\circ}\right)$ from the $+x$ direction. As the control input for the CPCPP was requesting thrust in the $+x$ direction, the actual thrust was lagging the control input by $1.2 \mathrm{rad}\left(69^{\circ}\right)$.

In Figure 8.16, the propeller was thrusting to port from a time $80 \mathrm{~s}<\mathrm{t}<210 \mathrm{~s}$, and the average angle of the thrust vector was determined to be $2.72 \mathrm{rad}\left(156^{\circ}\right)$. 
As the control input was requesting thrust in the $-x$ direction, the thrust from the propeller was lagging the control input by $0.42 \mathrm{rad}\left(24^{\circ}\right)$. From a time $250 \mathrm{~s}<\mathrm{t}<390 \mathrm{~s}$, the propeller was thrusting to starboard, and the average direction of thrust was $-0.28 \mathrm{rad}\left(-19^{\circ}\right)$ from the $+x$ direction. The control signal for this time was requesting thrust in the $+x$ direction, but the actual thrust was lagging the control input by $0.28 \mathrm{rad}\left(19^{\circ}\right)$.

Two important observations can be made from Figure 8.15 and Figure 8.16. The first observation is that the direction of the cyclic thrust produced is independent of the magnitude of cyclic thrust. This can be seen by the horizontal characteristics of the direction plots for the time frames discussed above. The second observation that can be made is that the direction of cyclic thrust is dependent on the magnitude of axial thrust produced by the propeller. While the no ahead speed condition has a lag of about $71^{\circ}$, the $50 \%$ ahead speed condition has a lag of about $21^{\circ}$. This presence of a variation in the maneuvering force directional lag was probably caused by changes in the unsteady flow around the oscillating propeller blades.

The unsteady flow generated from the oscillating propeller blades caused a lag in the maneuvering forces. This unsteady phenomenon was not foreseen when the propeller tests were planned, and was discovered as a result of analysis of the 
test data. The tests conducted for this thesis were designed to prove the functionality of the CPCPP, and were not designed to quantify the unsteady flow phenomenon. Further investigation will be required to determine how unsteady flow is related to ahead / astern thrust. Once the relationship has been quantified, unsteady flow effect can be incorporated into the control model for the CPCPP. However, despite of the lag in the phase of the maneuvering force, the CPCPP generated a useful maneuvering force for control purposes.

\subsection{Results for Test 3 (Ahead 50\%, Left to Right $100 \%$ )}

The third set of tests were designed to investigate the cyclic pitch function of the new propeller while thrusting ahead, and to gain an understanding about the maximum side thrust capabilities of the propeller for maneuvering purposes. During this third test, the propeller was stepped in $10 \%$ increments from hard to port to hard to starboard and then back to amidships while trusting ahead $50 \%$. The forces and moments were collected, tabulated and plotted in Figure 8.17 and Figure 8.18. For this set of tests, the supply voltage to the main motor was $40.5 \mathrm{VDC}$, and this resulted in a neutral velocity of 380 RPM. 


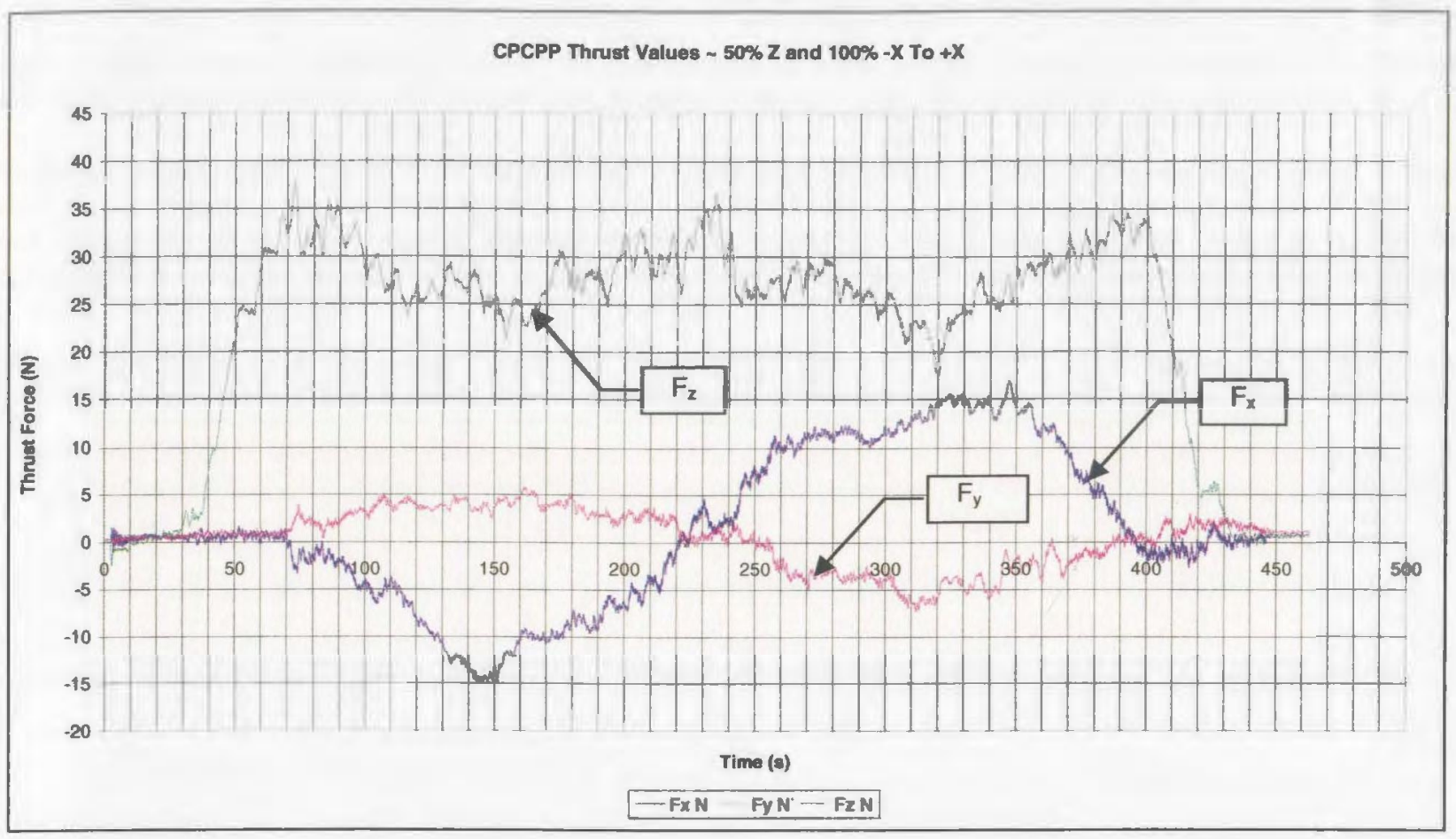

Figure 8.17: Force Results for Maneuvering While Thrusting Ahead

After the propeller was started during this test, the blades were pitched to $50 \%$ of their maximum angle of $29^{\circ}$. The result of this action can be seen in Figure 8.17, as the axial thrust $F z$ increased from zero to a value of about $33.4 \mathrm{~N}(7.5 \mathrm{lbf})$ for time $20 \mathrm{~s}<\mathrm{t}<70 \mathrm{~s}$. At this point, cyclic pitch was added to the blades of the propeller in $10 \%$ increments until the control input for the propeller was thrusting to port. This can be observed in Figure 8.17, as the value of $F_{X}$ increases negatively to $14.5 \mathrm{~N}(-3.25 \mathrm{lbf})$ and $F_{y}$ increases positively to $4.4 \mathrm{~N}$ (1 lbf) until $t=145 \mathrm{~s}$. During this time, $70 \mathrm{~s}<t<145 \mathrm{~s}$, the magnitude of $F_{z}$ decreases slightly to a value of $24.5 \mathrm{~N}(5.5 \mathrm{lbf})$ at $t=145 \mathrm{~s}$. This decrease in axial force was likely the result of a drop in propeller efficiency due to the changing inflow conditions. As the cyclic pitch of the propeller was stepped in the opposite 
direction, the magnitude of the maneuvering forces $F_{x}$ and $F_{y}$ decreased and $F_{z}$ increased until $t=225 \mathrm{~s}$. At this time the propeller was back in the ahead thrust only condition with the cyclic pitch set at zero. From this point the cyclic pitch continued to increase until $t=320 \mathrm{~s}$. The magnitude of the lateral forces $F_{x}$ and $F_{y}$ were now reversed as the propeller control input was set to thrust to starboard. As in the thrusting to port condition, the magnitude of $F_{z}$ again decreased as the amount of side thrust increased. The cyclic pitch of the propeller was then returned to zero, the amount of ahead thrust was returned to neutral and the propeller was stopped.

The moment values, recorded in Figure 8.18, also reflect the changes to the forces described above. Examination of the curve representing the propeller shaft torque $\left(\mathrm{M}_{\mathrm{z}}\right)$ indicates a steady rise in the required torque as the collective pitch of the propeller blades is increased. The value of $M_{z}$ then increases and decreases as the amount of cyclic pitch is increased and decreased. Similarly, the values of $M_{y}$ reflect the changes in the values of $F_{x}$ and the values of $M_{x}$ reflect the changes in the values of $F_{y}$. Inspection of Figure 8.18 also indicated that there was some asymmetry in the flow of the propeller, as $M_{x}$ exhibits a decrease in value for $265 \mathrm{~s}<\mathrm{t}<380 \mathrm{~s}$. The change in magnitude of $M_{x}$ is not visible in the coupled $F_{y}$ thrust value. This was most likely caused by the turbulence in the tank, and the reflection of the fluid off of the tank walls. Testing 
of the CPCPP in a larger facility would allow these anomalies to be studied in more detail.

The effects of the unsteady flow are also apparent in Figure 8.17 and Figure 8.18. The presence of a non-zero $F_{y}$ and $M_{x}$ indicates that there is some lag in the direction of the radial thrust vector. However, these effects become less pronounced as the magnitude of the forward thrust is increased. As discussed in Section 8.7, the incorporation of these unsteady flow effects into the next control model will allow the generated force to more accurately match the desired control direction.

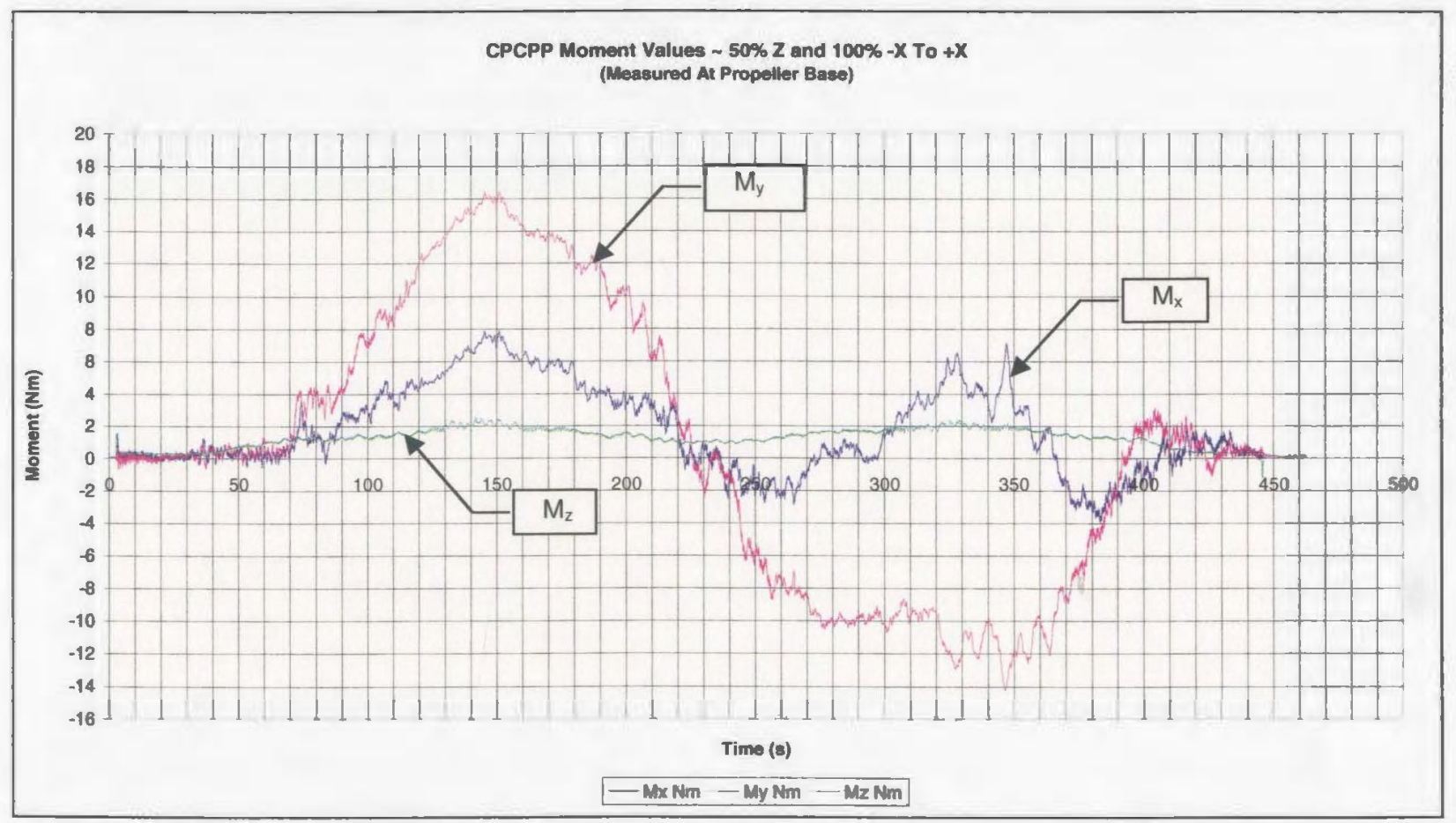

Figure 8.18: Moment Results for Maneuvering While Thrusting Ahead 


\subsection{Calculated Values for $\mathrm{K}_{\mathrm{T}}$ and $\mathrm{K}_{\mathrm{Q}}$ at Bollard Conditions}

While the plots of thrust and moment vs. time provide proof the propeller functioned as intended, propeller performance has typically been published as dimensionless values of advance coefficient $(\mathrm{J})$, thrust coefficient $\left(\mathrm{K}_{T}\right)$ and torque coefficient $\left(\mathrm{K}_{\mathrm{Q}}\right)$ [Lewis, 1988]. The values of $\mathrm{K}_{\mathrm{T}}$ and $\mathrm{K}_{\mathrm{Q}}$ are typically plotted against $\mathrm{J}$. However, all testing was done at a bollard condition. As $\mathrm{J}=0$ for the bollard condition, the data for $\mathrm{K}_{\mathrm{T}}$ and $\mathrm{K}_{\mathrm{Q}}$ were plotted against the dimensionless value of percentage of applied blade angle. These angles can be calculated accurately using the parametric model discussed in Section 5.7 due to the fixed relationships between actuator position and blade angle. The values of $\mathrm{K}_{\mathrm{T}}, \mathrm{K}_{\mathrm{Q}}$ and $\mathrm{J}$ are defined by the following equations.

$$
\begin{aligned}
& K_{T}=\frac{T}{\rho \cdot n^{2} \cdot d^{4}} \\
& K_{Q}=\frac{Q}{\rho \cdot n^{2} \cdot d^{5}} \\
& J=\frac{V_{A}}{n \cdot d}
\end{aligned}
$$


The subsequent load cell direction shall be represented in this thesis by a subscript for the required direction. For example, $\mathrm{K}_{T_{Z}}$, represents the thrust coefficient in the z-direction.

The values of $\mathrm{K}_{\mathrm{T}}$ and $\mathrm{K}_{\mathrm{Q}}$ for the CPCPP in the ahead / astern thrust configuration were calculated from the data presented in Figure 8.9 and Figure 8.10. The values for the thrust and torque were tabulated as the blade angle was increased in $10 \%$ increments. These increases and decreases in the blade angle left a small plateau after each increment was completed in the raw data before averaging. The time at which these plateaus occurred could be recorded and the corresponding value of $F_{x}, F_{y}, F_{z}, M_{x}, M_{y}$, and $M_{z}$ could be recorded from the plotted data. These values were then used to calculate $\mathrm{K}_{T}$ and $\mathrm{K}_{\mathrm{Q}}$ for both the ahead and the astern conditions as described in Lewis [1998]. The results were plotted in Figure 8.19.

The resulting plots for $\mathrm{K}_{\mathrm{T}}$ were nearly identical for the ahead and astern conditions. The blade rake and hub taper angle have a small effect on the thrust output of the propeller. The small difference in ahead and astern thrust is not the result of blade twist or blade camber. The blades used on the CPCPP are symmetric sections and have no twist. The astern condition provided $15 \%$ more thrust that the ahead condition. This difference in thrust was due to the poor 
hydrodynamics of the flow in the ahead condition. The propeller fairing collar at the propeller hub caused these poor hydrodynamics. A picture of the fairing collar can be seen in Figure 8.4. Once the propeller housing is faired into the $\mathrm{C}$ SCOUT vehicle, the $\mathrm{K}_{\mathrm{T}}$ values for the ahead condition should improve, as the fairing collar will blend in with the body fairing of the propeller. The cubic relation expressed by the data illustrates that the blade pitch relationship was nonlinear as expected. This cubic relationship can also be seen in the open water curve of $K_{T}$ for a B-series screw propeller for various Pitch to Diameter (P/D) ratios, see Figure 8.20. This relationship can be incorporated into the control model once it has been fully quantified.

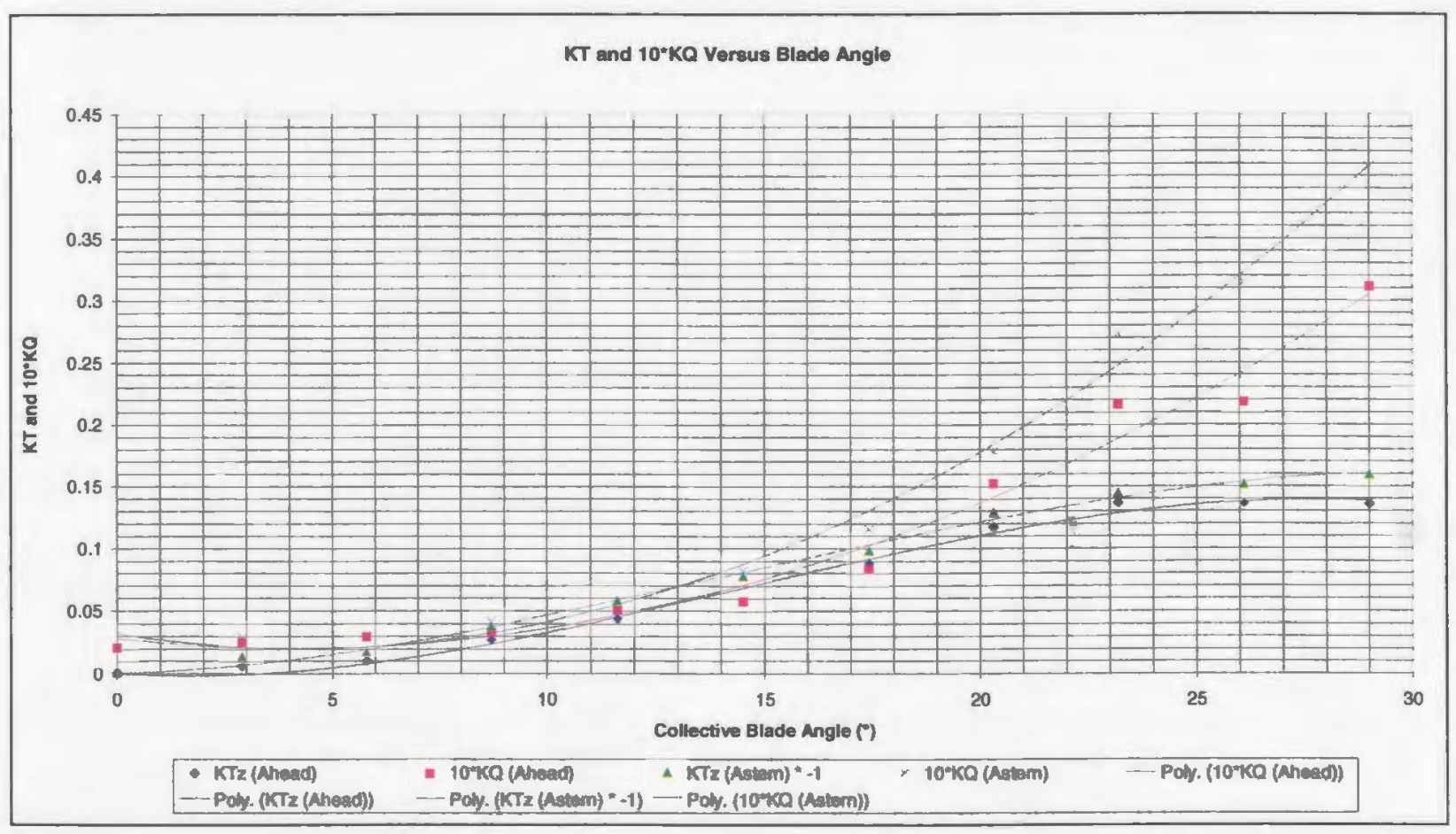

Figure 8.19: $\mathrm{K}_{\mathrm{T}}$ and $\mathrm{K}_{\mathrm{Q}}$ Plots for Varying Blade Angle (No Side Thrust) 
The values of $\mathrm{K}_{\mathrm{Q}}$ plotted in the Figure 8.19 showed a nonlinear increase in torque as the thrust output from the propeller increases. Once again the $K_{Q}$ values for the astern condition were higher than the $\mathrm{K}_{\mathrm{Q}}$ values for the ahead condition by $24 \%$. This result was expected, as the thrust produced in the astern condition was approximately $15 \%$ greater than the thrust produced in the ahead condition. A higher thrust output should result in a higher required propeller torque.

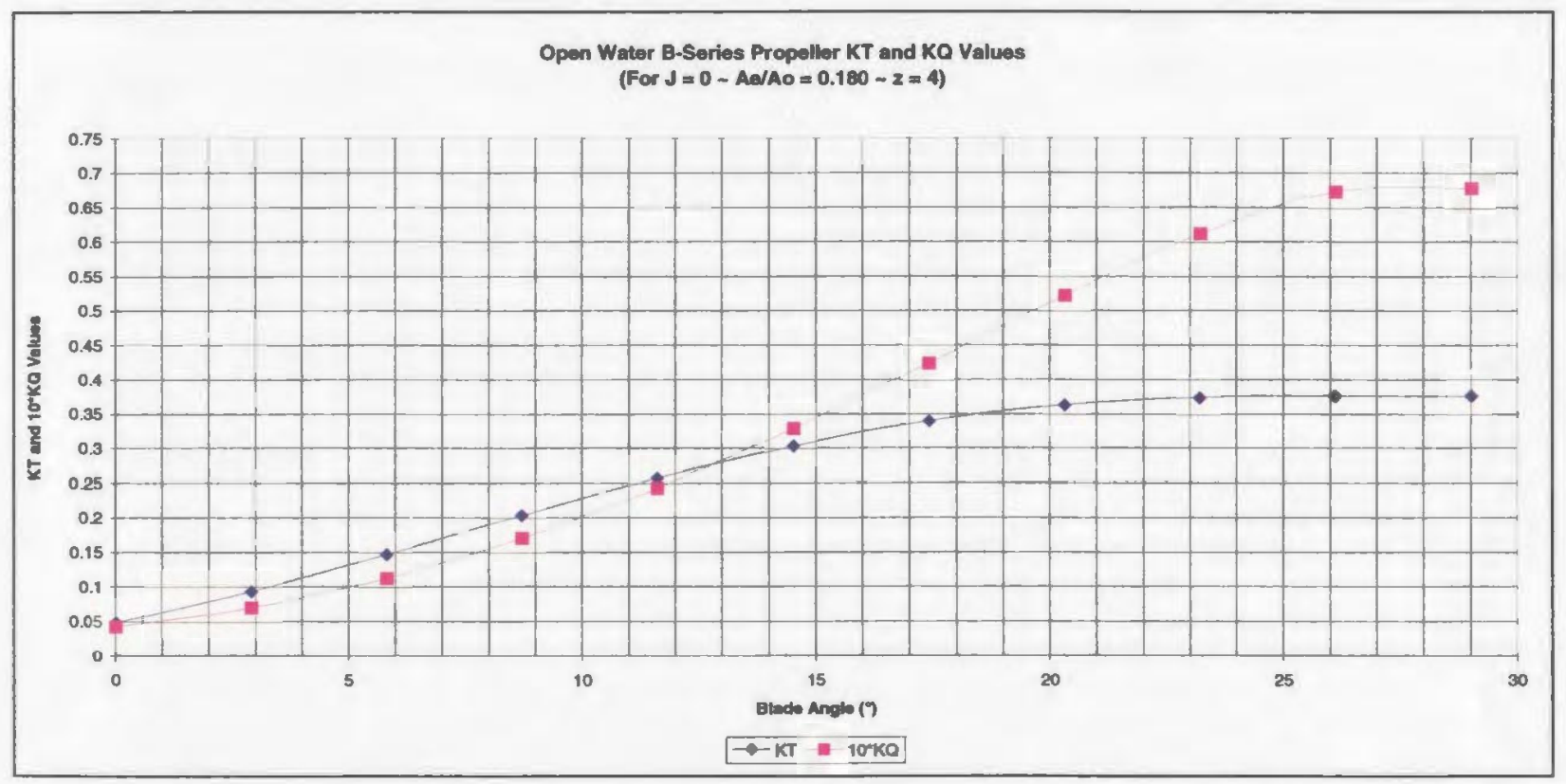

Figure 8.20: Open Water $\mathrm{K}_{\mathrm{T}}$ and $\mathrm{K}_{\mathrm{Q}}$ Curves for B-Series Screw Propeller

Comparison of the shape of the curves presented in Figure 8.19 and Figure 8.20 illustrate a similarity between the open water curves of the B-series propeller and the actual collected data for the CPCPP. This demonstrates that the CPCPP 
was behaving similar to a controllable pitch B-series propeller. The fitted polynomials, cubic for the $\mathrm{K}_{\mathrm{T}}$ values and quadratic for the $\mathrm{K}_{\mathrm{Q}}$ values reasonably match the trend of the plotted data points. The curves in Figure 8.20 were created using the B-series polynomials [Lewis, 1988]. The curves are based on the parameters of the propeller's operation using equations 8.6 and 8.7. The collective blade action of the propeller was modeled using pitch to diameter ratio, P/d. The number of blades, $z$, was four and the area ratio $A_{e} / A_{\circ}$ was 0.180 . The value of the advance coefficient, $\mathrm{J}$, was set at zero. The value of $\mathrm{K}_{\mathrm{T}}$ at a blade angle of $0^{\circ}$ in Figure 8.20 is not zero as in Figure 8.19 , because B-series propellers have cambered blades. Also, the experimental values presented in Figure 8.19 are delivered thrust and required torque. The values plotted in Figure 8.20 are open water values, and have not taken into account relative rotative efficiency and hull efficiency. By correcting the values of $\mathrm{K}_{T}$ and $\mathrm{K}_{\mathrm{Q}}$ of the B-series propeller for wake fraction and thrust deduction, a more direct comparison could be made between the two propellers. However, more specific measurements would be required to make these corrections, and this was not a requirement of the preliminary tests.

$$
\begin{aligned}
& K_{T}=\sum_{i=1}^{39}\left[C_{s, t, u, v_{i}} \cdot J_{i}{ }^{v} \cdot\left(\frac{P}{d}\right)_{i}^{t} \cdot\left(\frac{A_{e}}{A_{0}}\right)_{i}^{u} \cdot z_{i}^{v}\right] \\
& K_{Q}=\sum_{k=1}^{47}\left[C_{v, t, u, v_{j}} \cdot J_{k}{ }^{v} \cdot\left(\frac{P}{d}\right)^{t} \cdot\left(\frac{A_{e}}{A_{0}}\right)_{k}^{u} \cdot z_{k}{ }^{v}\right]
\end{aligned}
$$


Data was collected for the $20 \%$ astem condition, while increasing the port thrust blade angles in $20 \%$ increments. The thrust and torque generated was measured three times, allowing the tank to settle between measurements. This resulted in a series of data similar the ones plotted in Figure 8.13 and Figure 8.14. The average force and moment values for the three peaks in the graphs were averaged to quantify the thrust and the moments generated during each run. As with the data analysis discussed in Section 8.7, the moments were used to calculate the total side thrust generated by the propeller. The values of $\mathrm{K}_{\mathrm{T}}$ and $\mathrm{K}_{\mathrm{Q}}$ were calculated from the thrust values and plotted in Figure 8.21.

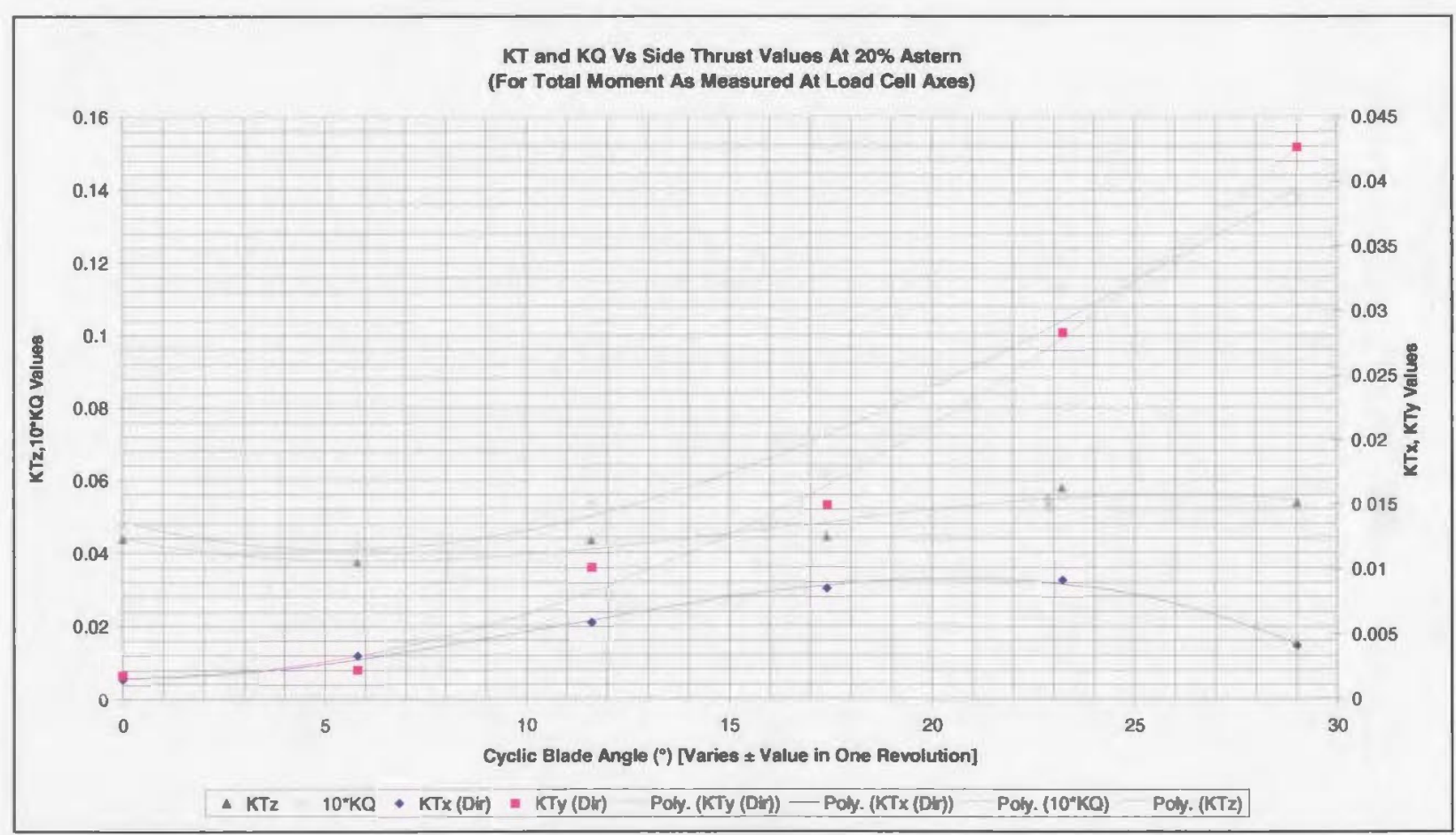

Figure 8.21: $\mathrm{K}_{\mathrm{T}}$ and $\mathrm{K}_{\mathrm{Q}}$ Plots for Varying Side Thrust Angle (20\% Astern) 
The values of $\mathrm{K}_{\mathrm{Tz}}$ and $\mathrm{K}_{\mathrm{Q}}$ were plotted on the left hand $\mathrm{y}$-axis of the graph, while the values of $\mathrm{K}_{\mathrm{Tx}}$ and $\mathrm{K}_{\mathrm{Ty}}$ were plotted on a secondary $\mathrm{y}$-axis located on the right side of the graph. $\mathrm{K}_{\mathrm{Tz}}$ represents the thrust coefficient for the axial direction of the propeller. $\mathrm{K}_{\mathrm{Tx}}$ and $\mathrm{K}_{\mathrm{Ty}}$ represent the thrust coefficients of the radial or lateral thrust directions.

The plot of $\mathrm{K}_{\mathrm{Q}}$ behaved as expected, showing an increase in propeller torque as the thrust level increased. The plot of $\mathrm{K}_{\mathrm{TZ}}$ showed that there was little change in the astern thrust level as cyclic pitch increases. This relative stability in the ahead / astern thrust level was expected, as collective pitch was not being varied for this test.

As with the test of side thrust conducted in Section 8.7, the unsteady flow effects caused the side thrust to lag the intended control direction. This is evident in the large value of $\mathrm{K}_{\mathrm{Ty}}$, which was perpendicular to the intended control direction. This large value of $\mathrm{K}_{\mathrm{Ty}}$ was expected, as the amount of astern thrust was only $20 \%$ of maximum. As discussed in Section 8.7 , an increase in the amount of astern thrust would result in a larger portion of the side thrust in the $\mathrm{K}_{\mathrm{Tx}}$ direction. The magnitude of $\mathrm{K}_{\mathrm{T} x}$ and $\mathrm{K}_{\mathrm{Ty}}$ exhibited an increase with an increase in the blade pitch angle, as expected. 
Figure 8.21 demonstrates that the CPCPP does generate a significant amount of side thrust for maneuvering purposes. The $K_{T y}$ value of 0.0425 was equivalent to about $40 \%$ of the available ahead / astern thrust. This side thrust of $K_{T y}=0.0425$ occurred at a collective astern thrust of $20 \%$. Figure 8.19 and Figure 8.21 demonstrated that this thrust could be as high as $76 \%$ of ahead thrust for the hard to port condition with $50 \%$ ahead thrust. The resulting turning moment of 18.9 Nm (167.7 in-lb) with a forward thrust of $26.7 \mathrm{~N}$ (6 lbf) would be sufficient to turn the C-SCOUT vehicle in 3.5 body lengths while traveling at a speed of 1.6 $\mathrm{m} / \mathrm{s}$ (3.1 knots) [Bijleveld, 2002]. This result was interpolated from Bijleveld's plot for required yaw moment vs. forward velocity. The turning circle was calculated using the hydrodynamic simulator developed by Perrault [2002]. This would result in a turning circle of $9.5 \mathrm{~m}(31.1 \mathrm{ft})$. In contrast, the best turning circle achieved with a conventional thruster and control surfaces tests at this speed was about $25 \mathrm{~m}$. The CPCPP would provide a substantial improvement over the existing vehicle configuration. 


\section{Chapter 9 \\ Conclusions and Recommendations}

\subsection{Conclusions}

A fully actuated, computer controlled collective and cyclic pitch propeller has been developed and constructed for the C-SCOUT AUV. A series of preliminary experiments have been conducted on this CPCPP using a locally placed sixcomponent balance to measure the forces and moments produced by the CPCPP. The following conclusions can be drawn from these preliminary series of experiments:

- A successful production prototype CPCPP has been designed, constructed and initially tested. All of the mechanical linkages and components functioned as intended when designed. The success of the development of this complex mechanical mechanism was due largely to the use of parametric modeling and kinematic simulation during the design phase of the project.

- The developed propeller generates substantial maneuvering thrust as predicted. The propeller is capable of generating a large $18.9 \mathrm{Nm}$ (168 inlb) moment to port with a forward thrust of $26.7 \mathrm{~N}(6 \mathrm{lbf})$. Although these values are for the bollard condition and are expected to reduce as forward 
speed increases, the CPCPP is capable of providing substantial maneuvering forces. This poses a significant improvement in turning radius over the existing fin and thruster arrangement of C-SCOUT. The system is also capable of turning the vehicle with no forward speed with a moment of $11.4 \mathrm{Nm}$ (101 lb-in).

- The CPCPP provides maneuvering forces for the control of an underwater vehicle. The effects of unsteady flow about the oscillating blades of the propeller, as discussed in Section 8.7, were an important consideration when designing a control scheme for the propeller. The unsteady flow effects were found to be independent of cyclic thrust magnitude, but dependent on axial thrust magnitude. These axial thrust relationships to unsteady flow effects are going to have to be incorporated into the control model for the propeller to provide thrust in the intended direction at all speeds of the vehicle.

Unfortunately, there are no data available to compare the effectiveness of the side thrust generated, as no free running tests were done with the propeller on a vehicle. However, the values collected from the preliminary tests of the CPCPP indicate that this type of propulsion could provide a significant improvement over existing propulsion and control systems. The ability to turn the vehicle while traveling at very slow or stopped forward speeds, makes the CPCPP ideal for 
many subsea surveying and mapping applications. The addition of a second CPCPP unit to the front of an underwater vehicle would provide the ability to hover the vehicle in nearly any orientation [Stenovec et al., 1987].

\subsection{Recommendations}

While a series of experiments were conducted to prove that the newly designed and constructed collective and cyclic pitch propeller produced axial and radial forces during operation, a more comprehensive study of the propeller and its hydrodynamic properties are required. The following actions are required before testing on an underwater vehicle could commence:

1. The relationship between axial thrust and unsteady flow lag in maneuvering forces needs to be quantified and fully understood.

2. The existing control model for propeller operation needs to be modified so the equations incorporate the following:

- The equations need to compensate for the non-linearity in the $K_{T}$ response curve to provide a linear thrust output for vehicle operation. While making the CPCPP controller algorithms more complicated, a linear control to thrust relationship allows the CPCPP to be easily installed on different vehicles. 
- The quantified relationship between the unsteady lag in the maneuvering forces and the axial thrust needs to be incorporated into the control model.

3. The stainless steel sliders inside of the propeller need to be replaced with brass or bronze to prevent any future gauling of the sliders and the main drive shaft. The secondary o-ring seals on the drive shaft need to be reworked to reduce the friction on the drive shaft of the propeller.

4. A series of self propulsion trials needs to be conducted using the CPCPP to provide a basis for a numerical model to predict the forces and moments generated by the complex flows around the propeller. This model would aid greatly in the optimization of blade shape for this type of propulsion system by allowing designers to model different blade geometries. This could potentially reduce the cost of manufacturing by making only effective blades.

5. The electronic control system needs to be integrated into the CPCPP housing and the control interface architecture developed. A triple axis accelerometer could be incorporated into the control system to a"low for the investigation of motion stabilization capabilities of the CPCPP.

Once these recommendations are completed, the CPCPP can be tested on an AUV such as C-SCOUT to evaluate the controllability and stability of the AUV in 
a free-swimming environment. The results of these tests can be used to develop the final modifications to the propeller's control architecture and control model. After these final modifications are complete, the CPCPP will be ready to be redesigned and manufactured as a full production propulsion unit for underwater vehicles. 


\section{Bibliography}

Abbott, I. and von Doenhoeff, A., 1959, "Theory of Wing Sections", McGraw-Hill, Dover, NY, USA.

Allegro Microsystems, 2002.

\section{http://allegromicro.com/datafile/97024.pdf}

Avallone, E. A. and Baumeister III, T., 1996, "Marks' Standard Handbook For Mechanical Engineers, Tenth Ed.", McGraw-Hill, Toronto.

Bijleveld, H. 2002, "Design of a Cyclic Pitch Propeller for the Autonomous Underwater Vehicle C-SCOUT: Masters Thesis, Delft University of Technology", Netherlands.

Cantrell, P., 2004, "Helicopter Aerodynamics"

\section{http://www.copters.com/helo aero.html}

Century Helicopter Products (CHP), 2004, "CN1000A Kit/CN1006A ARF HAWK Instruction Manual."

\section{http://www.centuryheli.com/support/manuals/cn100xHawk4/hawk4.html}

Cierva (De La), J., 1926, "The Development of the Autogyro", The Journal of the Royal Aeronautical Society, UK. 
Curtis, T., 2001, "The Design, Construction, Outfitting and Preliminary Testing of the C-SCOUT Autonomous Underwater Vehicle (AUV)", Masters Thesis, Memorial University of Newfoundland, Canada.

Domke, B., 2004, "Helicopter Rotorhead Close-Up Gallary."

\section{http://www.b-domke.de/Aviationlmages/Rotorhead.html}

Eckhardt, M. K. and Morgan, W. B., 1955, "A Propeller Design Method," SNAME Annual Meeting, New York, USA.

Erdman, A. G. and Sandor, G. N., 1997, "Mechanisms Design Analysis and Synthesis, Volume 1, Third Ed.", Prentice Hall Inc.

Gerber, H., 1990, "Elementary Linear Algebra," Brooks/Cole, Toronto.

Gazzola, J., 2003, "Helicopter History Site”, Argentina.

http://www.helis.com/introduction/prin.php

Haselton, F. R., 1963, US Patent 3,101,106.

Haselton, F. R., 1966, US Patent 3,291,086.

Haselton, F. R., 1969, US Patent 3,450,083.

Hess J.L., Smith, A.M.O.. Calculation of Potential Flow About Arbitrary Bodies, in Progress in Aeronautical Sciences, Vol. 8, 1967, pages 1-138.

Rumerman, J., "Helicopter Development in the Early Twentieth Century," US Centennial of Flight Commission, USA. 
http://www.centennialofflight.gov/essay/Rotary/early_20th_century/HE2.htm

Lechartier, V., 2002, "Cyclic Pitch Propellers", NRC-IMD, St. John's, Canada.

Leishman, J. G., 2000, "Evolution of Helicopter Flight," USA.

http://www.flight100.org/history/helicopter.html.

Lewis, E. V., 1988, "Principles of Naval Architecture, Second Revision", Volume II: Resistance, Propulsion and Vibration, SNAME, New Jersy.

McFarlane, J., 1993, "Development of Undenwater Work Systems", Oceans '93, Victoria, BC, Canada.

Marshall, B., 2000, "How Helicopters Work," HowStuffWorks, USA.

http://travel.howstuffworks.com/helicopter5.htm

Montgomery, D.G., 2001, "Design and Analysis of Experiments, $5^{\text {th }}$ Edition," Wiley, Toronto.

MUN and NRC-IOT, 2003, "Canadian Self Contained Of-the-self Underwater Testbed (C-SCOUT), Newfoundland, Canada. http://www.engr.mun.ca/\%7ecscout/index.html

Murray, B., Fraser, J., Dai, C, and Maskew, B., 1994, "Application of Cyclic Pitch Thrusters," Propellers/Shafting Symposium, Virginia, USA.

ON Semiconductor, 2004.

http://www.onsemi.com/pub/Collateral/MC33033-D.PDF 
Perrault, D. 2002, "Autonomous Underwater Vehicles (AUV) Sensitivity of Motion Response To Geometric and Hydrodynamic Parameters and AUV Behaviors With Control Plane Faults", PhD. Thesis, Memorial University of Newfoundland, Canada.

Rino Industries Ltd (RIL), 2002

\section{http://www.rino.co.uk/}

Saunders, A., 2001, "The Effect of Velocity and Orientation on the Simulation and Experimental Characterization of a Transversely Mounted Small-Diameter AUV Tunnel Thruster," Masters Thesis, University of Victoria, Canada.

Seddon, J., 1990, "Basic Helicopter Aerodynamics." Reston, VA: American Institute of Aeronautics and Astronautics.

Shevell, R. S., 1989, "Fundamentals of Flight, Second Edition," Prentice Hall, New Jersey.

Stenovec, G. M. and Haselton, F.R., 1987, "An Efficient Propulsion System For Untethered Submersible Vehicles," UUST Conference.

Stiffler, A. K., 1992, "Design with Microprocessors for Mechanical Engineers", McGraw-Hill, USA

Thomas, R., 2003, "Performance Evaluation of the Propulsion System for the Autonomous Underwater Vehicle "C-SCOUT", Masters Thesis, Memorial University of Newfoundland, Canada. 
Ultra Motion, 2002.

\section{http://www.ultramotion.com}

Van Manen, J. D., 1966, "Results of Systematic Tests with Vertical Axis

Propellers," International Shipbuilding Progress, Vol. 13.

Vickers, 1996, "Industrial Hydraulics Manual, Third Edition, Sixth Printing," Vickers, Rochester Hills, Michigan, USA.

Wernli, 2000, “AUV Commercialization - Who's Leading the Pack?", Oceans 2000 Proceedings, Rhode Island, USA. 


\section{Appendix A - Fabrication Drawings}



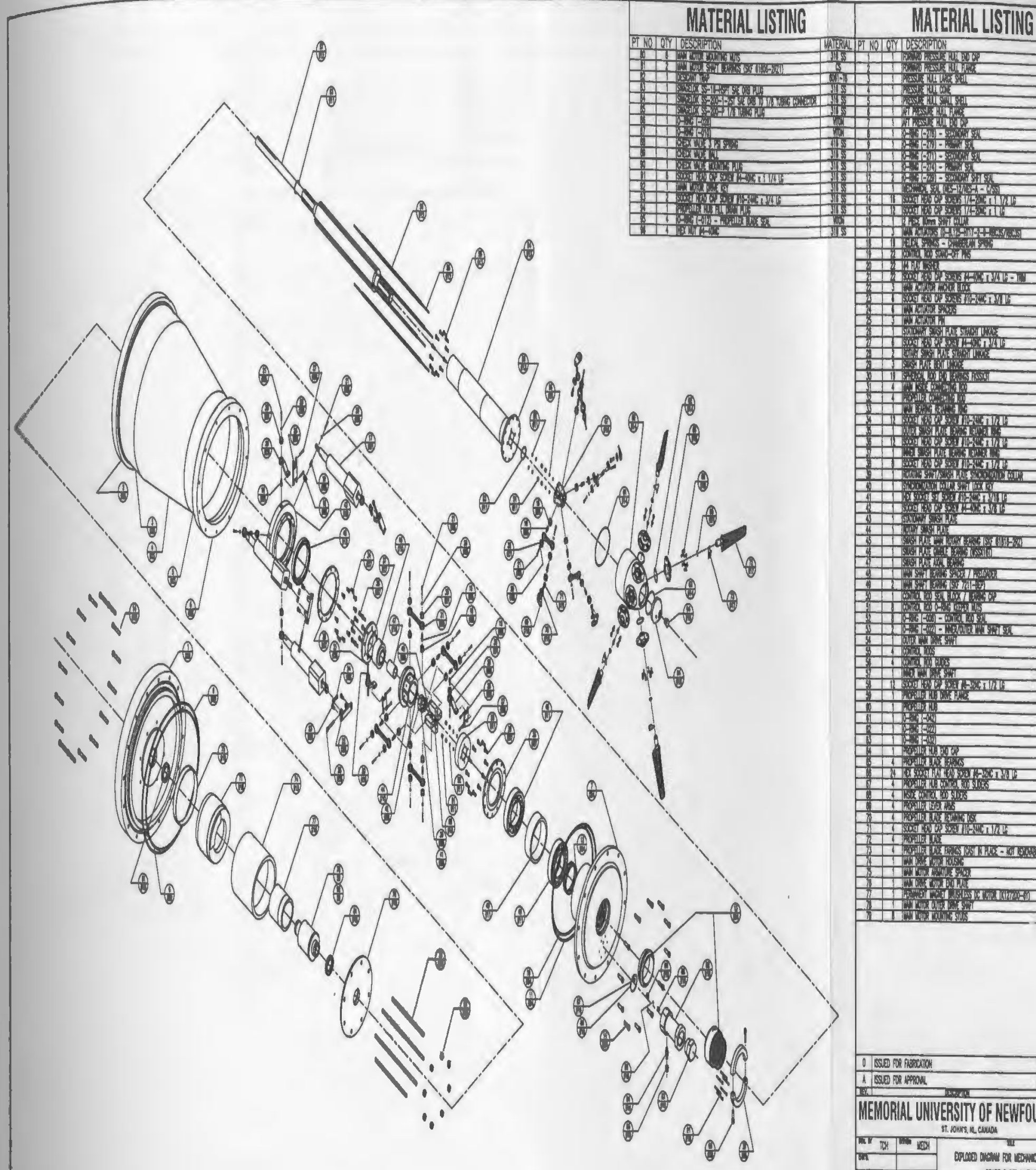

MAEERILL LSTING

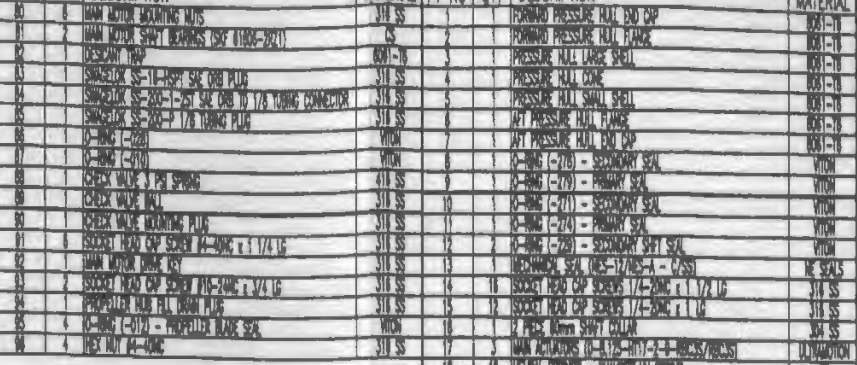

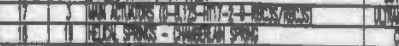

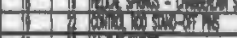

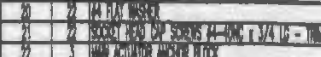

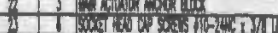

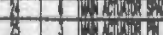

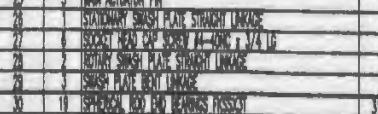

int

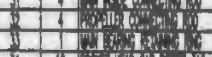

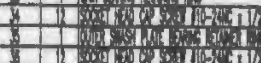

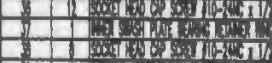

1)

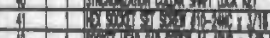

is rions

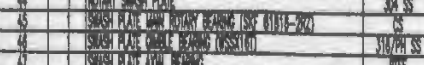

4 - Swish ant

4 .

1 (n)

i
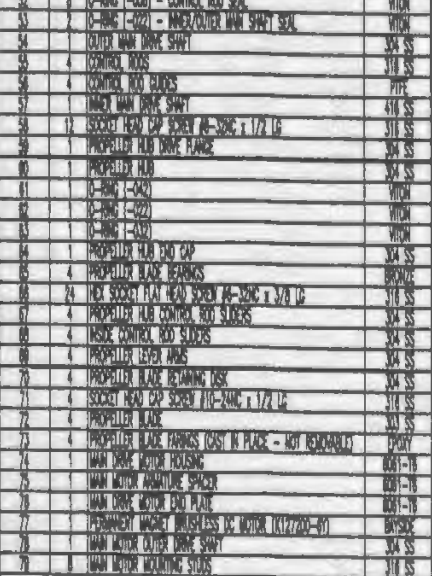

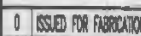

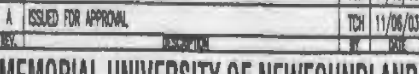

MEMORIAL UNIVERSTYY OF NEWFOUNOLAND

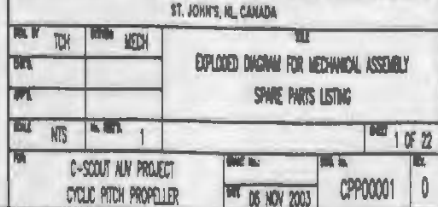




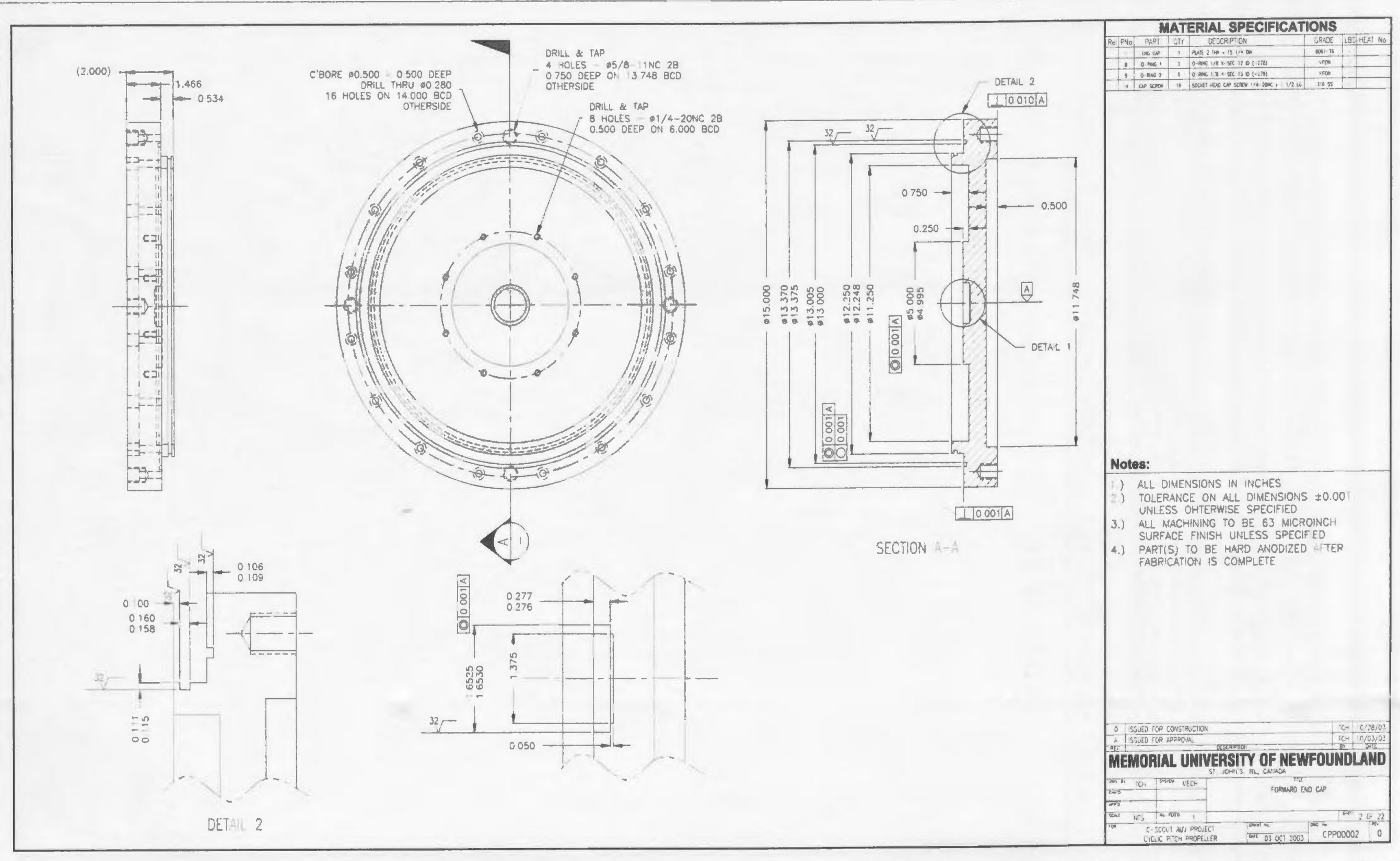




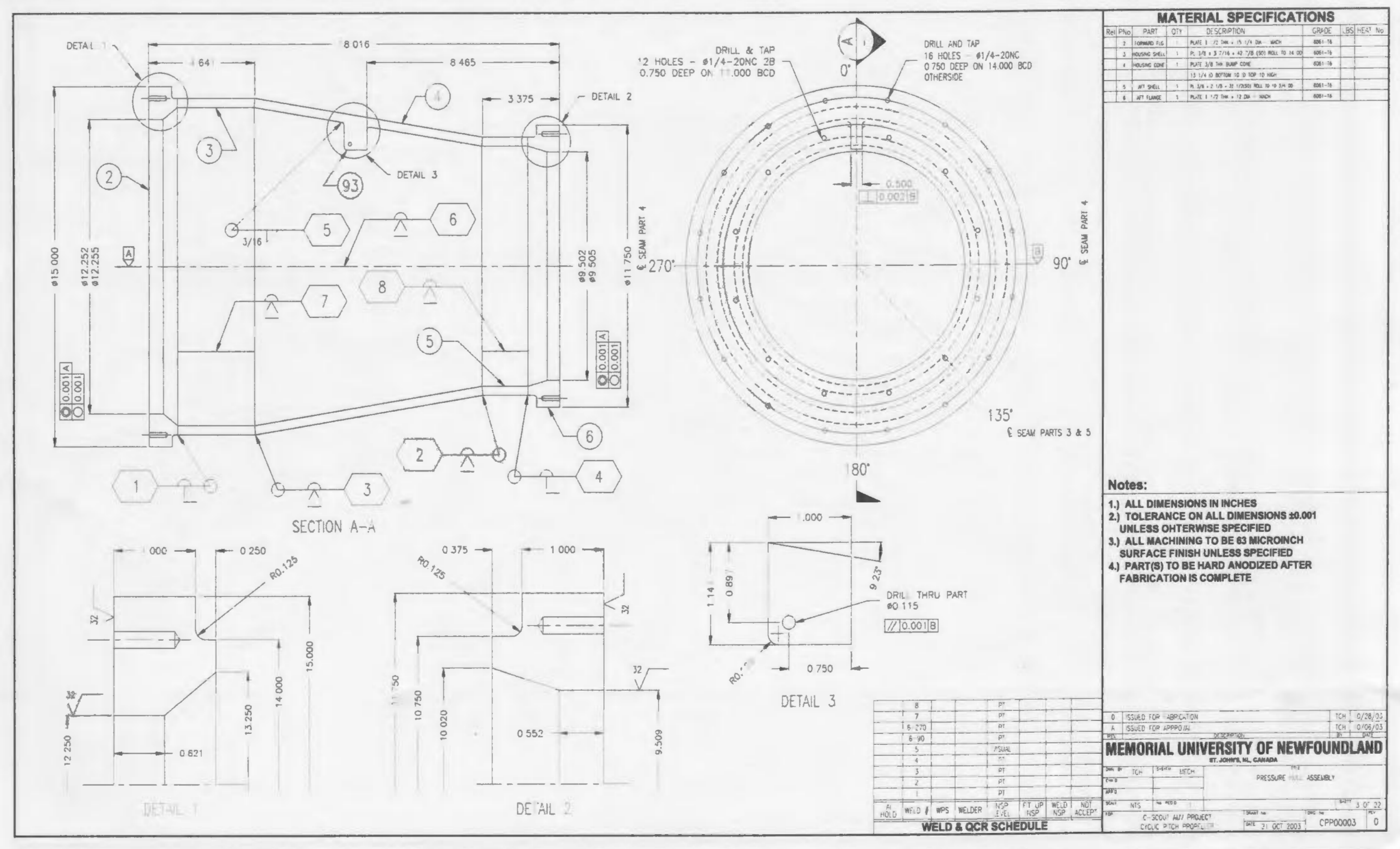




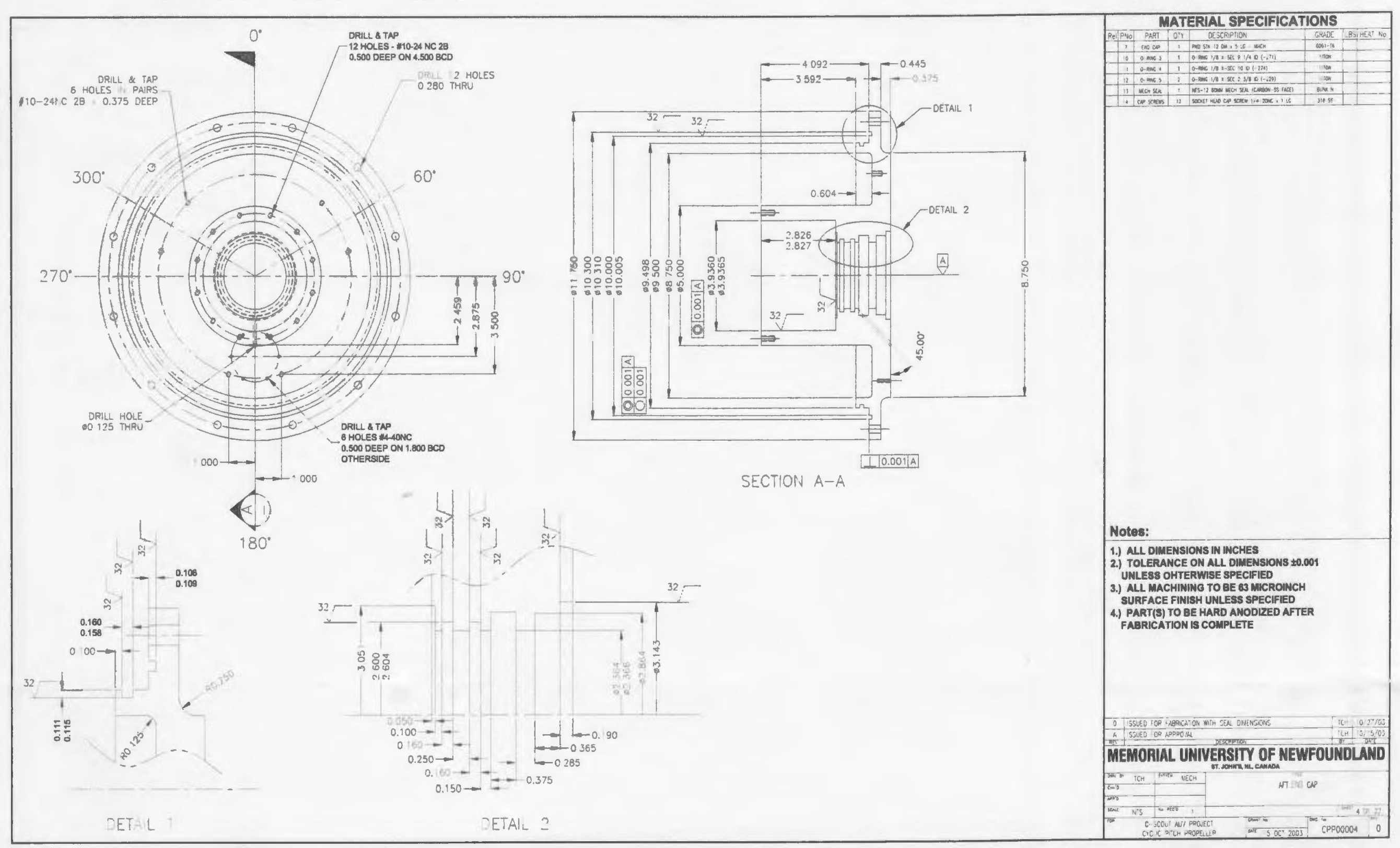




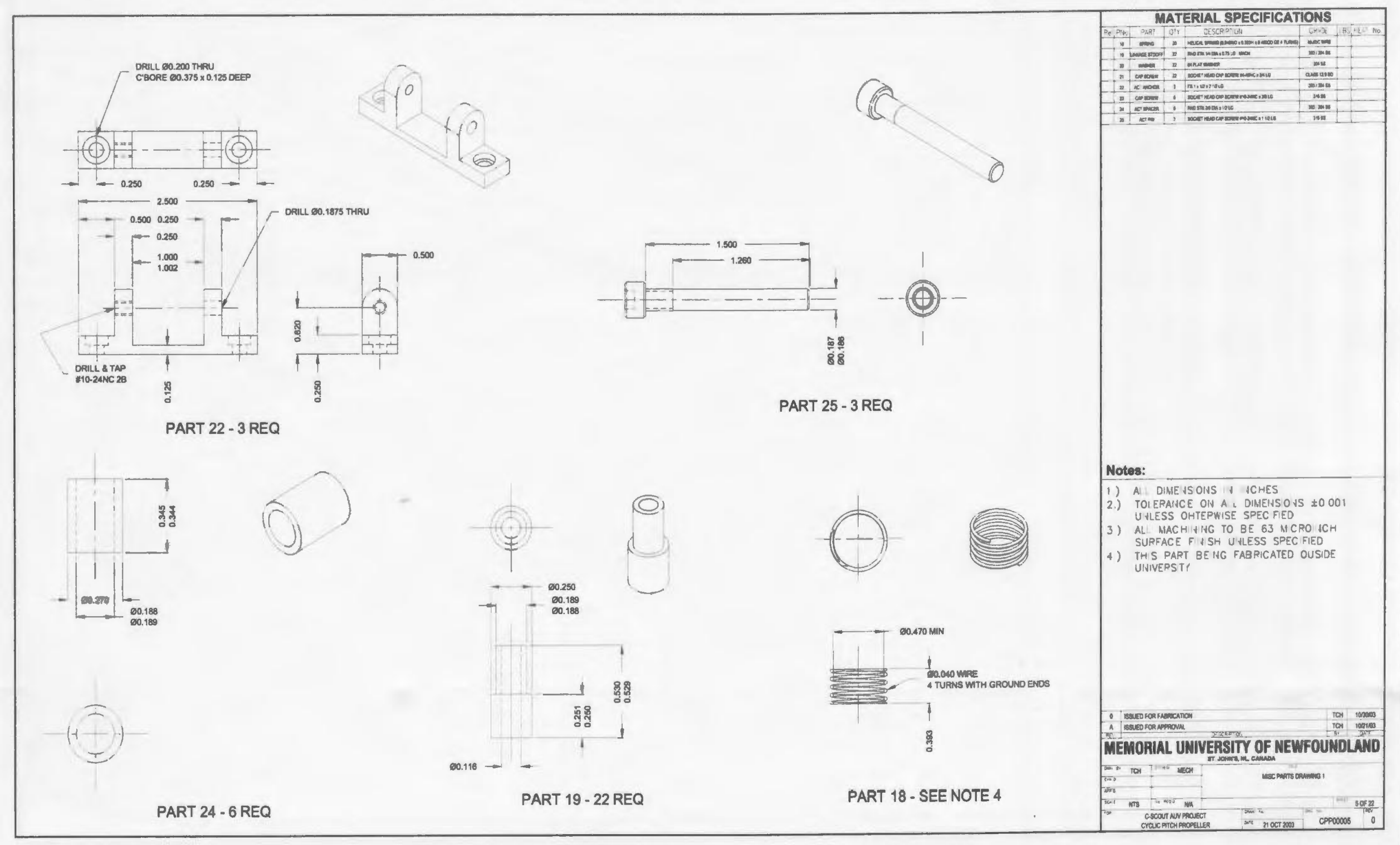




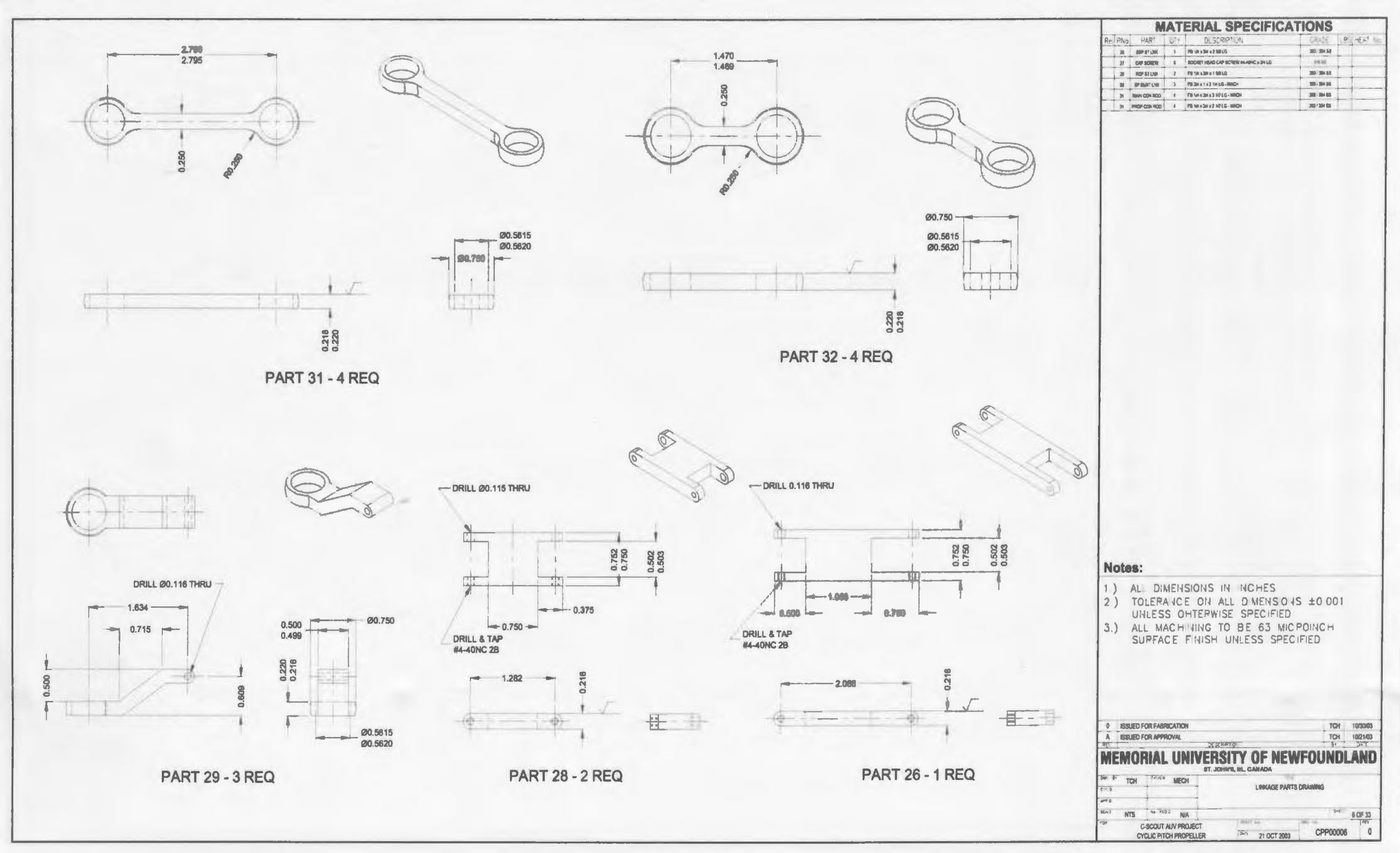




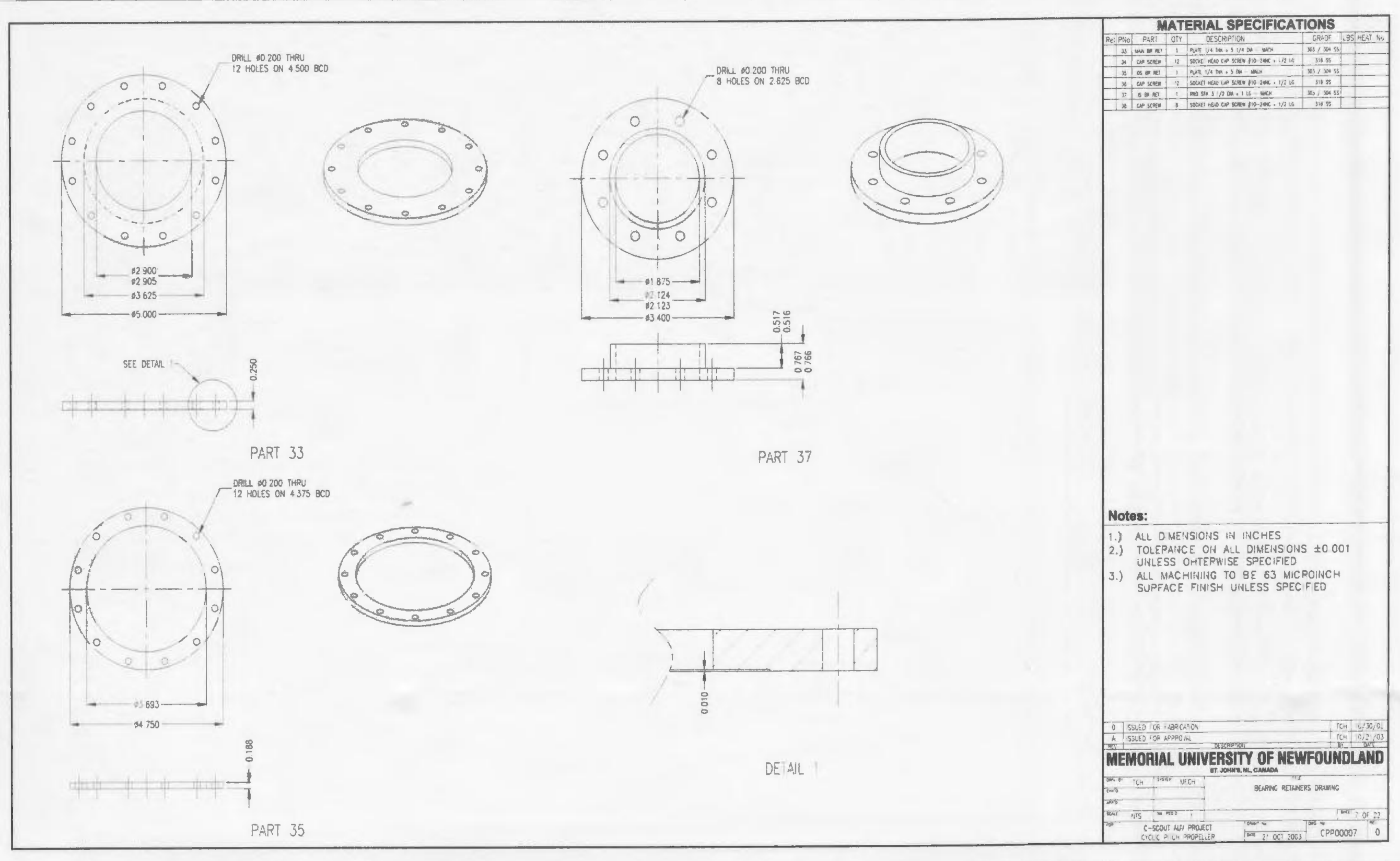




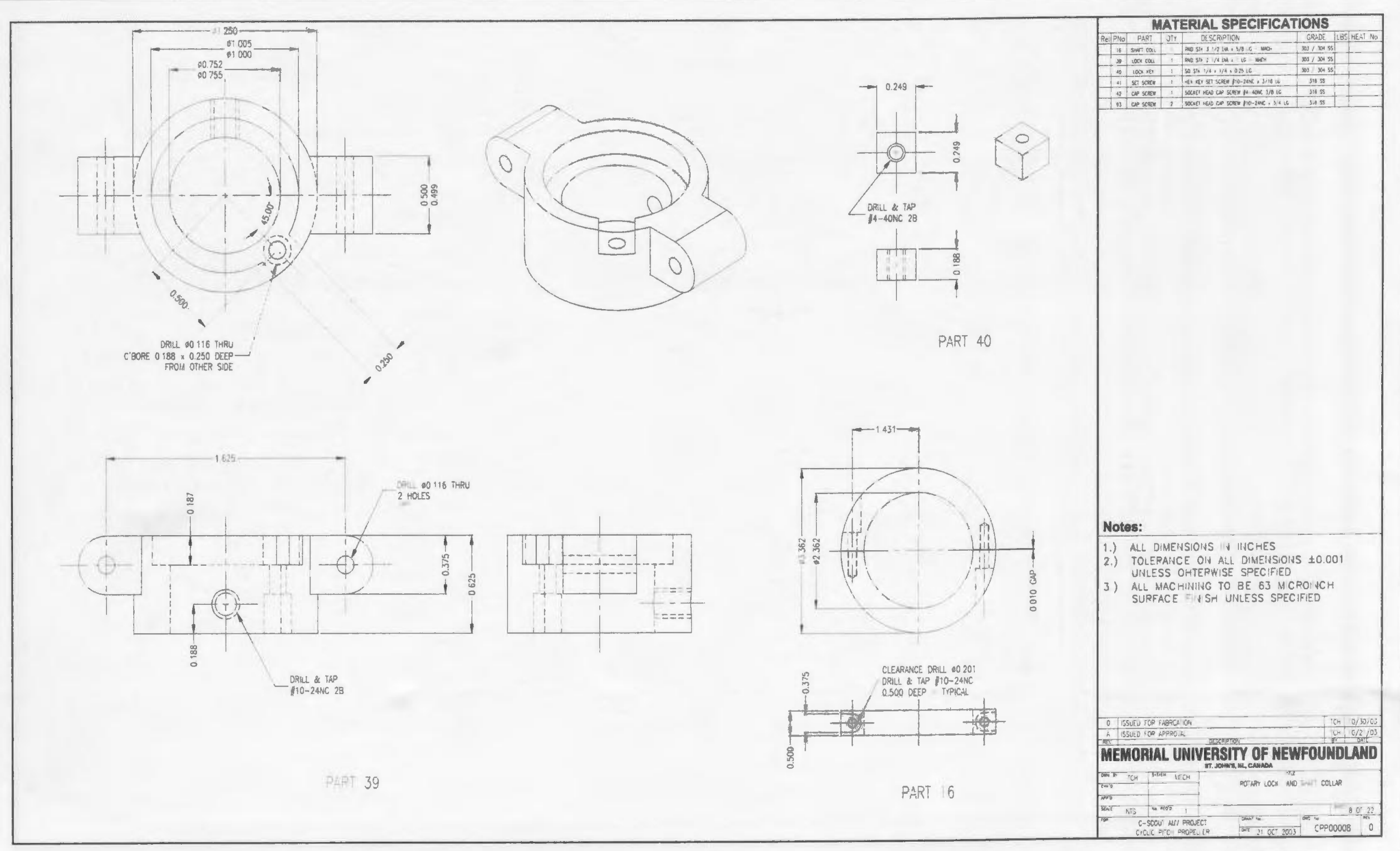




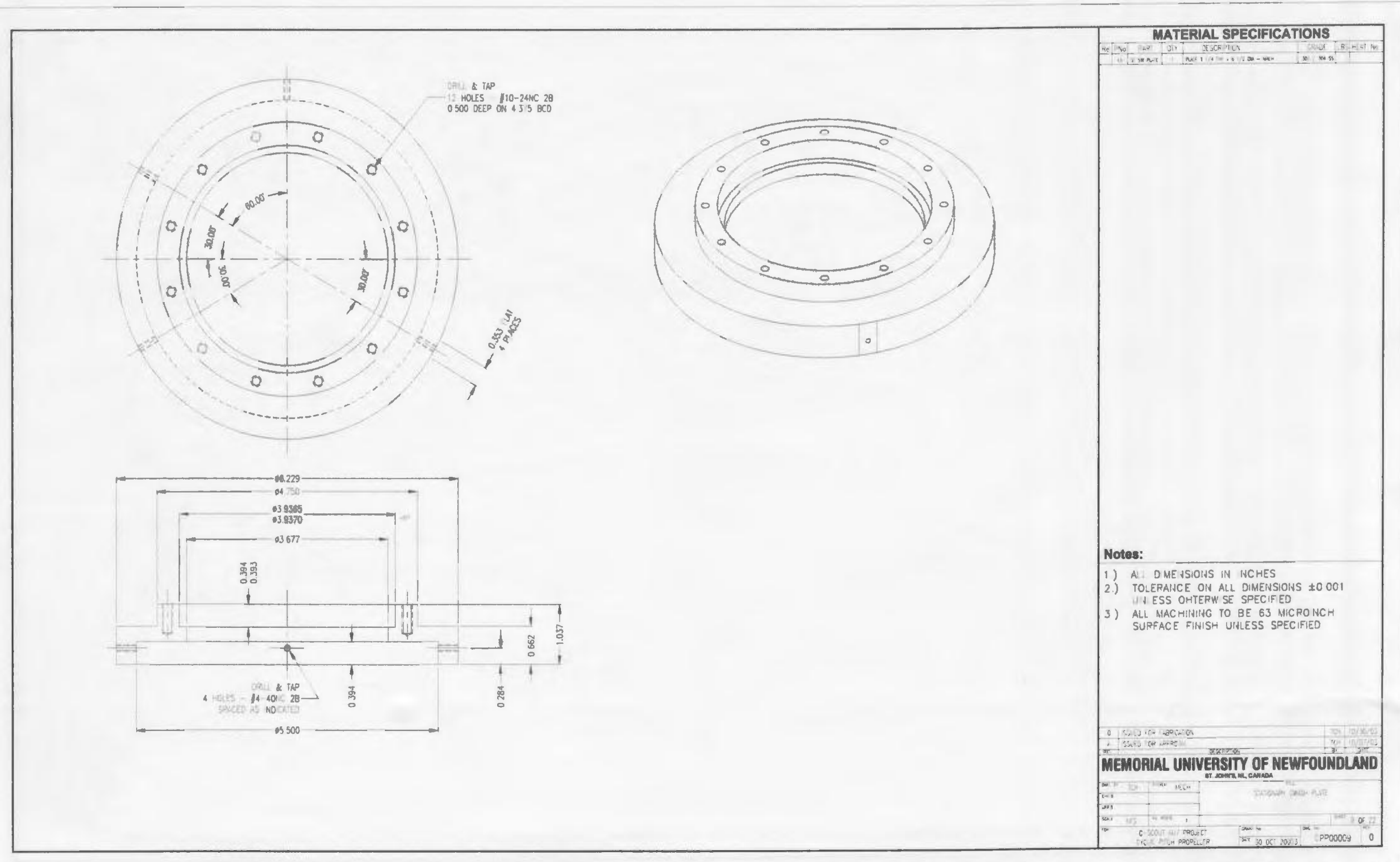




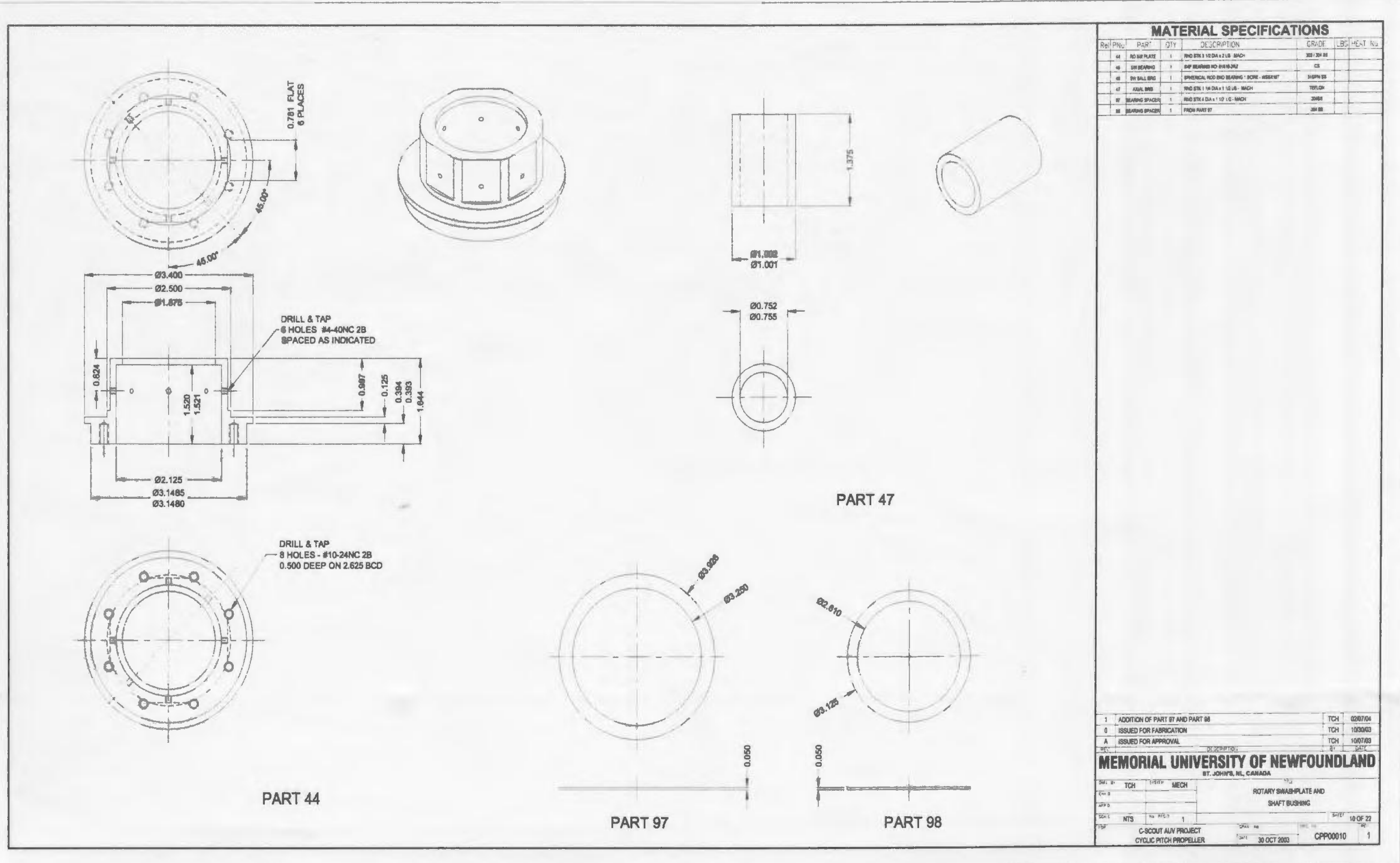




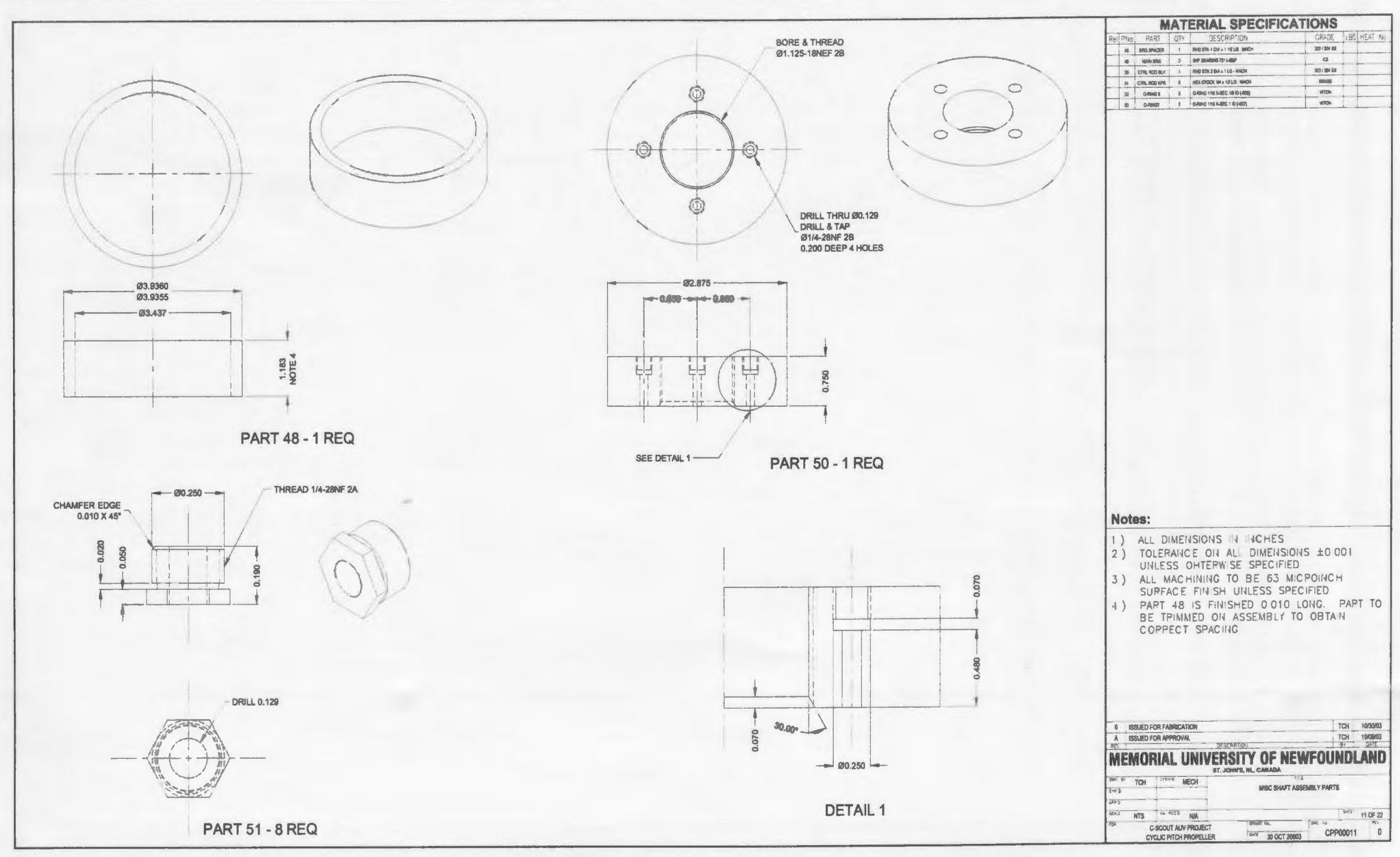



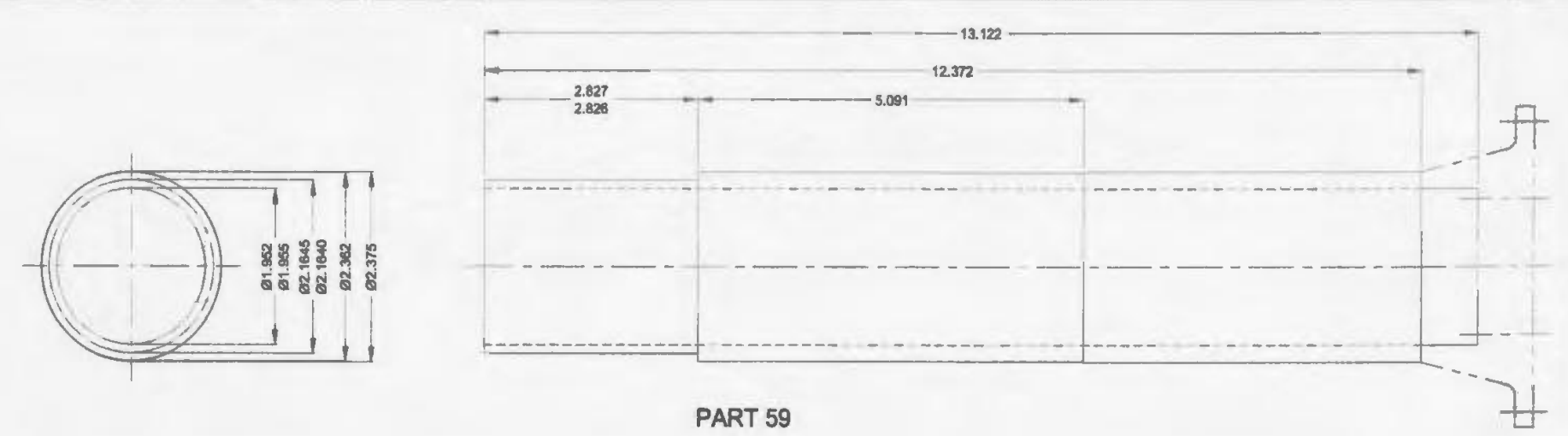

MATERIAL SPECIFICATIONS

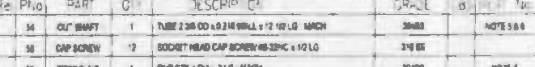

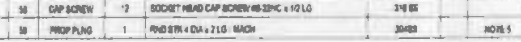

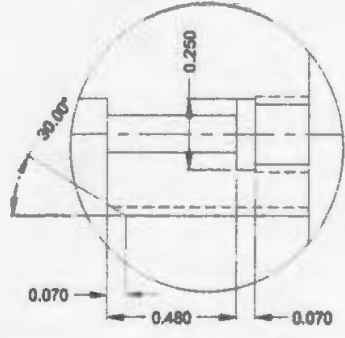

DETAIL 1

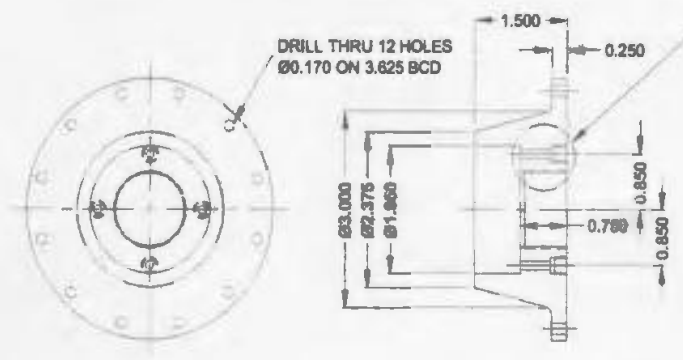

PART 54
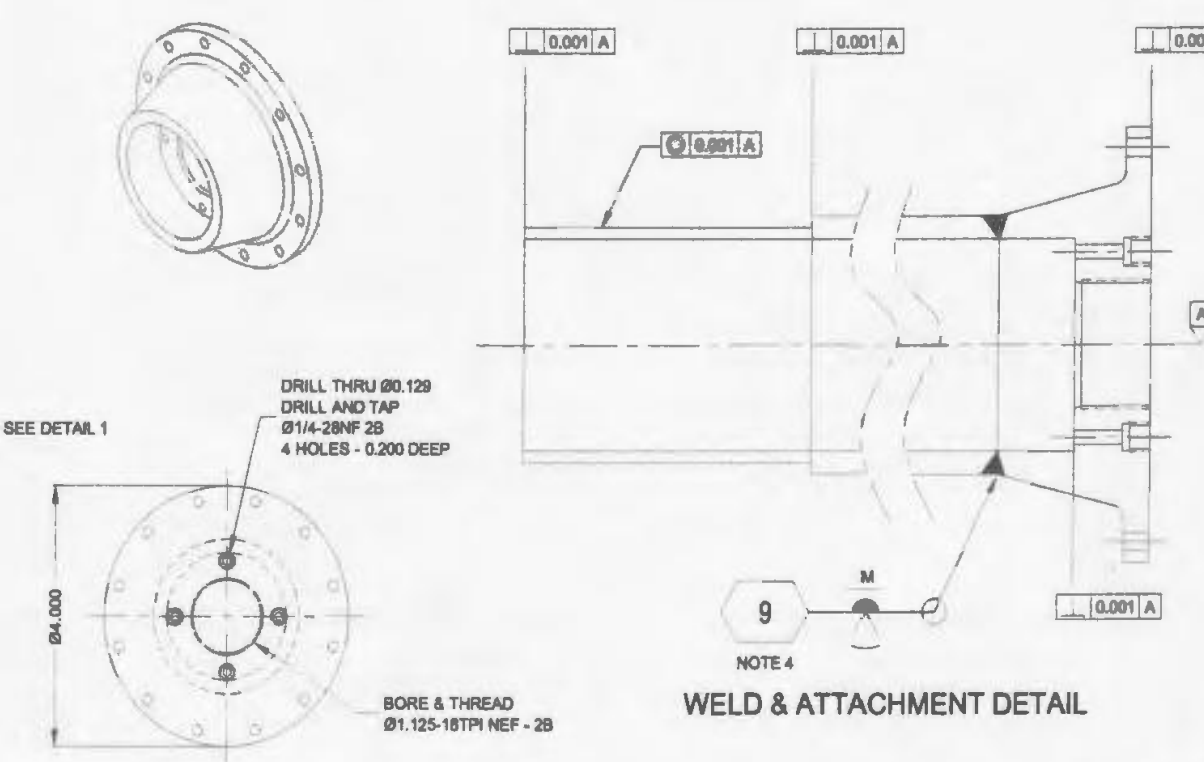

BORE \& THREAD

$$
9 \stackrel{M}{M-0.0001 A}
$$

NOTEA

WELD \& ATTACHMENT DETAIL

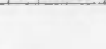

Notes:

1.) MLL DIMENSIONS I HCHES

2) TOLERANCE OHA A L D MELISIONS \pm 000

UIESS OHTEPH' SE SPEC FED

3.) ALL MAC I NC TO BE $63 \mathrm{MCPO}$ IC
SURFACE FIISH UII ESS SPEC FED

4) PUPGE BACKSDE OF KEID DUPI IG WELDHG

5) MIETAL FOP THESE PAPTS MUST GE 304SS

6) TMIS MATERIAL MUST BE TUB HG AND NOT COINSDEPAB HIGHEP

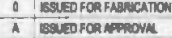

MEMORIAL UNIVERSTY OF MEMTEOUNDI MND

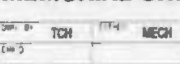

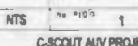

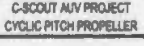




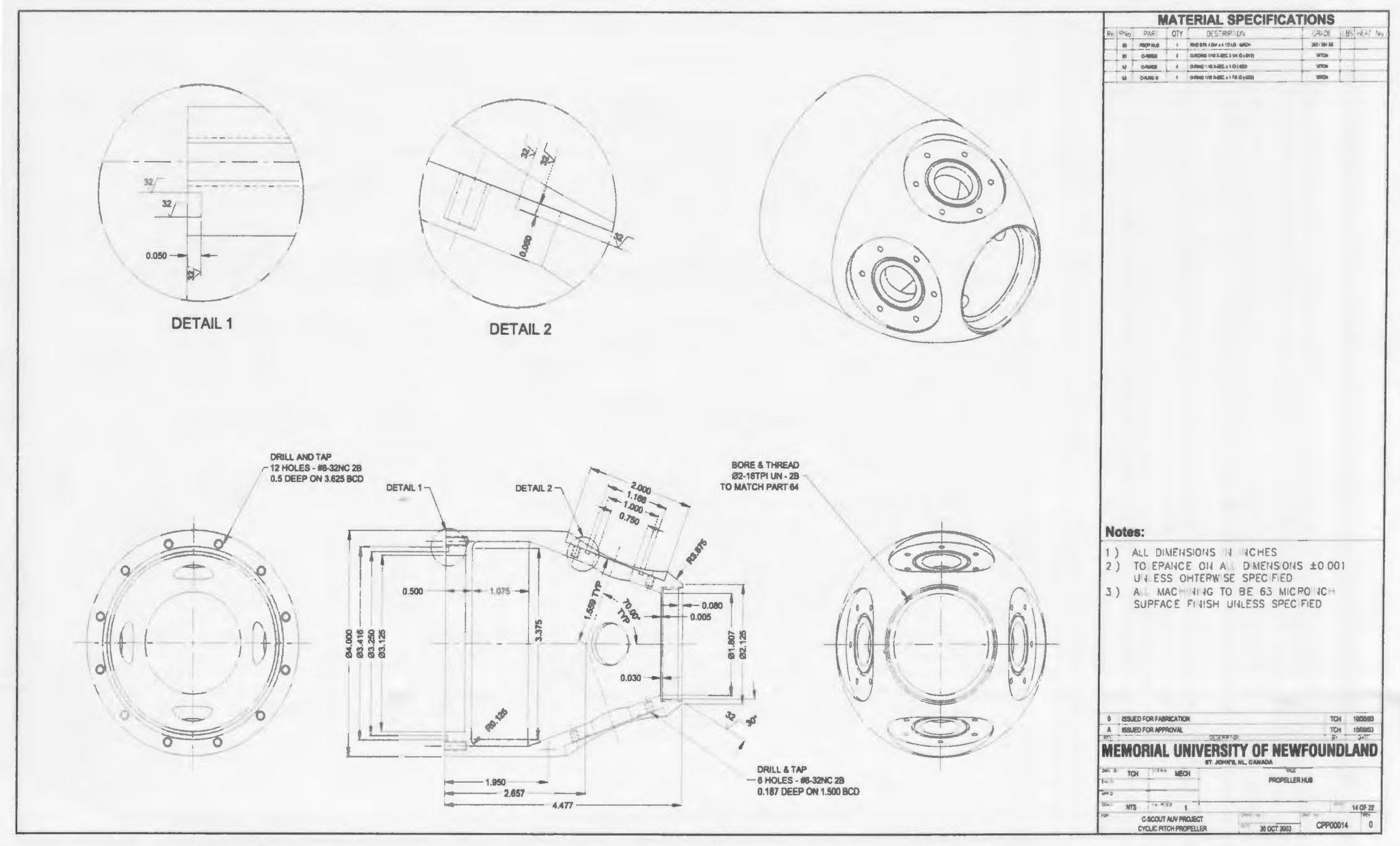




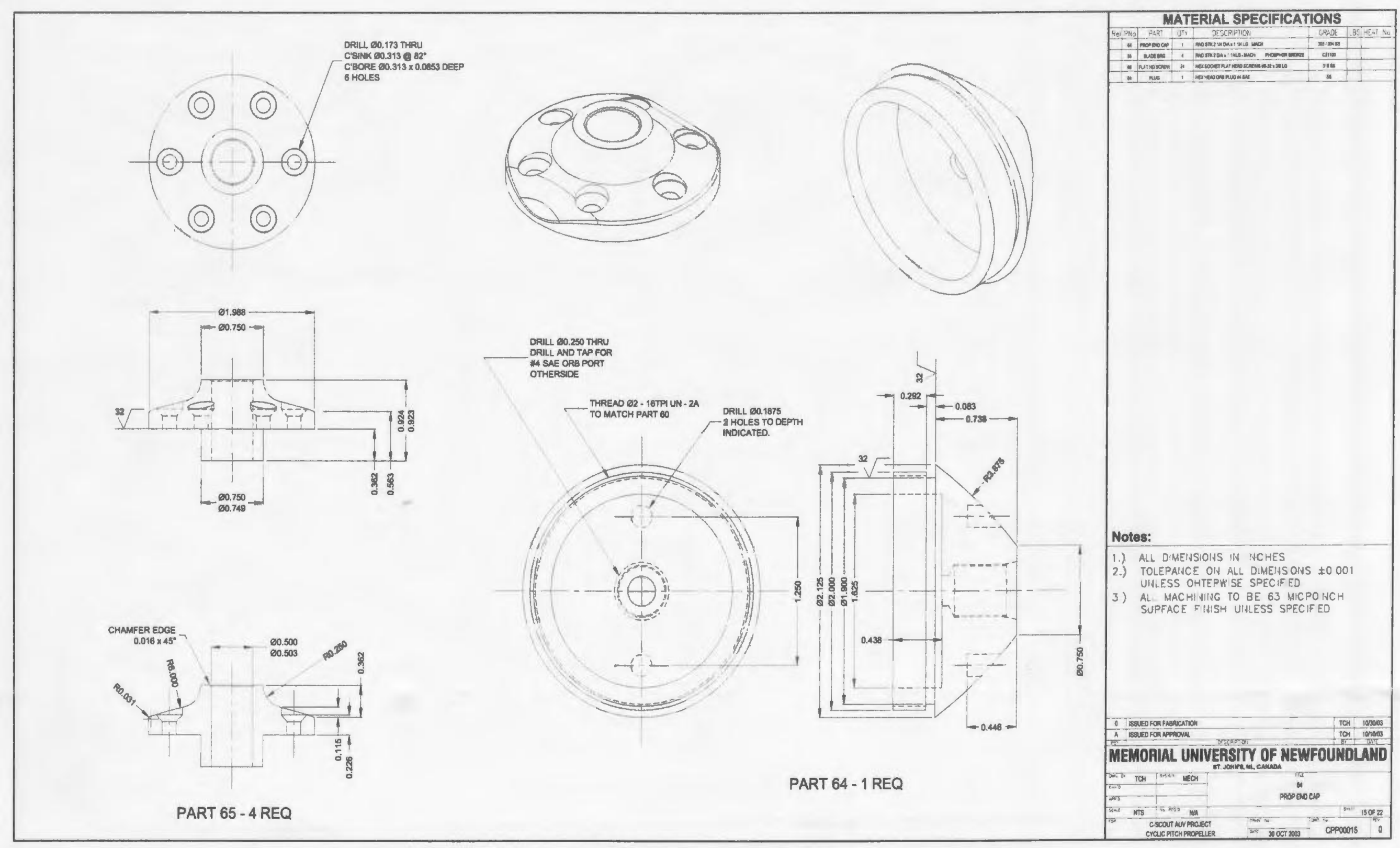




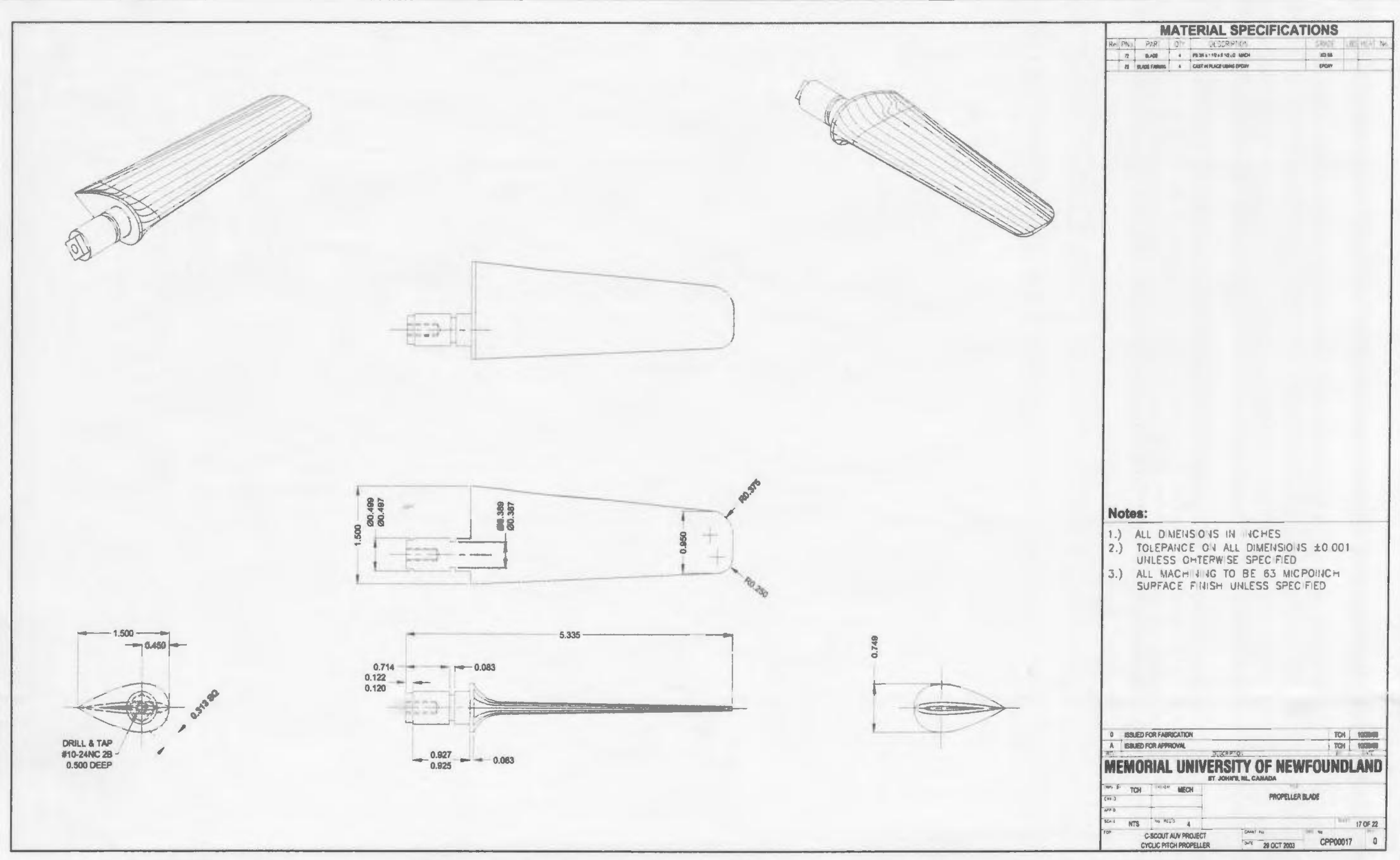




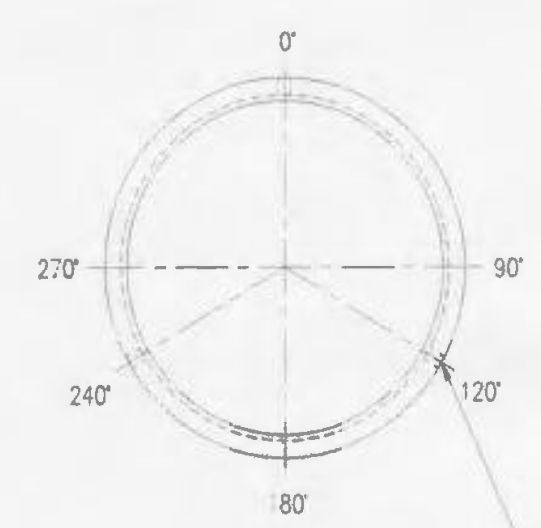

DELL LA TAP 8 HOES
10-24 NC 29 THRU

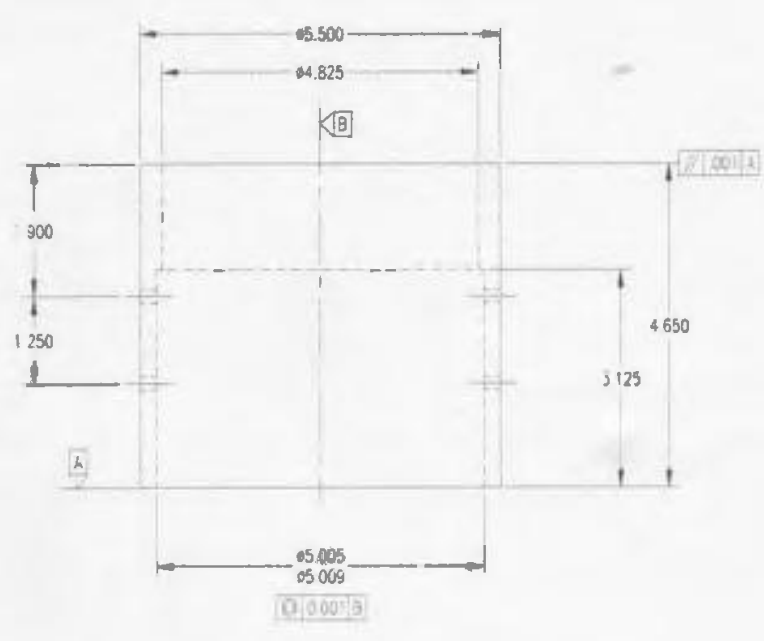

PAPT $\rightarrow$ H
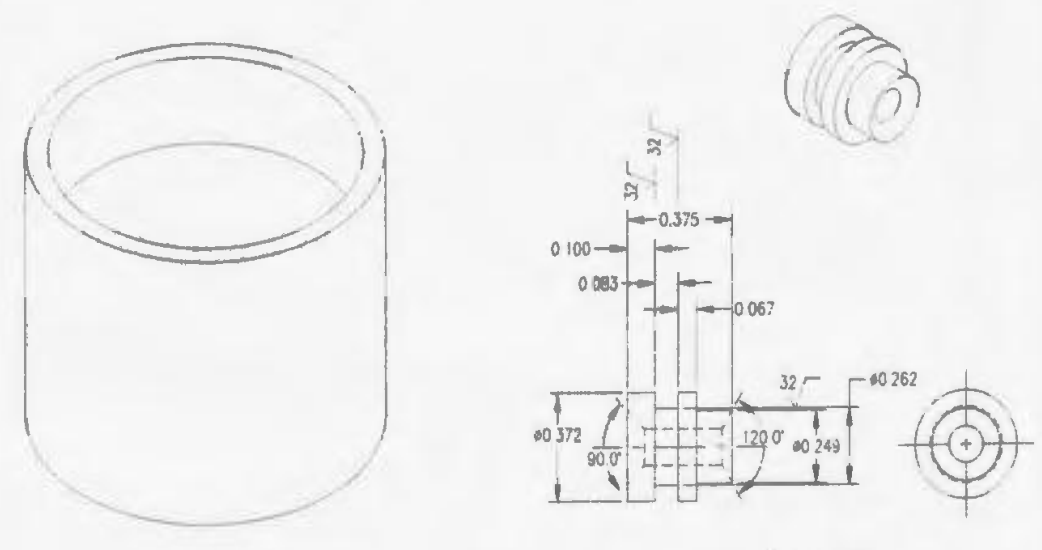

P RT 90
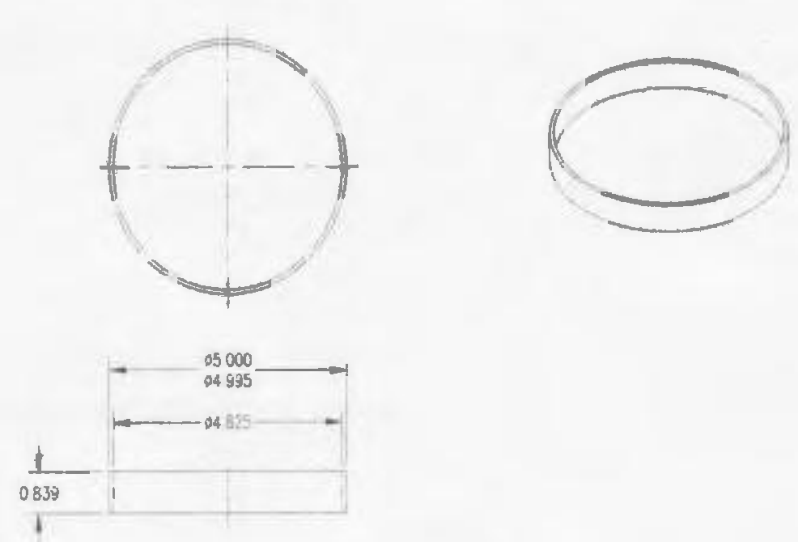

PAP -75
MATERIAL SPECIFICATIONS

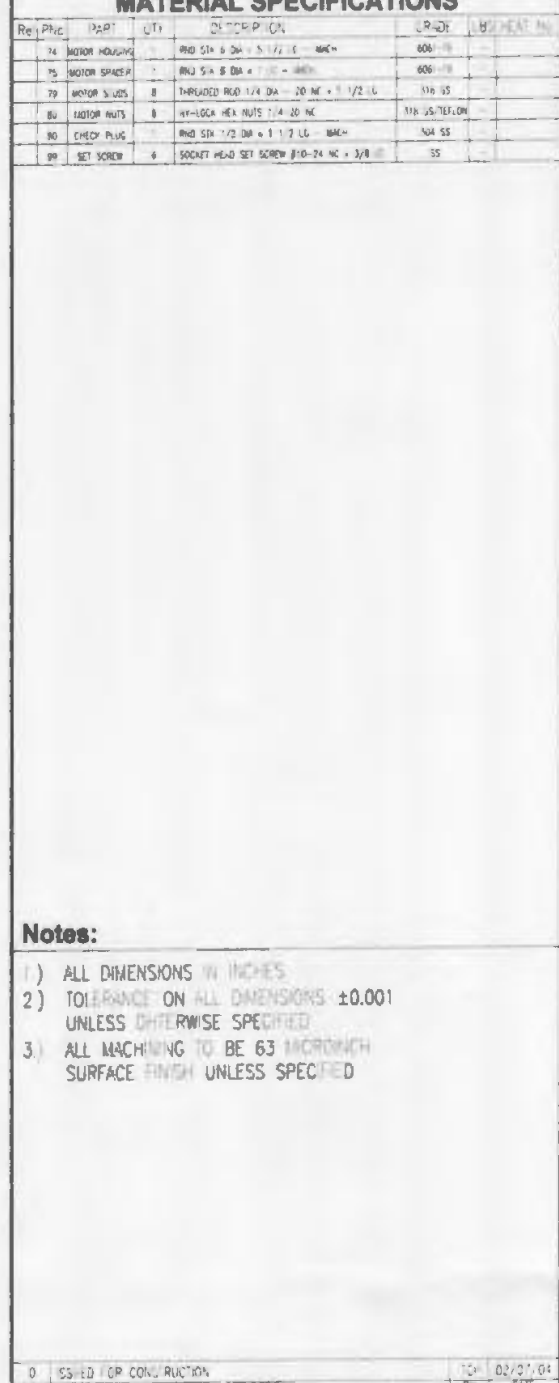

MEMORIAL UNIVERSITY OF NEWFOUNDLAND

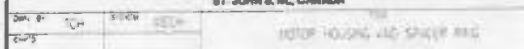

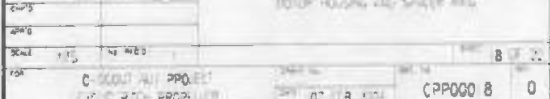




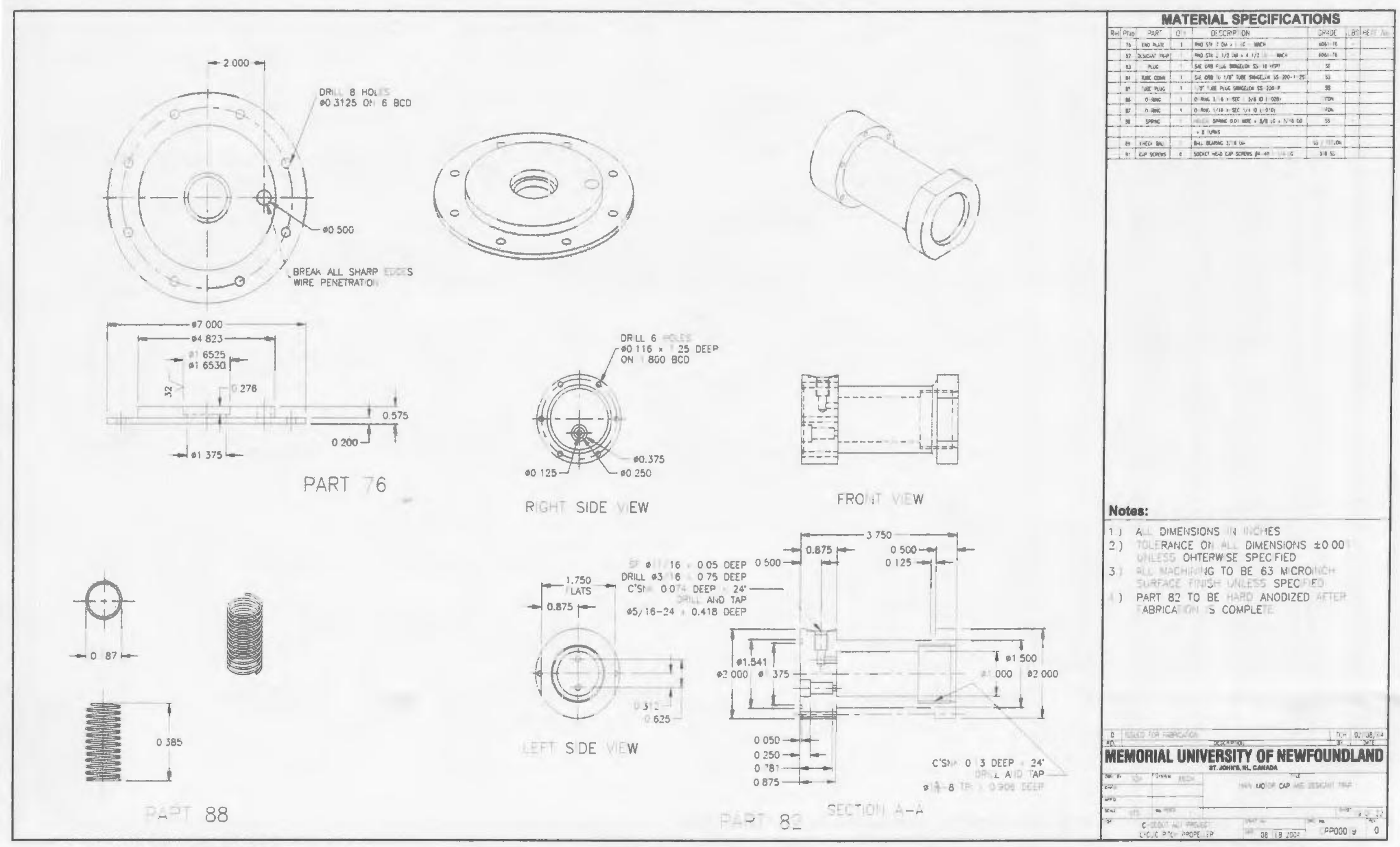



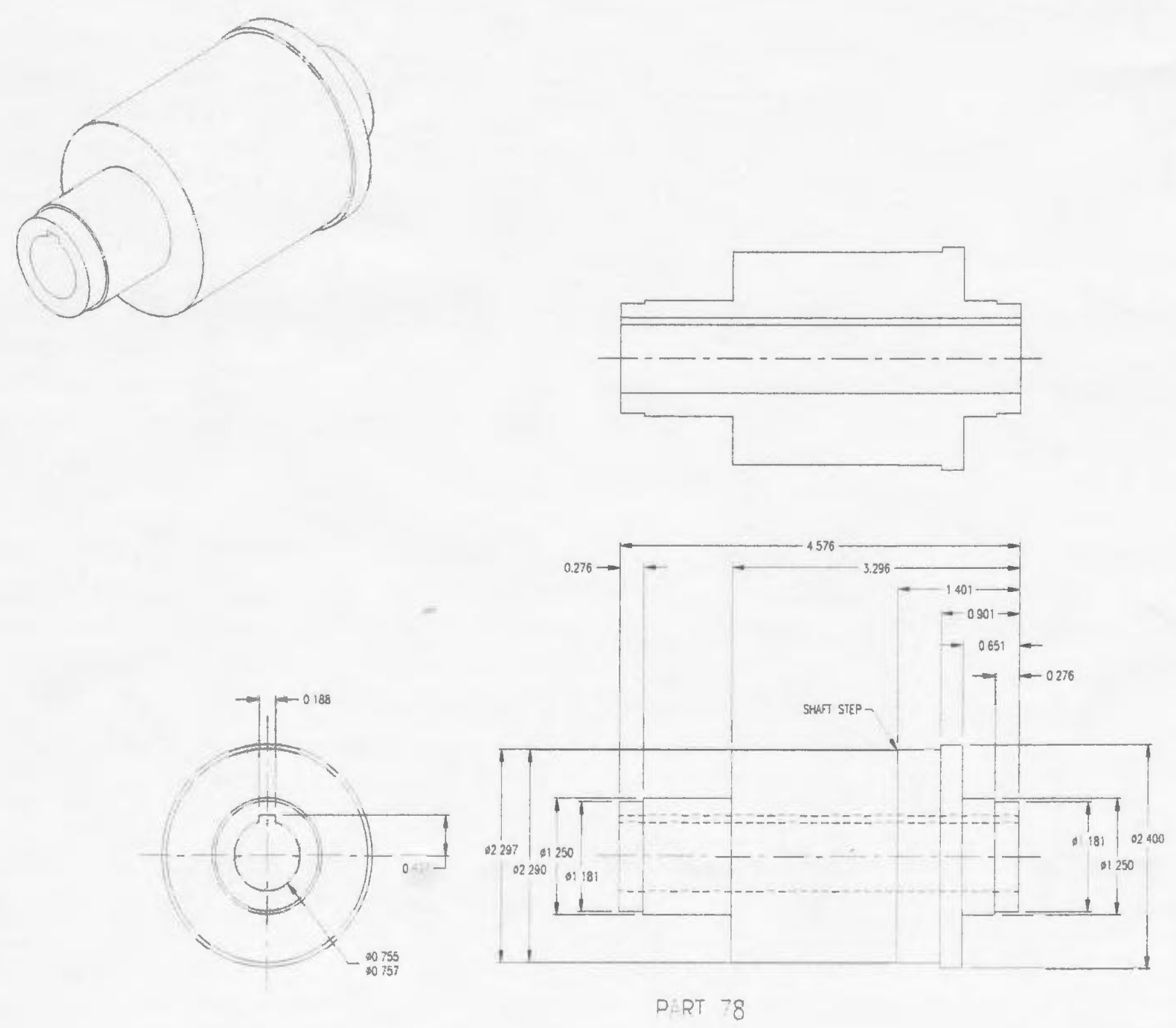

Notes:

1) ALI OMENSIONS IN NCHES

2) TOLERHACE ON ALL DMENSSIONS \pm 0.001

TOLERANCE ON ALL DMEENSIONS \pm 0.000
UNLESS OHTERWSE SPECFFED

3) ALL HACHNANG TO EE 63 HICRONCH

D RT 78

MEMORIAL UNIIEASITY OF MEWFOUNDLAND

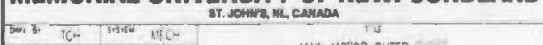

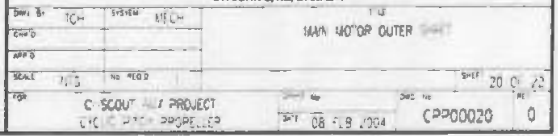




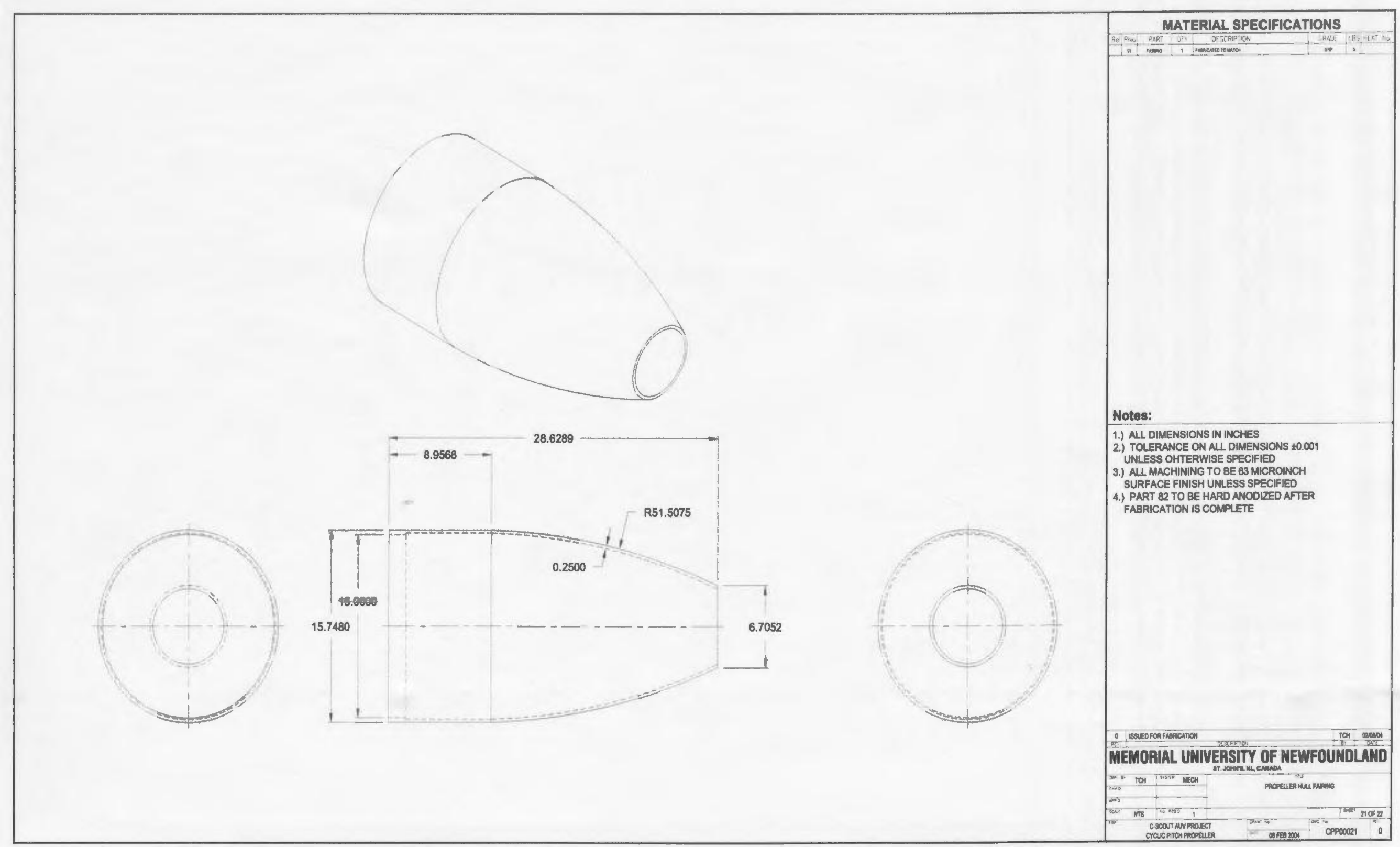




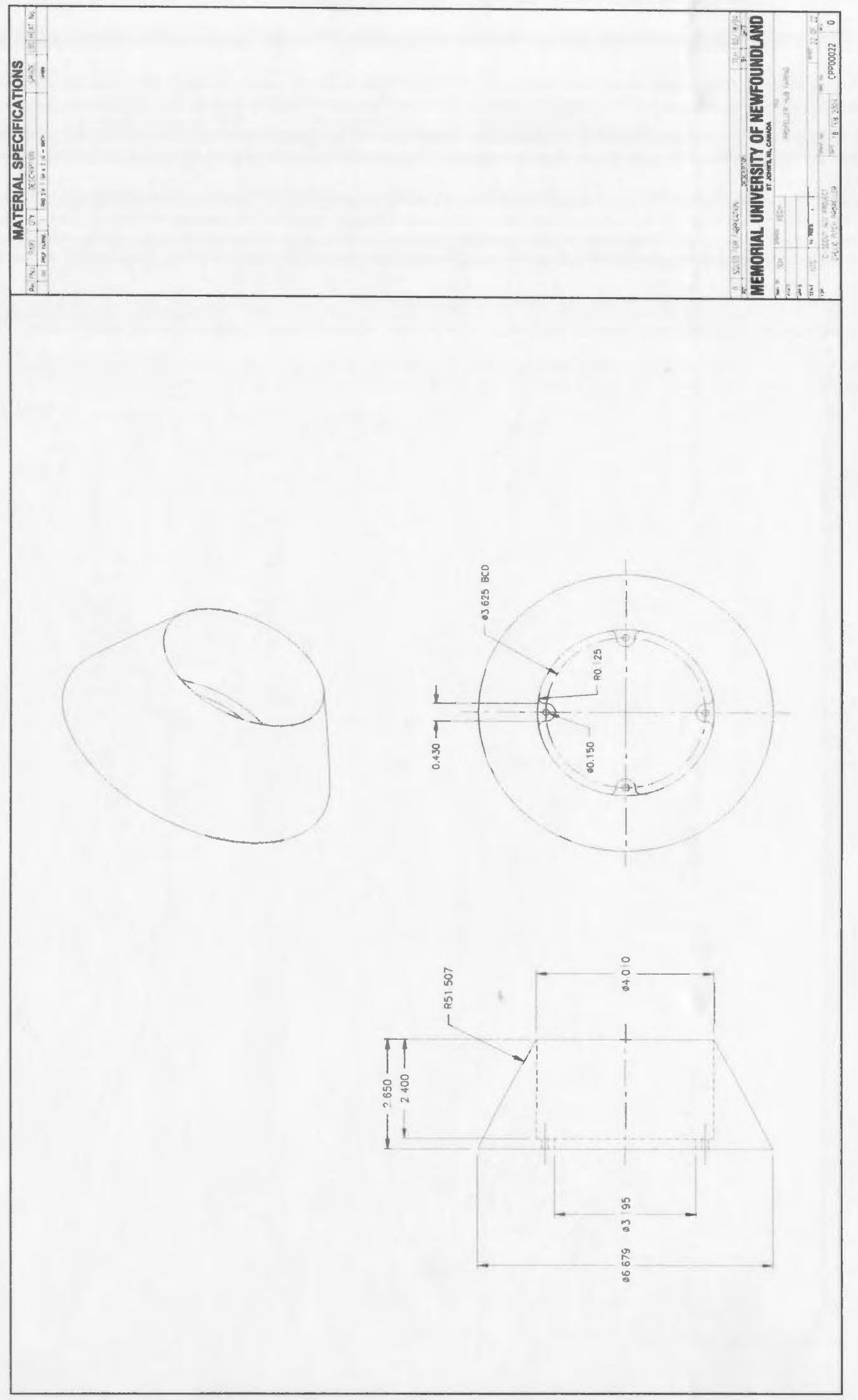


Appendix B - Fixed Size Component Data Sheets 


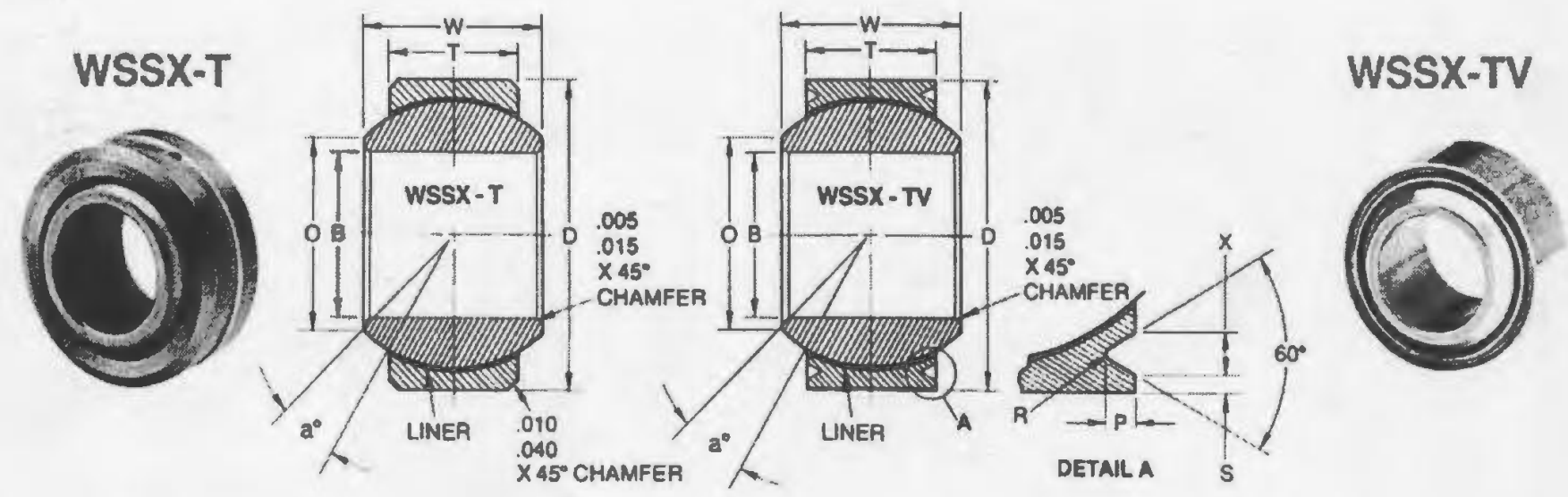

\begin{tabular}{|c|c|c|c|c|c|c|c|c|c|c|c|c|c|}
\hline & & \multirow{3}{*}{ BORE SIZE } & \multirow{3}{*}{$\begin{array}{l}\text { B DIA. } \\
.0000 \\
.0005\end{array}$} & \multirow{3}{*}{$\begin{array}{l}\text { D DIA. } \\
+.0000 \\
.0005 \\
\end{array}$} & \multirow{3}{*}{$\begin{array}{c}\text { W WIDTH } \\
+.000 \\
.002 \\
\end{array}$} & \multirow{3}{*}{$\begin{array}{l}\text { T WIDTH } \\
+1-005\end{array}$} & \multirow{3}{*}{$\begin{array}{c}\text { O } \\
\text { SHOULDER } \\
\text { DIAMETER } \\
\text { REF. }\end{array}$} & \multirow{4}{*}{$\begin{array}{l}\text { BALL DIA. } \\
\text { REF. } \\
0.531\end{array}$} & \multirow{4}{*}{$\begin{array}{l}a^{\circ} \\
\frac{R E F}{15}\end{array}$} & \multicolumn{3}{|c|}{ LOAD RATINGS (LBS.) } & \multirow{3}{*}{$\begin{array}{c}\text { APPROX. } \\
\text { WEIGHT } \\
\text { LBS. }\end{array}$} \\
\hline & & & & & & & & & & STATI & LIMIT & DYNAMIC & \\
\hline \multicolumn{2}{|c|}{ PART NUMBER } & & & & & & & & & $\begin{array}{l}\text { RADIAL } \\
\text { LBS }\end{array}$ & AXIAL LBS. & $\begin{array}{l}\text { OSCILLATING } \\
\text { RADIAL LOAD }\end{array}$ & \\
\hline WSSX3T & WSSX3TV & $3 / 16$ & 0.1900 & 0.6250 & 0.437 & 0.327 & 0.301 & & & 9,000 & 1,770 & 3,770 & 0.031 \\
\hline WSSX4T & WSSX4TV & $1 / 4$ & 0.2500 & 0.6250 & 0.437 & 0.327 & 0.301 & 0.531 & 15 & 9,000 & 1,770 & 3,770 & 0.031 \\
\hline WSSX5T & WSSX5TV & $5 / 16$ & 0.3125 & 0.6875 & 0.437 & 0.317 & 0.401 & 0.593 & 14 & 9,400 & 1,640 & 4,650 & 0.035 \\
\hline WSSX6T & WSSX6TV & $3 / 8$ & 0.3750 & 0.8125 & 0.500 & 0.406 & 0.466 & 0.687 & 8 & 13,700 & 2,630 & 6,390 & 0.060 \\
\hline WSSX7T & WSSX7TV & $7 / 16$ & 0.4375 & 0.9375 & 0.562 & 0.442 & 0.537 & 0.781 & 10 & 20,700 & 3,650 & 9,390 & 0.800 \\
\hline WSSX8T & WSSX8TV & $1 / 2$ & 0.5000 & 1.0000 & 0.625 & 0.505 & 0.607 & 0.875 & 9 & 27,500 & 4,970 & 12,150 & 0.100 \\
\hline WSSX9T & WSSX9TV & $9 / 16$ & 0.5625 & 1.1250 & 0.687 & 0.536 & 0.721 & 1.000 & 10 & 34,400 & 5,370 & 14,900 & 0.135 \\
\hline WSSX10T & WSSX10TV & $5 / 8$ & 0.6250 & 9.1875 & 0.750 & 0.567 & 0.747 & 1.062 & 12 & 39,000 & 6,130 & 16,700 & 0.160 \\
\hline WSSX12T & WSSX12TV & $3 / 4$ & 0.7500 & 1.3750 & 0.875 & 0.630 & 0.887 & 4.250 & 13 & 52,300 & 7,730 & 22,100 & 0.240 \\
\hline WSSX14T & WSSX14TV & $7 / 8$ & 0.8750 & 1.6250 & 0.875 & 0.755 & 1.061 & 1.375 & 6 & 67,300 & 10,800 & 28,200 & 0.350 \\
\hline WSSX16T & WSSX16TV & 1 & 1.0000 & 2.1250 & 1.375 & 1.005 & 1.269 & 1.875 & 12 & 137,000 & 19,300 & 53,700 & 0.970 \\
\hline
\end{tabular}


NE SEAL INDUSTRIAL PRODUCTS LTD.

TYPE NES-12 (DIN / Metric)

Equivalent to Vulcan Type 12

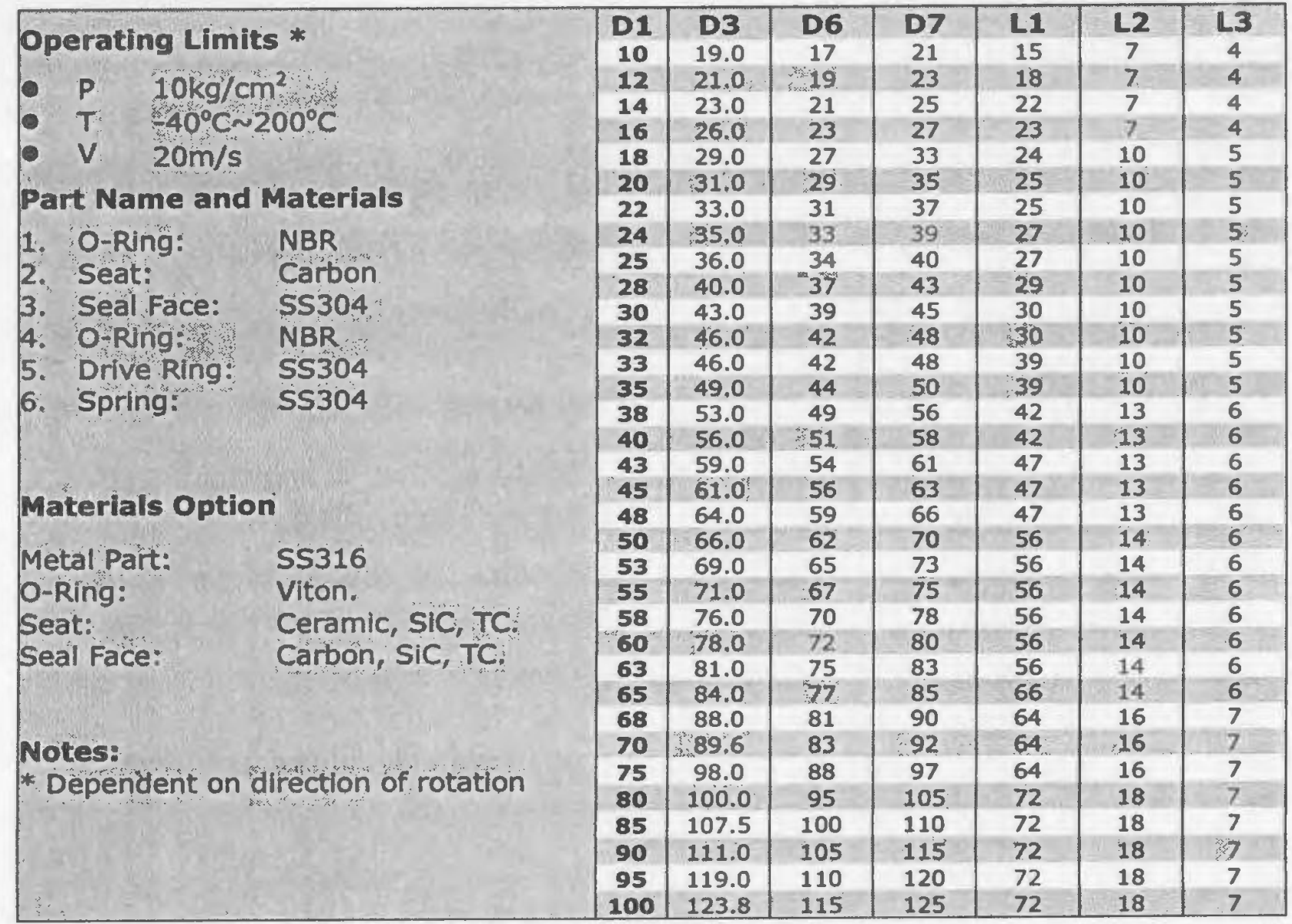

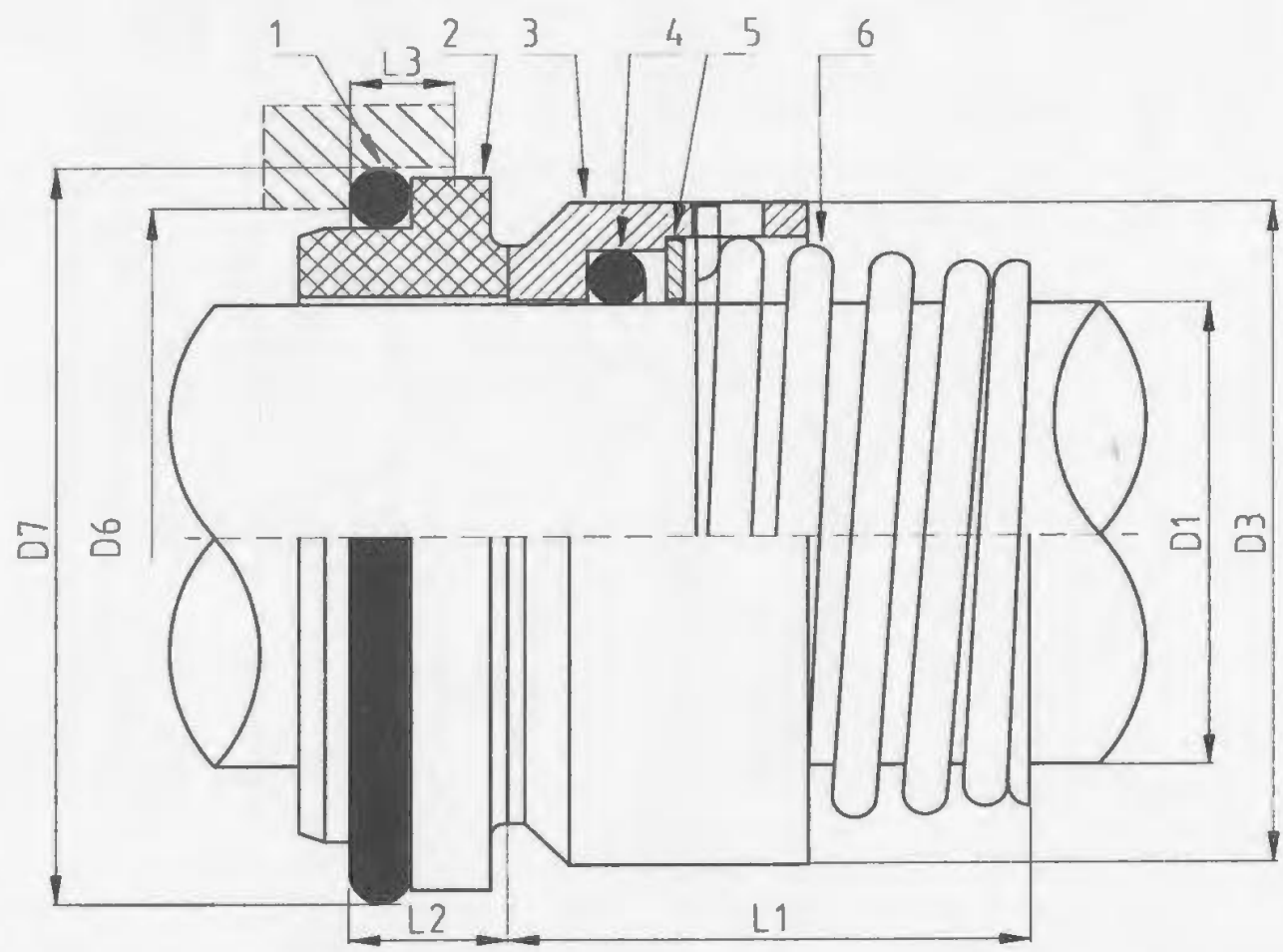


5KF

Angular contact ball bearings, single row

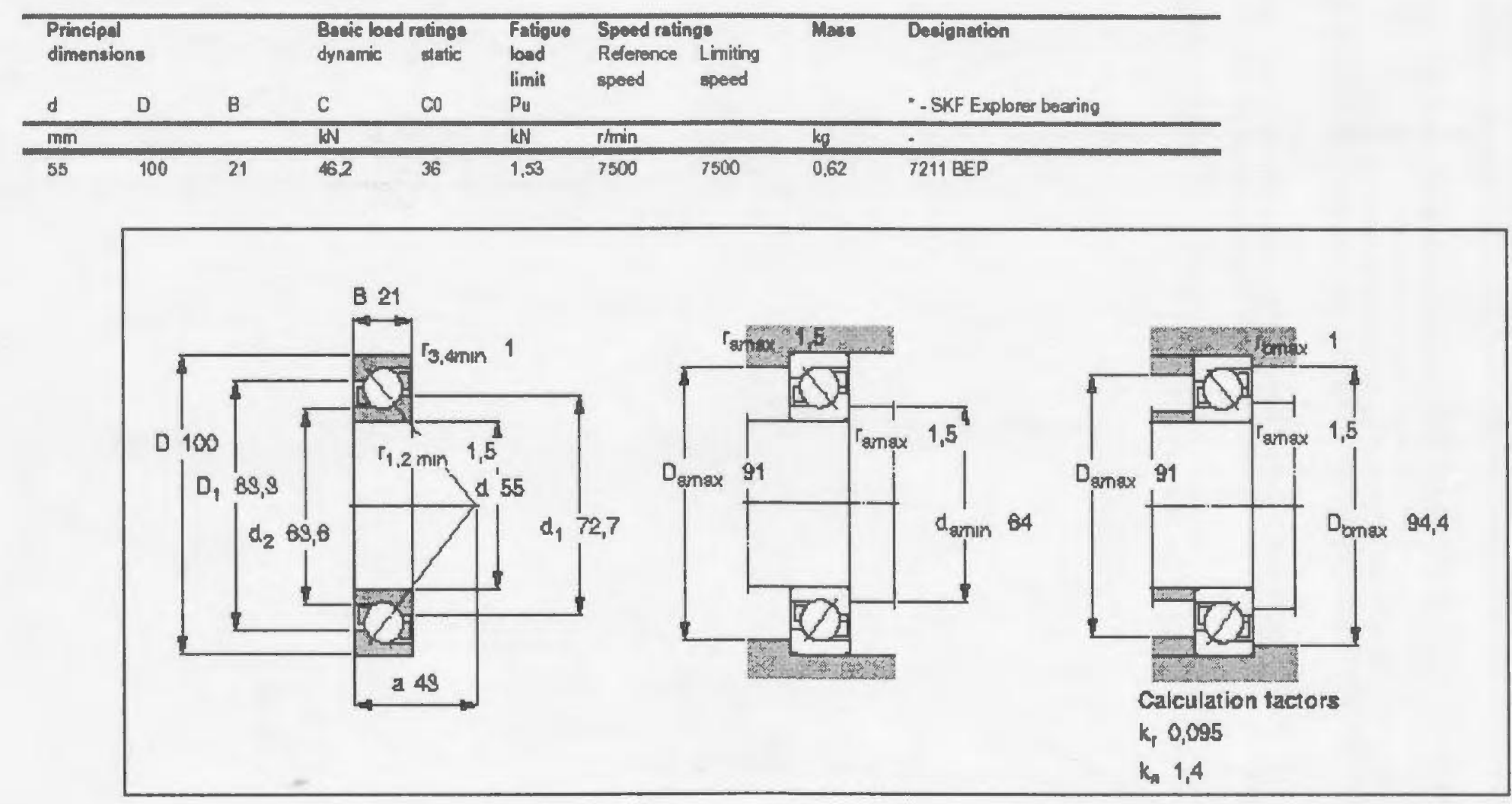


Deep groove ball bearings, single row

\begin{tabular}{|c|c|c|c|c|c|c|c|c|c|}
\hline \multicolumn{3}{|c|}{$\begin{array}{l}\text { Principd } \\
\text { dimensions }\end{array}$} & \multicolumn{2}{|c|}{$\begin{array}{l}\text { Bacie load ratings } \\
\text { dynamic static }\end{array}$} & \multirow{2}{*}{$\begin{array}{l}\text { Fatigue } \\
\text { land } \\
\text { limit } \\
\mathrm{Pu}\end{array}$} & $\begin{array}{l}\text { Speod ratin } \\
\text { Reference }\end{array}$ & Limiting & \multirow[t]{2}{*}{ Mass } & \multirow{2}{*}{$\begin{array}{l}\text { Designation } \\
\text { - SKF Explorer bearing }\end{array}$} \\
\hline$d$ & D & B & c & CO & & & & & \\
\hline $\mathrm{mm}$ & & & $\overline{k N}$ & & $\mathrm{kN}$ & $\mathrm{r} / \mathrm{min}$ & & $\mathrm{kg}$ & - \\
\hline 80 & 100 & 10 & 13 & 15 & 0,64 & 13000 & 6300 & 0.15 & $61816-2 R 2$ \\
\hline
\end{tabular}

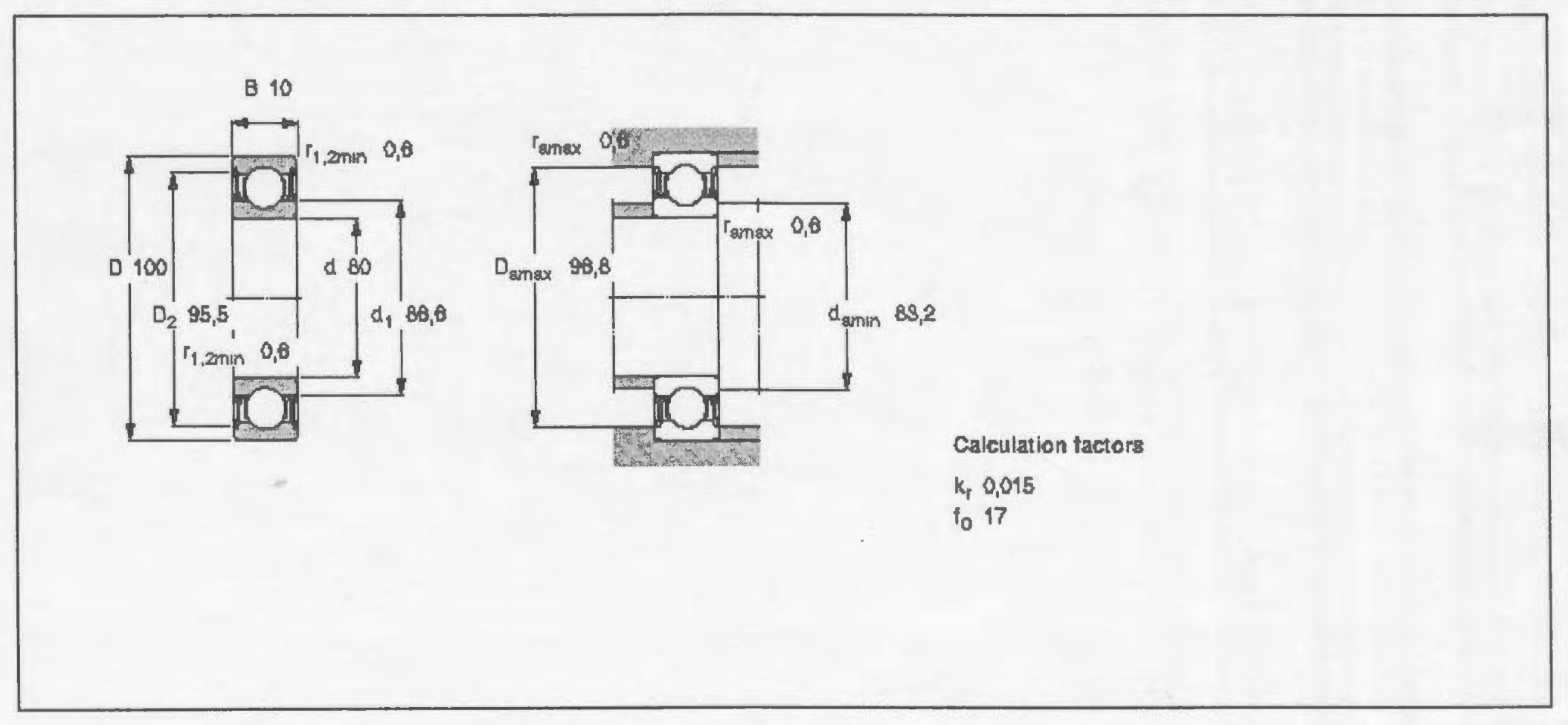




\section{SKF}

\section{Deep groove ball bearings, single row}

\begin{tabular}{|c|c|c|c|c|c|c|c|c|}
\hline \multicolumn{3}{|c|}{$\begin{array}{l}\text { Principal } \\
\text { dimensions }\end{array}$} & $\begin{array}{l}\text { Batic load ratings } \\
\text { dynamic static }\end{array}$ & \multirow{2}{*}{$\begin{array}{l}\text { Fatigus } \\
\text { load } \\
\text { limit } \\
\mathrm{p}_{u}\end{array}$} & \multirow{2}{*}{\multicolumn{2}{|c|}{$\begin{array}{l}\text { Speed ratings } \\
\text { Reference Liming } \\
\text { speod speed }\end{array}$}} & \multirow[t]{2}{*}{ Mase } & \multirow{2}{*}{$\begin{array}{l}\text { Designation } \\
\text { "- SKF Explorer bearing }\end{array}$} \\
\hline$d$ & D & B & $\mathrm{CO}$ & & & & & \\
\hline $\mathrm{mm}$ & & & WN & $\mathrm{kN}$ & rimin & & $\mathrm{kg}$ & - \\
\hline 30 & 42 & 7 & 4,49 & 0,146 & 32000 & 16000 & 0,027 & $61806-2 R 7$ \\
\hline
\end{tabular}

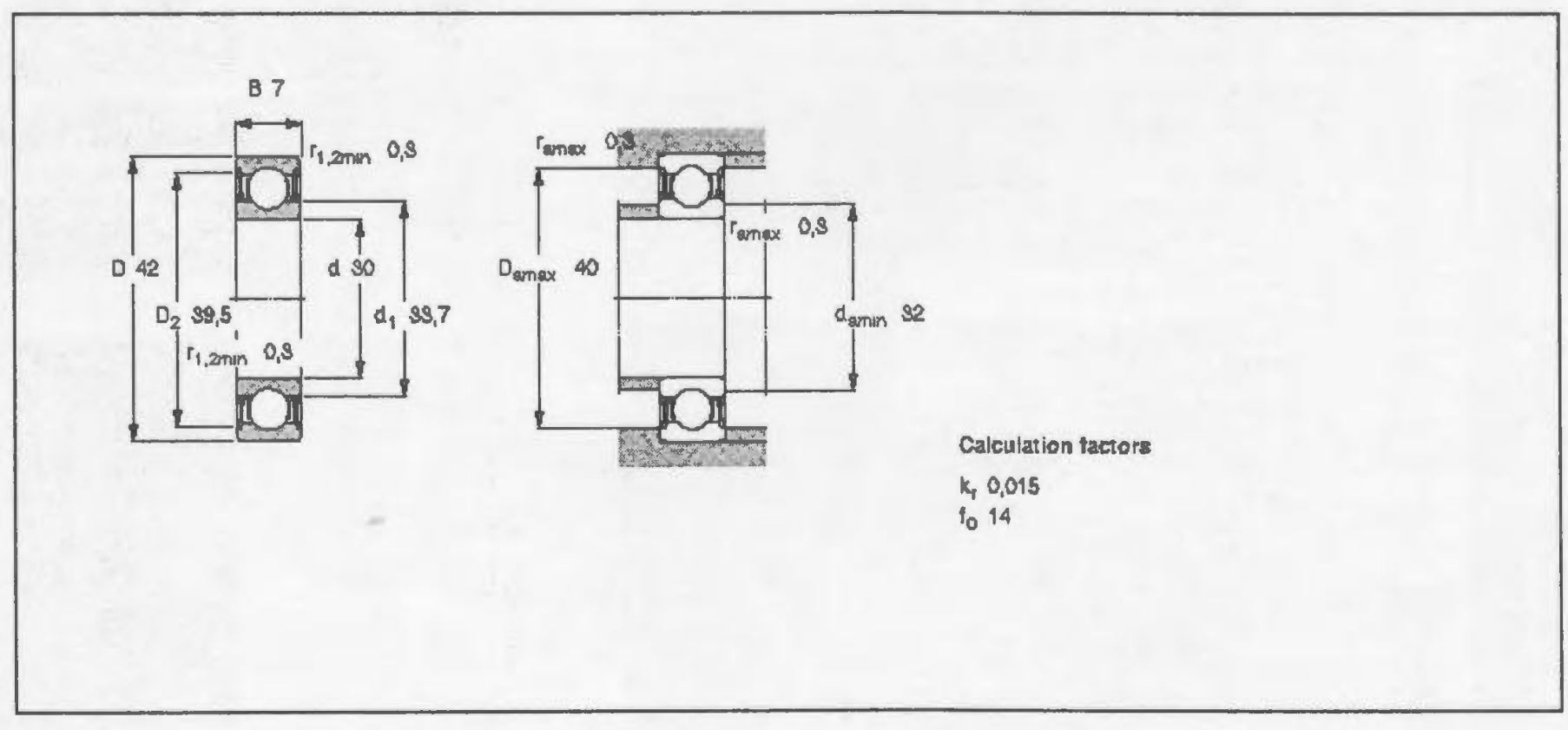


part number: D-B.125-HT17-2-P-RBC3S/RBC3S

max force: $97 \mathrm{lbs}$

max speed: $5.0 \mathrm{in} / \mathrm{sec}$

backlash: 0.002 in

linear step resolution: 1600 steps/in

actuator speed/force graph: D - B.125 - HT17

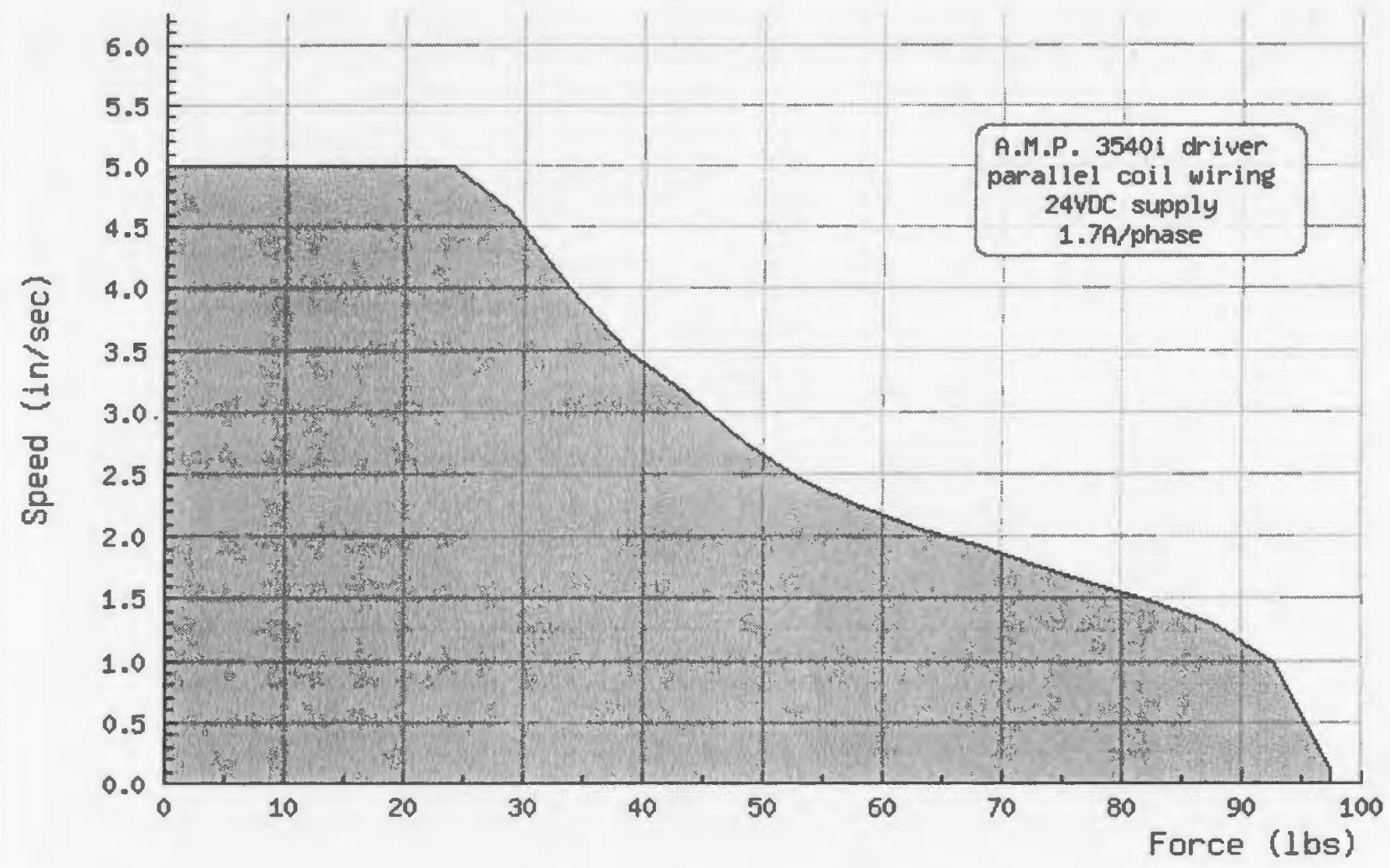

100\% Duty

lead screw: B.125 - Ball bearing nut, 0.1250 in/rev lead screw

pitch: $0.125 \mathrm{in} / \mathrm{rev}$

efficiency: $98 \%$

dynamic load: $5000 \mathrm{lb} * \mathrm{in} / \mathrm{sec}$ (100\% duty cycle)

motor: HT17 - High-torque NEMA 17 size stepper motor

coil impedance: $3.3 \mathrm{ohms}$

coil inductance: $3 \mathrm{mH}$ 


\begin{tabular}{|l|}
\hline $\begin{array}{l}\text { coil voltage: } 4 \text { volts } \\
\text { coil current: } 1.2 \text { amps } \\
\text { step angle: } 1.8 \text { degrees } \\
\text { drawing: PDF DXF }\end{array}$ \\
\hline stroke length: $\mathbf{2}$ inches \\
\hline potentiometer: $\mathbf{P}$ - Precision linear potentiometer \\
\begin{tabular}{|l} 
total resistance: $3 \mathrm{~K}$ ohms \\
linearity: $2 \%$
\end{tabular} \\
\hline base mount: $\mathbf{R B C} 3 \mathbf{S}$ - Small stainless steel base rod bearing clevis \\
\hline drawing: $\underline{\text { PDF }}$ DXF \\
\hline nose mount: $\mathbf{R B C 3 S}$ - Small stainless steel nose rod bearing clevis \\
\hline drawing: $\underline{\text { PDF }} \underline{\mathrm{DXF}}$ \\
\hline
\end{tabular}




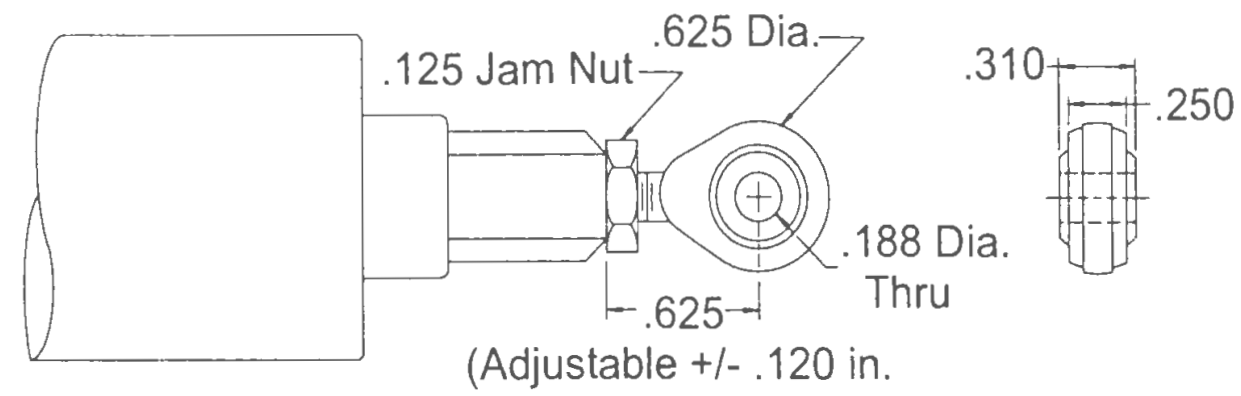

NOSE ROD BEARING CLEVIS - .188 ID 

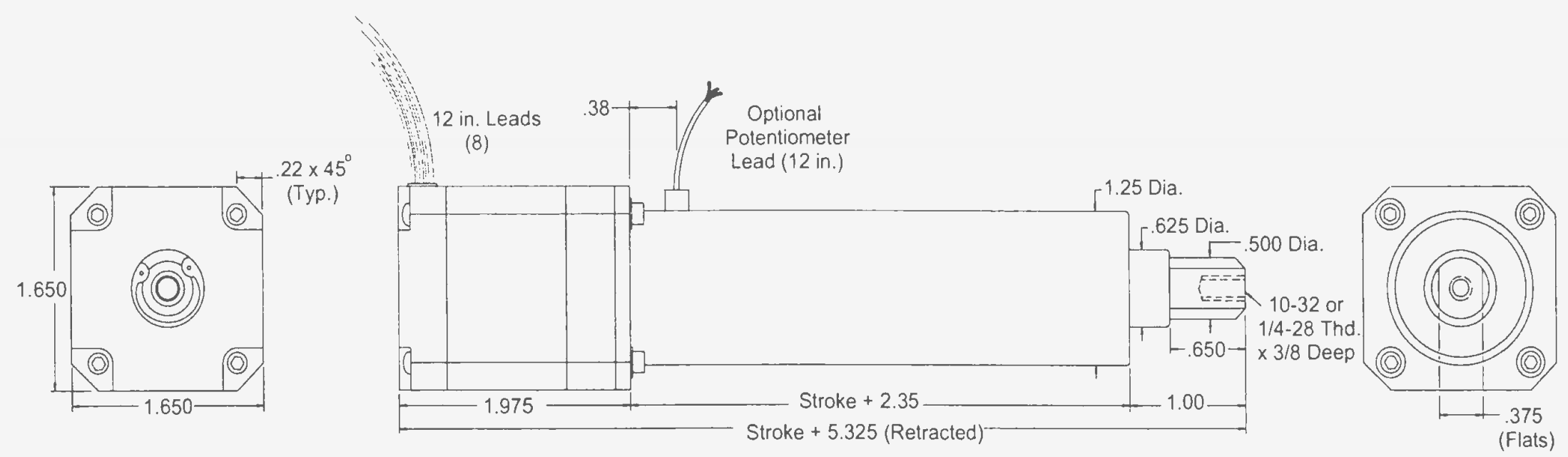

DIGIT 


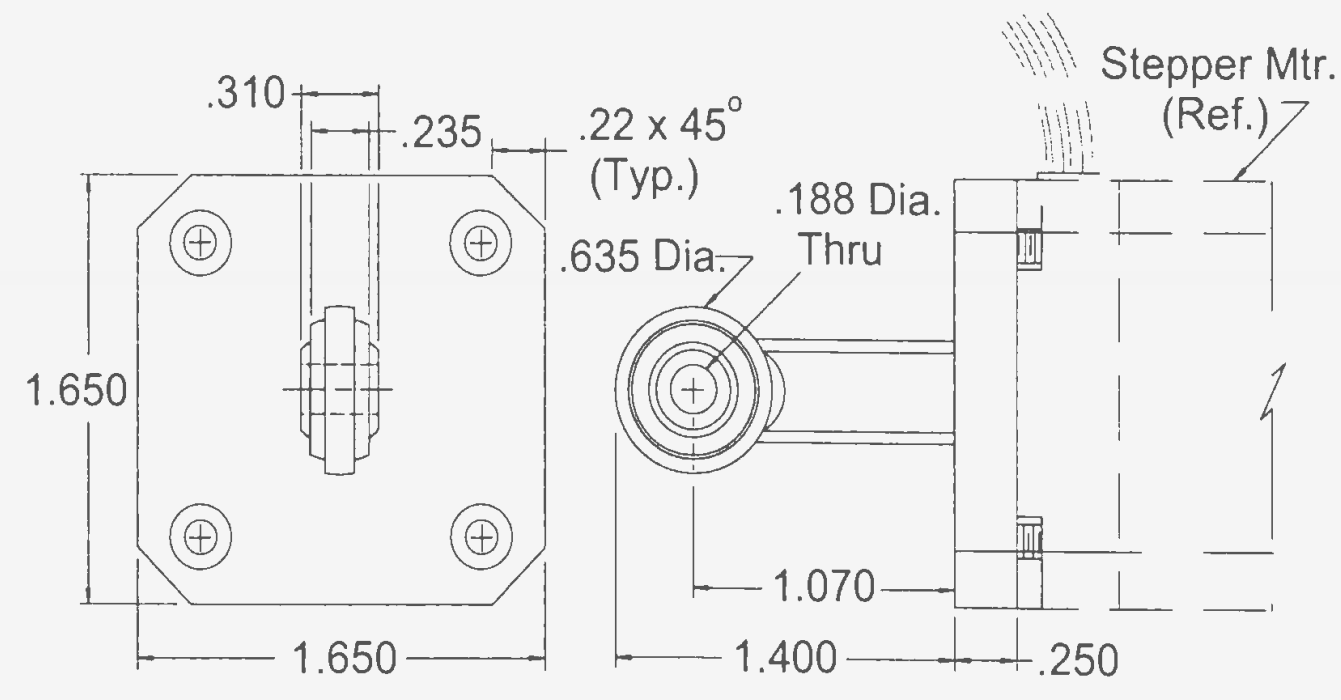

BASE ROD BEARING CLEVIS .188 Dia \& MOUNTING PLATE 


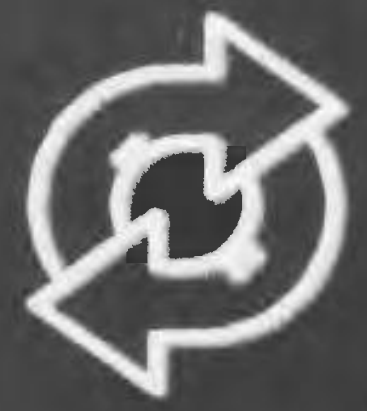

\section{When to Us:}

A significant cost savings

Reduced mechanical complexity

Greater design flexibility

High performance in a compact package

Improved dynamic response and settling

Minimum motor size per application space

Low cogging for smooth operation

Low inertia for high acceleration

\section{Dilio:tions:}

\section{Automotive}

Machine Tool

Material Handling

Packaging

Robotics

Semiconductor

\section{- Framaloss Motors series: Build Your Own High Performance Mlotor}

The frameless kit motors are ideal solutions for machine designs that require high performance in small spaces. The kit motors approach allow for direct integration with a mechanical transmission device, eliminating parts that add size and compliance. The use of frameless kit motors result in a smaller more reliable motor package.

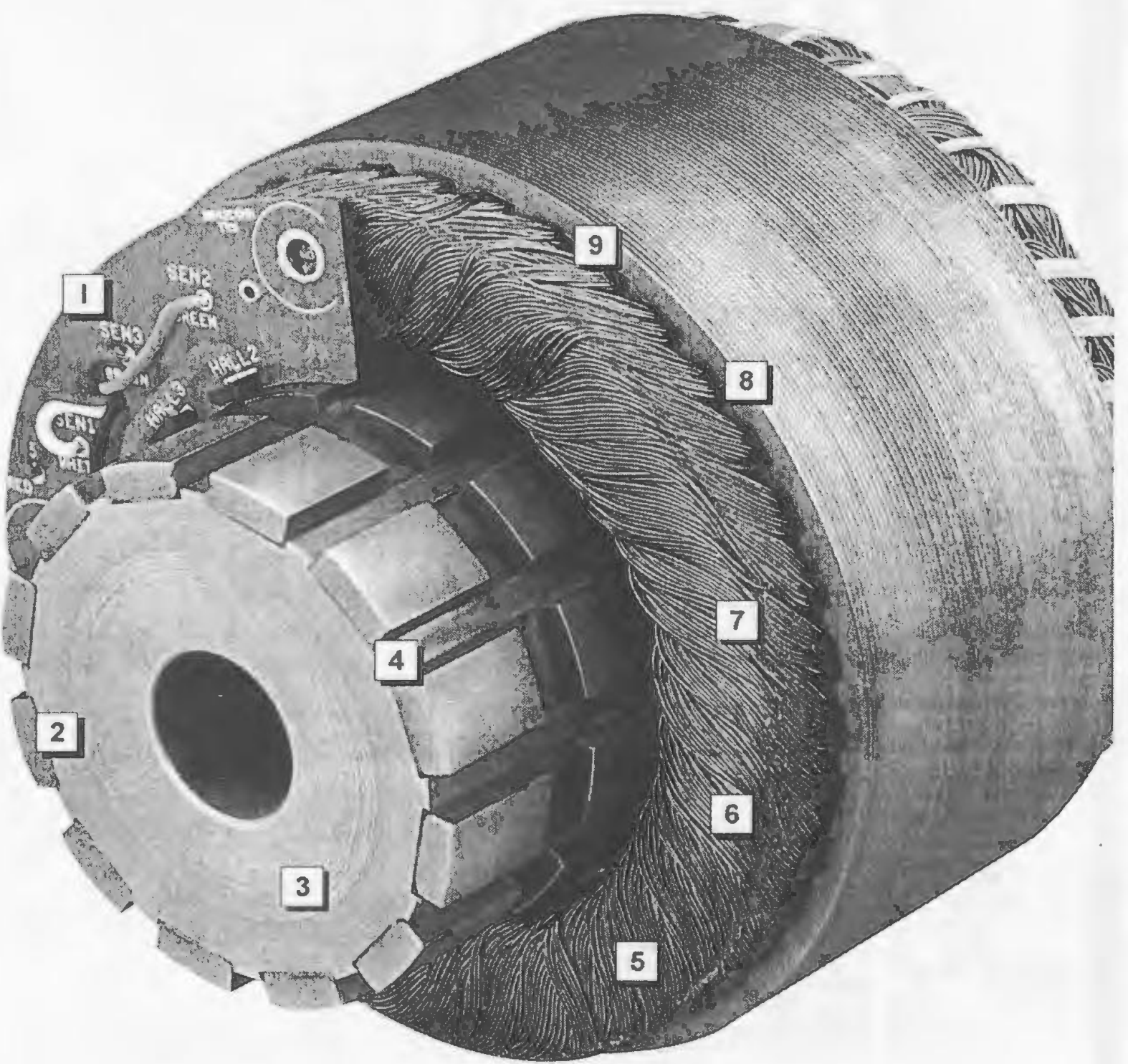


1 Pre-installed Integral Commutation Board with Hall Effects is prealigned for easy assembly. Motor and feedback as integrated unit.

\section{Rare Earth Magnets}

provide high flux in a small volume, high resistance to thermal demagnetizing

\section{Rotor Assembly}

for easy mounting directly on the drive shaft with or without keyway.

\section{Machined Grooves}

to securely lock magnets to rotor and ensures optimized radial location.

\section{Class $\mathrm{H}$ Insulation}

for high temperature operation (up to $155^{\circ} \mathrm{C}$ ) meeting UL approved requirements.

\section{6}

\section{High Density Copper Winding}

for low thermal resistance and consistent performance across all motors.

\section{7}

\section{Minimized End Turns}

to maximize performance. Formed to minimize motor size.

8

\section{Skewed Laminations}

with odd slot counts reduce cogging for precise rotary motion with drastically reduced torque ripple even at low speeds.

\section{9}

\section{What goes into our}

\section{Frameless Kit Motors...}

Our direct drive brushless kit motors consist of three components:

- The stator and winding

- The rotor with high energy product neodymium magnets

- Hall sensor device for motor commutation

\section{What comes out of our} Frameless Kit Motors...

- High Torque - from $0.06 \mathrm{Nm}$ $(0.5$ in $\mathrm{lb})$ to $9.7 \mathrm{Nm}(85.6 \mathrm{in} \mathrm{lb})$

- High Speeds - up to 50,000 RPM

- Superior Performance - high stiffiness and better response

- High Reliability - no mechanical transmission devices (couplings, flanges)

- Compact Design - minimizes producl size

- Low Cogging - unique magnetic circuit design decreases cogging

- No RFI-EMI generation

\section{Optimized Slot Fill}

for maximum torque-to-size ratio hand inserted to obtain highest slot fill possible maximizing ampere-tums.

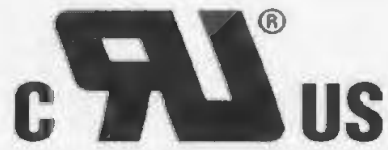




\section{Framaloss Motors series:}

\section{K032 to K0254 Motors}

Performance Specifications (six step/trapezoidal commutation)

\begin{tabular}{|c|c|c|c|c|c|c|c|c|c|c|c|c|c|c|c|}
\hline \multirow{3}{*}{$\begin{array}{l}\text { Frame } \\
\text { Size } \\
\text { K032025 }\end{array}$} & \multicolumn{2}{|c|}{$\begin{array}{l}\text { Slack } \\
\text { Length }\end{array}$} & $\begin{array}{l}\text { Continuous } \\
\text { Torque (1) }\end{array}$ & we (1) & & que & \multicolumn{2}{|c|}{$\begin{array}{c}\begin{array}{c}\text { Motor } \\
\text { Constant }\end{array} \\
K_{m}\end{array}$} & \multirow{2}{*}{$\begin{array}{c}\text { Core } \\
\text { Loss } \\
P_{C} \\
\text { W@1kRPM }\end{array}$} & \multirow{2}{*}{\multicolumn{2}{|c|}{$\begin{array}{c}\begin{array}{c}\text { Rotor* } \\
\text { Inertia }\end{array} \\
J_{m} \\
\left(g m \mathrm{~cm} \mathrm{sec}^{2}\right)\left(0 z \text { in } \sec ^{2}\right)\end{array}$}} & \multirow{2}{*}{$\begin{array}{c}\text { Electrical } \\
\text { Time } \\
\text { Constant } \\
T_{C} \\
\text { (msec) }\end{array}$} & \multirow{2}{*}{$\begin{array}{l}\text { Thermal } \\
\text { Resistance } \\
\left({ }^{\circ} \mathrm{C} / \mathrm{W}\right)\end{array}$} & \multicolumn{2}{|c|}{ Weight } \\
\hline & $(\mathrm{mm})$ & (in) & (Nm) & (or in) & (Nm) & (oz in) & $(\mathrm{Nm} / \sqrt{\mathrm{W}})$ & $(0 z$ in $/ \sqrt{W})$ & & & & & & (kg) & (oz) \\
\hline & 6.35 & 0.25 & 0.044 & 6.3 & 0.095 & 13.5 & 0.009 & 1.25 & 0.03 & 0.0016 & 0.000022 & 0.21 & 3.44 & 0.042 & 1.5 \\
\hline K032050 & 12.7 & 0.5 & 0.08 & 11.4 & 0.188 & 27 & 0.016 & 2 & 0.06 & 0.0032 & 0.000045 & 0.35 & 3.44 & 0.068 & 2.4 \\
\hline K032075 & 19.05 & 0.75 & 0.11 & 15.7 & 0.281 & 40 & 0.022 & 3 & 0.09 & 0.0048 & 0.000067 & 0.44 & 3.44 & 0.096 & 3.4 \\
\hline K032100 & 25.4 & 1 & 0.136 & 19.4 & 0.375 & 54 & 0.027 & 4 & 0.12 & 0.0064 & 0.000089 & 0.5 & 3.44 & 0.122 & 4.3 \\
\hline K032150 & 38.1 & 1.5 & 0.181 & 25.8 & 0.544 & 77.7 & 0.036 & 5.15 & 0.18 & 0.0096 & 0.000134 & 0.6 & 3.44 & 0.173 & 6.1 \\
\hline K032200 & 50.8 & 2 & 0.22 & 31.1 & 0.654 & 93.4 & 0.044 & 6.25 & 0.24 & 0.013 & 0.000178 & 0.66 & 3.44 & 0.26 & 9.2 \\
\hline K032300 & 76.2 & 3 & 0.33 & 46.5 & 0.99 & 139.5 & 0.054 & 7.56 & 0.36 & 0.0192 & 0.000268 & 0.7 & 3.44 & 0.36 & 12.8 \\
\hline K044025 & 6.35 & 0.25 & 0.119 & 17 & 0.357 & 50 & 0.02 & 3 & 0.11 & 0.0072 & 0.0001 & 0.39 & 2.36 & 0.085 & 3 \\
\hline K044050 & 12.7 & 0.5 & 0.214 & 30.6 & 0.642 & 90 & 0.035 & 5 & 0.24 & 0.014 & 0.0002 & 0.62 & 2.36 & 0.133 & 5 \\
\hline K044075 & 19.05 & 0.75 & 0.297 & 42.4 & 0.891 & 127 & 0.049 & 7 & 0.37 & 0.022 & 0.0003 & 0.76 & 2.36 & 0.200 & 7 \\
\hline K044100 & 25.4 & 1 & 0.364 & 52 & 1.092 & 156 & 0.06 & 9 & 0.49 & 0.03 & 0.00041 & 0.89 & 2.36 & 0.224 & 8 \\
\hline K044150 & 38.1 & 1.5 & 0.501 & 71 & 1.510 & 213 & 0.08 & 11.4 & 0.74 & 0.044 & 0.00061 & 1.05 & 2.36 & 0.311 & 11 \\
\hline K044200 & 50.8 & 2 & 0.607 & 86 & 1.820 & 258 & 0.097 & 13.8 & 1.11 & 0.06 & 0.00082 & 1.12 & 2.36 & 0.399 & 14.1 \\
\hline K044300 & 76.2 & 3 & 0.96 & 136.0 & 2.88 & 408 & 0.13 & 18.3 & 1.48 & 0.088 & 0.00122 & 1.3 & 2.36 & 0.549 & 19.4 \\
\hline K064025 & 6.35 & 0.25 & 0.31 & 44.3 & 0.93 & 133 & 0.048 & 6.88 & 0.37 & 0.046 & 0.00064 & 0.59 & 1.68 & 0.142 & 5 \\
\hline K064050 & 12.7 & 0.5 & 0.62 & 89 & 1.87 & 267 & 0.087 & 12.48 & 0.78 & 0.092 & 0.00128 & 0.98 & 1.68 & 0.286 & 10.1 \\
\hline K064075 & 19.05 & 0.75 & 0.85 & 121.7 & 2.56 & 365 & 0.122 & 17.44 & 1.19 & 0.138 & 0.00192 & 1.26 & 1.68 & 0.427 & 15.1 \\
\hline K064100 & 25.4 & 1 & 1.08 & 154 & 3.23 & 462 & 0.15 & 21.44 & 1.6 & 0.184 & 0.00256 & 1.47 & 1.68 & 0.572 & 20.2 \\
\hline K064150 & 38.1 & 1.5 & 1.46 & 209 & 4.39 & 627 & 0.204 & 29.12 & 2.37 & 0.276 & 0.00384 & $1 . \pi$ & 1.68 & 0.846 & 30.2 \\
\hline K064200 & 50.8 & 2 & 2.16 & 308 & 6.47 & 924 & 0.244 & 34.88 & 3.23 & 0.369 & 0.00512 & 1.97 & 1.68 & 1.129 & 40.3 \\
\hline K064300 & 76.2 & 3 & 2.91 & 410 & 8.73 & 1,230 & 0.33 & 46.6 & 4.74 & 0.552 & 0.00768 & 2.6 & 1.68 & 1.701 & 60.5 \\
\hline K089050 & 12.7 & 0.5 & 1.307 & 186.7 & 3.92 & 560 & 0.164 & 23.36 & 2.14 & 0.38 & 0.00528 & 1.26 & 1.02 & 0.498 & 17.6 \\
\hline K089075 & 19.05 & 0.75 & 1.96 & 280 & 5.88 & 840 & 0.235 & 33.6 & 3.35 & 0.576 & 0.008 & 1.64 & 1.02 & 0.747 & 26.4 \\
\hline K089100 & 25.4 & 1 & 2.618 & 374 & 7.84 & 1,120 & 0.283 & 40.64 & 4.42 & 0.792 & 0.0011 & 1.92 & 1.02 & 0.996 & 35.2 \\
\hline K089150 & 38.1 & 1.5 & 3.92 & 560 & 11.76 & 1,680 & 0.381 & 54.4 & 6.7 & 1.15 & 0.016 & 2.33 & 1.02 & 1.494 & 52.8 \\
\hline K089200 & 50.8 & 2 & 4.291 & 613 & 12.87 & 1,839 & 0.466 & 66.56 & 8.95 & 1.51 & 0.021 & 2.6 & 1.02 & 1.992 & 70.4 \\
\hline Kов9300 & 76.2 & 3 & 7.13 & 1,004 & 21.4 & 3,012 & 0.631 & 88.9 & 13.4 & 2.30 & 0.032 & 2.9 & 1.02 & 3.00 & 105.6 \\
\hline
\end{tabular}

(1) = Housed in a motor frame.

Typically an aluminum cylinder with $6.35 \mathrm{~mm}(0.250 \mathrm{in})$ thick walls,

$\mathrm{K032}$ K044 and K064 mounted to a $152 \mathrm{~mm} \times 152 \mathrm{~mm} \times 12.5 \mathrm{~mm}$ (6in $\times 6$ in $\times 0.5 \mathrm{in}$ ) aluminum plate K089 mounted to a $203 \mathrm{~mm} \times 203 \mathrm{~mm} \times 12.5 \mathrm{~mm}(8 \mathrm{in} \times 8$ in $\times 0.5 \mathrm{in})$ aluminum plate

- See Engineering Reference page 297 for inertia discussion.
Pole Count

K032 is 4

$\mathrm{K} 044$ is 6

$\mathrm{K} 064$ is 8

K089 is 12 


\begin{tabular}{|c|c|c|c|c|c|c|c|c|c|c|c|c|c|c|c|}
\hline \multirow[t]{2}{*}{$\begin{array}{l}\text { Frame } \\
\text { Size }\end{array}$} & \multicolumn{2}{|c|}{$\begin{array}{l}\text { Stack } \\
\text { Length }\end{array}$} & \multicolumn{2}{|c|}{$\begin{array}{c}\text { Continuous } \\
\text { Torque } \\
{ }^{(t)} \\
T_{C}\end{array}$} & \multicolumn{2}{|c|}{$\begin{array}{c}\text { Peak } \\
\text { Torque } \\
T_{p}\end{array}$} & \multicolumn{2}{|c|}{$\begin{array}{l}\text { Motor } \\
\text { Constant } \\
\mathrm{K}_{\mathrm{m}}\end{array}$} & \multirow{2}{*}{$\begin{array}{c}\text { Core } \\
\text { Loss } \\
P_{C} \\
\text { W@1kRPM }\end{array}$} & \multirow{2}{*}{\multicolumn{2}{|c|}{$\begin{array}{c}\begin{array}{c}\text { Rotor" } \\
\text { Inertia }\end{array} \\
J_{m} \\
\left.(g m \mathrm{~cm} \mathrm{sec})^{2}\right)\left(0 z \text { in } \mathrm{sec}^{2}\right)\end{array}$}} & \multirow{2}{*}{$\begin{array}{l}\text { Electrical } \\
\text { Time } \\
\text { Constant } \\
T_{C} \\
\text { (msec) }\end{array}$} & \multirow{2}{*}{$\begin{array}{l}\text { Thermal } \\
\text { Resistance } \\
\left({ }^{\circ} \mathrm{C} / \mathrm{W}\right)\end{array}$} & \multicolumn{2}{|c|}{$\begin{array}{l}\text { Weight } \\
\text { Wm }\end{array}$} \\
\hline & $(\mathrm{mm})$ & (in) & $(\mathrm{Nm})$ & $(0 z \mathrm{ln})$ & (Nm) & $(0 z \mathrm{in})$ & $(\mathrm{Nm} / \sqrt{\mathrm{W}})$ & $(0 z$ in $N \sqrt{W})$ & & & & & & (kg) & $(0 z)$ \\
\hline K375050 & 12.7 & 0.5 & 1.715 & 245 & 5.14 & 734 & 0.153 & 21.8 & 1.2 & 0.324 & 0.0045 & 1.45 & 1.02 & 0.611 & 21.6 \\
\hline K375075 & 19.05 & 0.75 & 2.401 & 343 & 7.19 & 1,027 & 0.213 & 30.4 & 1.8 & 0.497 & 0.0069 & 1.9 & 1.02 & 0.917 & 32.4 \\
\hline K375100 & 25.4 & 1 & 3.003 & 429 & 9 & 1,286 & 0.267 & 38.1 & 2.4 & 0.655 & 0.0091 & 2.24 & 1.02 & 1.095 & 38.7 \\
\hline K375150 & 38.1 & 1.5 & 4.025 & 575 & 12.6 & 1,723 & 0.357 & 51 & 3.6 & 1.01 & 0.014 & 2.68 & 1.02 & 1.554 & 54.9 \\
\hline K375200 & 50.8 & 2 & 4.935 & 705 & 14.82 & 2,117 & 0.438 & 62.6 & 4.8 & 1.30 & 0.018 & 3.03 & 1.02 & 2.02 & 71.1 \\
\hline K375300 & 76.2 & 3 & 6.69 & 942 & 20.1 & 2,826 & 0.592 & 83.4 & 7.2 & 2.02 & 0.028 & 3.5 & 1.02 & 2.94 & 103.5 \\
\hline K127050 & 12.7 & 0.5 & 3.94 & 563 & 11.83 & 1,690 & 0.29 & 41.4 & 4.7 & 1.15 & 0.016 & 2.38 & 0.7 & 1.087 & 38.4 \\
\hline K127100 & 25.4 & 1 & 6.98 & 997 & 21.04 & 3,006 & 0.513 & 73.3 & 9.6 & 2.38 & 0.033 & 3.7 & 0.7 & 1.766 & 62.4 \\
\hline K127150 & 38.1 & 1.5 & 9.56 & 1,365 & 28.66 & 4,094 & 0.702 & 100.3 & 14.5 & 3.53 & 0.049 & 4.6 & 0.7 & 2.355 & 83.2 \\
\hline K127200 & 50.8 & 2 & 11.75 & 1,678 & 35.24 & 5,034 & 0.864 & 123.4 & 19.4 & 4.75 & 0.066 & 5.23 & 0.7 & 2.99 & 105.6 \\
\hline K127300 & 76.2 & 3 & 16.1 & 2,263 & 48.3 & 6,789 & 1.18 & 166.1 & 29.0 & 7.06 & 0.098 & 6.1 & 0.7 & 3.65 & 147.2 \\
\hline K500050 & 12.7 & 0.5 & 3.05 & 435 & 9.14 & 1,306 & 0.224 & 32 & 1.6 & 1.15 & 0.016 & 2.6 & 0.7 & 1.087 & 38.4 \\
\hline K500100 & 25.4 & 1 & 5.49 & 784 & 16.46 & 2,352 & 0.403 & 57.6 & 3 & 2.30 & 0.032 & 4.5 & 0.7 & 1.766 & 62.4 \\
\hline K500150 & 38.1 & 1.5 & 7.92 & 1,131 & 23.76 & 3,394 & 0.582 & 83.2 & 4.8 & 3.46 & 0.048 & 6 & 0.7 & 2.355 & 83.2 \\
\hline K500200 & 50.8 & 2 & 9.44 & 1,349 & 28.32 & 4,046 & 0.694 & 99.2 & 6.4 & 4.61 & 0.064 & 6.4 & 0.7 & 2.988 & 105.6 \\
\hline K500300 & 76.2 & 3 & 15.4 & 2,170 & 46.2 & 6,510 & 1.13 & 159.3 & 8.6 & 6.92 & 0.096 & 8.0 & 0.7 & 4.18 & 147.2 \\
\hline K178050 & 12.7 & 0.5 & 10.12 & 1,445 & 16.18 & 2,312 & 0.627 & 89.6 & 9.1 & 4.75 & 0.066 & 4.16 & 0.5 & 2.4 & 84.8 \\
\hline K178100 & 25.4 & 1 & 18.06 & 2,580 & 28.89 & 4,127 & 1.12 & 160 & 18.7 & 9.36 & 0.13 & 6.54 & 0.5 & 3.71 & 131.2 \\
\hline K178150 & 38.1 & 1.5 & 24.75 & 3.535 & 39.59 & 5,655 & 1.534 & 219 & 14.4 & 14.4 & 0.2 & 8.15 & 0.5 & 4.98 & 176 \\
\hline K178200 & 50.8 & 2 & 30.7 & 4,386 & 49.12 & 7,017 & 1.904 & 272 & 18.7 & 18.7 & 0.26 & 9.31 & 0.5 & 6.34 & 224 \\
\hline K178300 & 76.2 & 3 & 43.1 & 6,078 & 69.0 & 9,724 & 2.68 & 377 & 28.8 & 28.8 & 0.4 & 12.2 & 0.5 & 8.90 & 313.6 \\
\hline K700050 & 12.7 & 0.5 & 5.05 & 722 & 8.09 & 1.155 & 0.314 & 44.8 & 7.70 & 7.7 & 0.107 & 2.9 & 0.4 & 2.4 & 84.8 \\
\hline K700100 & 25.4 & 1 & 9.57 & 1,367 & 15.32 & 2,188 & 0.594 & 84.8 & 15.4 & 15.4 & 0.214 & 5 & 0.4 & 3.71 & 131.2 \\
\hline K700150 & 38.1 & 1.5 & 13.55 & 1,935 & 21.67 & 3,096 & 0.84 & 120 & 23.2 & 23.2 & 0.322 & 6.8 & 0.4 & 4.98 & 176 \\
\hline K700200 & 50.8 & 2 & 17.52 & 2,503 & 28.03 & 4,004 & 1.086 & 155.2 & 30.9 & 31 & 0.429 & 8.5 & 0.4 & 6.34 & 224 \\
\hline K700300 & 76.2 & 3 & 27.5 & 3,876 & 44.0 & 6,200 & 1.53 & 215 & 46.4 & 46.4 & 0.644 & 10.7 & 0.4 & 8.91 & 313.6 \\
\hline K254050 & 12.7 & 0.5 & 18.78 & 2,683 & 30.04 & 4,292 & 1.043 & 149 & 17.9 & 17.9 & 0.248 & 6.05 & 0.4 & 4.48 & 158.4 \\
\hline K254100 & 25.4 & 1 & 33.92 & 4,846 & 54.27 & 7,753 & 1.883 & 269 & 35.5 & 35.5 & 0.493 & 9.63 & 0.4 & 6.79 & 240 \\
\hline K254150 & 38.1 & 1.5 & 46.84 & 6,692 & 74.95 & 10,707 & 2.597 & 371 & 53.1 & 53.1 & 0.738 & 12.5 & 0.4 & 9.056 & 320 \\
\hline K254200 & 50.8 & 2 & 58.35 & 8,336 & 93.37 & 13,338 & 3.234 & 462 & 71.0 & 71 & 0.986 & 14.7 & 0.4 & 11.32 & 400 \\
\hline K254300 & 76.2 & 3 & 80.9 & 11,400 & 129.4 & 18,240 & 4.49 & 632 & 106.2 & 106 & 1.478 & 18.0 & 0.4 & 15.9 & 560 \\
\hline
\end{tabular}

(1) = Housed in a motor frame. Typically an aluminum cylinder with $6.35 \mathrm{~mm}(0.250 \mathrm{in})$ thick walls, $\mathrm{K} 375, \mathrm{~K} 127$ and $\mathrm{K} 500$ mounted to a $305 \mathrm{~mm} \times 305 \mathrm{~mm} \times 12.5 \mathrm{~mm}$ (12in $\times 12 \mathrm{in} \times 0.5 \mathrm{in}$ ) aluminum plate. K178, K700 and K254 mounted to a $406 \mathrm{~mm} \times 406 \mathrm{~mm} \times 12.5 \mathrm{~mm}$ (16in $\times 16 \mathrm{in} \times 0.5 \mathrm{in}$ ) aluminum plate. - See Engineering Reference page 297 for inertia discussion.
Pole Count:

K127 \& K375 are 12

K700 \& K500 are 8

K178 \& K254 are 18 


\section{Frameless Motors series: K032 to K0254 Motors}

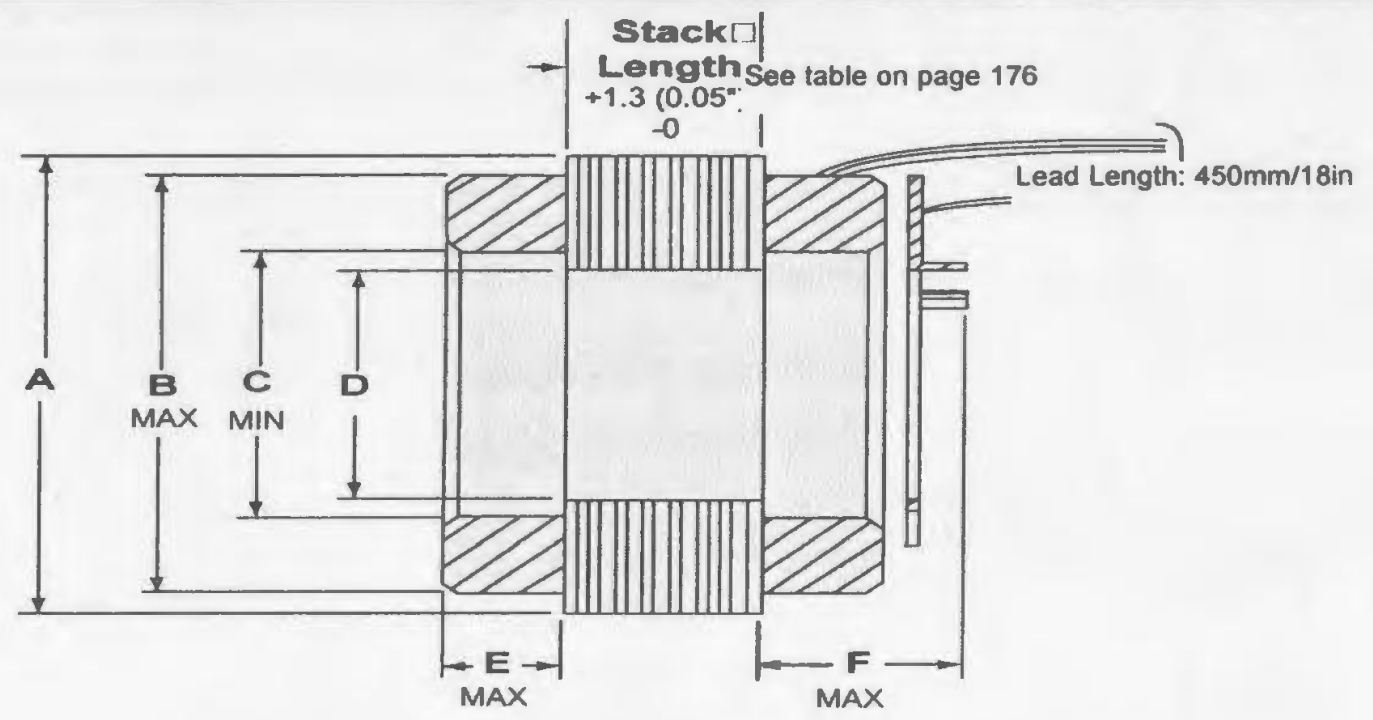

Stator Outline

\begin{tabular}{|c|c|c|c|c|c|c|c|c|c|c|c|c|}
\hline \multirow{2}{*}{$\begin{array}{c}\text { Frame } \\
\text { Size }\end{array}$} & \multicolumn{2}{|c|}{ O.D. } & \multicolumn{2}{|c|}{$\begin{array}{l}\text { B } \\
\text { End Turns } \\
\text { O.D. }\end{array}$} & \multicolumn{2}{|c|}{$\begin{array}{l}\text { C } \\
\text { End Turns } \\
\text { I.D. }\end{array}$} & \multicolumn{2}{|c|}{$\begin{array}{c}\text { D } \\
\text { I.D. }\end{array}$} & \multicolumn{2}{|c|}{$\begin{array}{l}\text { E } \\
\text { End Turns } \\
\text { Length }\end{array}$} & \multicolumn{2}{|c|}{$\begin{array}{c}\text { F } \\
\text { Commutation } \\
\text { Length }\end{array}$} \\
\hline & $(\mathrm{mm})$ & (in) & $(\mathrm{mm})$ & (in) & $(\mathrm{mm})$ & (in) & $(\mathrm{mm})$ & (in) & $(\mathrm{mm})$ & (in) & (mm) & (in) \\
\hline \multirow{2}{*}{ K032 } & 31.78 & 1.251 & 27.94 & 1.1 & 16.51 & 0.65 & 15.06 & 0.593 & 6.4 & 0.25 & 14.5 & 0.57 \\
\hline & 31.75 & 1.25 & & & & & 14.8 & 0.583 & & & & \\
\hline \multirow{2}{*}{ K044 } & 44.48 & 1.751 & 40.64 & 1.6 & 26.16 & 1.03 & 22.35 & 0.88 & 7.9 & 0.31 & 16.5 & 0.65 \\
\hline & 44.42 & 1.749 & & & & & 22.09 & 0.87 & & & & \\
\hline \multirow{2}{*}{ K064 } & 63.52 & 2.501 & 60.7 & 2.39 & 38.1 & 1.5 & 35.18 & 1.385 & 9.65 & 0.38 & 17.5 & 0.69 \\
\hline & 63.47 & 2.499 & & & & & 34.92 & 1.375 & & & & \\
\hline \multirow{2}{*}{ K089 } & 88.92 & 3.501 & 85.8 & 3.38 & 54.6 & 2.15 & 53.47 & 2.105 & 9.91 & 0.39 & 17.5 & 0.69 \\
\hline & 88.87 & 3.499 & & & & & 53.21 & 2.095 & & & & \\
\hline \multirow{2}{*}{ K375 } & 95.28 & 3.751 & 88.9 & 3.5 & 53.32 & 2.06 & 50.93 & 2.005 & 12.7 & 0.5 & 19.5 & 0.77 \\
\hline & 95.22 & 3.749 & & & & & 50.67 & 1.995 & & & & \\
\hline \multirow[t]{2}{*}{ K127 } & 127.02 & 5.001 & 122.17 & 4.81 & 74.17 & 2.92 & 72.49 & 2.854 & 12.7 & 0.5 & 19.5 & 0.77 \\
\hline & 126.97 & 4.999 & . & & & & 72.23 & 2.844 & & & & \\
\hline \multirow[t]{2}{*}{ K500 } & 127.05 & 5.002 & 115.32 & 4.54 & 70.6 & 2.78 & 68.2 & 2.685 & 20.5 & 0.81 & 30.5 & 1.2 \\
\hline & 126.95 & 4.998 & & & & & 67.94 & 2.675 & & & & \\
\hline \multirow[t]{2}{*}{ K178 } & 177.88 & 7.003 & 172.72 & 6.8 & 111.51 & 4.39 & 110.64 & 4.355 & 20.3 & 0.8 & * & \\
\hline & 177.72 & 6.997 & & & & & 110.38 & 4.345 & & & & \\
\hline \multirow[t]{2}{*}{ K700 } & 177.88 & 7.003 & 158.24 & 6.23 & 117.6 & 4.63 & 115.19 & 4.535 & 18.8 & 0.74 & * & \\
\hline & 177.72 & 6.997 & & & & & 114.93 & 4.525 & & & & \\
\hline \multirow[t]{2}{*}{ K254 } & 254.07 & 10.003 & 253.26 & 9.971 & 165.1 & 6.5 & 157.61 & 6.205 & 19.6 & 0.77 & $\star$ & \\
\hline & 253.92 & 9.997 & & & & & 157.35 & 6.195 & & & & \\
\hline
\end{tabular}



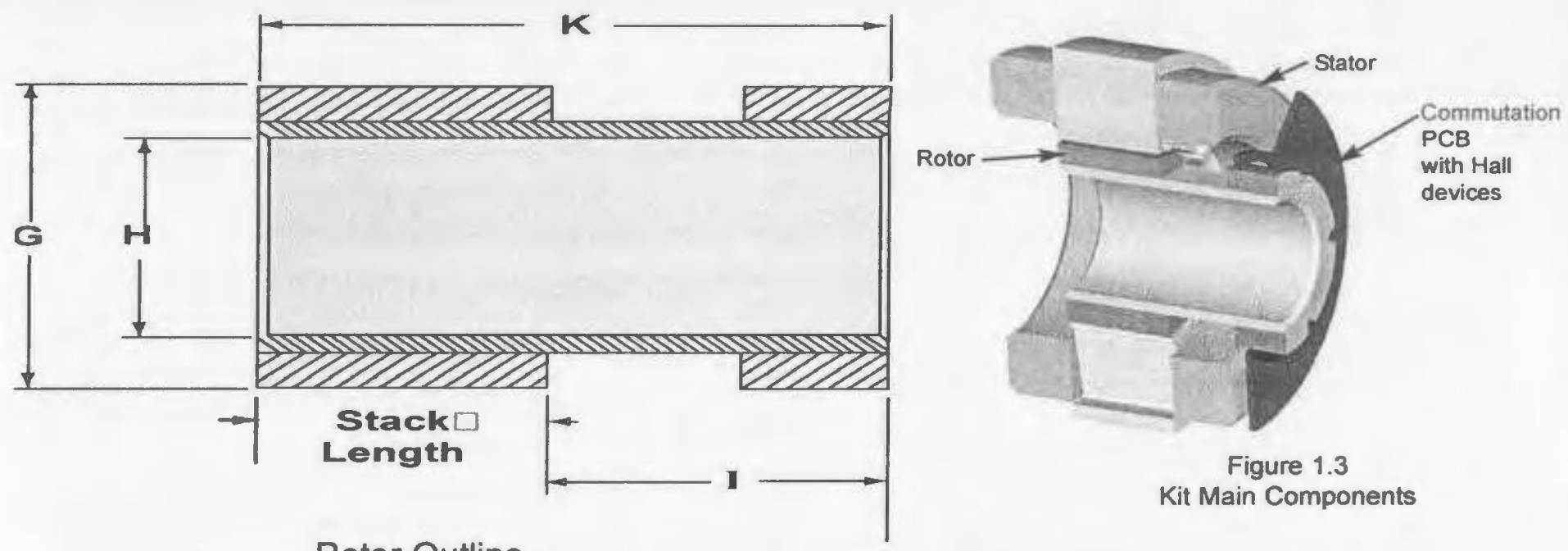

Figure 1.3

Kit Main Components

Rotor Outline

\begin{tabular}{|c|c|c|c|c|c|c|c|}
\hline \multirow{2}{*}{$\begin{array}{l}\text { Frame } \\
\text { Size }\end{array}$} & \multicolumn{2}{|c|}{$\begin{array}{c}\mathbf{G} \\
\text { Rotor } 0.0 .\end{array}$} & \multicolumn{2}{|c|}{$\begin{array}{c}\text { H } \\
\text { Rotor I.D. }\end{array}$} & \multicolumn{2}{|c|}{$\begin{array}{l}\text { I } \\
\text { Commutation Magnet } \\
\text { Length }\end{array}$} & \multirow{4}{*}{$\begin{array}{l}\text { without Commutation: } \\
K=\text { Stack Length }+0.76 \mathrm{~mm} \text { (0.030in) }\end{array}$} \\
\hline & $(\mathbf{m m})$ & (in) & $(\mathbf{m m})$ & (in) & $(\mathrm{mm})$ & (in) & \\
\hline \multirow{2}{*}{ K032 } & 13.94 & 0.549 & 7.62 & 0.3 & 13.21 & 0.52 & \\
\hline & 13.89 & 0.547 & 7.59 & 0.299 & & & \\
\hline \multirow{2}{*}{ K044 } & 21.23 & 0.836 & 13.97 & 0.55 & 14.73 & 0.58 & \\
\hline & 21.18 & 0.834 & 13.94 & 0.549 & & & with Commutation: \\
\hline \multirow{2}{*}{ K064 } & 34.04 & 1.34 & 23.52 & 0.926 & 16.51 & 0.65 & $K=$ Stack Length $+1+0.76 \mathrm{~mm}$ (0.030in) \\
\hline & 33.98 & 1.338 & 23.49 & 0.925 & & & \\
\hline \multirow{2}{*}{ K089 } & 51.84 & 2.041 & 40.64 & 1.6 & 16.71 & 0.66 & \\
\hline & 51.79 & 2.039 & 40.61 & 1.599 & & & \\
\hline \multirow{2}{*}{ K375 } & 49.28 & 1.94 & 38.1 & 1.5 & 19.56 & 0.77 & 1 \\
\hline & 49.15 & 1.935 & 38.07 & 1.499 & & & \\
\hline \multirow{2}{*}{ K127 } & 71.15 & 2.801 & 58.42 & 2.3 & 19.56 & 0.77 & \\
\hline & 71.09 & 2.799 & 58.39 & 2.299 & . & & . \\
\hline \multirow{2}{*}{ K500 } & 66.54 & 2.62 & 50.83 & 2.001 & 28.52 & 1.12 & \\
\hline & 66.5 & 2.618 & 50.8 & 2 & & & \\
\hline \multirow{2}{*}{ K178 } & 109.2 & 4.292 & 95.76 & 3.77 & * & & \\
\hline & 108.9 & 4.29 & 95.73 & 3.769 & & & \\
\hline \multirow{2}{*}{ K700 } & 113.54 & 4.47 & 95.25 & 3.75 & * & & \\
\hline & 113.49 & 4.468 & 95 & 3.74 & & & \\
\hline \multirow{2}{*}{ K254 } & 156.16 & 6.148 & 140.46 & 5.53 & * & & \\
\hline & 156.11 & 6.146 & 140.44 & 5.529 & & & \\
\hline
\end{tabular}




\section{Framaloss Motors series: Winding Selection}

e selection of a particular frame size and winding for an plication is dependent on:

Volume (diameter and length) requirement

Power (torque and speed) requirement

Voltage and current available or required

e first two items are dependent on the load and performance ecifications of the application. They result in the selection of a rticular frame size (032 through 254) and stack length.

e winding to be used will then be determined by voltage and rent available or required.

Voltage: The bus voltage and maximum speed will determine the required voltage constant $\left(K_{E}\right)$.

Current: The maximum load and acceleration will determine the amount of current required, determined by the torque constant $\left(\mathrm{K}_{\mathrm{T}}\right)$ associated with the selected voltage constant.

ample: Assume a requirement of $1,000 \mathrm{RPM}$ at $50 \mathrm{oz}$ in

If a motor with a particular winding having $K_{E}=18.24 \mathrm{~V} / 1,000 \mathrm{RPM}$ and $K_{\mathrm{T}}=24.62 \mathrm{oz} \mathrm{in} / \mathrm{amp}$ is chosen, it will now require a voltage (BEMF) of 18 volts and current of 2 amp.
NOTE: $K_{E}$ and $K_{r}$ are directly proportional to each other. Increasing $K_{E}$ will also increase $K_{T}$; Decreasing $K_{E}$ will also decrease $\mathrm{K}_{\mathrm{T}}$.

The result is that as the voltage requirement changes, the current requirement changes inversely.

Bayside has a range of $\mathbf{2 7}$ windings available for each frame size and stack length, providing for virtually any practical combination of voltage and current required for your application.

The following pages show just a small representative sample of speed/torque curves for each of the 10 frame sizes available.

For the $044,064,089$ and 127 frame sizes, the speed/torque curves are for stators that are used in the standard BM / GM motor products.

They make a good starting point for determining your specific application requirements and working with Bayside application engineers to choose the proper motor size and power.

The following table lists the range of $K_{E}$ and $K_{T}$ available for each of the 10 frame sizes.

Detailed information for all these windings can be found on the web site: mmarbaysidemotion.com

\begin{tabular}{|c|c|c|c|c|c|c|}
\hline \multirow{2}{*}{$\begin{array}{l}\text { Frame } \\
\text { Size }\end{array}$} & \multicolumn{2}{|c|}{ Stack Range } & \multicolumn{2}{|c|}{$\mathbf{K}_{\mathbf{E}}$ Range } & \multicolumn{2}{|c|}{$\mathbf{K}_{\mathrm{T}}$ Range } \\
\hline & $(\mathrm{mm})$ & (in) & (V/1,000 RPM) & (V/rad/sec) & (Nm/amp) & (oz in/amp) \\
\hline K032 & 6.35 to 50.8 & 0.25 to 2.00 & 0.14 to 65.52 & 0.0013 to 0.625 & 0.0013 to 0.625 & 0.18 to 88.45 \\
\hline K044 & 6.35 to 50.8 & 0.25 to 2.00 & 0.28 to 126.3 & 0.0027 to 1.2 & 0.0027 to 1.2 & 0.38 to 170.6 \\
\hline K064 & 6.35 to 50.8 & 0.25 to 2.00 & 0.66 to 291.8 & 0.0063 to 2.78 & 0.0063 to 2.78 & 0.89 to 394 \\
\hline K089 & 6.35 to 50.8 & 0.25 to 2.00 & 1.35 to 605 & 0.013 to 5.77 & 0.013 to 5.77 & 1.83 to 817 \\
\hline K375 & 6.35 to 50.8 & 0.25 to 2.00 & 1.27 to 566 & 0.012 to 5.40 & 0.012 to 5.40 & 1.71 to 765 \\
\hline K127 & 12.7 to 50.8 & 0.50 to 2.00 & 3.73 to 827 & 0.036 to 7.88 & 0.036 to 7.88 & 5.04 to 1116 \\
\hline K500 & 12.7 to 50.8 & 0.50 to 2.00 & 3.38 to 714 & 0.032 to 6.81 & 0.032 to 6.81 & 4.56 to 964 \\
\hline K178 & 12.7 to 50.8 & 0.50 to 2.00 & 8.26 to 1716 & 0.079 to 16.4 & 0.079 to 16.4 & 11.18 to 2,323 \\
\hline K700 & 12.7 to 50.8 & 0.50 to 2.00 & 4.14 to 872 & 0.039 to 8.31 & 0.039 to 8.31 & 5.59 to 1,177 \\
\hline K254 & 12.7 to 50.8 & 0.50 to 2.00 & 11.44 to 2,537 & 0.109 to 24.2 & 0.109 to 24.2 & 15.5 to 3,425 \\
\hline
\end{tabular}

NOTE: Longer stacks and special windings are available. Call 1-800-305-4555 


\section{Framaloss Motors series: Sneed/Toruue Gurves}

\section{K032150-TY}

$\mathrm{K}_{\mathrm{T}}=0.051 \mathrm{Nm} / \mathrm{amp}(7.19 \mathrm{oz}-\mathrm{in} / \mathrm{amp}) \quad R_{\mathrm{T}-\mathrm{T}}=2.05 \Omega \quad \mathrm{I}_{\mathrm{comt}}=3.6 \mathrm{amp}$ $K_{E}=0.051 \mathrm{v} / \mathrm{rad} / \mathrm{sec}(5.32 \mathrm{~V} / \mathrm{kRPM}) \mathrm{L}_{T-\mathrm{T}}=1.16 \mathrm{mH} \mathrm{I}_{\text {peak }}=10.8 \mathrm{amp}$

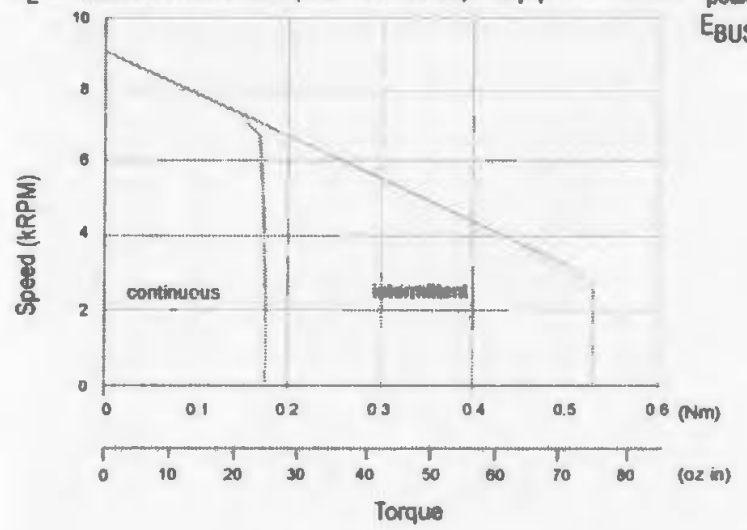

\section{K044300-8Y}

$\mathrm{K}_{\mathrm{T}}=0.28 \mathrm{Nm} / \mathrm{amp}(39.6 \mathrm{0z}-\mathrm{in} / \mathrm{amp}) \quad \mathrm{R}_{\mathrm{T}-\mathrm{T}}=4.8 \Omega \quad \mathrm{I}_{\text {cont }}=3 \mathrm{amp}$ $K_{E}=0.28 \mathrm{~V} / \mathrm{rad} / \mathrm{sec}(29.3 \mathrm{~V} / \mathrm{kRPM}) \quad \mathrm{L}_{T-T}=6.2 \mathrm{mH} \quad \mathrm{I}_{\text {peak }}=9 \mathrm{amp}$

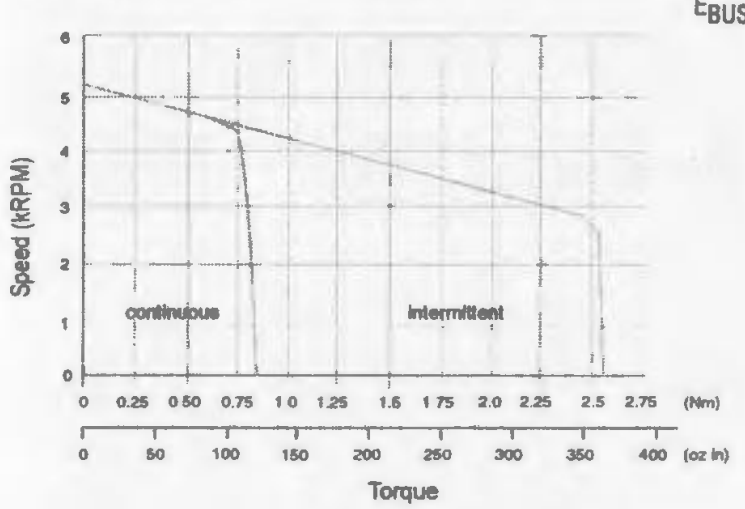

\section{K064300-6Y}

$\mathrm{K}_{\mathrm{T}}=0.42 \mathrm{Nm} / \mathrm{amp}(59.9 \mathrm{oz}-\mathrm{in} / \mathrm{amp}) \quad R_{\mathrm{T}-\mathrm{T}}=1.6 \Omega \quad \mathrm{I}_{\text {cont }}=7 \mathrm{amp}$

$K_{E}=0.42 \mathrm{~V} / \mathrm{rad} / \sec (44.3 \mathrm{~V} / \mathrm{kRPM}) \quad L_{T-T}=3.8 \mathrm{mH} \quad I_{\text {peak }}=21 \mathrm{amp}$ $E_{\text {Bus }}=160 \mathrm{VdC}$

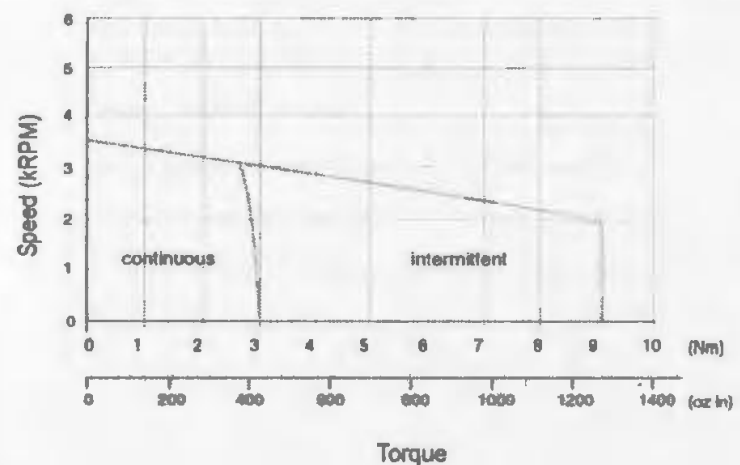

\section{K044150-FY}

$\mathrm{K}_{\mathrm{T}}=0.28 \mathrm{Nm} / \mathrm{amp}(39.6 \mathrm{az}-\mathrm{in} / \mathrm{amp}) \quad \mathrm{R}_{\mathrm{T}-\mathrm{T}}=11.8 \Omega \quad \mathrm{I}_{\text {cont }}=2 \mathrm{amp}$ $K_{E}=0.28 \mathrm{v} / \mathrm{rad} / \sec (29.3 \mathrm{~V} / \mathrm{kRPM}) \quad \mathrm{L}_{\mathrm{T}-\mathrm{T}}=12.5 \mathrm{mH} \mathrm{I}_{\text {peak }}=6 \mathrm{amp}$

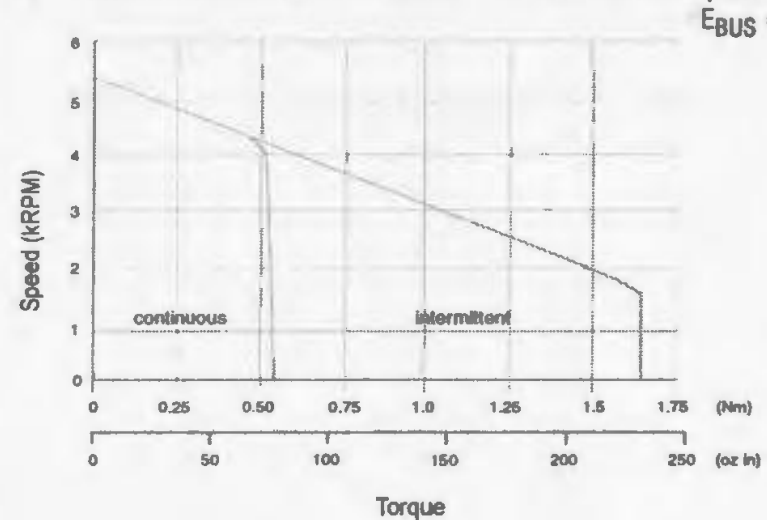

K064150-8Y

$\mathrm{K}_{\mathrm{T}}=0.33 \mathrm{Nm} / \mathrm{amp}$ (46.1 0z-in/amp) $\quad R_{T-\mathrm{T}}=2.5 \Omega \quad \mathrm{I}_{\text {cont }}=6 \mathrm{amp}$ $K_{E}=0.33 \mathrm{v} / \mathrm{rad} / \mathrm{sec}(34.1 \mathrm{~V} / \mathrm{KRPM}) \quad L_{T-T}=4.5 \mathrm{mH} \quad I_{\text {peak }}=18 \mathrm{amp}$ $E_{B U S}=160 \mathrm{Vdc}$

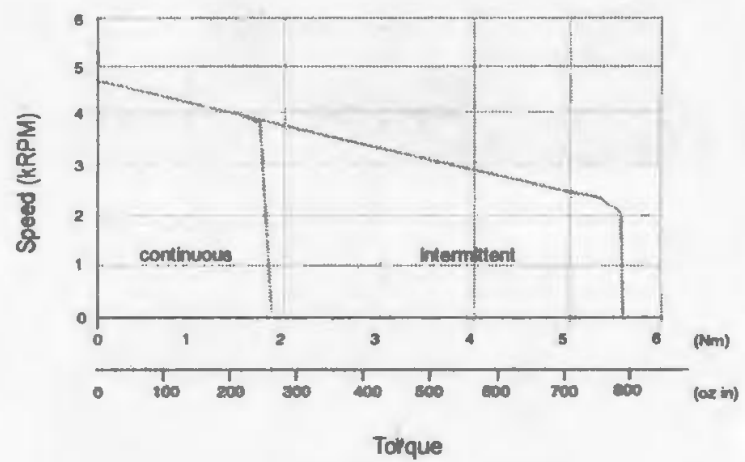

\section{K375150-6Y}

$K_{T}=0.41 \mathrm{Nm} / \mathrm{amp}(57.92 \mathrm{oz}-\mathrm{in} / \mathrm{amp}) \quad R_{\mathrm{T}-\mathrm{T}}=1.21 \Omega \quad \mathrm{I}_{\text {cont }}=10 \mathrm{amp}$ $K_{E}=0.41 \mathrm{~V} / \mathrm{rad} / \mathrm{sec}(47.82 \mathrm{~V} / \mathrm{kRPM}) \quad L_{T-T}=3.45 \mathrm{mH} I_{\text {peak }}=30 \mathrm{amp}$ $E_{\text {BUS }}=160 \mathrm{Vdc}$

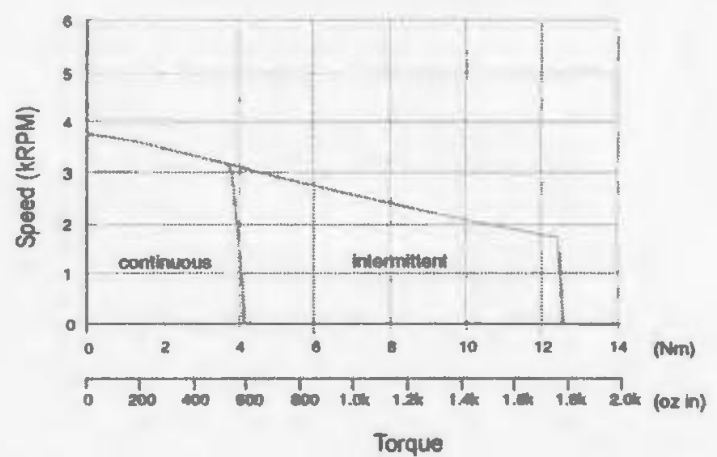




\section{Frameless Motors series: Sneed/Torulue Gurves}

\section{K089150-6Y}

$K_{T}=0.43 \mathrm{Nm} / \mathrm{amp}(61.60 z-\mathrm{in} / \mathrm{amp}) \quad R_{T-T}=1.2 \Omega \quad \mathrm{I}_{\text {cont }}=11 \mathrm{amp}$

$K_{E}=0.43 \mathrm{~V} / \mathrm{rad} / \mathrm{sec}(45.6 \mathrm{~V} / \mathrm{kRPM}) \quad \mathrm{L}_{T-T}=2.9 \mathrm{mH} \quad \mathrm{I}_{\text {peak }}=33 \mathrm{amp}$

$E_{\text {BuS }}=160 \mathrm{Vdc}$

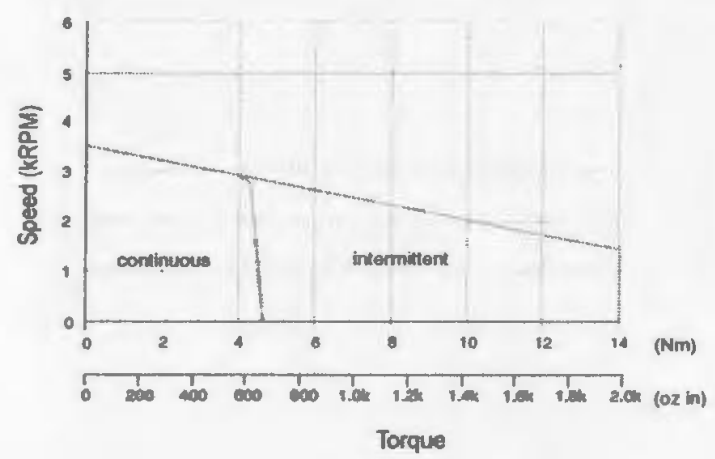

\section{K127250-4Y}

$K_{T}=0.61 \mathrm{Nm} / \mathrm{amp}(86.9 \mathrm{oz}-\mathrm{in} / \mathrm{amp}) \quad R_{\mathrm{T}-\mathrm{T}}=0.35 \Omega \quad \mathrm{I}_{\text {cont }}=20 \mathrm{amp}$ $K_{E}=0.61 \mathrm{v} / \mathrm{rad} / \mathrm{sec}(64.2 \mathrm{~V} / \mathrm{kRPM}) \quad L_{T-T}=2.1 \mathrm{mH} \quad \mathrm{I}_{\text {peak }}=60 \mathrm{amp}$
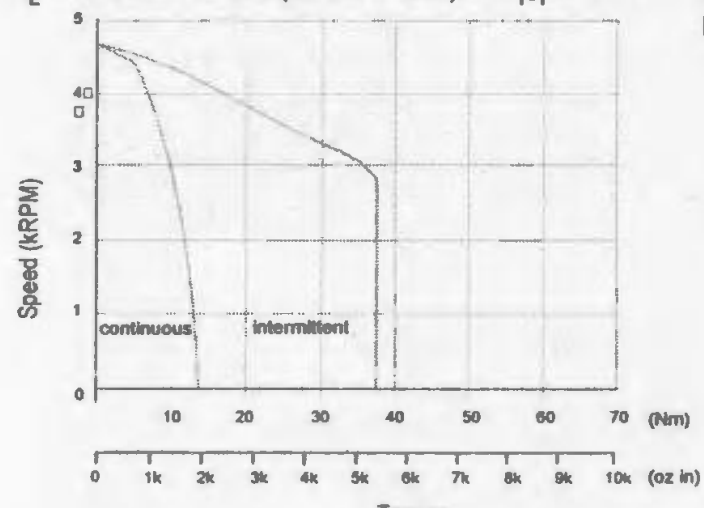

Torque

\section{K500150-5Y}

$K_{\mathrm{T}}=0.45 \mathrm{Nm} / \mathrm{amp}(63.78 \mathrm{az}-\mathrm{in} / \mathrm{amp}) \quad R_{\mathrm{T}-\mathrm{T}}=0.49 \Omega \quad \mathrm{I}_{\text {cont }}=18 \mathrm{amp}$ $K_{E}=0.45 \mathrm{v} / \mathrm{rad} / \mathrm{sec}(47.19 \mathrm{~V} / \mathrm{kRPM}) \quad L_{T-T}=2.72 \mathrm{mH} \mathrm{I}_{\text {peak }}=53 \mathrm{amp}$ $E_{\text {BUS }}=300 \mathrm{Vdc}$

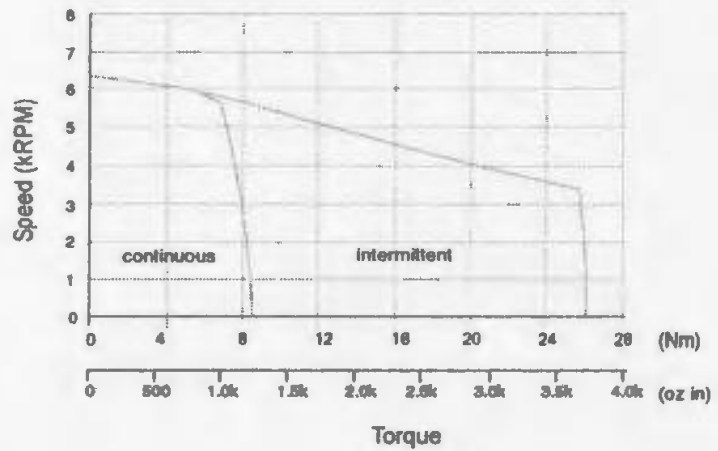

\section{K089300-4Y}

$K_{T}=0.54 \mathrm{Nm} / \mathrm{amp}(75.8 \mathrm{oz}-\mathrm{in} / \mathrm{amp}) \quad R_{T-T}=0.73 \Omega \quad I_{\text {cont }}=15 \mathrm{amp}$ $K_{E}=0.54 \mathrm{~V} / \mathrm{rad} / \mathrm{sec}(56.1 \mathrm{~V} / \mathrm{kRPM}) \quad \mathrm{L}_{\mathrm{T}-\mathrm{T}}=2.2 \mathrm{mH} \quad l_{\text {peak }}=45 \mathrm{amp}$ $E_{\text {BUS }}=160 \mathrm{Vdc}$

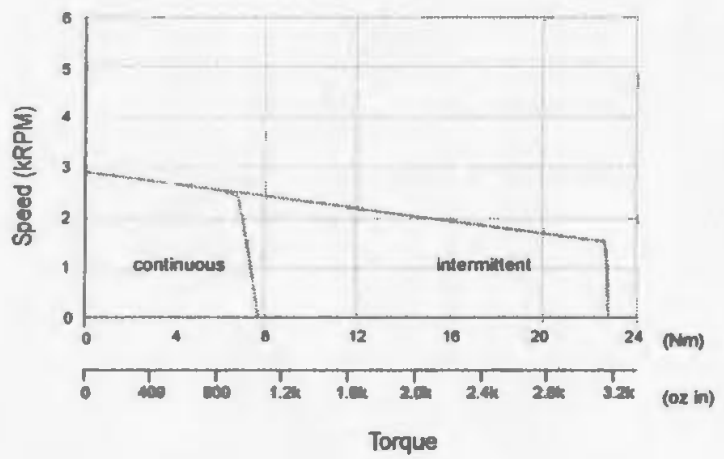

\section{K127500-3Y}

$K_{T}=0.92 \mathrm{Nm} / \mathrm{amp}(130.4 \mathrm{oz}-\mathrm{in} / \mathrm{amp}) \quad R_{T-T}=0.34 \Omega \quad \mathrm{I}_{\text {cont }}=24 \mathrm{amp}$ $K_{E}=0.92 \mathrm{~V} / \mathrm{rad} / \mathrm{sec}(96.4 \mathrm{~V} / \mathrm{kRPM}) \quad L_{T-T}=2.3 \mathrm{mH} \quad \mathrm{I}_{\text {peak }}=72 \mathrm{amp}$

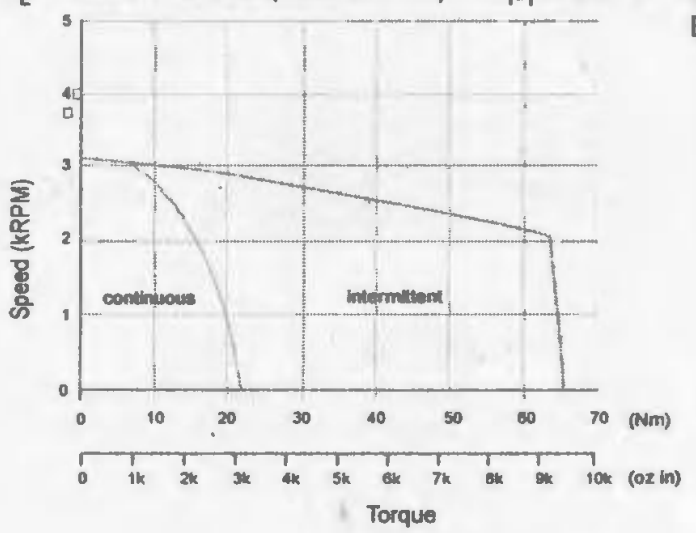

\section{K178150-5Y}

$K_{T}=0.93 \mathrm{Nm} / \mathrm{amp}(130.5 \mathrm{oz}-\mathrm{in} / \mathrm{amp}) \quad R_{\mathrm{T}-\mathrm{T}}=0.37 \Omega \quad \mathrm{I}_{\mathrm{cont}}=27 \mathrm{amp}$ $K_{E}=0.93 \mathrm{~V} / \mathrm{rad} / \mathrm{sec}(96.2 \mathrm{~V} / \mathrm{kRPM}) \quad L_{T-T}=2.95 \mathrm{mH} I_{\text {peak }}=43 \mathrm{amp}$ $E_{\text {BUS }}=300 \mathrm{Vdc}$

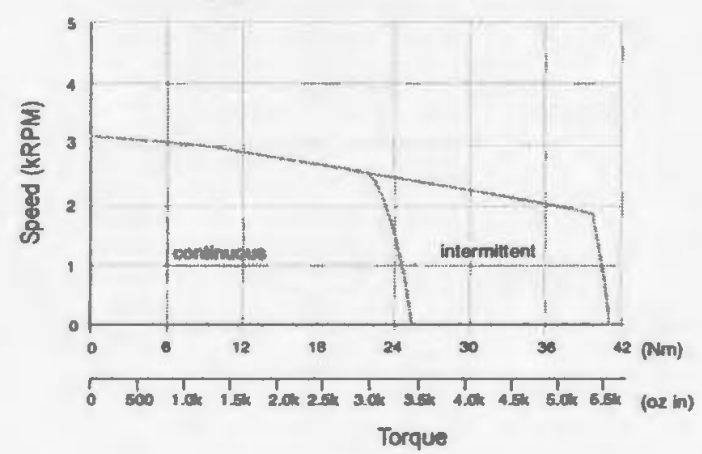




\section{Framaless Motors series: How to Oriler}

\section{K700150-TY}

$K_{T}=0.78 \mathrm{Nm} / \mathrm{amp}$ (110.35 oz-in/amp) $\mathrm{R}_{T-T}=0.84 \Omega \mathrm{I}_{\text {cont }}=18 \mathrm{amp}$

$K_{E}=0.78 \mathrm{v} / \mathrm{rad} / \mathrm{sec}(81.71 \mathrm{~V} / \mathrm{kRPM}) \quad L_{T-T}=5.79 \mathrm{mH} \mathrm{I}_{\text {peak }}=28 \mathrm{amp}$

$\mathrm{E}_{\mathrm{BUS}}=300 \mathrm{Vdc}$

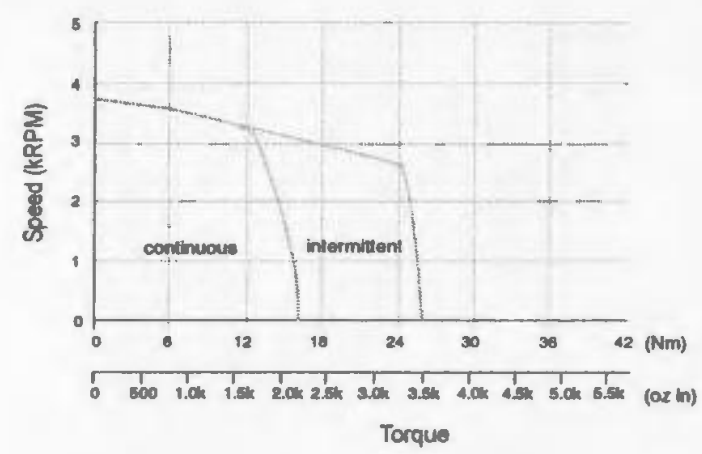

\section{K254150-5Y}

$K_{T}=1.42 \mathrm{Nm} / \mathrm{amp}$ (199.7 oz-in/amp) $R_{T-T}=0.78 \Omega \quad I_{\text {cont }}=34 \mathrm{amp}$

$K_{E}=1.42 \mathrm{~V} / \mathrm{rad} / \mathrm{sec}(147.6 \mathrm{~V} / \mathrm{kRPM}) \mathrm{L}_{\mathrm{T}-\mathrm{T}}=3.6 \mathrm{mH} \quad \mathrm{I}_{\text {peak }}=54 \mathrm{amp}$

$\mathrm{E}_{\text {BUS }}=300 \mathrm{Vdc}$

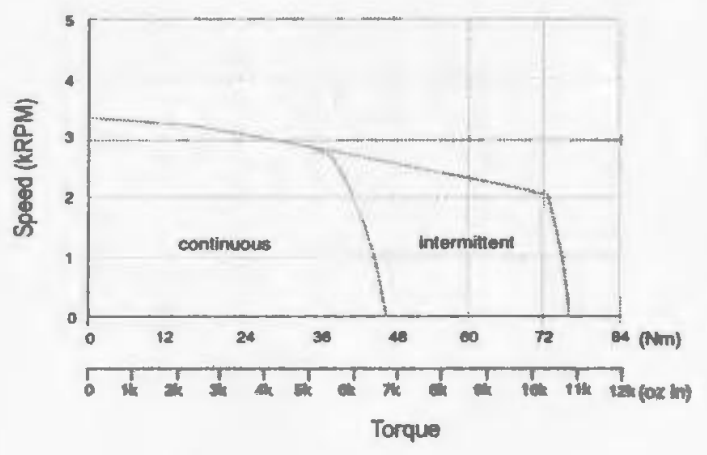

\section{How to Order}

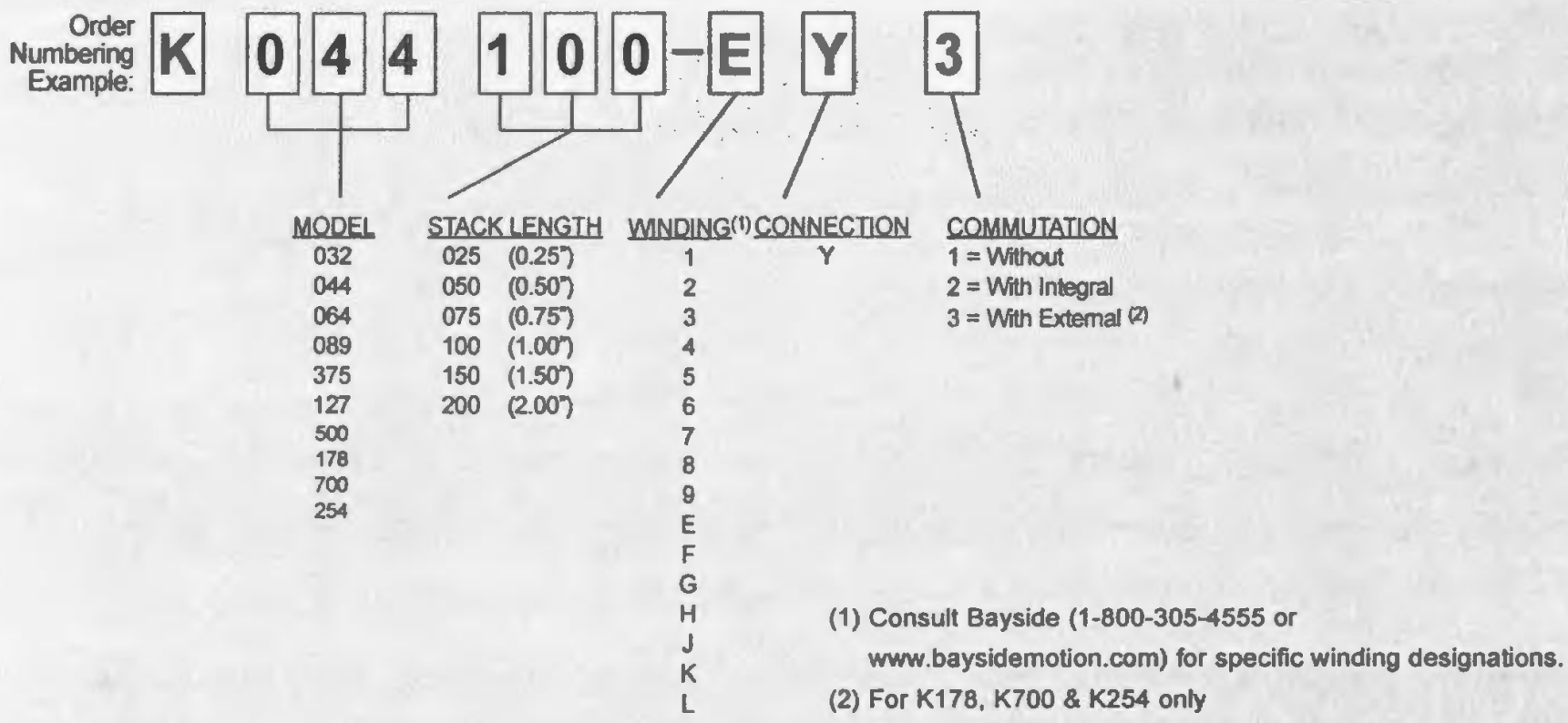

Bayside Kit Motors are supported by a worldwide network of offices and local distributors.

Call 1-800-305-4555 for application engineering assistance or for the name of your local distributor.

Information can also be obtained at www.baysidemotion.com. 
Appendix C - Electronic Data Sheets 


\section{M Step Motor Drive}

\section{Microstepping}

\section{5 amps, 40 VDC}

Features

- DC bus voltage 12-42 VDC motor supply (including ripple)

- Switch selectable currents from 0.4-3.5 amps/ phase motor current

- Switch selectable Step resolutions: 400,1000 , 2000, 12800 steps/rev. Other resolutions are available upon request

- Switch selectable idle current reduction, 0 or $50 \%$

- Optically isolated 5 VDC inputs for step, direction and enable

- Enable input to turn off current to the motor

- Self test, switch selectable

- 140 watts of usable power

- Screw terminal connectors. Pin headers available upon request

- MOSFET, dual H-bridge, inaudible PWM amplifier

- 3 state, pulse width modulated current control, switching at $20-30 \mathrm{KHz}$.

- Drives 4,6 or 8 lead size $11,14,17,23$ or 34 step motors

- CE compliant

\section{Description}

The $3540 \mathrm{M}$ step motor driver is a microstepping drive from 400 to 12,800 steps per revolution, with custom resolutions available upon request, step phase sequencer with MOSFET three state switching amplifiers and optoisolated circuits. The drive also includes an automatic feature to lower motor current by $50 \%$ anytime the motor is left at rest for more than one second. This feature can be disabled. Additional there is a switch selectable selftest which rotates the motor $1 / 2$ revolution in each direction at 100 steps/second.

The amplifier regulates motor current by chopping at a constant, inaudible frequency. Phase current is selected from 32 levels by a DIP switch. Microstepping resolution is also selected by DIP switch.

Recommended motors for the $3540 \mathrm{M}$ drive:

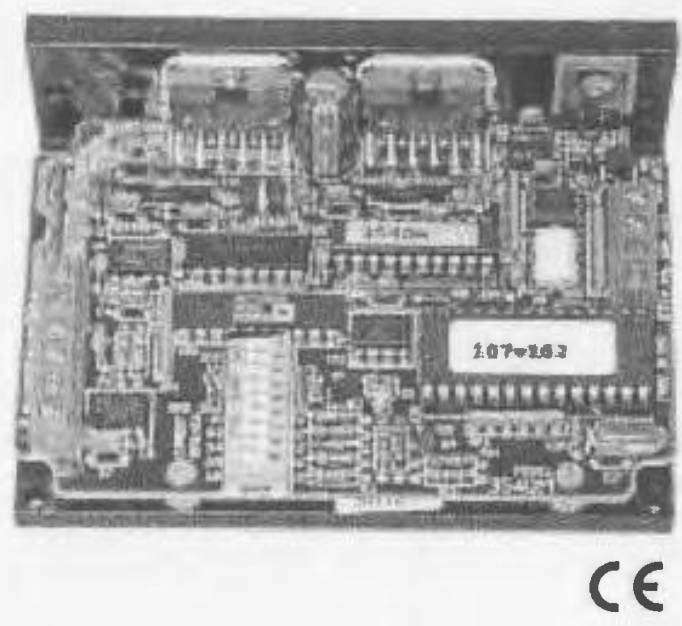

\section{MECHANICAL OUTLINE}

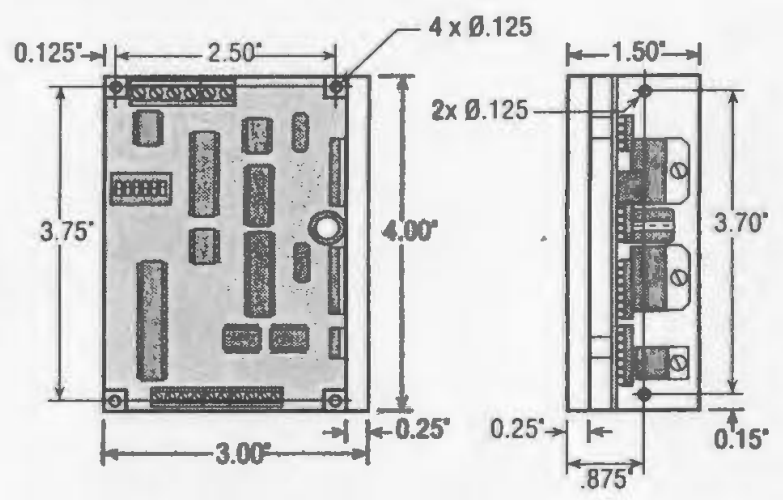

\section{BLOCK DIAGRAM}

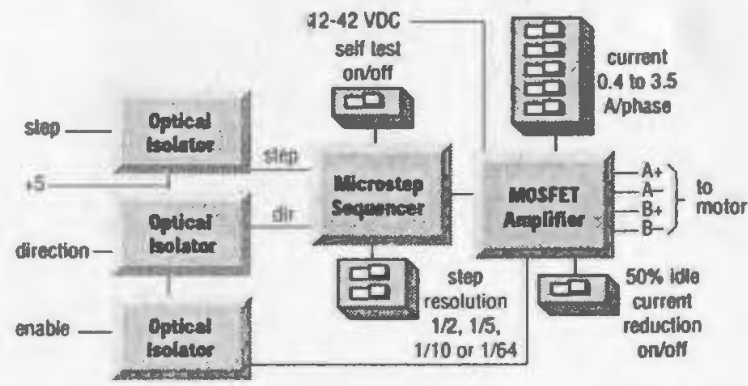

\begin{tabular}{|c|c|c|c|c|}
\hline Size 11 & Size 14 & Size 17 & Size 23 & Size 34 \\
\hline $\begin{array}{l}\text { HT11-012 } \\
\text { HT11-013 }\end{array}$ & $5014-842$ & $\begin{array}{l}\text { HT17-068 } \\
\text { HT17-071 } \\
\text { HT17-075 }\end{array}$ & $\begin{array}{l}\text { HT23-394 } \\
\text { HT23-397 } \\
\text { HT23-400 }\end{array}$ & $5034-348$ \\
\hline
\end{tabular}




\section{M Torque Curves}

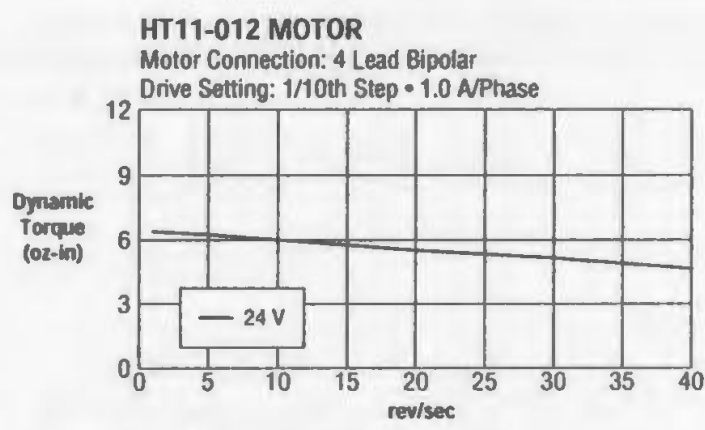

5014-842 MOTOR

Motor Connection: Parallel

Drive Selting: 1/10th Step - 1.0 A/Phase

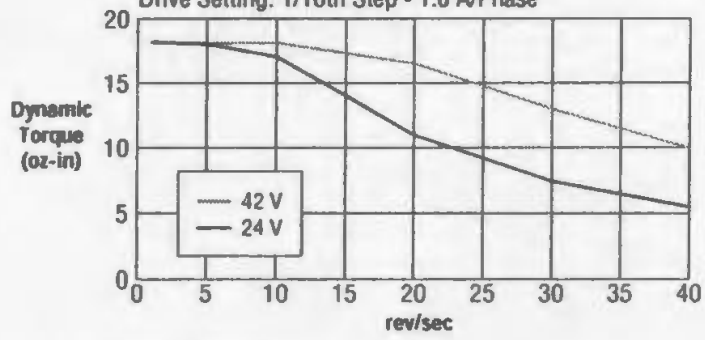

HT17-071 MOTOR

Motor Connection: Parallel

Drive Setting: 1/10th Resolution - 1.7 APhase

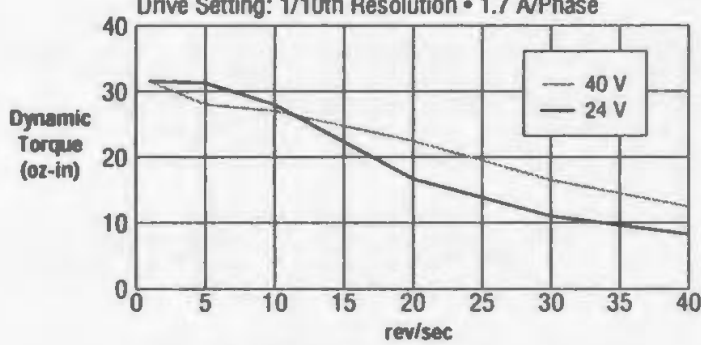

HT23-394 MOTOR

Motor Connection: Paralle!

Drive Setting: $1 / 10$ th Step $\bullet 2.8$ A/Phase

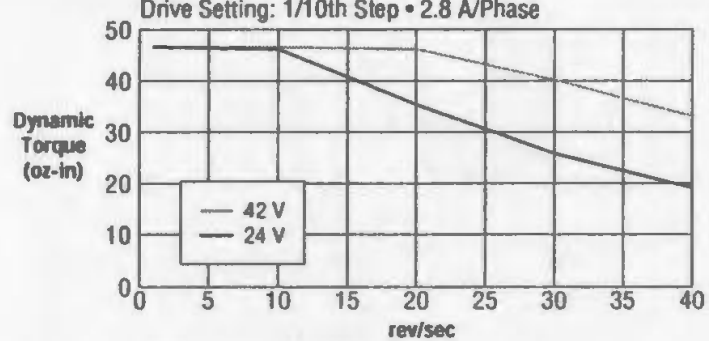

HT23-400 MOTOR

Motor Connection: Paraliel

Drive Setting: 1/10th Step • 2.8 APhase

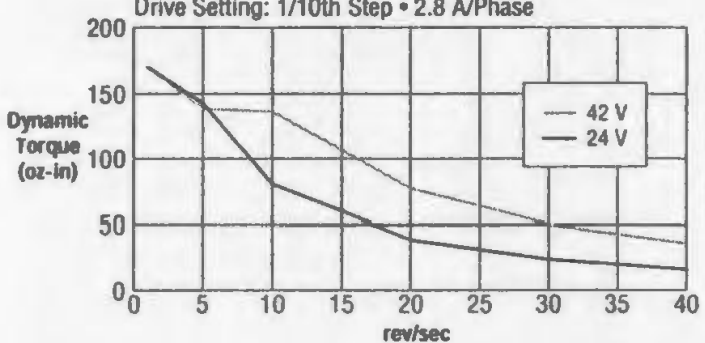

HT11-013 MOTOR

Motor Connection: 4 Lead Bipolar

Drive Setting: 1/10th Step - 1.0 APhase

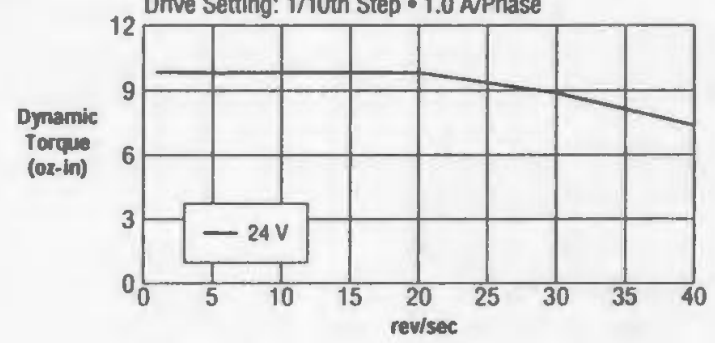

HT17-068 MOTOR

Motor Connection: Parailel

Drive Setting: 1/10th Step - 1.3 A Phase

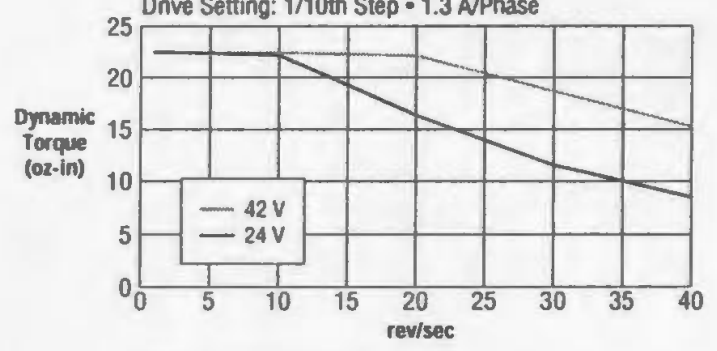

HT17-075 MOTOR

Motor Connection: Parallel

Drive Setting: 1/10th Step - 1.75 A/Phase

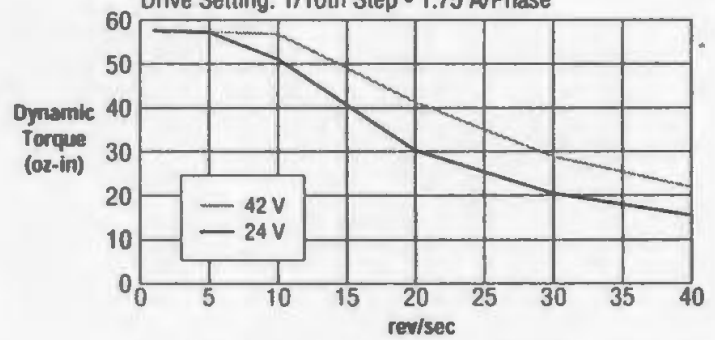

HT23-397 MOTOR

Motor Connection: Parallel

Drive Selting: 1/10th Step - 2.8 APhase

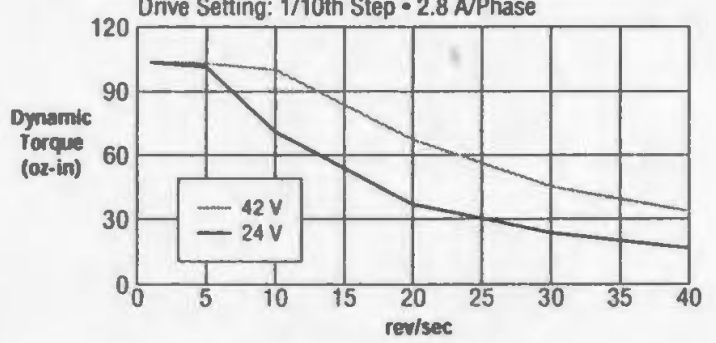

5034-348 MOTOR

Motor Connection: Parallel

Drive Setting: 1/10th Step - 3.5 APhase

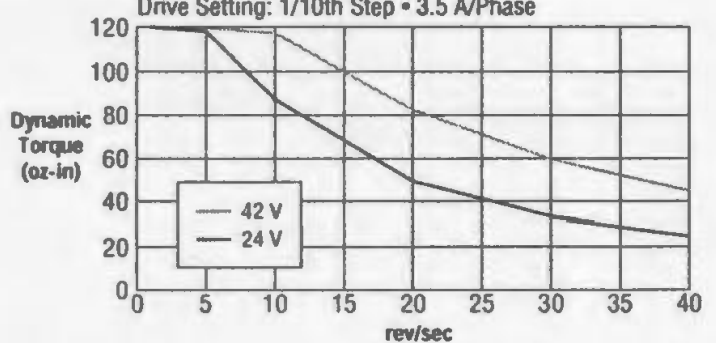




\section{B30A SERIES BRUSHLESS SERVO AMPLIFIERS Models: B30A8, B25A20, B40A8, B40A20}

FEATURES:

- Surface-mount technology

- Small size, low cost, ease of use

- Optional input signal isolation

- DIP switch selectable modes: current, open loop, tachometer, or HALL velocity

- Four quadrant regenerative operation

- Agency Approvals:
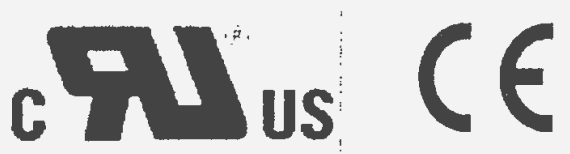

BLOCK DIAGRAM:
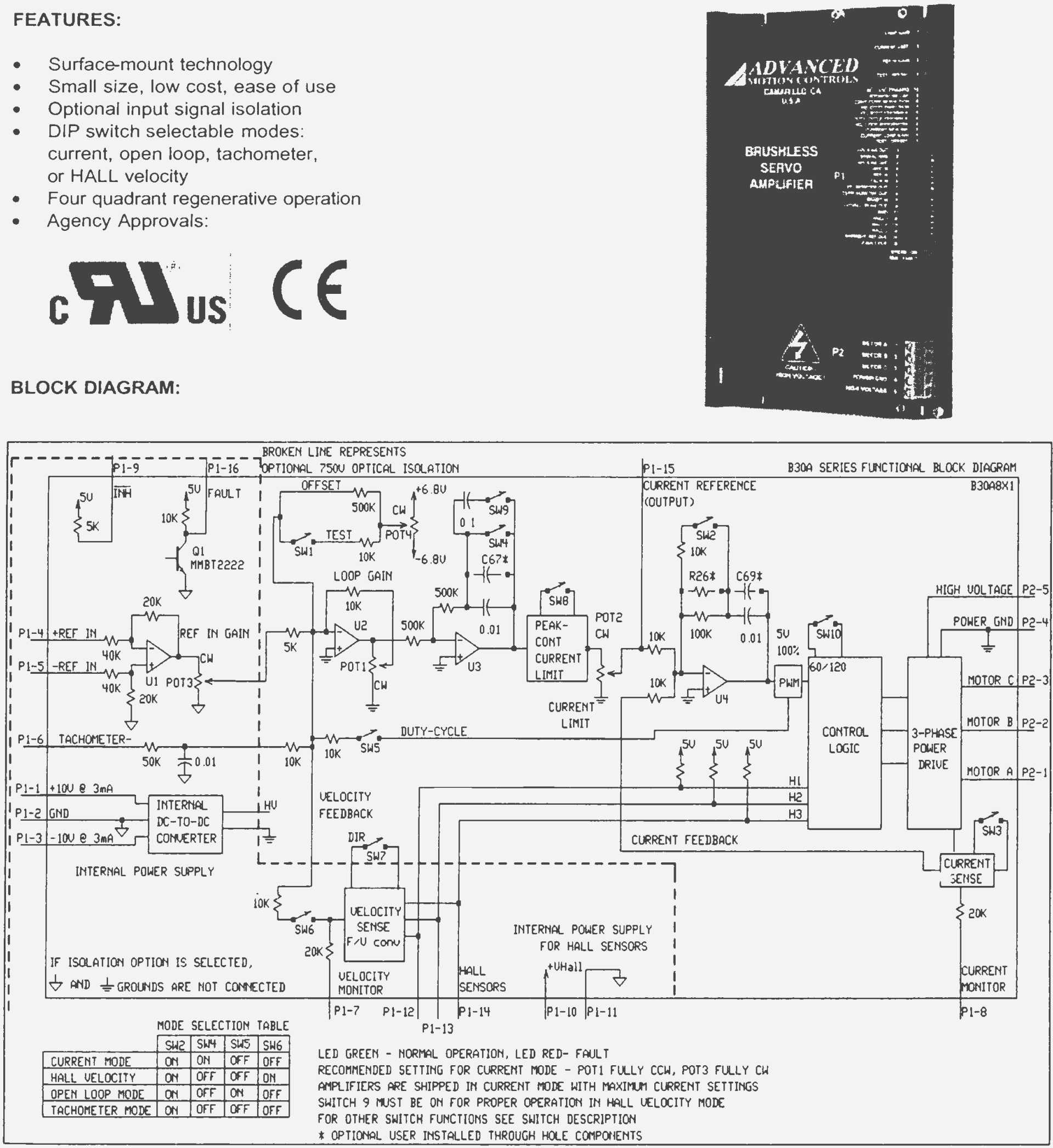
DESCRIPTION: The B3OA Series PWM servo amplifiers are designed to drive brushless DC motors at a high switching frequency. They are fully protected against over-voltage, over-current, over-heating and short-circuits. All models interface with digital controllers or can be used as stand-alone drives. They require only a single unregulated DC power supply. A single red/green LED indicates operating status. Loop gain, current limit, input gain and offset can be adjusted using 14-turn potentiometers. The offset adjusting potentiometer can also be used as an on-board input signal for testing purposes when SW1 (DIP switch) is ON.

\section{SPECIFICATIONS:}

\begin{tabular}{|c|c|c|c|c|}
\hline \multirow[b]{2}{*}{ POWER STAGE SPECIFICATIONS } & \multicolumn{4}{|c|}{ MODELS } \\
\hline & B30A8 & B25A20 & B40A8 & B40A20 \\
\hline DC SUPPLY VOLTAGE & $20-80 \mathrm{~V}$ & $40-190 \mathrm{~V}$ & $20-80 \mathrm{~V}$ & $40-190 \mathrm{~V}$ \\
\hline PEAK CURRENT (2 sec. max., internally limited) & $\pm 30 \mathrm{~A}$ & $\pm 25 \mathrm{~A}$ & $\pm 40 \mathrm{~A}$ & $\pm 40 \mathrm{~A}$ \\
\hline MAX. CONT. CURRENT (internally limited) & $\pm 15 \mathrm{~A}$ & $\pm 12.5 \mathrm{~A}$ & $\pm 20 \mathrm{~A}$ & $\pm 20 \mathrm{~A}$ \\
\hline MINIMUM LOAD INDUCTANCE* & $200 \mu \mathrm{H}$ & $250 \mu \mathrm{H}$ & $200 \mu \mathrm{H}$ & $250 \mu \mathrm{H}$ \\
\hline SWITCHING FREQUENCY & \multicolumn{4}{|c|}{$22 \mathrm{kHz} \pm 15 \%$} \\
\hline HEATSINK (BASE) TEMPERATURE RANGE & \multicolumn{4}{|c|}{$0^{\circ}$ to $+65^{\circ} \mathrm{C}$, disables if $>65^{\circ} \mathrm{C}$} \\
\hline POWER DISSIPATION AT CONTINUOUS CURRENT & $60 \mathrm{~W}$ & $125 \mathrm{~W}$ & $80 W$ & $200 \mathrm{~W}$ \\
\hline OVER-VOLTAGE SHUT-DOWN (self reset) & $86 \mathrm{~V}$ & $195 \mathrm{~V}$ & $86 \mathrm{~V}$ & $195 \mathrm{~V}$ \\
\hline BANDWIDTH (load dependent) & \multicolumn{4}{|c|}{$2.5 \mathrm{kHz}$} \\
\hline
\end{tabular}

\begin{tabular}{||l|c||}
\hline \multicolumn{2}{|c|}{ MECHANICAL SPECIFICATIONS } \\
\hline \hline POWER CONNECTOR & Screw terminals \\
\hline SIGNAL CONNECTOR & Molex connector \\
\hline \multirow{2}{*}{ SIZE } & $7.35 \times 4.40 \times 1.00$ inches \\
& $186.7 \times 111.7 \times 25.4 \mathrm{~mm}$ \\
WEIGHT & $1.5 \mathrm{lb}$. \\
& $0.68 \mathrm{~kg}$ \\
\hline
\end{tabular}

* Low inductance motors require external inductors. 
PIN FUNCTIONS:

\begin{tabular}{|c|c|c|c|c|}
\hline CONNECTOR & PIN & NAME & DESCRIPTION / NOTES & $1 / 0$ \\
\hline \multirow{16}{*}{ P1 } & 1 & +10V@ @ mA OUT & For customer use & O \\
\hline & 2 & SIGNAL GND & Reference ground & SGND \\
\hline & 3 & -10V@3 mA OUT & For customer use & 0 \\
\hline & 4 & +REF IN & \multirow{2}{*}{$\begin{array}{l}\text { Differential reference input, Maximum } \pm 15 \mathrm{~V} \text {, } \\
40 \mathrm{~K} \text { input resistance }\end{array}$} & \multirow{2}{*}{1} \\
\hline & 5 & -REF IN & & \\
\hline & 6 & $-\mathrm{TACH} I \mathrm{~N}$ & $\begin{array}{l}\text { Tachometer input, max. } \pm 60 \text { VDC, } 60 \mathrm{~K} \text { input } \\
\text { resistance }\end{array}$ & 1 \\
\hline & 7 & $\begin{array}{l}\text { VELOCITY MONITOR } \\
\text { OUT }\end{array}$ & $\begin{array}{l}\text { Velocity monitor, } 1 \mathrm{~V}=133 \mathrm{~Hz} \text { HALL sensor } \\
\text { frequency }\end{array}$ & 0 \\
\hline & 8 & $\begin{array}{l}\text { CURRENT MONITOR } \\
\text { OUT }\end{array}$ & $\begin{array}{l}\text { Current monitor. } \\
\text { Models } B 30 A 8 \text { and } B 25 A 20 \text { : } \\
\text { when SW } 3 \text { is OFF, } 1 \mathrm{~V}=2 \mathrm{~A} \text {, } \\
\text { when SW } 3 \text { is ON, } 1 \mathrm{~V}=4 \mathrm{~A} \text {. } \\
\text { Models } \mathrm{B} 40 \mathrm{~A} 8 \text { and } \mathrm{B} 40 \mathrm{~A} 20 \text { : } \\
\text { when SW } 3 \text { is OFF, } 1 \mathrm{~V}=4 \mathrm{~A} \text {, } \\
\text { when SW } 3 \text { is ON, } 1 \mathrm{~V}=8 \mathrm{~A}\end{array}$ & $\mathrm{O}$ \\
\hline & 9 & INHIBIT IN & $\begin{array}{l}\text { This TT level input signal turns off all power } \\
\text { devices of the "H" bridge when pulled to ground. } \\
\text { This inhibit will cause a fault condition and a red } \\
\text { LED. For inverted inhibit input, see section "G". }\end{array}$ & 1 \\
\hline & 10 & +V HALL 30 mA OUT & \multirow{2}{*}{$\begin{array}{l}\text { Power for HALL sensors, } \\
\text { short circuit protected, }+6 \vee @+30 \text { mA }\end{array}$} & 0 \\
\hline & 11 & GND & & SGND \\
\hline & 12 & HALL 1 & \multirow{3}{*}{$\begin{array}{l}\text { HALL sensor inputs, logic levels, internal } 5 \mathrm{~K} \Omega \text { pull- } \\
\text { up. Maximum low level input is } 1.5 \mathrm{~V} \text {, minimum } \\
\text { high level input is } 3.5 \mathrm{~V} \text {. }\end{array}$} & \multirow{3}{*}{1} \\
\hline & 13 & HALL 2 & & \\
\hline & 14 & HALL 3 & & \\
\hline & 15 & $\begin{array}{l}\text { CURRENT } \\
\text { REFERENCE OUT }\end{array}$ & $\begin{array}{l}\text { Monitors the input signal connected directly to the } \\
\text { internal current amplifier. } 7.25 \mathrm{~V}=\text { max peak } \\
\text { current. See current limit adjustment information } \\
\text { below. }\end{array}$ & 0 \\
\hline & 16 & FAULT (red LED) & $\begin{array}{l}\text { TTL level output. Becomes high during output short } \\
\text { circuit, over-voltage, over temperature, inhibit, and } \\
\text { during power-up reset. Fault condition indicated by } \\
\text { red LED. }\end{array}$ & 0 \\
\hline \multirow{5}{*}{$\mathrm{P} 2$} & 1 & MOTOR A & Motor phase A connection & 0 \\
\hline & 2 & MOTOR B & Motor phase B connection & 0 \\
\hline & 3 & MOTOR C & Motor phase C connection & 0 \\
\hline & 4 & POWER GND & Power ground & PGND \\
\hline & 5 & HIGH VOLTAGE & DC power input & 1 \\
\hline
\end{tabular}


SWITCH FUNCTIONS:

\begin{tabular}{|c|c|c|c|}
\hline \multirow{2}{*}{ SWITCH } & \multirow{2}{*}{ FUNCTION DESCRIPTION } & \multicolumn{2}{|c|}{ SETTING } \\
\hline & & ON & OFF \\
\hline 1 & $\begin{array}{l}\text { Test / Offset. Sensitivity of the "offset" pot. } \\
\text { Used as an on-board reference signal in test } \\
\text { mode. }\end{array}$ & Test & Offset \\
\hline 2 & Current loop gain & Decrease & Increase \\
\hline 3 & $\begin{array}{l}\text { Current scaling. When OFF, increases } \\
\text { sensitivity of current sense thus reducing both } \\
\text { peak and continuous current limit by } 50 \% \text {. }\end{array}$ & $100 \%$ & $50 \%$ \\
\hline 4 & $\begin{array}{l}\text { Velocity loop integrator. This capacitor normally } \\
\text { ensures "error-free" operation in velocity mode by } \\
\text { reducing the error-signal (output of summing } \\
\text { amplifier) to zero. }\end{array}$ & $\begin{array}{l}\text { Shorts out the } \\
\text { velocity/voltage loop } \\
\text { integrator capacitor }\end{array}$ & $\begin{array}{l}\text { Velocity/voltage loop } \\
\text { integrator } \\
\text { Operating }\end{array}$ \\
\hline 5 & Internal duty-cycle feedback for open loop mode. & On & Off \\
\hline 6 & $\begin{array}{l}\text { Velocity feedback. Connects the internally } \\
\text { generated velocity signal from HALL sensors. }\end{array}$ & On & Off \\
\hline 7 & $\begin{array}{l}\text { Velocity direction. Changes the polarity of the } \\
\text { velocity monitor signal. }\end{array}$ & & \\
\hline 8 & $\begin{array}{l}\text { Continuous current reduction. Reduces } \\
\text { continuous current limit by } 50 \% \text {. }\end{array}$ & $\begin{array}{l}\text { Continuous / peak } \\
\text { current limit ratio is } \\
50 \%\end{array}$ & $\begin{array}{l}\text { Continuous / peak current } \\
\text { limit ratio is } 25 \%\end{array}$ \\
\hline 9 & $\begin{array}{l}\text { Integrator capacitor. Adjusts the value of the } \\
\text { integrator capacitor in velocity mode. }\end{array}$ & Increase & Decrease \\
\hline 10 & $60 / 120$ degree commutation phase setting & 120 degree phasing & 60 degree phasing \\
\hline
\end{tabular}

\section{POTENTIOMETER FUNCTIONS:}

\begin{tabular}{|c|l|c||}
\hline POTENTIOMETER & DESCRIPTION & TURNING CW \\
\hline \hline Pot 1 & $\begin{array}{l}\text { Loop gain adjustment in open loop \& velocity modes. Turn this } \\
\text { pot fully ccw in current mode. }\end{array}$ & Increases icup gain \\
\hline Pot 2 & $\begin{array}{l}\text { Current limit. It adjusts both continuous and peak current limit } \\
\text { maintaining selected ratio (50\%). }\end{array}$ & Increases current limit \\
\hline Pot 3 & $\begin{array}{l}\text { Reference in gain. It adjusts the ratio between input signal and } \\
\text { output variables (voltage, current, velocity). }\end{array}$ & $\begin{array}{l}\text { Increases reference } \\
\text { input gain }\end{array}$ \\
\hline Pot 4 & $\begin{array}{l}\text { Test / Offset. Used to adjust any imbalance in the input signal or } \\
\text { in the amplifier. When SW1 (DIP switch) is ON, the sensitivity of } \\
\text { this pot is greatly increased thus it can be used as an on-board } \\
\text { signal source for testing purposes. See section "G". }\end{array}$ & N/A \\
\hline
\end{tabular}


TEST POINTS FOR POTENTIOMETERS: See section "G".

\section{OPERATING MODE SELECTION:}

These modes can be selected by the DIP switches according to the chart in the functional block diagram.

- Current mode

- Open loop mode

- Tachometer mode

- HALL velocity mode

See section "G" for more information.

SET-UP: See section "G" for engineering and installation notes.

\section{CURRENT LIMIT ADJUSTMENTS:}

These amplifiers feature separate peak and continuous current limit adjustments. The current limit adjustment Pot 2 adjusts both peak and continuous current limit at the same time. It has 12 active turns plus 1 inactive turn at each end and is approximately linear. Thus, to adjust the current limit turn the potentiometer fully counter-clockwise, then turn clockwise to the appropriate value.

In many applications it is sufficient to use only the DIP switches for current limit adjustments. SW3 reduces both peak and continuous current limit by $50 \%$ when OFF. SW8 reduces only the continuous current limit by $50 \%$ when OFF:

\begin{tabular}{|c|c|}
\hline SW8 & CONTINUOUS / PEAK CURRENT LIMIT RATIO \\
\hline \hline ON & $50 \%$ \\
\hline OFF & $25 \%$ \\
\hline
\end{tabular}

P1-15 is the input to the internal current amplifier stage. Since the output current is proportional to P1-15, the adjusted current limit can easily be observed at this pin without connecting the motor. Note that a command signal must be applied to the reference inputs to obtain a reading on P1-15. The maximum peak current value equals $7.25 \mathrm{~V}$ at this pin and the maximum continuous current value equals $3.63 \mathrm{~V}$ at this pin. If $S W 3=O N$, peak rated amplifier current $=7.25 \mathrm{~V}$. If $S W 3=O F F, 1 / 2$ peak rated amplifier current $=7.25 \mathrm{~V}$. Example: using the B30A8 with $S W 3=O N, 30 A=7.25 \mathrm{~V}$ and with $S W 3=O F F, 15 A=7.25 \mathrm{~V}$.

The actual current can be monitored at pin P1-8.

\section{OPTIONAL INPUT SIGNAL ISOLATION:}

$750 \mathrm{~V}$ optical input signal isolation is available for this amplifier series. It is recommended to use this option in transformer-less systems where the high voltage power is generated directly by rectifying the $120 \mathrm{~V} \mathrm{AC} \mathrm{line,} \mathrm{or} \mathrm{whenever}$ one leg of the AC input to the power supply rectifier is grounded. All input and output signals are isolated from the power stage except CURRENT MONITOR OUT (P1-8) and CURRENT REFERENCE OUT (P1-15). P1-8 and P1-15 are referenced to POWER GND (P2-4). 
B30A Series

ORDERING INFORMATION:

Models: B30A8X, B25A20X, B40A8X, B40A20X

With isolation:

Models: B30A8IX, B25A20IX, B40A8IX, B40A20IX

$X$ indicates the current revision letter.

TYPICAL SYSTEM WIRING: See section "G".

MOUNTING DIMENSIONS: See page F-9. 


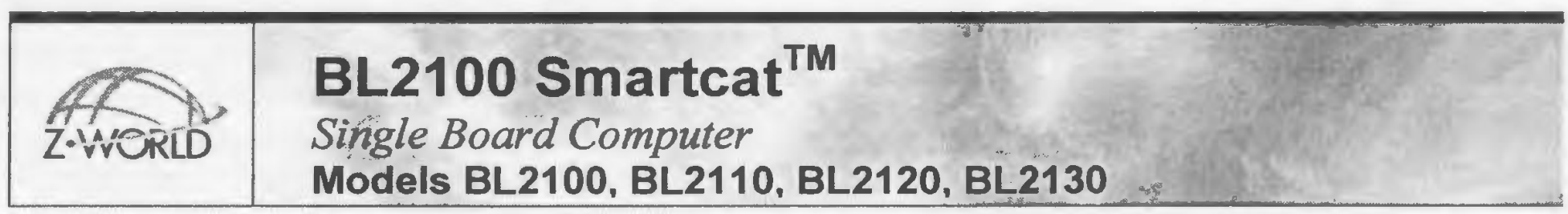

Designed for medium-scale control and monitoring applications, the Smartcat is a high-performance singleboard computer that gives OEM designers Ethernet and keypad/display options all in one low-cost package. The Smartcat offers sinking/sourcing digital $1 / O$ with $A D$ and D/A, providing comprehensive integrated control capabilities in a compact 4.14" $\times 3.41^{\prime \prime}(105 \times 87 \mathrm{~mm})$ form factor. Ethernet models are ideal for remotely monitoring and supervising another programmable system or web-enabling new or existing products. The Ethernet interface is fully supported by software to enable network and Internet connectivity.

\section{Features}

- Rabbit 2000 microprocessor @ $22.1 \mathrm{MHz}$

- 40 sinking/sourcing digital I/O

- 11 AND and 4 D/A

- 4 serial ports

- $\quad$ 10Base-T Ethernet with RJ-45

- Optional 512K Flash/512K SRAM

- Software support enables network connectivity, E-mail, web server

- Optional backlit 122 × 32 pixel graphic display, 7 user-relegendable keys, 7 LED

Available in four flexible configurations-two with Ethernet, two without-all Smartcat models feature 40 digital I/O, 3 RS-232/485 serial ports (plus one programming port), Rabbit $2000^{\mathrm{Tm}}$ microprocessor at $22.1 \mathrm{MHz}, 7$ timers, and battery-backed real-time clock. Memory configurations up to 512K Flash and 512K SRAM are available. For the most demanding applications, the BL2100 and BL2120 models

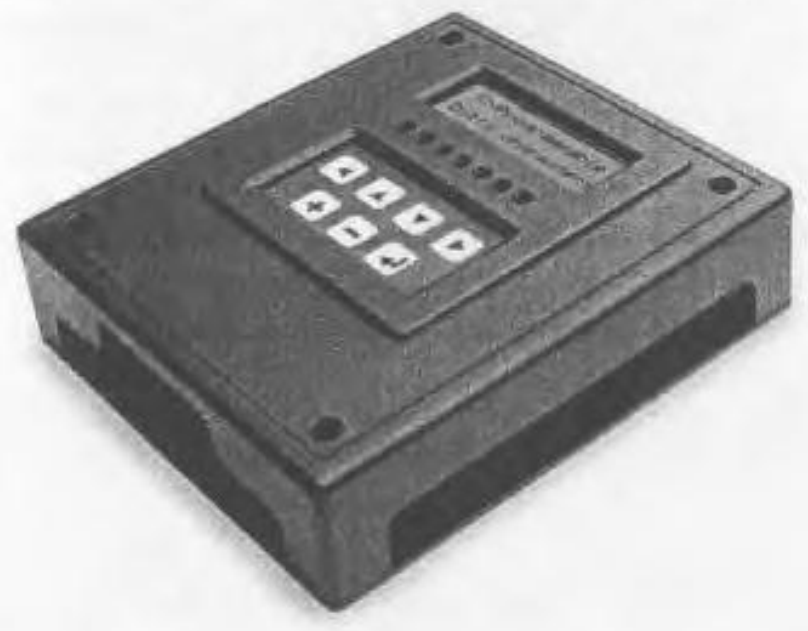
include 11 channels of 12-bit resolution AD input and 4 channels of 12-bit D/A output. The Smartcat's 16 digital push/pull outputs allow per-point sinking or sourcing, addressing the needs of both the domestic and international markets.

A 7-key, $122 \times 32$ graphic display is available as a cost-effective user interface. A panel-mount, water-resistant NEMA 4 version is also available. Keypad legends are easily modified using customizing printed paper inserts. User-programmable LEDs provide quick-status feedback. The entire board/display/keypad assembly mounts in an integrated plastic enclosure.

The Smartcat is available as an unenclosed printed circuit board, mounted on a plastic baseplate, in a plastic enclosure with a display, or with a panel-mounted display connected to the board with a flat cable.

\section{Programming the Smartcat}

Programs are developed using Z-World's industry-proven Dynamic Coftware development system via RS-232 interface. Software libraries and a built-in converter program facilitate display of international characters, bitmap images, and graphic constructs such as circles, lines, and squares. An extensive library of drivers and sample programs is provided, along with royalty-free TCP/IP stack with source. All Smartcat models can be programmed and debugged over Ethernet/Internet using appropriate accessory hardware. 


\begin{tabular}{|c|c|c|c|c|}
\hline \multicolumn{5}{|c|}{ BL2100 Smartcat Specifications } \\
\hline Features & BL2100 & BL2110 & BL2120 & BL2130 \\
\hline Microprocessor & \multicolumn{4}{|c|}{ Rabbit 2000T@22.1 MHz } \\
\hline Ethernet Port & \multicolumn{2}{|c|}{ 10Base-T, RJ-45, link and activity LEDs } & \multicolumn{2}{|c|}{ None } \\
\hline Flash & \multicolumn{2}{|c|}{ 256K (standard) } & \multicolumn{2}{|c|}{$256 \mathrm{~K}$} \\
\hline SRAM & \multicolumn{2}{|c|}{$128 \mathrm{~K}$ (standard) } & \multicolumn{2}{|c|}{$128 \mathrm{~K}$} \\
\hline Backup Battery & \multicolumn{4}{|c|}{ Socketed 3-V lithium coin-type, $265 \mathrm{~mA}$ h, supports RTC and SRAM } \\
\hline Keypad/Display & \multicolumn{4}{|c|}{ See keypad/display option (below) and our "OP" products (for senial display options) } \\
\hline Digital Inputs & \multicolumn{4}{|c|}{ 24: protected toz $\pm 36 \vee D C$} \\
\hline Digital Outputs & \multicolumn{4}{|c|}{ 16: source/sink $200 \mathrm{~mA}$ each, 36 V DC max. } \\
\hline Analog Inputs & $\begin{array}{l}11 \text { at } 1 \mathrm{M} \Omega, 12 \text {-bit } \\
\text { resolution, } \pm 10 \mathrm{~V} \mathrm{DC} \\
\text { up to } 4,100 \text { samples/sec. }\end{array}$ & None & $\begin{array}{c}11 \text { at } M \Omega, 12 \text {-bit } \\
\text { resolution, } \pm 10 \mathrm{~V} \mathrm{DC} \text { up } \\
\text { to } 4,100 \text { samples/sec } \\
\end{array}$ & None \\
\hline Analog Outputs & $\begin{array}{l}\text { Four 12-bit resolution 0- } \\
10 \mathrm{VDC} C^{*} 0-10 \mathrm{VDC} \\
\text { update rate } 12 \mathrm{kHz}\end{array}$ & None & $\begin{array}{l}\text { Four } 12 \text {-bit resolution } 0 \text { - } \\
10 \mathrm{VDC} 0-10 \mathrm{VDC} \\
\text { update rate } 12 \mathrm{kHz}\end{array}$ & None \\
\hline Serial Ports & \multicolumn{4}{|c|}{$\begin{array}{l}4 \text { total: two 3-wire (or one 5-wire) RS-232, } 1 \text { RS-485, and one } 5 \text { V CMOS-compatible } \\
\text { (programming) }\end{array}$} \\
\hline Serial Rate & \multicolumn{4}{|c|}{$\begin{array}{l}\text { Max. burst rate }=\mathrm{CLK} / 32 \\
\text { Max. sustained rate }=\text { burst } / 2\end{array}$} \\
\hline Connectors & \multicolumn{4}{|c|}{ Screw terminals support max. 14 AWG/1.5 mm² (standard) } \\
\hline Real-Time Clock & \multicolumn{4}{|c|}{ Yes } \\
\hline Timers & \multicolumn{4}{|c|}{ Five 8-bit timers (four cascadable from the first) and one 10-bit timer with 2 match registers } \\
\hline Watchdog/Supervisor & \multicolumn{4}{|c|}{ Yes } \\
\hline Power & \multicolumn{4}{|c|}{ 9-36 V DC, 1.5 W max. (without display) } \\
\hline Operating Temp. & \multicolumn{4}{|c|}{$-40^{\circ}$ to $+70^{\circ} \mathrm{C}$} \\
\hline Humidity & \multicolumn{4}{|c|}{$5-95 \%$ non-condensing } \\
\hline Board Size & \multicolumn{4}{|c|}{$\begin{array}{l}4.14^{n} \times 3.41^{\prime \prime} \times 0.93^{n} \\
(105 \times 87 \times 24 \mathrm{~mm})\end{array}$} \\
\hline $\begin{array}{l}\text { Pricing } \\
\text { (qty. 1/100) } \\
\text { Part Number }\end{array}$ & $\begin{array}{c}\$ 339 / 298 \\
101-0461 \\
\end{array}$ & $\begin{array}{r}\$ 249 / 219 \\
101-0462 \\
\end{array}$ & $\begin{array}{c}\$ 299 / 263 \\
101-0463\end{array}$ & $\begin{array}{r}\$ 209 / 184 \\
101-0464\end{array}$ \\
\hline $\begin{array}{l}\text { Starter Packages } \\
\text { Part Number }\end{array}$ & $\begin{array}{c}\$ 539 \\
\text { U.S 101-0482 Int'l 101-0483 }\end{array}$ & $\begin{array}{c}\$ 449 \\
\text { U.S 101-0482 Int'l 101-0483 }\end{array}$ & $\begin{array}{c}\$ 499 \\
\text { U.S 101-0482 Int'| 101-0483 }\end{array}$ & $\begin{array}{c}\$ 409 \\
\text { U.S 101-0482 Int'। 101-0483 }\end{array}$ \\
\hline
\end{tabular}

\begin{tabular}{|c|c|}
\hline \multicolumn{2}{|r|}{ Keypad / Display Options } \\
\hline Feature & Specification \\
\hline LCD Panel & $\begin{array}{l}122 \times 32 \text { graphic LCD in two stacked sections (with programmable backlight), relegendable keypad with 7-key / 7- } \\
\text { LED interface. }\end{array}$ \\
\hline LEDs & 7 user-programmable: 1 red, 4 green, 2 yellow \\
\hline Operating Temp. & $0^{\circ}-50^{\circ} \mathrm{C}$ \\
\hline Board Size & $\begin{array}{c}3.00^{n} \times 2.60^{n} \times 0.75^{n} \\
(76 \times 66 \times 19 \mathrm{~mm})\end{array}$ \\
\hline Enclosure Size & $\begin{array}{l}5.600^{n} \times 4.875^{n} \times 1.500^{n} \\
(142 \times 124 \times 38 \mathrm{~mm})\end{array}$ \\
\hline
\end{tabular}




\section{CPCPP PORT PINOUT}

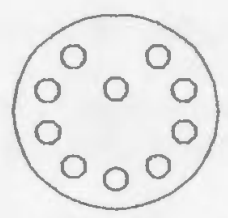

RABBIT PROG. PORT

1.) $R X A$

2.) GND

3.) CLKA

4.) VCC

5.) /RESET

6.) $T X A$

7.) N.C.

8.) STATUS

9.) SMODEO

10.)SMODE1

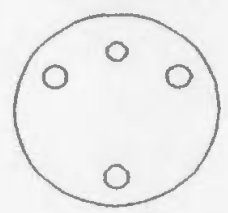

MAIN MOTOR POWER

1.) +24VDC

2.) GND

3.) $-24 \mathrm{VDC}$

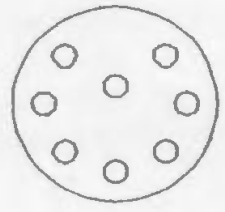

TCP/IP CONTROL PORT

1.) $\mathrm{TX}+$

2.) $T X-$

3.) $R X+$

4.) N.C.

5.) N.C.

6.) $R X-$

7.) N.C.

8.) N.C.

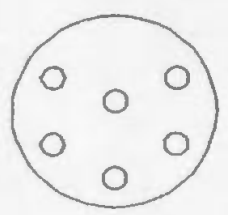

CONTROL SYSTEM POWER

1.) +12VDC

2.) ANALOG GND

3.) $-12 \mathrm{VDC}$

4.) $+5 V D C$

5.) +24VDC

6.) DIGITAL GND 
Appendix D - Load Cell Mounting 
JR3 Sensor Model 45E15A-163 50L350S

Ser. No. 2885

Nominal Diameter: 4.50 inches Nom. Height: 1.50 inches Nom. Weight: $1.8 \mathrm{lb}$

\begin{tabular}{lccc} 
& $\begin{array}{c}\text { Electrical } \\
\text { Load Settings }\end{array}$ & $\begin{array}{c}\text { Sensor } \\
\text { Load Ratings }\end{array}$ & $\begin{array}{c}\text { Calibration } \\
\text { Loads used }\end{array}$ \\
\hline Fx & $50.0 \mathrm{lbs}$ & $150.0 \mathrm{lbs}$ & $50.0 \mathrm{lbs}$ \\
$\mathrm{Fy}$ & $50.0 \mathrm{lbs}$ & $150.0 \mathrm{lbs}$ & $50.0 \mathrm{lbs}$ \\
$\mathrm{Fz}$ & $300.0 \mathrm{lbs}$ & $300.0 \mathrm{lbs}$ & $300.0 \mathrm{lbs}$ \\
$\mathrm{Mx}$ & $350.0 \mathrm{in}-\mathrm{lbs}$ & $675.0 \mathrm{in}-\mathrm{lbs}$ & $330.0 \mathrm{in}-\mathrm{lbs}$ \\
$\mathrm{My}$ & $350.0 \mathrm{in}-\mathrm{lbs}$ & $675.0 \mathrm{in}-\mathrm{lbs}$ & $330.0 \mathrm{in}-\mathrm{lbs}$ \\
$\mathrm{Mz}$ & $500.0 \mathrm{in}-\mathrm{lbs}$ & $675.0 \mathrm{in}-\mathrm{lbs}$ & $550.0 \mathrm{in}-\mathrm{lbs}$
\end{tabular}

Date of Manufacture:

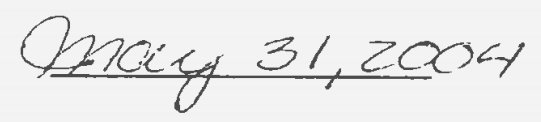

Calibration Date:

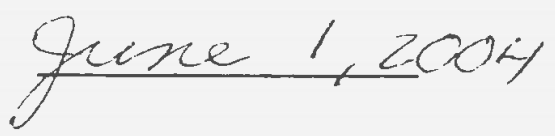

Final Inspection:

Calibration Matrix
Axis Orientation
Units are lb \& inlb
Hardware Correct
Label Correct
Functional Test

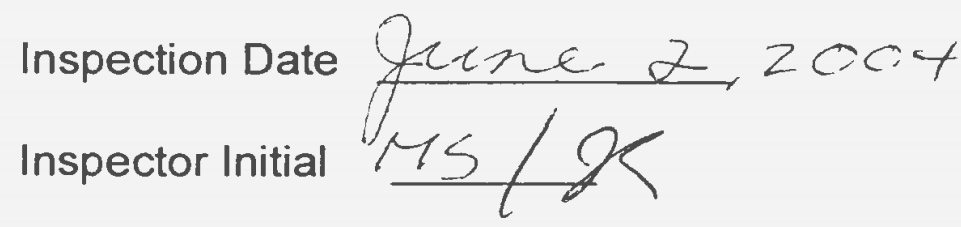




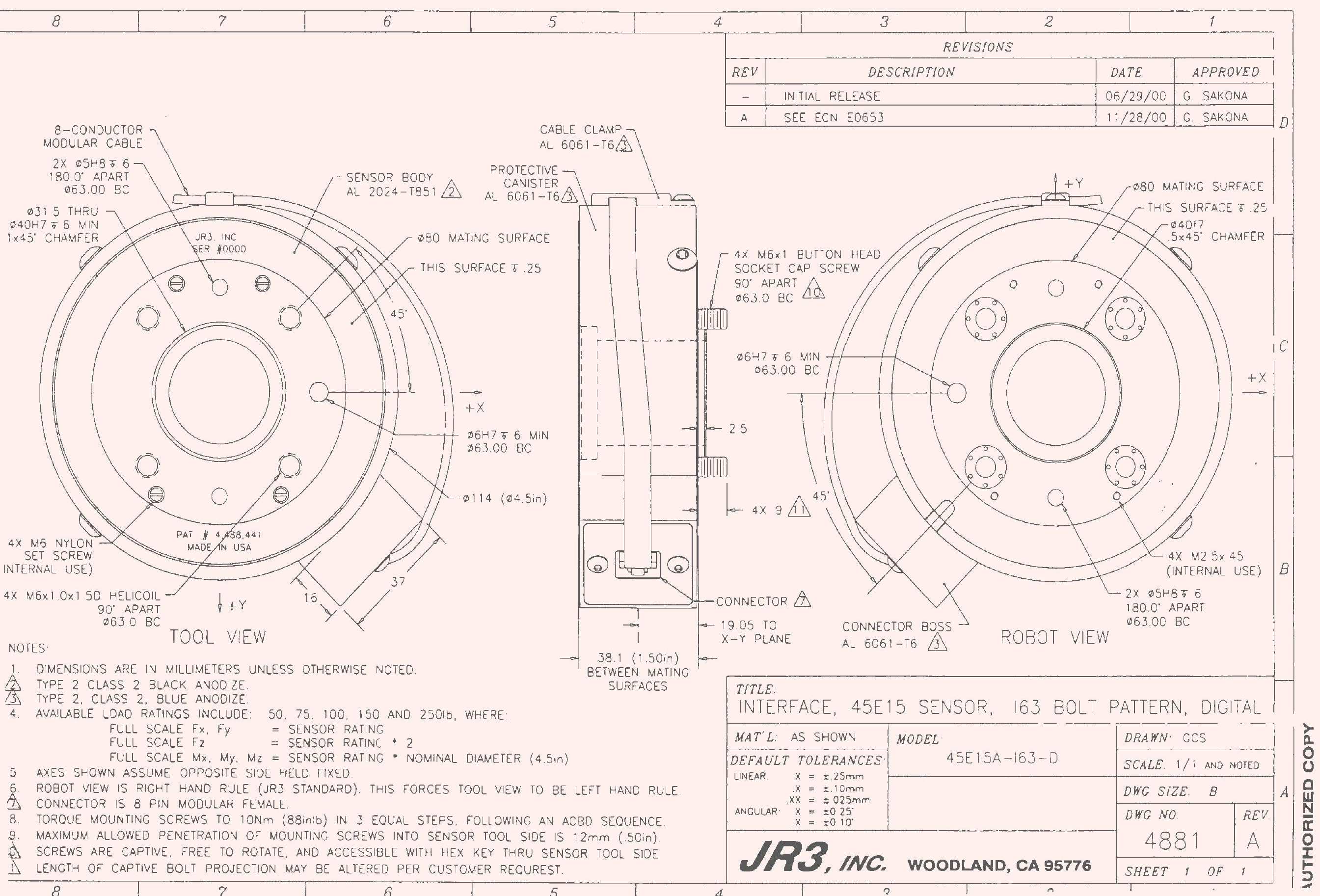




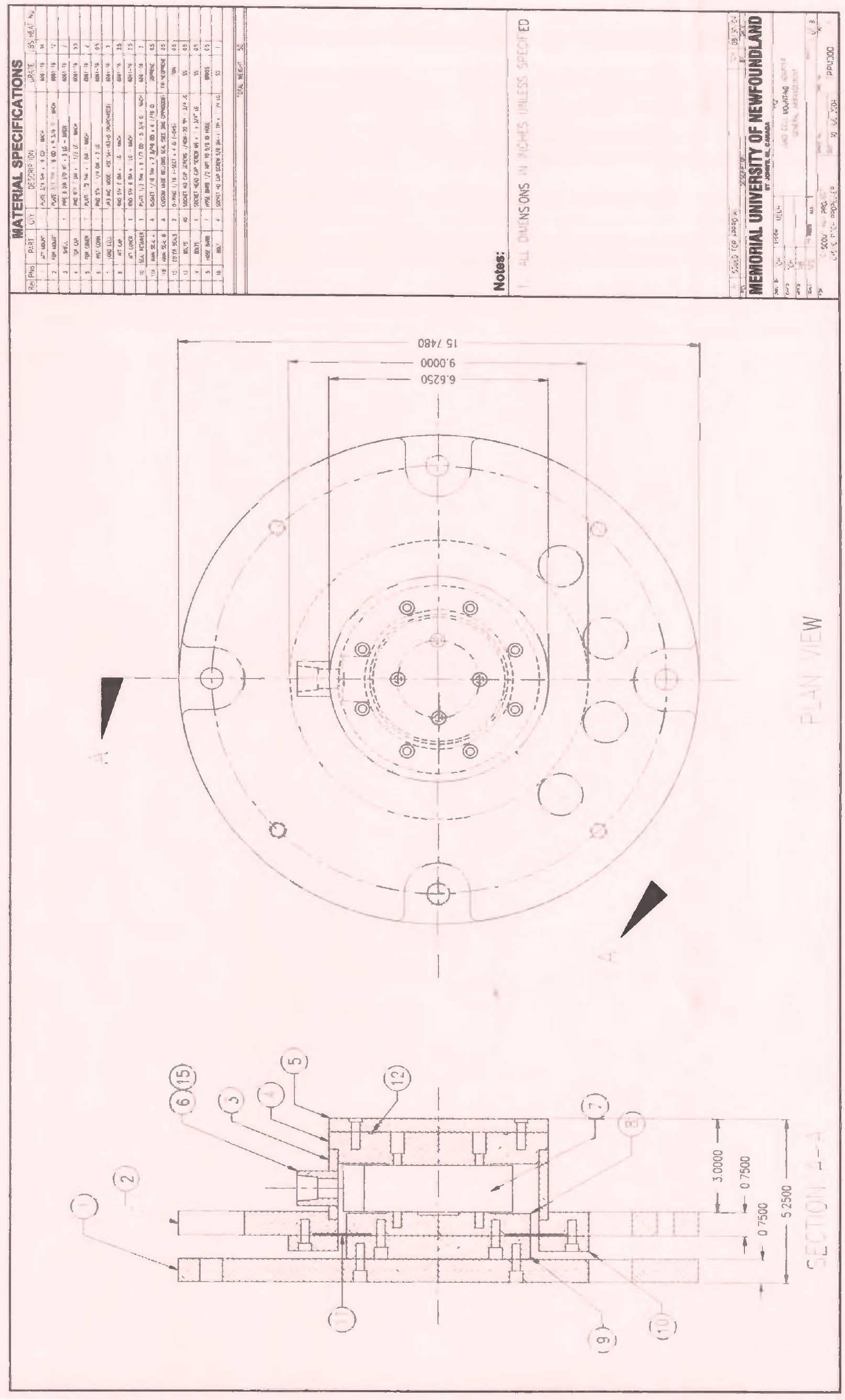




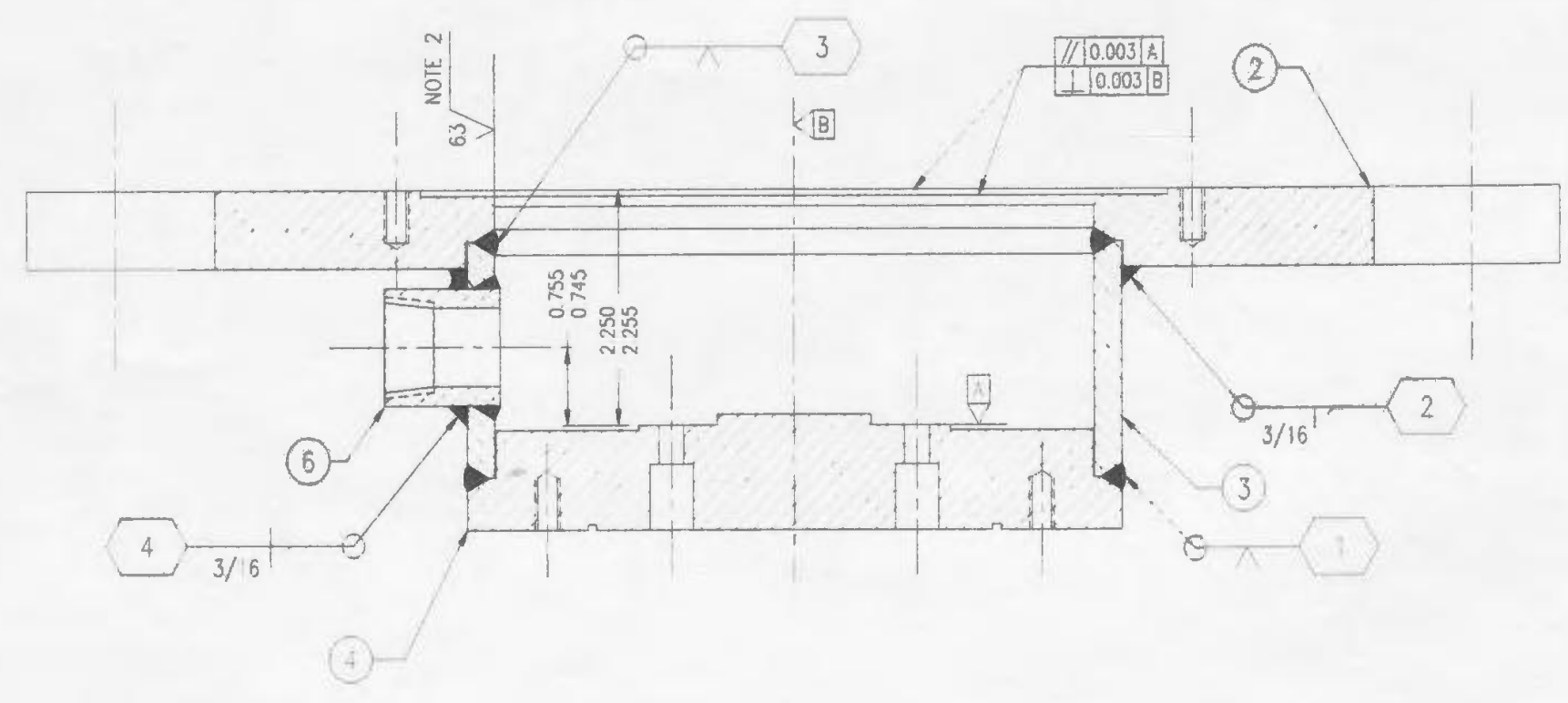

Notes:

1. DIHENSWNS IN INCHES UNLESS SPECIFED BORE TO BE CLEANUP MACHINED AFTER

3. NOZZZ TO BE ORIENTED AI $\sigma^{*}$ WI RESPECT 70) PiR 


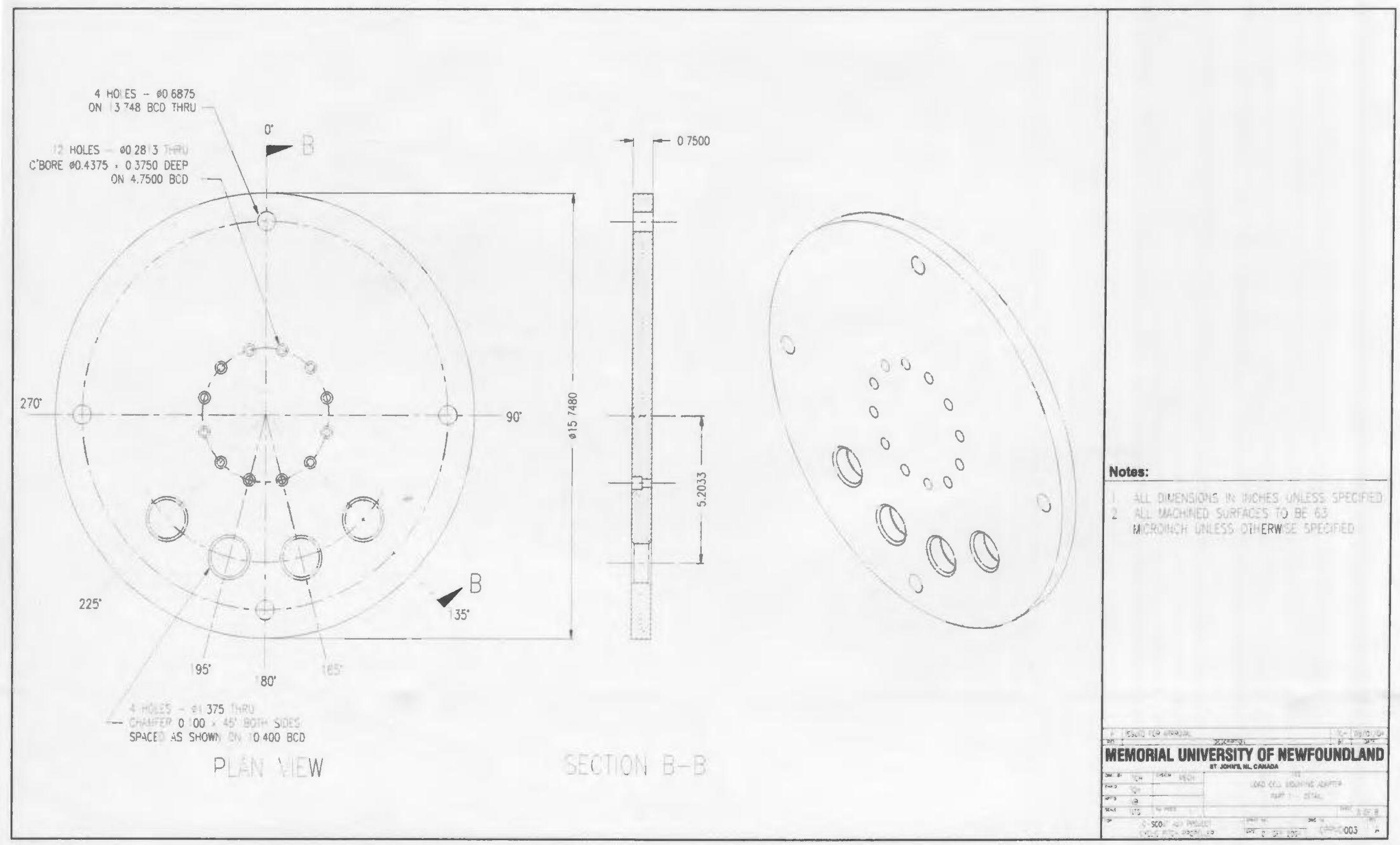




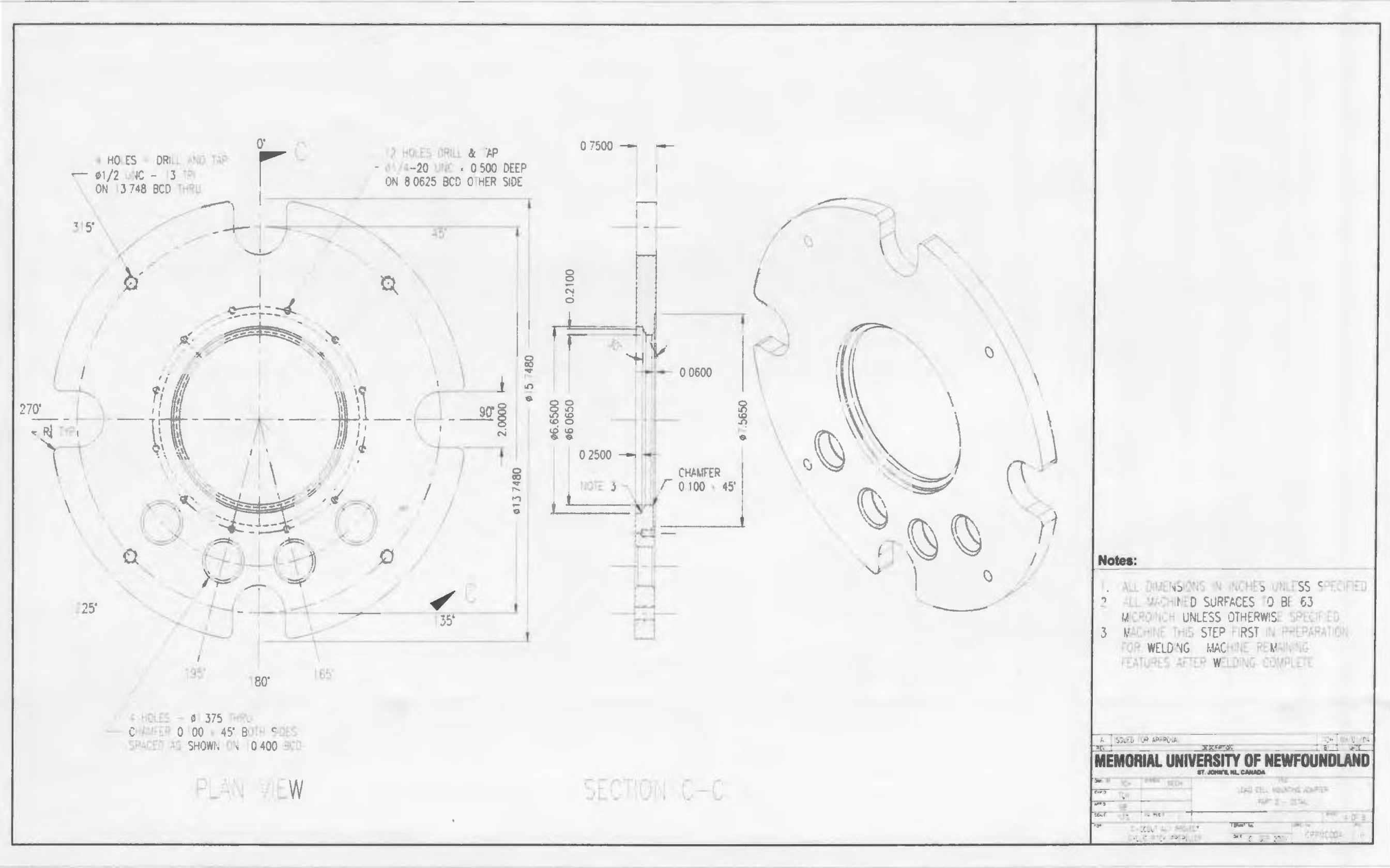




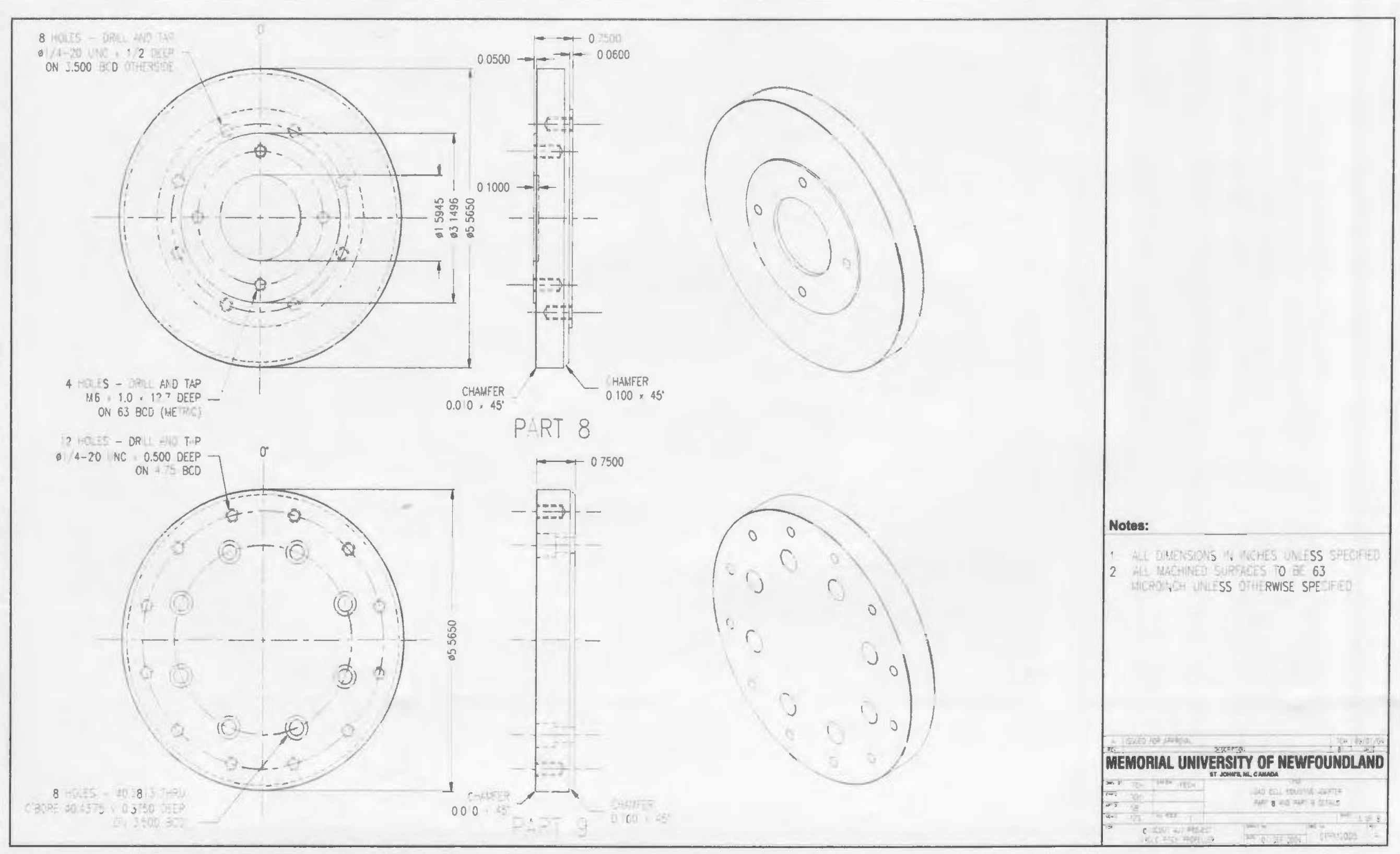




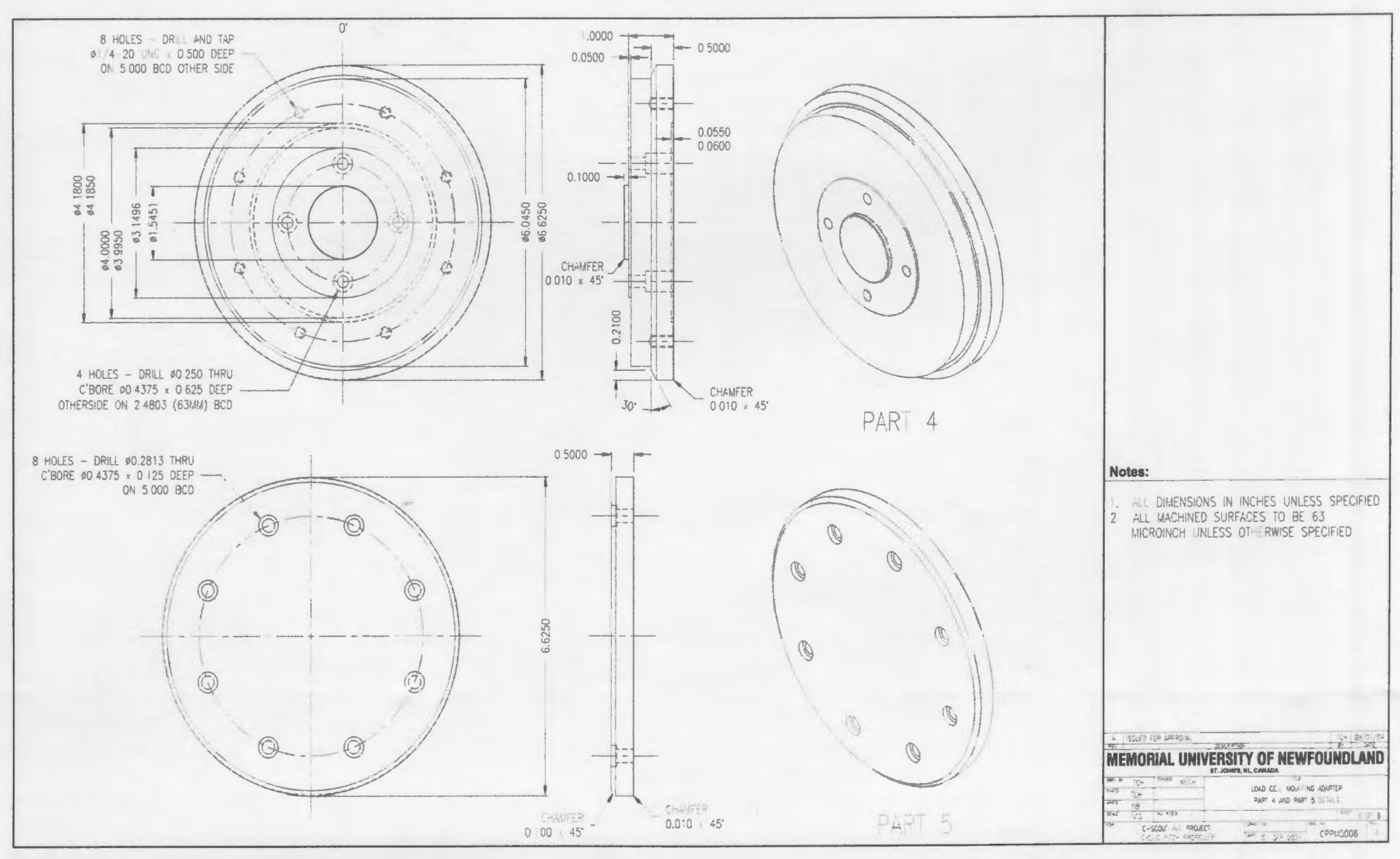




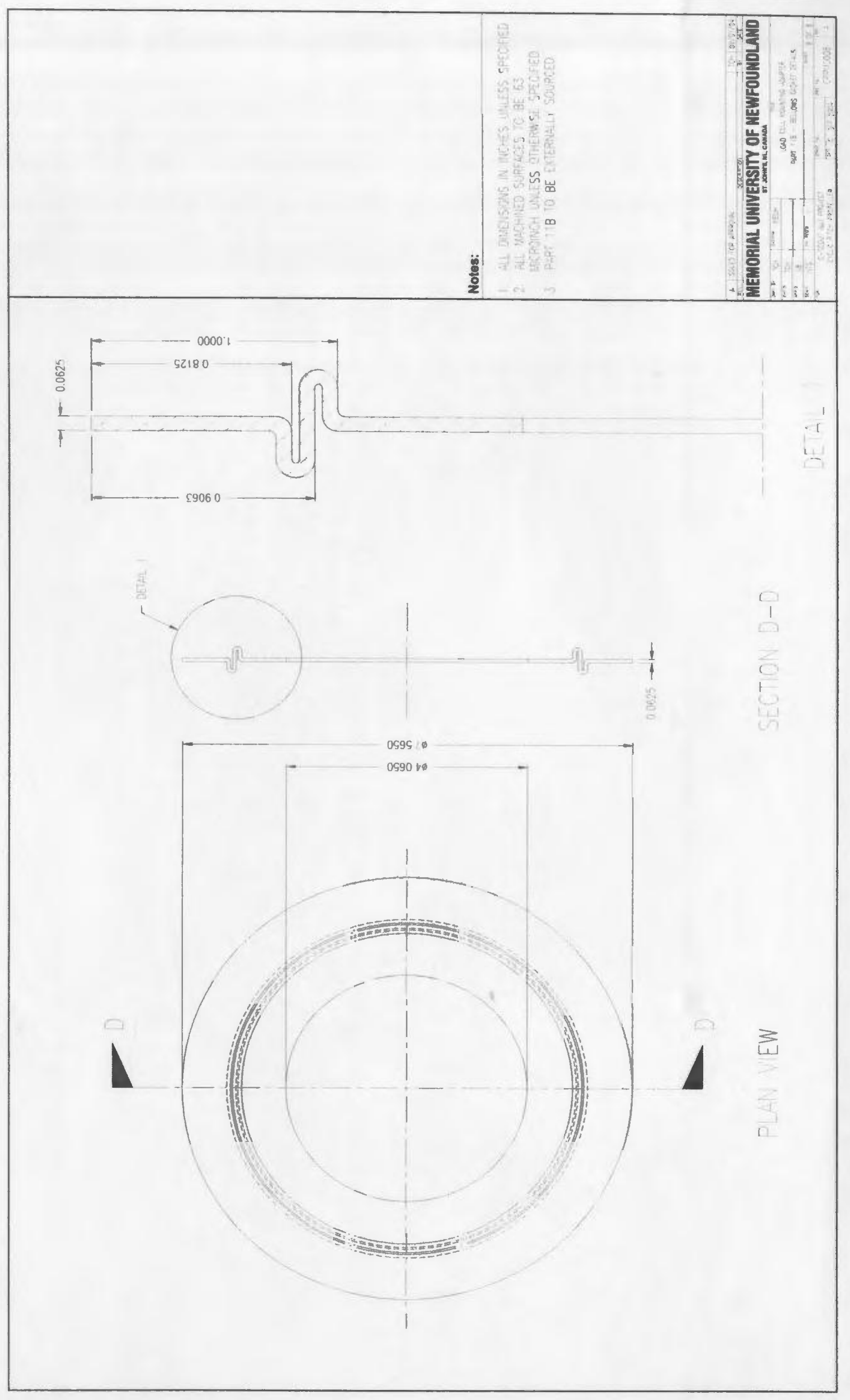




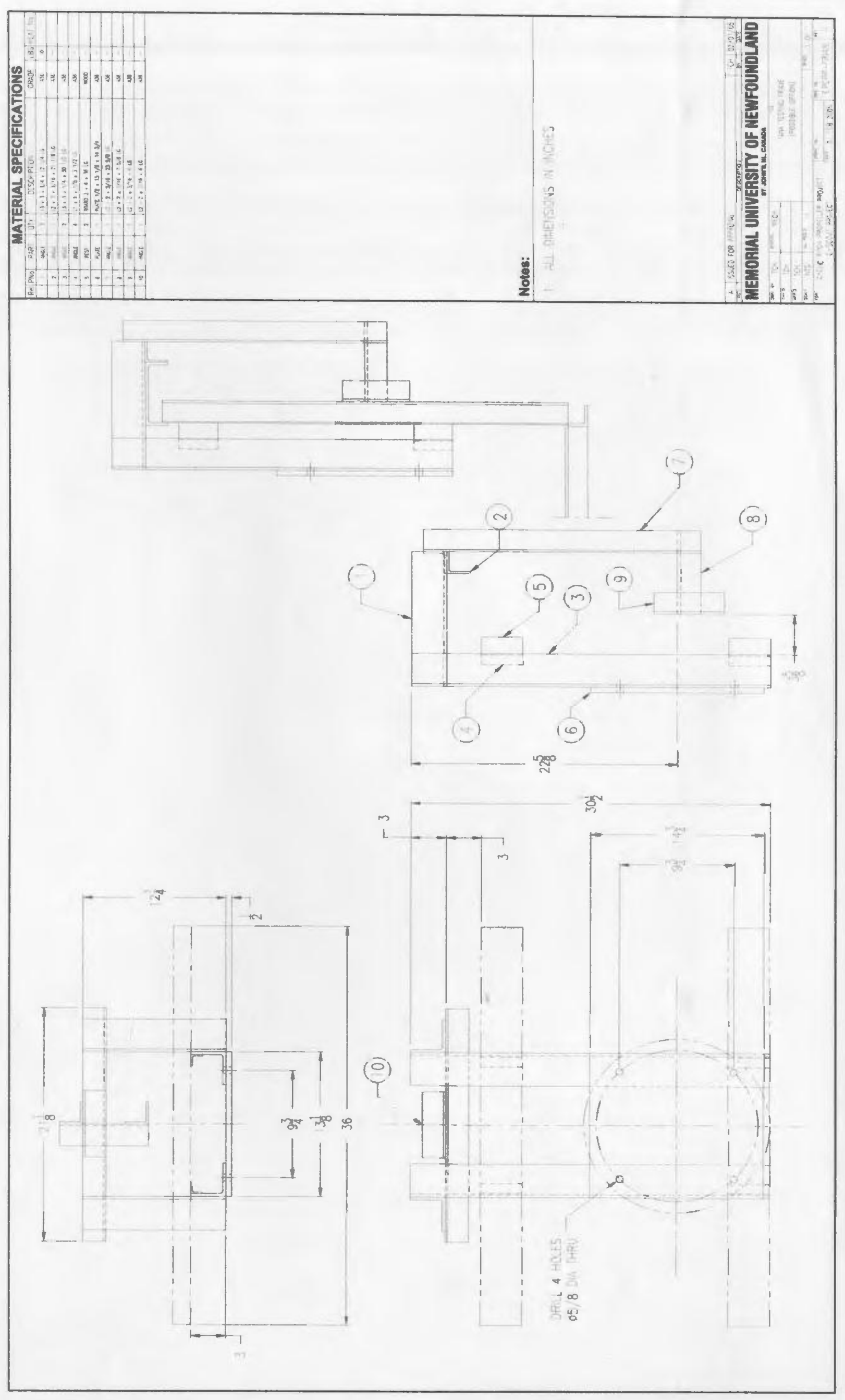



